\title{
6 Die bosnisch-kroatische Division „Handschar“
}

\section{1 Übersicht}

Seit den ersten Rekrutierungen für die Division „Prinz Eugen“ war noch nicht einmal ein Jahr verstrichen, als Reichsführer SS Heinrich Himmler Adolf Hitler am 6. Dezember 1942 die Aufstellung einer „bosnischen“ Division innerhalb der neuen Grenzen des NDH, der seit seiner Gründung am 10. April 1941 auch bosnische, herzegowinische und syrmische Gebiete einschloss, vorschlug. Als Verantwortlichen für Rekrutierungen und den Aufbau der Division beabsichtigte er, den Kommandeur der SS-Freiwilligen-Division „Prinz Eugen“, SS-Gruppenführer und Generalleutnant der Waffen-SS Artur Phleps einzusetzen. ${ }^{1}$ Zwei Monate später, am 10. Februar 1943, gab Hitler schließlich den Befehl zur Aufstellung einer „Kroatischen SS-Freiwilligen-Division“. ${ }^{2}$ Nur drei Tage später, am 13. Februar, gratulierte Himmler Phleps zu seinen Erfolgen mit der Division „Prinz Eugen“ und frohlockte bereits, dass sich letzterer auf die „Aufstellung einer Kroatischen SS-FreiwilligenDivision" vorbereiten solle. ${ }^{3}$

Um möglicher Kritik vorzubeugen und die verwandtschaftliche Nähe dieser ersten „fremdvölkischen“ Waffen-SS-Division zu betonen, wurde darauf hingewiesen, dass die Rekruten „völkisch-rassisch gesehen (überwiegend dinarisch) zur germanischen Welt, weltanschaulich geistig gesehen aber zur arabischen Welt“ gehören. ${ }^{4}$ Die Chimäre des „Germanentums“ sollte damit vorerst noch aufrechterhalten werden, wie Leleu dieses Vorgehen bezeichnet. ${ }^{5}$ Um Einwänden in

1 Vgl. Lepre, Himmler's Bosnian Division, S. 19.

2 Vgl. Jüttner an Sonderverteiler/70 Ausfertigungen, betr. „Aufstellung der Kroatischen SSFreiwilligen-Division“, 30.4.1943, BArchB, NS19/3523, Bl. 34. Vgl. Tessin, Verbände, Bd. 3, S. 282. Vgl. auch Mirko D. Grmek, Louise L. Lambrichs, Les révoltés de Villfranche. Mutinerie d'un bataillon de Waffen-SS, septembre 1943, Paris: Seuil 1998, S. 151. Lepre gibt hier den 13.2.1943 an. An diesem Tag besprachen Himmler und Hitler den Aufbau der Division in der Wolfsschanze. Vgl. Lepre, Himmler's Bosnian Division, S. 19.

3 Vgl. Funkspruch Himmler an Phleps, 13.2.1943, BArchB NS19/2601, Bl. 2. Kasche war spätestens seit dem 18.2.1943 informiert. Vgl. hierzu auch Redžić, Muslimansko autonomaštvo, S. 81.

4 SS-Hauptsturmführer, Unterschrift nicht lesbar, Abschrift „Betr. Weltanschaulich geistige Erziehung der muselmanischen SS-Division. Bez: Mündlicher Befehl Chef SS-Hauptamt“, 19.5.1943, BArchB, NS 19/2601, Bl. 245.

5 Leleu, Jenseits der Grenzen, S. 36.

Ә Open Access. ( 2021 Franziska Anna Zaugg, publiziert von De Gruyter. (c))BY Dieses Werk ist lizenziert unter einer Creative Commons Namensnennung 4.0 International Lizenz. https://doi.org/10.1515/9783110730777-006 
Bezug auf die slawische Abstammung der zukünftigen Waffen-SS-Soldaten zuvorzukommen, ${ }^{6}$ wurden bei diesen Rekrutierungsabsichten nun vor allem ethnischreligiöse Aspekte betont. So forderte Himmler bereits in einem Funkspruch vom 13. Februar 1943, dass die Division „tunlichst aus Bosniaken mohamedanischer Religion zu bestehen“ habe. ${ }^{7}$ Dass schließlich auf Druck des Poglavnik (Führer), Ante Pavelić, auch Katholiken der Division beitraten, wird noch näher erläutert werden. ${ }^{8}$

Der Name der Division wechselte während ihres zweijährigen Bestehens viermal. Zuerst galt die Bezeichnung „Kroatische SS-Freiwilligen-Division“. Am 30. April 1943 wurde sie in „Kroatische SS-Freiwilligen-Gebirgs-Division“ umbenannt. Im Oktober 1943 wurden sämtliche Waffen-SS-Divisionen durchnummeriert - nun hieß sie „13. Kroatische SS-Freiwilligen-Gebirgs-Division“. Erst am 15. Mai 1944 erhielt die Division den Namen, unter welchem sie heute am besten bekannt ist: „13. Waffen-Gebirgs-Division der SS ,Handschar‘ (kroatische Nr. 1)“.9 Leleu erkennt in dieser hohen Frequenz von Umbenennungen Indikatoren des organisatorischen Durcheinanders und der Schwierigkeit der SS-Führung, eine Division, die jeder rassenideologischen Logik entbehrte, in das Konstrukt „Waffen-SS“ einzugliedern. ${ }^{10}$ Daneben wurde die Division zwischen Herbst 1943 und Frühjahr 1944 auch als bosnisch-herzegowinische Division bezeichnet, was ihrem eigentlichen Charakter zwar näher kam, allerdings das Missfallen der kroatischen Regierung erregte. ${ }^{11}$ Trotz der sich lange hinziehenden Namensgenese

6 Siehe zur Überheblichkeit und Geringschätzung gegenüber der slawischen Bevölkerung allgemein etwa Umbreit, Auf dem Weg zur Kontinentalherrschaft, S. 268-277.

7 Himmler an Divisionskommandeur der 7. SS-Freiwilligen-Gebirgs-Division „Prinz Eugen“, SS-Gruppenführerund Generalleutnant der Waffen-SS Artur Phleps, 13.2.1943, BArchB, NS 19/ 2601, Bl. 2. Vgl. Petke, Stefan: Militärische Vergemeinschaftungsversuche muslimischer Soldaten in der Waffen-SS. Die Beispiele der Division „Handschar" und des „Osttürkischen Waffenverbands der SS“, in: Schulte, Jan Erik/Lieb, Peter/Wegner, Bernd (Hgg.): Die Waffen-SS. Neue Forschungen, S. 248 und Zaugg, Albanische Muslime, S. 187.

8 Erhellend hierzu: Phleps an Chef des SS-Führungshauptamt, SS-Gruppenführer Hans Jüttner, „Zwischenbericht über Werbeaktion muselmanischer Freiwilliger“, 19.4.1943, BArchB, NS 19/2601, Bl. 8.

9 Vgl. Klietmann, Waffen-SS: eine Dokumentation, S. 187 f. Tessin nennt Juni 1944 als Zeitpunkt der Umbenennung. Vgl. Tessin, Verbände, Bd. 3, S. 283.

10 Leleu, La Waffen-SS, S. 73 f.

11 Vgl. bspw. Abteilung VI, „Dienstanweisung für Imame der 13. SS-Freiwilligen b.h. Geb.Div. (Kroatien)“, 15.3.1944, BArchB, NS 19/2601, Bl. 248. In einem nicht unterzeichneten Schreiben, wahrscheinlich von Hafiz Mohammed Pandža, wird als Name für die Division „Der Drache von Bosnien“ vorgeschlagen, weil diese Bezeichnung „durch den Namen allein der Tendenz der politischen Autonomie von Bosnien und Herzegovina herangezogen sein wird.“ Schreiben ohne Unterschrift und Adressat, BArchB NS 19/2601, Bl. 34. 
soll aufgrund der Lesbarkeit im Folgenden auch dann von „Handschar“ die Rede sein, wenn es sich um ihre Erwähnung vor Mitte Mai 1944 handelt. $^{12}$

Der Divisionsstab wurde bereits am 9. März 1943 in Berlin aufgestellt und bezog Anfang April Quartier in Zagreb. ${ }^{13}$ In Goslar wurde die Nachrichten-Abteilung aufgestellt. ${ }^{14}$ Nach einer ersten Aufstellungsphase auf dem Gebiet des NDH, welche von April bis August 1943 dauerte, kam die Division zur Ausbildung in das rückwärtige Heeresgebiet nach Südfrankreich, wo der Divisionsstab in Le Puy unterkam. ${ }^{15}$

Eine wichtige Zäsur in der Geschichte der Division stellte die Meuterei in Villefranche-de-Rouergue im September 1943 dar. ${ }^{16}$ Als direkte Folge davon ließ Himmler die gesamte Division auf den Truppenübungsplatz nach Neuhammer in Schlesien verlegen, wo ihre Ausbildung fortgeführt und Anfang 1944 beendet wurde. $^{17}$ Ende Februar 1944, nach Überschreiten der bosnischen Grenze, bereitete Sauberzweig die Albaner der „Handschar“ bereits auf ihre Verlegung in die geplante Division „Skanderbeg“ vor, die im April erfolgte. ${ }^{18}$ Auf ihrem Weg nach Ostbosnien soll die Division zahlreiche Kriegsverbrechen begangen haben. ${ }^{19} \mathrm{Im}$ Sommer setzten Massendesertionen ein, die Ende September 1944 eine Zusammenlegung der beiden Schwesterdivisionen „Handschar“ und „Kama“ erforderten. Im Herbst 1944 sollte die auf 6.015 Mann geschrumpfte Division durch rund 3.000 Soldaten der Wehrmacht, die vorher in Kreta eingesetzt waren, verstärkt werden. ${ }^{20}$ Zahlreiche Bosnier und Kroaten wurden im Winter 1944/45 aus der

12 „Handžar“ bezeichnet einen Krummdolch - „Handschar“ ist die davon abgeleitete deutsche Schreibweise.

13 Vgl. Lepre, Himmler's Bosnian Division, S. 25. Tessin hingegen ist der Meinung, dieser sei direkt in Zagreb aufgestellt worden. Vgl. Tessin, Verbände, Bd. 3, S. 283.

14 Vgl. Tessin, Verbände, Bd. 3, S. 283.

15 Vgl. ebd.

16 Mirko Grmek und Louise Lambrichs widmeten dieser Meuterei eine ganze Studie: Grmek, Lambrichs, Les révoltés. Die Meuterei und ihre Hintergründe werden im Kapitel 6.11.2 Zwei Meutereien und Massendesertionen näher erläutert.

17 Vgl. Kaltenegger, Totenkopf und Edelweiss, S. 55. Vgl. Lepre, Himmler's Bosnian Division, S. 117.

18 Vgl. Divisionskommandeur Sauberzweig an Mannschaft der 13. SS-Division, Brief Nr. 8, 25.2.1944, BArchB, NS 19/2601, Bl. 210. Vgl. Lepre, Himmler’s Bosnian Division, S. 151 f, 165.

19 Vgl. bspw. Ferhadbegović, Vor Gericht, S. $238 \mathrm{f}$.

20 Siehe zur deutschen Kriegführung und das Vorgehen gegen Partisanen auf Kreta: Anestis Nessou, Griechenland 1941-1945, deutsche Besatzungspolitik und Verbrechen gegen die Zivilbevölkerung - eine Beurteilung nach dem Völkerrecht, Göttingen: V\&R unipress 2009, S. 98, 199-203, 303.Vgl. auch Rondholz, Eberhard: „Schärfste Maßnahmen gegen die Banden sind notwendig“: Partisanenbekämpfung und Kriegsverbrechen in Griechenland. Aspekte der deutschen Okkupationspolitik 1941-1944, in: Meershoek, Guus u. a.(Hgg.): Repression und Kriegsverbrechen: Die 
Division entlassen oder kamen an der Ostfront, die mittlerweile im Grenzgebiet zwischen Ungarn, Serbien und Kroatien verlief, zum Einsatz. ${ }^{21}$ Eine große Anzahl dieser Waffen-SS-Soldaten gerieten schließlich im Frühjahr 1945 in Slowenien in britische Kriegsgefangenschaft. ${ }^{22}$ Viele von ihnen kamen in weitere Gefangenenlager im Tirol oder in Italien, andere wurden von den Briten an Jugoslawien ausgeliefert, was ihr oft tödliches Schicksal besiegelte. ${ }^{23}$

Obwohl nationalistische Kreise gerade in Südosteuropa, aber auch anderen europäischen Staaten, noch immer das Bild vermitteln, viele dieser ,fremdvölkischen“ Rekruten wären aus voller Überzeugung der Waffen-SS beigetreten, stellte der bekannte Südosteuropahistoriker Holm Sundhaussen bereits 1971 in einem Aufsatz fest, dass sie oft unter Zwang in die Waffen-SS gedrückt worden wären. Diese „größtenteils zwangsweise Anwerbung fremder Staatsbürger zur Waffen-SS“ verstieß, so Sundhaussen, gegen das in der Haager Landkriegsordnung festgelegte Kriegsvölkerrecht. ${ }^{24}$

Inwieweit für den Beitritt zur Waffen-SS nun eher Zwang oder bestimmte Versprechungen entscheidend waren, ob und in welchem Maße dabei verschiedene Motivationen bei der Bevölkerung mitspielten und welchen Mehrwert sich die deutschen Akteure von den Rekrutierungen in Südosteuropa erhofften, soll in den folgenden Kapiteln gezeigt werden.

\subsection{Bürgerkriegsähnliche Zustände: Der schwere Stand der Muslime}

Seit dem Balkanfeldzug 1941 hatten die deutschen Besatzer die Konflikte in Südosteuropa nicht beilegen können, vielmehr war ein permanenter Nebenkriegsschauplatz entstanden, der nur bedingt kontrollierbar war. ${ }^{25}$ Diese Entwicklung

Bekämpfung von Widerstands- und Partisanenbewegungen gegen die deutsche Besatzung in West- und Südeuropa, Berlin: Assoziation A 1997, S. 130-170.

21 Vgl. Lepre, Himmler's Bosnian Division, S. 276-291.

22 Vgl. Tessin, Verbände, Bd. 3, S. 283. Kaltenegger, Totenkopf und Edelweiss, S. 56.

23 Vgl. Ferhadbegović, Vor Gericht, S. 247. Siehe detailliert zur Historiographie über Bleiburg und die Todesmärsche nach der Auslieferung zehntausender Soldaten an Jugoslawien durch die Briten: Martina Grahek Ravančić Bleiburg i križni put 1945. Historiografija, publicistika i memoarska literatura, Zagreb: Hrvatski institut za povijest, 2015. Vgl. Hoare, Bosnian Muslims, S. $3 \mathrm{f}$.

24 Sundhaussen, Waffen-SS in Kroatien, S. 176.

25 Vgl. OB Südost (Heeresgr. F) Generalfeldmarschall Maximilian von Weichs, H.Q., „Die große Absetzbewegung im Südosten“, Januar 1945, BArchF, RH 19-XI/86, S. 1. 
ließ sich nicht verhindern, obwohl die Deutschen und Italiener das eroberte Gebiet umgehend aufgeteilt und als „kleinsten gemeinsamen Nenner deutscher und italienischer Großmachtinteressen“ den Unabhängigen Staat Kroatien (NDH) unter Ante Pavelić etabliert hatten. ${ }^{26}$ Der NDH umfasste die Gebiete Kroatien, Bosnien-Herzegowina, Slawonien, Syrmien sowie Teile Dalmatiens. Drau, Drina und Donau bildeten, wie vor 1918, die Nord- und Ostgrenzen zu Ungarn und Serbien. Die Bevölkerung teilte sich in schätzungsweise 50\% katholische Kroaten, $30 \%$ orthodoxe Serben und beinahe 12\% Muslime auf. $6 \%$ gehörten zu anderen Bevölkerungsgruppen, vor allem zu Juden und Roma. ${ }^{27}$ Insbesondere in solchen ethnisch stark gemischten Grenzgebieten schwelten die Konflikte verschiedener Parteien untereinander und gegen deutsche Einheiten seit Frühjahr 1941 weiter und entwickelten sich zu blutigen Bürgerkriegen. ${ }^{28}$ In diesen Regionen hatten schließlich Warlords und Milizchefs das Sagen, staatliche Strukturen spielten so gut wie keine Rolle mehr. ${ }^{29}$

Als ein wichtiger Akteur bildeten sich die von Pavelić kommandierten Ustaša-Milizen heraus, die seit den ersten Tagen der Existenz des NDH in brutalster Weise gegen Serben, Juden und Roma - und manchmal auch gegen Muslime vorgingen. ${ }^{30}$ Der ab 24. August 1943 eingesetzte Sonderbevollmächtigte des Auswärtigen Amtes für den Südosten Hermann Neubacher schreibt rückblickend:

Das Pravoslavenkonzept des Ustaschaführers und Poglavnik (Staatsführers) Kroatiens, Ante Pavelić, erinnert an Religionskriege blutigsten Andenkens: ,ein Drittel muss katholisch werden, ein Drittel muss das Land verlassen, ein Drittel muss sterben!' Der letzte Programmpunkt wurde durchgeführt. “31

Pavelić vermochte die Ustaša-Milizen nur bedingt zu kontrollieren und forderte nur zwei Monate nach der deutschen Invasion in einer außerordentlichen Gesetzesverordnung die Auflösung „wilder“ Ustaša-Einheiten. Der von ihm beauftragte militärische Sondergesandte für die Herzegowina, Feldmarschallleutnant Vladimir Laxa, verlangte nicht nur die Auflösung irregulärer Ustaša-Einheiten, sondern

26 Vgl. Korb, Im Schatten des Weltkriegs, S. 67.

27 Vgl. Rochas, La Handschar, S. 21.

28 Vgl. Klaus Olshausen, Die deutsche Balkanpolitik 1940-1941, in: Funke, Manfred (Hg.), Hitler, Deutschland und die Mächte. Materialien zur Außenpolitik des Dritten Reiches, Kronberg 1978, S. 724.

29 Korb, Im Schatten des Weltkriegs, S. 72. Vgl. auch Lijljana Radonić, Krieg um die Erinnerung, S. 82.

30 Vgl. Rochas, La Handschar, S. 20. Vgl. Korb, Im Schatten des Weltkriegs, S. 15. Zur Entstehung der Ustascha siehe ebd., S. 54-63.

31 Neubacher, Sonderauftrag Südost, S. 31. 
aller Ustaša-Milizen, da er in ihnen einen wesentlichen Faktor für die zunehmende Destabilisierung der Region erkannte. ${ }^{32}$

Auf Druck führender Wehrmachtskreise, die der Meinung waren, die Ustaša würde die deutschen Befriedungsabsichten nicht unterstützen, sondern Öl ins Feuer interethnischer Konflikte gießen, berief der Militärbefehlshaber Serbien, General der Artillerie Paul Bader Anfang Februar 1942 in Belgrad eine Sitzung ein. Dabei wurde bereits eine mögliche Zusammenarbeit mit dem anti-kommunistischen Četnik-Führer Major Jezdimir Dangić für den Raum Ostbosnien besprochen. Denn die Unruhe in diesem Gebiet, so der Abgesandte Walter Hewel an Ribbentrop, würde sowohl die Stabilität im NDH als auch in Serbien gefährden. ${ }^{33}$

Serbien selbst verblieb unter deutscher Militärherrschaft und bildete „einen Gewaltraum, der mit dem USK [NDH] eng korrespondierte. “34 Aufgrund der bürgerkriegsähnlichen Situation in den bosnischen Gebieten reichten verschiedene bekannte Ustaša-Gegner, darunter sowohl Muslime und Serben als auch Kroaten, bereits 1941 ein Memorandum an die deutschen Besatzer ein. Darin wurde die direkte deutsche Militärverwaltung für ganz Bosnien-Herzegowina gefordert. ${ }^{35}$ Am 7. Januar 1942 schrieb der Bergingenieur Erich Franke in einem Bericht „über die Entwicklung der Verhältnisse in Jugoslavien [sic] (Serbien) seit Beendigung des Jugoslavischen Krieges“, dass der Hass zwischen den einzelnen Stämmen und Glaubensrichtungen durch die Ereignisse des vergangenen Sommers (1941) so groß sei, dass ihm „eine Befriedung ohne das Eingreifen einer starken Hand ausgeschlossen schien.“" ${ }^{36}$ In Srebrenica wären 200 Muslime von Četniks unter der Führung von Major Jezdimir Dangić ermordet worden: „Der Grund? Weil sie Muselmanen waren und sich unter der Ustaša viele Muselmanen befinden. Es ist verständlich, dass die Muselmanen nur auf eine passende Gelegenheit warten, um über die Serben herzufallen.“37 Die Zunahme von solchen gegenseitigen Übergriffen, insbesondere aber von Ustaša-Anhängern an Serben und auch an Muslimen, waren ein zentraler Diskussionspunkt auf dem von Bader im Februar 1942 einberufenen Treffen in Belgrad, an welchem der deutsche Gesandte Siegfried Kasche, der Deutsche Bevollmächtigte General in Kroa-

32 Vgl. Korb, Im Schatten des Weltkriegs, S. $348 \mathrm{f}$.

33 Vgl. Enver Redžić, Bosnia and Herzegovina in the Second World War, S. 21-23.

34 Korb, Im Schatten des Weltkriegs, S. 73. Siehe zur vorgeschlagenen muslimischen Delegation für die Verhandlungen zur Grenzziehung auch das Schreiben von Emir Chekib Arslan an Max von Oppenheim, 20.4.1941 und das Schreiben von Oppenheim an Hentig, 29.4.1941, PAAA, R103345, 175-180.

$35 \mathrm{Vgl}$. Hoare, Bosnian Muslims, S. $40 \mathrm{f}$.

36 Bergingenieur Erich Franke, Bericht „über die Entwicklung der Verhältnisse in Jugoslavien (Serbien) seit Beendigung des Jugoslavischen Krieges“, BarchB, R 43-II/680, Bl. 54.

37 Ebd. 
tien Edmund Glaise von Horstenau, Staatssekretär des NDH Vjekoslav Vrančić und ein Vertreter des Generalstabs der kroatischen Armee teilnahmen. ${ }^{38}$ Im Frühjahr desselben Jahres sorgten die blutigen Auseinandersetzungen zwischen Serben, Muslimen und Kroaten vor allem in Ostbosnien, im Gebiet zwischen den Flüssen Save, Bosna und Drina, für Diskussionen bis in höchste deutsche Militärkreise, da die deutschen Generale einen engen Zusammenhang zwischen den dort wütenden Ustaša-Mitgliedern und der Zunahme lokaler Aufstände sahen. ${ }^{39}$

Der deutsche Informant Nedim Salihbegović beschrieb den in Bosnien wütenden Bürgerkrieg zur Information für deutsche Dienststellen mit folgenden Worten:

In Bosnien waren die Fanale der neuen Zeit Mordgruben mit hunderten von Menschen, Plünderungen und das rücksichtsloseste Gewaltregime, das diese Länder je kennengelernt haben. Die serbische Bevölkerung mit ihren Sympathien auf der alliierten Seite vogelfrei erklärt, war eine leichte Beute der englisch-bolschewistischen Agitatoren und flüchtete in den Wald. Anstatt wenigstens zu versuchen, die Sympathien der moslemischen Bevölkerung zu gewinnen, setzte das heutige Regime alles daran, auch die Moslems schwer zu verbittern. Man wollte dabei schlau vorgehen. Immer haben die amtlichen Stellen vom Poglavnik angefangen - nur die schönsten Worte für die Moslems gehabt, aber in Wirklichkeit erklärte man die ganze moslemische Intelligenz und Studentenschaft für kommunistenfreundlich und sperrte man sie [sic] in Polizeigefängnisse oder transportierte sie in Konzentrationslager. Alle Einwände der Moslems, dass das nicht stimmt, weil die Haltung der richtige Ausdruck der Gesinnung ist - der größte Prozentsatz der kroatischen Freiwilligen für die Ostfront waren Moslems - lehnte man ohne weiteres ab und führte die Gewaltmaßnahmen weiter durch. Jetzt sah die ganze Bevölkerung Bosniens, die nicht katholisch war, ihre Ausrottung in dem neuen Staate bevorstehen und manche, die niemals mit den Partisanen sympathisierten, flüchteten in den Wald. ${ }^{40}$

Gezwungen sich der Unübersichtlichkeit verschiedener Konfliktherde und Kriegsparteien zu stellen, suchten die Deutschen nach geeigneten Lösungen, um ihre Ressourcen zu sparen und eigene Interessen vor Ort zu schützen. Indem sie gleichzeitig mit drei verschiedenen Lagern in Kontakt standen, versuchten sie, die eigene Position zu stärken: So stützten sie einerseits das Regime von Ante Pavelić, der wiederum die Ustaša-Bewegung anführte, andererseits überprüften sie Möglichkeiten einer Kollaboration mit den Četniks, beispielsweise in Person des bereits erwähnten Major Dangić, ${ }^{41}$ und drittens machten sie

38 Vgl. Redžić, Bosnia and Herzegovina, S. 22. Siehe zur Zusammenarbeit mit Četnik-Verbänden beispielsweise auch Schmider, Partisanenkrieg, S. 369.

39 Vgl. Redžić, Bosnia and Herzegovina, S. 21, Vgl. hierzu auch den Führer der nationalen serbischen Freischärler in Bosnien, Major Jedimir Dangić an RAM Ribbentrop, 24.3.1942, PAAA, R 27531.

40 Nedim Salihbegovic, „Bericht zur Lage“, 25.9.1943, BArchB, NS 19/2601, Bl. 30.

41 Vgl. Redžić, Bosnia and Herzegovina, S. 22. Vgl. auch Schmider, Partisanenkrieg, S. 371. 
gegenüber den muslimischen Bosniern Autonomieversprechungen und stellten durch den Aufbau und die Unterstützung militärischer Formationen wie der Division „Handschar“ und „Kama“ Schutz, Bewaffnung und eine militärische Ausbildung in Aussicht. ${ }^{42}$

Die Verlegung der „Kroatischen SS-Freiwilligen-Gebirgs-Division“ zu Ausbildungszwecken nach Frankreich im Sommer 1943 widersprach jedoch dem von deutscher Seite gemachten Versprechen bezüglich des Schutzes der lokalen Bevölkerung und ließ die Anzahl der Übergriffe an der muslimischen Bevölkerung in die Höhe schnellen. Eine Intensivierung der bürgerkriegsähnlichen Zustände war die Folge. Anfang November 1943 versuchte Phleps Himmler auf die prekäre Situation im NDH aufmerksam zu machen, da er die „kroatische Frage für sehr kritisch“ hielt. Er wusste, dass es zu weiteren ethnisch motivierten Massakern kommen würde, sollten die Deutschen nicht in der Lage sein, zeitnahe Lösungen zu finden. ${ }^{43}$ Die Bevölkerung im NDH hatte das Vertrauen in die Verwaltung verloren, und der Staat befand sich in einem Selbstauflösungsprozess. Aufgrund des geringen Lohns waren selbst Offiziere und Beamte gezwungen einem Nebenverdienst nachzugehen. In der Armee herrschten derart „desolate Zustände in der Verwaltung, Disziplin und Ausbildung“, dass ein „Versagen bei allen Kampfhandlungen“ die Folge war und Domobranen ${ }^{44}$ sich oft kampflos den Partisanen ergaben. ${ }^{45}$

Falls die deutschen Besatzer nicht in der Lage waren, die Situation zu stabilisieren und enttäuschte kroatische Soldaten für ihre Dienste zu gewinnen, konnte die Schwäche des NDH und das unübersichtliche Gegeneinander verschiedener Gruppierungen auch den Besatzern gefährlich werden. Nach Džaferbeg Kulenović, einem führenden Muslim in Pavelićs Regierung, hätten sich kurz nach dem Balkanfeldzug 1941 Hunderttausende freiwillig für die Waffen-SS gemeldet, wenn zu diesem Zeitpunkt rekrutiert worden wäre. ${ }^{46}$ Nun war aber bereits das Jahr 1943 angebrochen, die Kriegssituation hatte sich verändert, und auch die Lage in Südosteuropa hatte sich in den vergangenen zwei Jahren nicht beruhigt - im Gegenteil. Trotz radikaler deutscher Sühnemaßnahmen von 1:50 zu erschießender

42 Eine Versorgung mit Waffen, um sich zu schützen, wurde aber auch von den westlichen Alliierten gefordert, wie etwa das albanische Beispiel zeigt. Vgl. Zaugg, Muslimische Albaner, S. 97. Die Situation schien der muslimischen Elite zeitweise so aussichtlos, dass sie über eine Evakuierung aller bosnischen Muslime in die Türkei diskutierten. Vgl. Hoare, Bosnian Muslims, S. 111 .

43 Vgl. Schreiben Phleps an Himmler, 5.11.1943, BArchB NS19/3893, S. 2 f.

44 Als „Hrvatsko domobransko“/,Kroatische Heimwehr“ bezeichnete man die reguläre Armee im NDH.

45 Vgl. Schreiben Phleps an Himmler, 5.11.1943, BArchB NS19/3893, S. 2 f.

46 Vgl. Lepre, Himmler's Bosnian Division, S. 23. 
Geiseln für jeden verletzten und 1:100 für jeden getöteten deutschen Soldaten, wuchs die Zahl ihrer Gegner. ${ }^{47}$ Verschiedene Unternehmen, beispielsweise die Operationen „Weiß“ und „Schwarz“ im Frühjahr und Sommer 1943, zeugen zwar von der Brutalität deutscher Truppen, aber die Partisanen ließen sich auch durch solche Einsätze nicht wie geplant vernichten. ${ }^{48}$ Im Gegenteil sahen sich die Deutschen seit 1943 einer exponentiell wachsenden Partisanenarmee von Kommunisten und einer ebensolchen von Četniks gegenüber. ${ }^{49}$

\subsection{Ausgangslage und Absichten auf deutscher Seite}

Auf deutscher Seite lassen sich die Bedingungen und Absichten hinsichtlich der Rekrutierungen in fünf größere Themenkomplexe gliedern: Erstens hatte sich die Gesamtsituation deutscher Verbände in Südosteuropa in dem Jahr, das seit der Aufstellung der „Prinz Eugen“ verstrichen war, durch die extremen Verluste an der Ostfront im Winter 1942/43, inklusive der Niederlage von Stalingrad, verändert. Somit war ein Kernziel der Rekrutierung „Fremdvölkischer“, eigene (deutsche) knappe Personalressourcen zu schonen. Zweitens sahen sich die deutschen Verbände der Wehrmacht und Waffen-SS in Südosteuropa einer wachsenden Partisanenarmee gegenüber - und drittens, eng damit zusammenhängend, mit der Zunahme bürgerkriegsähnlicher Konflikte verschiedener Parteien in der Region und dem damit einhergehenden schwindenden Vertrauen der Bevölkerung konfrontiert. Diese war durch wahllose drakonische „Sühnemaßnahmen“ von deutscher Seite, aber auch wiederkehrende Übergriffe und Massaker durch alle anderen beteiligten Parteien in den vergangenen zwei Jahren misstrauisch geworden. Ähnlich wie bereits bei der „Prinz Eugen“ war es daher viertens ein wichtiges Ziel, durch diese Rekrutierung das Vertrauen bestimmter Bevölkerungsgruppen, in diesem Fall das der bosnischen Muslime, wiederzugewinnen und damit andere Bevölkerungsteile unter Kontrolle zu bringen. Diese Faktoren unterscheiden sich von den nächstgenannten, weil sie die Rekrutierung so genannter „Fremdvölkischer“ einem äußeren Druck folgend beeinflussten und

47 Vgl. Calic, Geschichte Jugoslawiens, S. 142f.

48 Auch bekannt unter den Namen Schlacht an der Neretva und Schlacht an der Sutjeska.

49 Vgl. Schmider, Partisanenkrieg, S. 568. Dieses Wachstum hing in den Anfängen der kommunistischen Widerstandsbewegung mit der Willkürherrschaft und der Brutalität des UstašaRegimes und mit den extremen Sühnemaßnahmen der Deutschen zusammen, im letzten Kriegsjahr aber war es vor allem eine Folge der zunehmenden Unterstützung der Partisanen durch die Briten und der seit Stalingrad offensichtlich gewordenen Schwäche deutscher Truppen. 
förderten. Der fünfte Faktor, welcher bei der Bildung einer ersten „muslimischen“ Division eine wesentliche Rolle spielte, war die Instrumentalisierung des Islam für nationalsozialistische Zwecke: Die SS-Spitze versuchte gezielt, Berührungspunkte und eine ideologische Verwandtschaft zwischen Nationalsozialismus und Islam zu konstruieren. Dabei sollte die Division „Handschar“ als Vorzeigedivision für weitere Verbände und eine zukünftige Zusammenarbeit mit arabischen Staaten dienen. ${ }^{50}$

Trotz dieser schlagenden Argumente für eine rasche Aufstellung verursachten Kompetenzgerangel, abweichende Handlungsintentionen und weder geregelte noch abgegrenzte Kompetenzen unterschiedlicher NS-Institutionen immer wieder Verzögerungen und Änderungen beim Aufbau der Division. ${ }^{51}$

\subsubsection{Personalmangel und Rückgewinnung des Vertrauens in der Bevölkerung}

Noch bevor die Rekrutierungen angelaufen waren, meldete Phleps große Schwierigkeiten bei der „Beistellung von Führer- und Unterführerpersonal“ an Himmler. ${ }^{52}$ Ende September 1943, sieben Monate nach Beginn der Aufstellungen der „Handschar“, wurde auch Gottlob Berger durch Karl-Gustav Sauberzweig auf große Schwierigkeiten bei der Suche nach geeigneten Führern und Unterführern aufmerksam gemacht. ${ }^{53}$ In der extrem aufgeheizten politischen Situation in Südosteuropa sollte Sauberzweigs Division „der ruhende Pol der Muselmanen auf dem Balkan“ werden. ${ }^{54}$ Er äußerte gegenüber SS-Obersturmbannführer Brandt und Berger, dass aufgrund des Mangels an Führungspersonal wertvolle Zeit bei der Ausbildung des „guten Menschenmaterials“ verloren ginge, die „Handschar“ aber nur „richtig ausgebildet und diszipliniert das schärfste Schwert des Balkans“" werden würde. ${ }^{55}$

Es war Sauberzweig unverständlich, „weshalb gerade diese Division nicht mit den besten reichsdeutschen Führern und Unterführern besetzt wurde, denn nur sie

50 Vgl. Reichsführer SS, SS-Hauptamt A I/M, Vermerk betr. „Mobilisierung des Islam“, 28.2.1944, BArchB, NS 31/42, Bl. 6. Vgl. Zaugg, völkische islamophile Orientalistik, S. 1201-1205. Vgl. auch Wegner, Hitlers politische Soldaten, S. 284.

$51 \mathrm{Zu}$ Kompetenzkonflikten vgl. Sundhaussen, Improvisierte Ausbeutung, S. 55-75.

52 Vgl. Phleps an Himmler, BArchB, NS19/3523, Bl. 39.

53 Vgl. Sauberzweig an Berger, 30.9.1943, BArchB, NS 19/2601, Bl. 27. Vgl. auch Sauberzweig an Brandt, 30.9.1943, BArchB, NS 19/2601, Bl. 25.

54 Vgl. Petke, Vergemeinschaftungsversuche, S. 253.

55 Vgl. auch Sauberzweig an Brandt, 30.9.1943, BArchB, NS 19/2601, Bl. 25. Vgl. Sauberzweig an Berger, 30.9.1943, BArchB, NS 19/2601, Bl. 27. 
können Vorbild sein und das Vertrauensverhältnis schaffen, das wir brauchen.“ Er schlug deshalb vor, aus jeder Kompanie der Waffen-SS zwei fronterfahrene Unterführer zur „Handschar“ zu versetzen. Der Reichsführer SS hätte diesen Vorschlag zwar freudig entgegengenommen, doch Sauberzweig war sich nicht sicher, ob er jemals ausgeführt werden würde - und er lag richtig mit seiner Einschätzung: Im Gegensatz zu anderen Divisionen der Waffen-SS sollte die „Handschar“ stets nur mit zweitrangigen Führern und Unterführern ausgestattet werden. ${ }^{56}$

Entsprechend war es Sauberzweig in Neuhammer auch nicht möglich, die Division nach den Ausschreitungen in Frankreich „von allen hemmenden Elementen [zu] befreien“, denn dann würde die Division „an Führern und Unterführern so dünn besetzt sein, dass man sie nicht mehr als führungsfähig bezeichnen kann.“57 Als Beispiel führte Sauberzweig das Gebirgsjäger-Regiment 27 der „Handschar“ an, in welchem kein einziger Führer oder Unterführer anzutreffen wäre, der an Infanteriegeschützen oder am schweren Granatwerfer ausgebildet sei. Ähnlich verhielte es sich beim Gebirgsjäger-Regiment 2 dieser Division. ${ }^{58}$ Sauberzweig fragte: „Was nutzen die besten Waffen, was nutzt das beste Material, wenn nicht führungsmäßig das gegeben wird, was notwendig ist.“ In der Ausbildung würde zuviel Zeit verloren gehen, wenn das Führungspersonal fehlt und „die Anlieferung von Waffen in demselben Schneckentempo vor sich geht wie bisher."59 Denn das Kernproblem der unfertigen Division blieb seiner Ansicht nach, dass die dringend nötige sofortige Versetzung von Führern und Unterführen nicht erfolgte. ${ }^{60}$ Aber auch bei den Mannschaften hatte die Division mit Personalmangel zu kämpfen, denn die erwartete Masse von Freiwilligen blieb aus. ${ }^{61}$

Der zunehmende Personalmangel, welchen Sauberzweig beschreibt, trat aber nicht erst während der Aufstellung der „Handschar“ zutage, sondern ist eher als Grund für die Aufstellung der 13. Waffen-Gebirgs-Division der SS zu verstehen. ${ }^{62}$ Himmler beabsichtigte, durch die Rekrutierungen den Raum mit lokalem Personal zu befrieden, einerseits um knappe Personalressourcen zu sparen, andererseits auch in der Absicht, die bürgerkriegsähnliche Situation unter Kontrolle zu bringen. Zudem sollte die Rekrutierung lokaler Personen auch der Aufbau weiterer

56 Vgl. Petke, Vergemeinschaftungsversuche, S. 253.

57 Sauberzweig an Berger, 30.9.1943, BArchB, NS19/2601, Bl. 26.

58 Vgl. Sauberzweig an Berger, 30.9.1943, BArchB, NS19/2601, Bl. 26.

59 Ebd., Bl. 27.

60 Ebd., Bl. $27 \mathrm{f}$.

61 Ferhadbegović, Sabina, Schuldig, im Namen des Volkes, in: Themenportal Europäische Geschichte, www.europa.clio-online.de (14.3.2018), S. 2.

62 Vgl. Petke, Vergemeinschaftungsversuche, S. 248. 
Partisaneneinheiten erschweren. ${ }^{63}$ Laut Lepre stand bei Himmlers Überlegungen zur Aufstellung einer bosnisch-kroatischen Division zudem eher der Schutz der „volksdeutschen“ Bevölkerungsteile in Syrmien im Vordergrund, als der der muslimischen Bevölkerung, wie propagandistisch oft betont wurde. ${ }^{64}$ Himmler war sich sicher, durch die Aufstellung das Vertrauen der lokalen Bevölkerung zurückzugewinnen. $^{65}$

Nachdem die Rekrutierungsanstrengungen jedoch nicht die gewünschten Erfolge gezeigt hatten, ließ Hitler Ende 1943 die bisherigen Sühne- und Vergeltungsmaßnahmen für den südosteuropäischen Raum anpassen. Grund für diesen Sinneswandel waren sowohl die ausbleibenden Erfolge dieser Strategie die Partisaneneinheiten wuchsen trotz drakonischer Vergeltungsmaßnahmen weiter an - wie auch die Tatsache, dass der Sonderbeauftragte Südost, Hermann Neubacher, der die politische Zusammenarbeit am Balkan koordinierte, sich gegen die hohen Quoten von Erschießungen aussprach. Laut dem Oberbefehlshaber Südost, Generaloberst Alexander Löhr, sollte durch diese Anpassung „eine einheitliche Gegenaktion gegen die kommunistische Gefahr im Südosten“ durchgeführt werden. „Die bisher üblichen Sühne-, Straf-, und Vergeltungsmaßnahmen“ sollten der „neuen politischen Zielsetzung“ - auch hinsichtlich der Rekrutierungen für die Division „Handschar“ - angepasst werden. ${ }^{66}$ Löhr schien nun eine umsichtigere Vorgehensweise angebracht:

Erster Grundsatz muss sein, bei Anschlägen, Sabotageakten usw. die Täter selbst zu fassen und Sühnemaßnahmen erst in zweiter Linie zu ergreifen, wenn durch Sühnemaßnahmen die Verhütung künftiger Anschläge zu erwarten ist. [...] Das Verfahren, nach dem Überfall oder Sabotageakt aus der näheren Umgebung des Tatortes wahllos an Personen und Wohnstätten Sühnemaßnahmen zu vollziehen, erschüttert das Vertrauen in die Gerechtigkeit der Besatzungsmacht und treibt auch den loyalen Teil der Bevölkerung in die Wälder. ${ }^{67}$

Löhrs Aussage zeigt deutlich, dass Wehrmacht und Waffen-SS auf die Mit- und Zusammenarbeit der lokalen Bevölkerung angewiesen waren - und somit Wege finden mussten, diese auf möglichst freiwilliger Basis $\mathrm{zu}$ rekrutieren; umso-

$63 \mathrm{Zu}$ dieser Taktik gibt es sehr anschauliche Beispiele aus dem albanisch-serbischen Grenzgebiet. Vgl. Zaugg, Albanische Muslime, S. 312.

64 Vgl. Lepre, Himmler's Bosnian Division, S. 18.

65 Vgl. Himmler an SS-Führungshauptamt, SS-Personalhauptamt, SS-Hauptamt, SS-Gruppenführer Phleps und SS-Brigadeführer von Oberkamp, 31.3.1943, BArchB NS19/2601, Bl. 7.

66 Oberbefehlshaber Südost, Generaloberst Alexander von Löhr, Abschrift „Sühnemaßnahmen“, 22.12.1943, BArchF, RW 40/89, S. 1.

67 Ebd. 
mehr, weil das Vertrauen der Zivilbevölkerung in die Besatzungsmacht seit 1941 schwer gelitten hatte. ${ }^{68}$

\subsubsection{Eine Brücke bauen? Nationalsozialismus und Islam}

Die Brücke, die zwischen der Pseudoreligion „Nationalsozialismus“ und dem Islam geschlagen werden sollte, zeigt sich in Bezug auf die südosteuropäischen SS-Divisionen bei den Rekrutierungen für die „Handschar“ besonders deutlich. Hier spielte vor allem der Modellcharakter, welcher der 13. Waffen-Gebirgs-Division der SS zugedacht war, eine zentrale Rolle. Sie sollte nämlich als Aushängeschild für zukünftige Rekrutierungen in arabischen Staaten dienen. In Himmlers Vorstellung warteten Millionen Muslime darauf, für den Nationalsozialismus zu kämpfen. ${ }^{69}$ Er war der Meinung, dass diese erste von drei südosteuropäischen, muslimisch geprägten Divisionen

erstmalig eine Verbindung zwischen Islam und Nationalsozialismus bezw. [sic] zwischen der arabischen und der germanischen Welt auf offener, ehrlicher Grundlage [schaffen würde], da die Division bluts- und rassemäßig vom Norden, weltanschaulich geistig dagegen vom Orient gelenkt wird. ${ }^{70}$

Den bosnischen Muslimen dachte Himmler eine Brückenfunktion zu, so Ferhadbegović: Als nationalsozialistisches Verbindungsglied zwischen Okzident und Orient sollten sie der Türöffner in die Welt des Islams werden. ${ }^{71}$ Die Namensgebung betonte sowohl den orientalisch-osmanischen Charakter als auch die Wehrhaftigkeit des neu aufzustellenden Verbands: „Handžar“ ist ein traditioneller Krummdolch, der sowohl in Persien (Khanjar) als auch dem Osmanischen Reich (Hançer) unter diesem Namen bekannt war. Er wurde bei Zeremonien getragen, hat in arabischen Staaten bis heute Symbolcharakter und ziert beispielsweise die Nationalflagge Omans. Ein weiteres Symbol, welches die orientalistische Ausrichtung der „Handschar“ erahnen lässt, ist der Fez als Kopfbedeckung in Feldgrau. $^{72}$

Die Nationalsozialisten zählten die Bosnier „völkisch-rassisch gesehen (überwiegend dinarisch) zur germanischen Welt, weltanschaulich geistig gesehen

68 Vgl. Nedim Salihbegovic, „Bericht zur Lage“, 25.9.1943, BArchB, NS 19/2601, Bl. 30.

$69 \mathrm{Vgl}$. Zaugg, Völkische islamophile Orientalistik, S. $1202 \mathrm{f}$.

70 SS-Hauptsturmführer, Unterschrift nicht lesbar, Abschrift „Betr. Weltanschaulich geistige Erziehung der muselmanischen SS-Division. Bez: Mündlicher Befehl Chef SS-Hauptamt“, 19.5.1943, BArchB, NS 19/2601, Bl. 245.

71 Vgl. Ferhadbegović, Vor Gericht, S. 231.

72 Vgl. Gesandter Kasche an AA, 23.3.1943, PAAA Inland IIg R00998. 
aber zur arabischen Welt"“ ${ }^{73}$ Zentraler Berührungspunkt zwischen Islam und Nationalsozialismus sollte der Antisemitismus werden. ${ }^{74}$ Um den vermeintlich zu großen Teilen deckungsgleichen ideologischen Konzepten zwischen Nationalsozialismus und Islam und dem hohen Stellenwert, den der Islam in der neu aufzustellenden Division haben sollte, Ausdruck zu verleihen wurden bereits für die Werbephase Imame hinzugezogen. Diese sollten auch in der Ausbildung und schließlich im Divisionsalltag die politisch-ideologische und religiöse Schulung beaufsichtigen. ${ }^{75}$ Sie erhielten eine Ausbildung sowohl in religiösen als auch weltanschaulichen Bereichen und waren entsprechend ideologisch geschult, wie etwa der Divisions-Imam, SS-Hauptsturmführer Husein Đozo, der gegenüber Himmler die Bereitschaft der bosnischen Muslime betonte, „unser Leben im Kampf für den großen Führer Adolf Hitler und das Neue Europa einsetzen zu wollen“ ${ }^{76}$

Bei der Analyse der Aufstellung dieser ersten muslimischen Division muss das Fernziel Himmlers immer mitgedacht werden: Mit dieser Division wollte er einen guten Eindruck bei anderen, auch nicht-europäischen, muslimischen Staaten erzielen. Denn in seinen Augen waren diese Muslime, „die dem Aufruf der islamischen Führung gehorchend, aus Hass gegen den gemeinsamen englisch-jüdisch-bolschewistischen Feind und aus Verehrung und Treue zu dem von allen Mohamedanern verehrten Führer Adolf Hitler“ in Südosteuropa in den Reihen der Waffen-SS kämpften, nur die Speerspitze einer weitaus größeren Zahl potentieller muslimischer Soldaten, die er für weitere Kriegsjahre in Betracht zog. Aus diesem Grund verbot er auch ,jedes sonst im Kameradenkreis beliebte Witzeln oder ,Auf den Arm nehmen“ der mohammedanischen Freiwilligen“, denn diese „in die Zehntausende gehende Anzahl fanatischer Freiwilliger“ sollte nicht „wegen der Torheit und Engstirnigkeit eines Einzelnen“ geschmälert werden. ${ }^{77}$ Obwohl der Islam wie auch die Imame in der ersten Zeit der Werbung einen wichtigen Stellenwert einnahmen, verringerte sich ihr Einfluss bis Herbst 1943 drastisch. Dieser Umstand war einerseits der allgemeinen Kriegslage geschuldet, hing aber auch mit der Verlegung der „Handschar“ nach

73 SS-Hauptsturmführer, Unterschrift nicht lesbar, Abschrift „Betr. Weltanschaulich geistige Erziehung der muselmanischen SS-Division. Bez: Mündlicher Befehl Chef SS-Hauptamt“, 19.5.1943, BArchB, NS 19/2601, Bl. 245 (Hervorhebung im Original).

74 Vgl. Zaugg, Völkische islamophile Orientalistik, S. 1204.

75 13. SS-Division / Flugblatt-Entwurf Nr. 3, BArchB, NS 19/2601, Bl. 171.

76 Divisions-Imam der „Handschar“ SS-Hauptsturmführer Đozo an Sauberzweig zur Weiterleitung an Himmler, 6.12.1943, BArchB, NS 19/2061, Bl. 47.

77 Entwurf Himmler, August 1943, BArchB, NS 19/2601, Bl. 148. 
Südfrankreich und schließlich mit der sporadischen Zusammenarbeit mit Četnikverbänden zusammen. ${ }^{78}$

\subsubsection{Brückenbauer Mohammed Amin al-Huseini}

In dieselbe Richtung weist die enge Zusammenarbeit mit dem Großmufti von Jerusalem, Mohammed Amin al-Huseini, der sowohl für die Werbung von Freiwilligen als auch die religiöse Ausrichtung der Division verantwortlich zeichnen sollte. Al-Huseini selbst gilt innerhalb der Forschung als kontroverse, bisweilen zwielichtige Figur. Obwohl bereits sein Großvater das Amt des Großmuftis bekleidet hatte, ließ die dazu notwendige religiöse Bildung al-Huseinis zu wünschen übrig. Gensicke betont, dass die einzigen Anhaltspunkte in dieser Richtung aus dem Jahr 1912 stammen, als al-Huseini dem Kreis der Schüler des Scheichs Muhammed Rashid Rida in Kairo angehörte. ${ }^{79}$ Nachdem er 1913 nach Mekka gepilgert war, begann er ein Studium an einer Verwaltungshochschule in Istanbul und besuchte die Militärakademie. ${ }^{80}$ Im Ersten Weltkrieg diente er als Artillerie-Offizier im Osmanischen Heer. Noch 1918 unterstützte er die Briten bei den Rekrutierungen von Palästinensern für die „Sherif-Armee“. Doch als die in der Balfour-Deklaration geäußerte Unterstützung der Engländer für den Aufbau eines jüdischen Staates durchsickerte, wandte sich al-Huseini von diesen ab. ${ }^{81}$ Als es 1920 in Jerusalem zu Unruhen kam, bei welchen mehrere Juden ihr Leben verloren und über 200 verletzt wurden, wurde al-Huseini in Abwesenheit von den Briten zu zehn Jahren Gefängnis verurteilt. Ihm wurde vorgeworfen, zu diesen Ausschreitungen aufgerufen zu haben. Nachdem 1921 eine britische Zivilverwaltung die Militärverwaltung Palästinas abgelöst hatte, wurde al-Huseini durch den Hochkommissar des britischen Völkerbundsmandats für Palästina, Herbert Louis Samuel, zum Mufti von Jerusalem ernannt. Dieser Ernennung waren einige Ungereimtheiten bei der Wahl des Großmuftis vorausgegangen - al-Huseini hatte sich weder unter den ersten drei platzieren können, noch war seine religiöse Qualifikation für dieses Amt ausreichend. ${ }^{82}$

78 Vgl. Bougarel, La division Handschar, S. 335.

79 Vgl. Klaus Gensicke, Der Mufti von Jerusalem und die Nationalsozialisten: eine politische Biographie Amin el-Husseinis, Darmstadt: Wissenschaftliche Buchgesellschaft 2007, S. 18.

80 Ebd.

81 Ebd. Vgl. auch Rede al-Huseinis zur Eröffnung des Islamischen Zentral-Instituts in Berlin, 18.12.1942, in: Höpp, Mufti-Papiere, S. 124.

82 Vgl. Gensicke, Mufti von Jerusalem, S. 20. 
Als 1937 Lewis Andrews, Distriktbeauftragter für Galiläa, im Zuge antibritischer Auseinandersetzungen ermordet wurde, floh al-Huseini, um einer Verhaftung zu entkommen. 1941 gelangte er schließlich mit gefälschtem Pass über die Türkei nach Italien und von dort nach Deutschland, wo er der nationalsozialistischen Regierung mehrmals seine Zusammenarbeit anbot. Zuerst wurde diese Zusammenarbeit nur zögerlich in Anspruch genommen, aber als sich die personelle Situation der deutschen Armee aufgrund hoher Verluste während der Kriegsjahre 1941/42 rasch verschlechterte, erschien das Angebot des Großmuftis in neuem Licht. Über ihn hofften Himmler und Berger in den arabischen Ländern Gehör zu finden und diese von den Vorteilen einer militärischen Zusammenarbeit zu überzeugen. ${ }^{83}$ Auch der Mufti selbst war sich im Klaren darüber, dass sich seine eigenen politischen Ziele nur verwirklichen ließen, „wenn die Achsenmächte siegreich aus diesem Krieg hervorgingen.“84

Anfang Oktober 1942 schrieb er dem deutschen Diplomaten Erwin Ettel: „A number of strong bonds tie the German and Arab nations together. Germany is the only power, which is trying to liquidate the Jewish problem completely, and is destroying the power of Britain and of Communism. "85 Diese drei Eckpfeiler sollten als Fundament für die Rekrutierungspropaganda al-Huseinis und der Nationalsozialisten auf internationaler Ebene dienen. Auf lokaler Ebene waren es weitaus pragmatischere Töne, welche Berlin anschlug: Autonomieversprechungen für Bosnien, Schutz und die Versorgung mit Waffen versprachen höhere Rekrutierungserfolge. ${ }^{86}$

Dass al-Huseini seinen bevorstehenden Einsatz als Werbeleiter zukünftiger Rekrutierungen für die erste muslimische Waffen-SS-Division in einem größeren Zusammenhang sah, belegt auch sein Schreiben an Ribbentrop vom Oktober 1942:

Herr Reichsaußenminister! In dem Augenblick, in welchem die militärischen Ereignisse die Truppen der Achse näher an die arabischen Länder des Nahen Ostens heranführen, habe ich mit reinem Gewissen und in dem Gefühl voller Verantwortung gegenüber dem arabischen Volk [...] den Wunsch, meine ganze Person und die ganze gläubige Kraft meiner Gefolgsleute für die aktive Zusammenarbeit mit Deutschland und Italien einzusetzen. ${ }^{87}$

83 Bereits 1947 belegte Simon Wiesenthal mit seiner Publikation über al-Huseini dessen Tätigkeit im Auftrag des NS-Regimes. Wiesenthal, Simon, Großmufti: Großagent der Achse, Salzburg 1947.

84 AA, Ausland Abwehr, gez. Erwin Ettel, 2.12.1942, BArchB, nach: Höpp, Muftipapiere, S. 42.

85 Memorandum al-Huseini an Ettel, Anfang Oktober 1942, nach: Höpp, Muftipapiere, S. 80.

86 Vgl. etwa Lepre, Himmler's Bosnian Division, S. 25.

87 Al-Huseini an Ribbentrop, 10.10.1942, nach: Höpp, Muftipapiere, S. 91, 116. 
Al-Huseini versprach Unterstützung bei der Suche nach geeigneten Formulierungen und Themen bei Propagandaschriften für den arabischen Raum und hielt am 11. November 1942 eine als „Märtyrerrede“ bekannt gewordene Rundfunkansprache. ${ }^{88}$

Am 30. März 1943 trat al-Huseini schließlich gemeinsam mit Vertretern des SS-Hauptamtes eine Reise durch Bosnien an, „um dort aufklärend und werbend für die Aufstellung der muselmanischen SS-Division zu wirken und vor allen Dingen die Widerstände zu beseitigen, die sich innerhalb der muselmanischen Bevölkerung - bedingt durch die derzeitigen Umstände und die militärische Lage im kroatischen Raum ergeben hatten“. ${ }^{89}$ Im Januar 1944 absolvierte er einen zweiten Besuch bei der Division, diesmal auf dem Truppenübungsplatz in Neuhammer. Beide Reisen wurden dokumentiert und propagandistisch genutzt. ${ }^{90}$

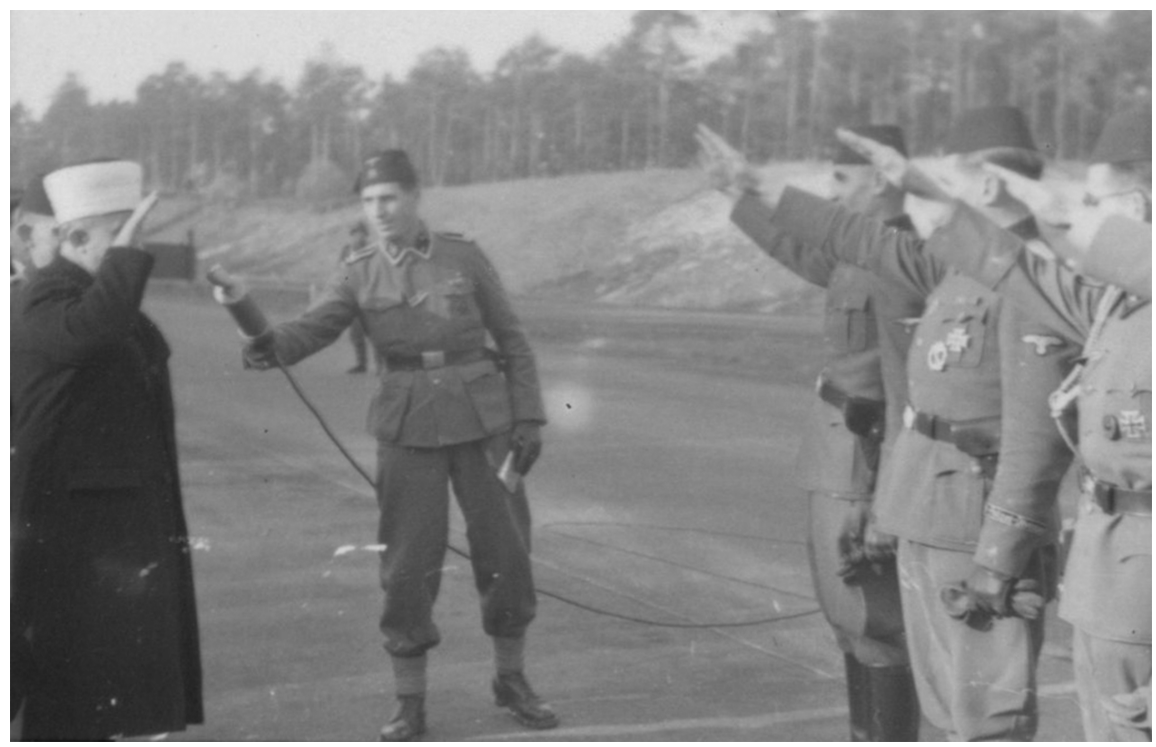

Abb. 15: Al-Huseini und Sauberzweig begrüßen sich. ${ }^{91}$

88 Memorandum al-Huseinis an Kapp, November 1942 und al-Huseinis Rundfunkrede an die Araber („Märtyrerrede“), 11.11.1942, nach: Höpp, Muftipapiere, S. 93-97 und 103-107.

89 RFSS Himmler, Geschichte und Entstehung der SS-Freiwilligen-b.h.-Geb. Division (13. SSDivision) v.10.11.1943, IfZ, Nbg.Dok., NO-3577, nach: Gensicke, Mufti von Jerusalem, S. 116. Siehe zu den Werbeinsätzen al-Huseinis allgemein: Gensicke, Mufti von Jerusalem, S. 116-119. 90 Fotoserie Kriegsberichter Mielke, NARA.

91 Kriegsberichter Mielke, NARA, Nr. 7. 


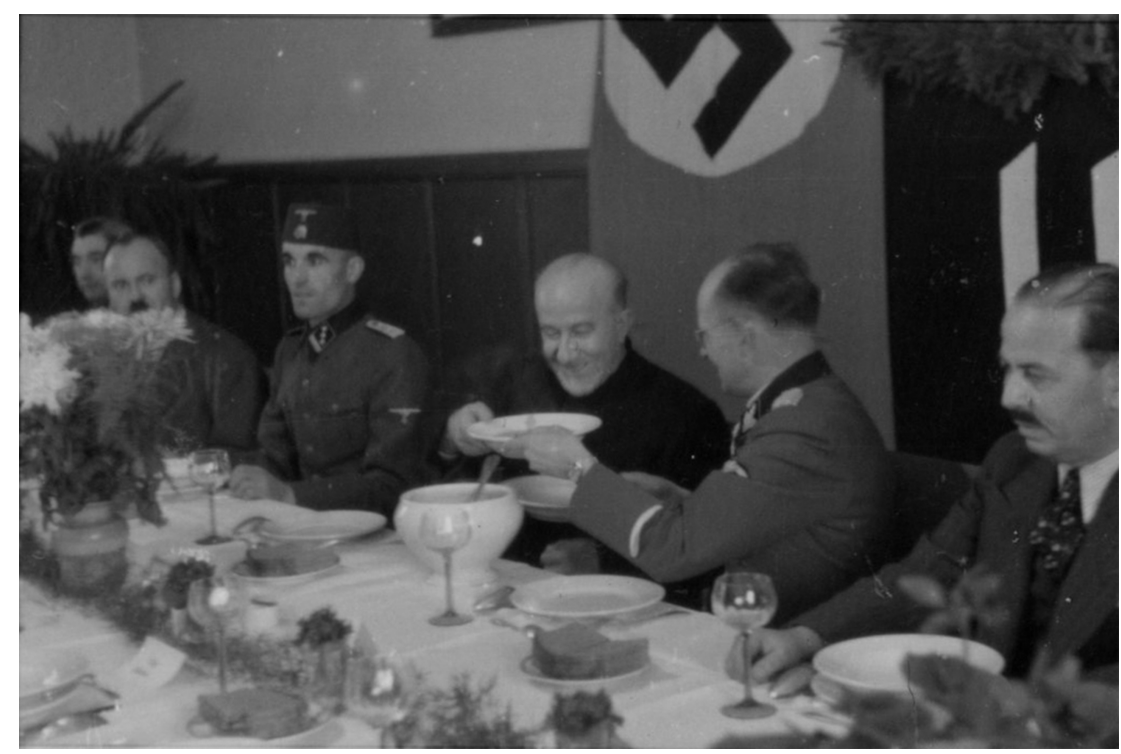

Abb. 16: Husein Đozo, Al-Huseini und Sauberzweig beim gemeinsamen Essen. ${ }^{92}$

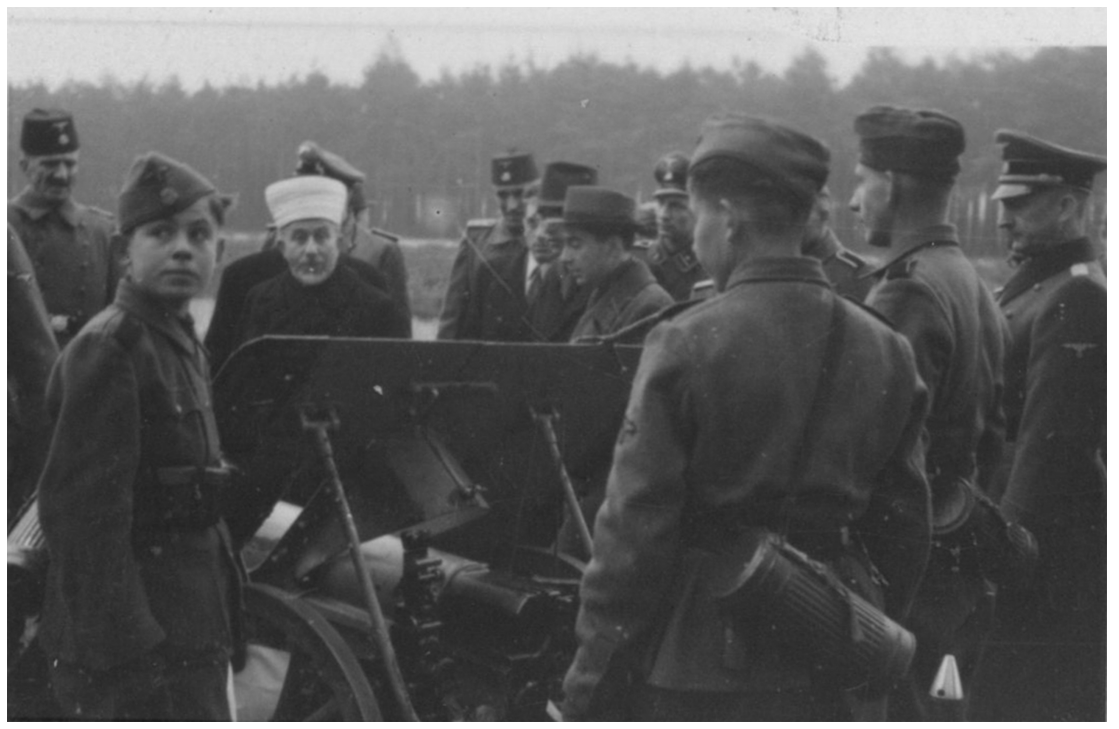

Abb. 17: Al-Huseini bei den Truppen mit einem jugendlichen Soldaten im Vordergrund. ${ }^{93}$

92 Kriegsberichter Mielke, NARA, Nr. 26.

93 Kriegsberichter Mielke, NARA, Nr. 6. 


\subsubsection{An die k.u.k.-Zeit anschließen: Das Bild vom treuen Bosniaken}

Ein wichtiger Faktor bei den Überlegungen zur Aufstellung einer bosnischen Division war auch das positive „Bosniaken-Bild“, welches die Deutschen im Allgemeinen hatten. In einer diplomatischen Korrespondenz vom 27. April 1939 hieß es: „Als Freund wie als Gegner nötigte der südslawische Soldat im Weltkrieg den Angehörigen des alten Reichsheeres höchste Achtung ab."94 Im Ersten Weltkrieg hatten in 36 Divisionen der österreichisch-ungarischen Vielvölkerarmee Bataillone mit Bosniern und Herzegowinern gekämpft. Die Soldaten dieser Einheiten wurden bis 1918 als Bosniaken bezeichnet, aber nur rund ein Drittel davon waren muslimischen Glaubens. Bis zum Zweiten Weltkrieg fand eine Begriffsverschiebung statt; der Begriff „Bosniaken“ bezeichnete nun vor allem die bosnischen Muslime. Wenn die Vertreter des Dritten Reiches von Bosniaken sprachen, meinten sie damit meistens die muslimische Bevölkerung Bosniens; war von den Bosniaken in der k.u.k. Armee die Rede, meinten sie sowohl muslimische als auch katholische Soldaten. $^{95}$

Zahlreiche Zeugnisse von Deutschen und „eingedeutschten“ Österreichern, oft Offiziere aus dem Ersten Weltkrieg, „bezeugen den Mut, die Loyalität und die Opferbereitschaft bosnischer Soldaten. “96 Auch im Sandžak, dem zweiten Rekrutierungsgebiet für die Division „Handschar“, waren die Muslime gegenüber den Österreichern größtenteils zuvorkommend aufgetreten. Offiziere berichteten, dass einflussreiche Familien ihre Zusammenarbeit angeboten hätten. ${ }^{97}$ Dieses Verhalten stieß auf österreichischer Seite auf fruchtbaren Boden,

94 Deutsche diplomatisch-politische Korrespondenz, Kz/St, Berlin, 27.4.1939, PAAA, R 103345, Bl. 036.

95 Vgl. Zaugg, „Ruhe, Sicherheit und Gerechtigkeit“. Erinnerungen bosnischer Waffen-SS Soldaten an die österreichisch-ungarische Herrschaft im Ersten Weltkrieg, in: Clemens Ruthner/Tamara Scheer, Annäherungen an eine Kolonie. Österreich-Ungarn und Bosnien-Herzegowina, Tübingen: Francke 2018, S. 441.

96 Ahmed Pašić, Bosniaks in WWI: Loyal, Obedient, Different, in: Luthar, Oto (Hg.), The Great War and Memory in Central and South-Eastern Europe, Leiden: Brill 2016, S. 91. Nedad Memić, Bewacht von Bosniaken, in: http://www.wienerzeitung.at/themen_channel/wissen/ge schichte/666823_Bewacht-von-Bosniaken.html (Stand: 17.1.2018). Christoph Neumayer, Erwin A. Schmidl, Des Kaisers Bosniaken. Die bosnisch-herzegowinischen Truppen in der k.u.k. Armee, Wien: Militaria 2008, S. 99, 103.

97 Vgl. Scheer, A Reason to Break the Haag Convention? The Habsburg Occupation Policy toward Balkan Muslims during World War I, in: M. Hakan Yavuz, Feroz Ahmad (Hgg.): War and Collapse. World War I and the Ottoman Empire, Salt Lake City: University of Utah Press 2016, S. 1013. 
denn in den Rängen der österreichisch-ungarischen Militärverwaltung hatte sich das Bild des „Muselmanen“ vom Feind (Osmanisches Reich) hin zum Verbündeten und potentiellen Opfer der Serben gewandelt. ${ }^{98}$ Einige dieser Bosniaken schafften es bis in habsburgische Eliteeinheiten, die als Sinnbild für Mut auf den Schlachtfeldern in Galizien, Serbien, an der Isonzo-Front und den Dolomiten fortdauerten. ${ }^{99}$

Natürlich waren auch der NS-Führung solche Erzählungen bekannt, und Hermann Neubacher, „Sonderbeauftragter Südost“ des Dritten Reiches, schrieb nachträglich, dass sich Hitler, um die militärischen Ressourcen zu nutzen, auf dem Balkan für eine „positive Muselmanenpolitik“ aussprach und „damit in die Fußstapfen des Wiener Ballhausplatzes [trat], dessen Politik im okkupierten Bosnien-Herzegowina von peinlicher Rücksichtnahme auf die Empfindlichkeit der islamischen Welt diktiert war“. ${ }^{100}$ Bereits im Frühjahr 1943 war sich Himmler während der laufenden Verhandlungen mit der kroatischen Regierung sicher, dass die potentiellen Rekruten „als Bosniaken [...] sicherlich treue Soldaten auf unserer Seite sein [würden]. “101 Die erste Ausgabe der Divisionszeitung „Handžar“, die auf Deutsch und Bosnisch erschien, widmete sich den Verdiensten der bosnisch-herzegowinischen Regimenter im Ersten Weltkrieg. Der Titel „Eine alte Tradition lebt neu auf“ verweist auf die Absicht, dass die neue Waffen-SS-Division an die Erfolge aus dem Ersten Weltkrieg anknüpfen sollte. $^{102}$

\subsubsection{Die involvierten deutschen Dienststellen}

Während der gesamten Dauer der Rekrutierungen von Muslimen im NDH und angrenzenden Gebieten für die Waffen-SS herrschte zwischen den Vertretern der Waffen-SS, der Allgemeinen SS, des Auswärtigen Amtes und der Wehrmacht Uneinigkeit. Bereits 1971 stellte Sundhaussen zur Ausgangslage und Entwicklung zwischen diesen Institutionen in Bezug auf die Rekrutierungen für die „Hand-

98 Vgl. Franziska Zaugg, Ruhe, Sicherheit und Gerechtigkeit, S. 442.

99 Pašić, Bosniaks in WWI, S. 85.

100 Neubacher, Sonderauftrag Südost, S. 33.

101 Himmler an Phleps, „Blitz-Fernschreiben“, 20.2.1943, BArchB, NS 19/3523, Bl. 41f. Mit der Bezeichnung „Bosniaken“ stellte er einen klaren Bezug zu den bosniakischen Regimentern der Donaumonarchie her.

102 Bernwald, Muslime in der Waffen-SS, S. $338 \mathrm{f}$. Vgl. Lepre, Himmler's Bosnian Division, S. 25. 
schar“ fest, dass die Werbung kroatischer Staatsbürger für die Waffen-SS nicht nur dem allgemeinen Völkerrecht, sondern auch der Haager Landkriegsordnung zuwiderlief und „darüber hinaus das Verhältnis einzelner Dienststellen der Gesamtorganisation-SS [sic] untereinander wie auch ihre Stellung zu den staatlichen Institutionen des Dritten Reiches deutlich [machte], vor allem zum Auswärtigen Amt und zur Wehrmacht. “103 Doch so intensiv der Konkurrenzkampf zwischen den deutschen Dienststellen vor Ort auch sein mochte, gewisse Akteure innerhalb des deutschen Besatzungsapparats sahen durchaus positive Seiten einer Zusammenarbeit. ${ }^{104}$ So schrieb beispielsweise der Sonderbeauftrage Südost über seine Zusammenarbeit mit dem Oberbefehlshaber Südost, Generalfeldmarschall Maximilian Freiherr von Weichs:

In meinem Auftrage stand der Satz: ,Ich mache dem Oberbefehlshaber Südost und dem Sonderbevollmächtigten des Auswärtigen Amtes für den Südosten die engste kameradschaftliche Zusammenarbeit zur Pflicht.‘ Diese Pflicht, mit dem perfekten Kavalier Generalfeldmarschall Freiherr von Weichs kameradschaftlich zusammenzuarbeiten, wurde mir in der düsteren Partisanen- und Bürgerkriegswelt, in die ich gestellt wurde, ein Vergnügen, an das ich gern zurückdenke. ${ }^{105}$

Ganz anders stand es um die Zusammenarbeit zwischen Vertretern der WaffenSS und dem deutschen Gesandten in Agram, Siegfried Kasche, deren Verhältnis eher von persönlicher Abneigung geprägt war. Zwischen Wehrmacht und Waffen-SS hingegen gaben vor allem die knappen Personalressourcen immer wieder Anlass zu Auseinandersetzungen.

In die Rekrutierungen für die muslimische SS-Division in Kroatien waren zahlreiche Stellen und Personen involviert: Dies waren auf oberster Ebene der Reichsführer SS Heinrich Himmler und der Chef des SS-Hauptamtes Gottlob Berger, der Kommandeur des V. Gebirgskorps und Kommandeur der bereits bestehenden Division „Prinz Eugen“ Artur Phleps sowie zahlreiche weitere Protagonisten, die bei der Werbung und Aufstellung der „Handschar“ mithalfen, so der erste Divisionskommandeur, SS-Standartenführer Herbert von Obwurzer, der spätere Divisionskommandeur Karl-Gustav Sauberzweig, HSSPF Kroatien Konstantin Kammerhofer, HSSPF Serbien und Montenegro Hermann Behrends sowie SSPF Sandžak Karl vonKrempler. Dem Aufstellungsstab, welcher am 9. März 1943 in Berlin zusammengestellt wurde, gehörten SS-Standartenführer Herbert von Obwurzer, SS-Sturmbannführer Erich Braun, der zum Ia der Division ernannt

103 Sundhaussen, Waffen-SS in Kroatien, S. 176.

104 Vgl. hierzu auch Gerlach, Rivalry and Competition, S. $13 \mathrm{f}$.

105 Neubacher, Sonderauftrag Südost, S. 128. 
wurde, sowie SS-Hauptsturmführer Götz Berens von Rautenfeld, SS-Hauptsturmführer Otto Küster und SS-Obersturmführer Walter Lüth an. ${ }^{106}$ Himmler wies explizit darauf hin, dass er auch HSSPF Kammerhofer an den Rekrutierungen beteiligt wissen wollte. ${ }^{107}$ Jede dieser Stellen pflegte selbst Kontakte zu kroatischen Institutionen und trat somit in Konkurrenz zur deutschen Gesandtschaft in Agram. Selbst vor Intrigen schreckten die Konkurrenten nicht zurück: So habe das Auswärtige Amt der Ustaša davon abgeraten, enge Bindungen mit der SS einzugehen, während Berger den kroatischen Botschafter in Berlin, Mile Budak, seinerseits vor Unterstaatssekretär Luther warnte. ${ }^{108}$

\subsubsection{Auseinandersetzungen zwischen Auswärtigem Amt und SS}

Nach einer Besprechung zwischen Hitler und Himmler am 13. Februar 1943 in der Wolfsschanze über den Aufbau dieser ersten muslimischen Division informierte Himmler Phleps über seine zukünftigen Aufgaben. ${ }^{109}$ Phleps wiederum benachrichtigte den deutschen Gesandten in Zagreb Siegfried Kasche am 18. Februar 1943, der zunächst nicht abgeneigt reagierte. ${ }^{110}$ Dies sollte sich jedoch schon bald ändern.

Kasche hatte den Rang eines SA-Obergruppenführers und war von Hitler als Gesandter I. Klasse in Agram eingesetzt worden. Während des Röhm-Putschs 1934 entging er seiner Ermordung nur, weil er Hermann Göring überredete, ihn zu verschonen. Laut Sundhaussen habe aber Himmler ihn ermorden lassen wollen. ${ }^{111}$ Sein Verhältnis zur SS war demnach nicht von Vertrauen geprägt, und auch von der muslimischen Bevölkerung im NDH hielt Kasche nicht viel. Entsprechend unterstützte er bis zum Schluss das Ustaša-Regime. ${ }^{112}$ Konsultiert man die zahlreichen Akten, die sein Verhalten hinsichtlich der Aufstellung einer kroa-

106 Vgl. Lepre, Himmler's Bosnian Division, S. 25.

107 Vgl. ebd., S. 24, 27. Kroatien hatte offiziell keinen HSSPF, Kammerhofer war in der Funktion eines HSSPF als Beauftragter des Reichsführer SS beim Befehlshaber der deutschen Truppen in Kroatien. Vgl. Schulz, Wegmann, Zinke, Die Generale der Waffen-SS und der Polizei, Bd. 2, S. 437.

108 Vgl. Korb, Im Schatten des Weltkriegs, S. 112.

109 Vgl. Lepre, Himmler's Bosnian Division, S. 19. Vgl. Funkspruch Himmler an Phleps, 13.2.1943, BArchB NS19/2601, Bl. 2 .

110 Kasche an Ribbentrop, 18.2.1943, PAAA, Inland IIg, R100998.

111 Sundhaussen, Waffen-SS in Kroatien, S. 186. Vgl. auch Korb, Im Schatten des Weltkriegs, S. 111 .

112 Vgl. Motadel, Islam and the Nazi Germany's War, S. 185. 
tisch-bosnischen SS-Division widerspiegeln, könnte man gar zur Überzeugung gelangen, er habe absichtlich gegen die SS gearbeitet: In seiner Rolle als Gesandter schaffte er es immer wieder, Himmlers Vorhaben hinsichtlich der Rekrutierungen von Bosniaken und später von Albanern zu verzögern und einzuschränken. Zahlreiche Dokumente belegen die gegenseitige Missgunst zwischen SS und Kasche im NDH-Staat. ${ }^{113}$ Die geplanten Rekrutierungen von bosnischen Muslimen boten Kasche mannigfaltig Gelegenheit, sich an der SS zu rächen, etwa indem er über wichtige Besprechungen nicht informierte oder sich mit Hinweis auf seine Funktion auf die Seite der kroatischen Regierung stellte. ${ }^{114}$ Sauberzweig meldete Berger hinsichtlich Kasches Verhalten Ende September 1943, „dass [die Werbung] zur Zeit in den Händen derjenigen Leute liegt, die die Aufstellung der Division [„Handschar“] sabotieren. “"115 Berger ging sogar noch einen Schritt weiter und beschuldigt Kasche, die Meuterei in der „Handschar“ provoziert zu haben, da er darauf bestanden habe, 2.800 Katholiken in die Division aufzunehmen. ${ }^{116}$ Zum selben Zeitpunkt äußerte Kasche die Meinung, dass alle deutschen Dienststellen dem NDH als ihrem Verbündeten Respekt entgegenbringen und in einheitlicher Weise handeln sollten. Der Idee einer autonomen Region Bosnien-Herzegowina und einer muslimischen Waffen-SS-Division stand er bis zum Ende ablehnend gegenüber. ${ }^{117}$ Kasche machte mehrmals deutlich, dass er gegen die Rekrutierung von Muslimen im NDH war, in einem Brief an Himmler vom 26. November 1943 wurde aber offenkundig, dass sich die Möglichkeiten seiner Einflussnahme im Ustaša-Staat verringert hatten und er dem Reichsführer SS das Recht zur Werbung in seiner Argumentationsweise nicht länger absprechen konnte. Dennoch versuchte Kasche Himmler vom Projekt der Rekrutierung bosnischer Muslime in die Waffen-SS weiterhin abzubringen und betonte dessen Undurchführbarkeit und die negativen politischen Auswirkungen. ${ }^{118}$ Bei späteren Verhandlungen versuchte Berger Kasche zu isolieren, indem er über Kontingente mit dem zuständigen Beauftragten des Auswärtigen Amtes in Belgrad, Felix Benzler, verhandelte oder ihn zu wichtigen Besprechungen nicht mehr einlud. ${ }^{119}$

113 Vgl. Zaugg, Albanische Muslime, S. 111. Korb, Im Schatten des Weltkriegs, S. 106, 111-115. 114 Vgl. Schreiben betr. „Aufstellung einer SS-Legion aus bosnischen Mohammedanern“, Chef Sicherheitspolizei und SD Ernst Kaltenbrunner an Reichsführer SS Heinrich Himmler, 24.4.1943, BArchB NS19/2601, Bl. 11.

115 Sauberzweig an Berger, 30.9.1943, BArchB, NS 19/2601, Bl. 28.

116 Vgl. Berger an Himmler, 25.9.1943, BArchB, NS 19/2601, Bl. 22.

117 Vgl. Redžić, Bosnia and Herzegovina, S. 44.

118 Vgl. Birn, Höhere SS- und Polizeiführer, S. 270.

119 Vgl. Berger an das AA, „Betreff: Freiwillige für die 13. (kroatische) SS-Division aus dem Sandžakgebiet“, 9.4.1943, PAAA, R100998, H297616.Vgl. Voelkers an Kasche, 14.8.1944, PAAA, 


\subsubsection{Konkurrenz um Personal zwischen Wehrmacht und Waffen-SS}

Die Waffen-SS hatte bei ihren Rekrutierungen nicht nur mit der kroatischen Regierung und den Ressentiments Kasches zu kämpfen, auch die Wehrmacht stellte Ansprüche auf kroatische Soldaten. ${ }^{120}$ Diese Konkurrenz zwischen der deutschen Wehrmacht als traditionelle staatliche Institution bzw. „Waffenträger der Nation“121 und der Waffen-SS als erst 20-jährige nationalsozialistische Organisation trat nicht nur im NDH zutage. Auch für andere Gebiete Südost- und Osteuropas kann der Kampf um Personalressourcen, der seit Kriegsbeginn immer wieder in Erscheinung trat, anhand verschiedener Quellen nachgewiesen werden. ${ }^{122}$ Die gezielte Rekrutierung von Muslimen stellte gerade für Einheiten und Verbände der Wehrmacht kein Novum dar, sondern setzte bereits 1942 ein, so etwa mit den Aushebungen für das „Turkbataillon 450“, den „krimtatarischen Selbstschutzeinheiten“ oder den 53 Infanteriebataillonen mit bis zu 53.000 Mann, die in die sogenannten Ostlegionen eingegliedert wurden. Mit der Aufstellung einer muslimischen Division trat Himmler nun in direkte Konkurrenz zu jenen Wehrmachtseinheiten. ${ }^{123}$ Edmund Glaise-Horstenau, der Deutsche Bevollmächtigte General in Kroatien, hatte in den Rekrutierungsvorbereitungen stets seinen Kooperationswillen gegenüber der Waffen-SS betont. Im März 1943 meldete sich schließlich der Chef des Oberkommandos der Deutschen Wehrmacht Wilhelm Keitel selbst zu Wort. Zu Recht bemerkte er, dass die Waffen-SS sich mit der Aufstellung der muslimischen Division eines ganzen Pools neuer ausländischen Soldaten bemächtigen wolle. ${ }^{124}$ Denn Himmlers erklärtes Ziel war, es nicht bei dieser einen muslimischen Division zu belassen, sondern ,dieses vermeintlich enorme Rekrutierungs- und Mobilisierungspotenzial für sich zu erschließen“. ${ }^{125}$ Keitel verlangte daher, dass

Inland IIg/R 100998. Korb merkt an, dass Kasches Einfluss ab 1942 stetig abgenommen habe. Vgl. Korb, Im Schatten des Weltkriegs, S. 113.

120 Vgl. ebd., S. 113, 115.

121 Vgl. Reichswehrministerium (Hg.), Waffenträger der Nation, Berlin: Verlag für vaterlämndische Literatur 1934.

122 Vgl. bspw. Bernhard R. Kroener, Die personellen Ressourcen des Dritten Reiches im Spannungsfeld zwischen Wehrmacht, Bürokratie und Kriegswirtschaft 1939-1942, in: Bernhard R Kroener, Rolf-Dieter Müller, Hans Umbreit, Organisation und Mobilisierung des deutschen Machtbereichs, hg. vom Militärgeschichtlichen Forschungsamt Potsdam, Das Deutsche Reich und der Zweite Weltkrieg, Bd. 5/1, Stuttgart: Deutsche Verlags-Anstalt 1988, S. 830-832.

123 Vgl. Petke, Muslime in der Wehrmacht und Waffen-SS, S. 263-272. Vgl. Petke, Militärische Vergemeinschaftungsversuche, S. 249. Vgl. detailliert auch Joachim Hoffmann, Die Ostlegionen 1941-1943.

124 Chef OKW Wilhelm Keitel, 8.3.1943, BArchB, NS19/1485.

125 Petke, Militärische Vergemeinschaftungsversuche, S. 249. 
sämtliche Rekrutierungsabsichten von der Wehrmacht und der Waffen-SS erst durch den Deutschen Bevollmächtigten General in Kroatien abgesegnet werden müssten ${ }^{126}$ und wies darauf hin, dass sich Himmler bereit erklärt habe, seinen Bedarf dort anzumelden. Dadurch sollte vermieden werden, „dass durch getrennte Anmeldungen ein Wettlauf der deutschen Dienststellen untereinander um die besten kroatischen Soldaten entsteht“. ${ }^{127}$ Doch vier Monate später meldete Berger Himmler verärgert, dass diese Weisung Keitels nun dazu missbraucht würde, die „Ersatzgestellung in Kroatien unter allen Umständen zu hemmen. “ ${ }^{128}$ Bergers Enttäuschung war groß, denn er und Himmler hatten angenommen, dass ihnen, indem sie ihre Kontingentwünsche bei der Wehrmacht anmeldeten, Soldaten zugeführt würden. Er schloss mit der spitzen Bemerkung, dass die Waffen-SS-Divisionen in Kroatien „nachweislich stehen und nicht wie die von der Wehrmacht aufgestellten [Verbände] zu den Banden überlaufen“ würden. Er war der Meinung, dass deshalb vor allem die Verbände der Waffen-SS ausgebaut und gestärkt werden müssten. ${ }^{129}$ Doch nicht nur die deutsche und kroatische Wehrmacht, selbst der Kommandeur der Schwesterdivision „Prinz Eugen“ zögerte, Personal an die „Handschar“ abzugeben. Der Befehlshaber der deutschen Truppen in Kroatien lehnte schließlich die Versetzung von Muslimen aus kroatischen Einheiten der deutschen Wehrmacht ab, da die Herauslösung eine Schwächung bedeutete und somit Auswirkungen auf alle deutschen Truppen in Südosteuropa hätte. ${ }^{130}$

\subsection{Ausgangslage und Absichten auf kroatischer, bosnisch- herzegowinischer und albanischer Seite}

Im folgenden Kapitel soll aufgezeigt werden, welche Absichten lokale Akteure auf verschiedenen Ebenen bezüglich der Rekrutierungen verfolgten und welches Vorgehen sie wählten. Auch dem Umstand, dass sich die Rekruten aus kroatischen, bosnisch-herzegowinischen und selbst serbischen und montenegrinischen Gebieten (Sandžak) zusammensetzen, sie daher je nach Heimatort

126 Chef OKW Wilhelm Keitel, 8.3.1943, BArchB, NS19/1485.

127 Ebd.

128 Vgl. Berger an Himmler, 7.7.1943, BArchB, NS19/1485.

129 Vgl. ebd.

130 Vgl. Kammerhofer an Berger, „Betr.: Aufstellung der Muselmanen-Division.“, vom 3. August 1943, BArch NS 19/3504, Bl. 39 und NS 19/ 3504, Bl. 30-36 nach Petke, Muslime in der Waffen-SS. Das Beispiel der 13. Waffen-Gebirgs-Division der SS „Handschar“ (kroatische Nr. 1) (unveröffentlichte Magisterarbeit Universität Potsdam), S. 77. 
unterschiedliche Ausgangslagen hatten und sich dadurch auch variierende Handlungsintentionen ergaben, soll hier Rechnung getragen werden. Auf übergeordneter Ebene spielten für den geplanten Aufbau einer „bosnischen“ bzw. „kroatischen“ Division auch die Handlungsintentionen und Verhaltensweisen staatlicher und nicht-staatlicher Institutionen sowie lokaler weltlicher und geistlicher Eliten eine zentrale Rolle.

\subsubsection{Auf der Suche nach Schutz vor Übergriffen}

Zum Rekrutierungsverhalten der Muslime im NDH schrieb SS-Brigadeführer und Generalmajor der Waffen-SS Ernst Fick im März 1944 an Himmler Folgendes: „Die Mohamedaner, die im Allgemeinen von Cetniks [sic] und Ustaschas bekämpft wurden, gehen z. T. zwangsläufig zu den Freiw. Verbänden der SS oder den Partisanen, um nicht weiterhin von Ustaschas, Cetniks [sic] und Partisanen gemordet zu werden. “131 Auch SS-Hauptsturmführer Hasan Bajraktarević nannte als Beitrittsgrund in die Waffen-SS den Wunsch der Muslime nach öffentlicher Sicherheit und Ordnung, die vor allem von Angriffen von Četniks und Partisanen betroffen waren. Bajraktarević sah den Grund für die Übergriffe in erster Linie darin, dass sich die muslimische Bevölkerung während und nach dem Balkanfeldzug den Deutschen gegenüber loyal gezeigt hatte: „Der Tatsache bewusst, dass die Muselmanen nach der Vorschrift ihres Glaubens aber auch nach dem natürlichen Idealismus gegenüber den Deutschen, als solche ein loyales Element, sind, beschlossen die Cetniks [sic] und Partisanen, sie zu vernichten.“132

Den brutalen Konflikten zwischen nationalen Streitkräften, Paramilitärs und Zivilisten während des Zweiten Weltkriegs waren „zwei Jahrzehnte erbitterten Streits wegen sozialer und nationaler Fragen im Königreich Jugoslawien“ vorausgegangen. ${ }^{133}$ Nach Ferhadbegović handelte es sich um einen Bürgerkrieg, in dem

131 Schreiben SS-Brigadeführer und Generalmajor der Waffen-SS Ernst Fick an Himmler, 16.3.1944, BArchB, NS 19/2601, Bl. 82. Vgl. Zaugg, Muslimische Albaner, S. 200.

132 Reisebericht SS-Hauptsturmführer Hasan Bajralitarović[Bajraktarević] an Phleps, 15.11.1943, BArchB, NS19/2601, Bl. 59.

133 Ferhadbegović, Vor Gericht, S. 229. Für detaillierte Ausführungen zur partiellen Zusammenarbeit und Konflikten zwischen den einzelnen Parteien (Partisanen, Ustaša und Četniks) im Zweiten Weltkrieg siehe Attila Hoare, Genocide and Resistance in Hitler's Bosnia. The Partisans and the Chetniks, 1941-1943, London: Oxford University Press 2006. Leider vergisst Hoare in diesem Buch, die durchaus intensive Zusammenarbeit zwischen Deutschen und Bosniern bzw. Kroaten in Bezug auf die Aufstellung und die Einsätze der Division „Handschar“ zu erläutern. Auch im Folgeband: The Bosnian Muslims in the Second World War räumt er der Division 
jeder gegen jeden kämpfte: Ustaša mordeten Serben, Juden und Roma; Četniks mordeten und plünderten in bosnischen und kroatischen Dörfern; kroatische und serbische Partisanen kämpften nicht nur gegen die deutschen und italienischen Truppen, sondern auch gegen Ustaša und Četniks. Und obwohl sich vor allem in den letzten beiden Kriegsjahren ein partielles Zusammengehen von Četnik-Einheiten mit deutschen Verbänden abzeichnete, existierten bis Kriegsende auch Četniks, die gegen die Deutschen kämpften. Gefangen zwischen all diesen Fronten fanden zahlreiche Zivilisten allein aufgrund ihrer nationalen, ethnischen oder religiösen Zugehörigkeit den Tod. ${ }^{134}$

Stellvertretend für die unzähligen Übergriffe und oft grausamsten Gewalteskalationen soll an dieser Stelle ein Bericht von Latif Moćević, Bürgermeister von Bukovica, stehen. Verfasst wurde er am 10. Februar 1943, kurz bevor die Rekrutierungen für die „Handschar“ einsetzten:

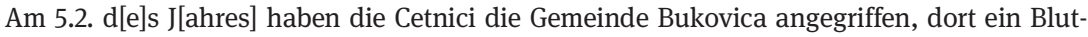
bad angerichtet und etwa 500 Männer, Frauen und Kinder verbrannt. Allein im Dorfe Mocevicima hat eine Abteilung der ,Befreiungstruppen“ übernachtet und dort 81 Dorfbewohner abgeschlachtet; sie haben Frauen, Kinder und Greise in die Häuser getrieben und diese mit den eingeschlossenen Menschen verbrannt. Sie haben die Leichen in eine vergrößerte Latrine geworfen und darüber eine Aufschrift angebracht: ,Die moslimische Moschee! Es wurden Mädchen gefunden, die man nach erfolgter Vergewaltigung gepfählt hatte. Jede der vielen Mädchen und auch Frauen in anderen Umständen sind von einer Reihe von Banditen vergewaltigt worden. Mehrere Mädchen wurden von den Banditen verschleppt und über ihr Schicksal ist bis heute nichts bekannt. Im Dorf Strazice wurde [die] Leiche des Hadschi Tahirović gefunden, dem man die Haut von den Kniekehlen über den Rücken und Kopf auf die Brust gezogen und daran eine Aufschrift befestigt hatte: ,Die Moslemin in der Feredze (Feredze=Verschleierung). In der Gemeinde wurden alle Moslimischen Wohnhäuser und Ställe niedergebrannt. ${ }^{135}$

Bereits im Laufe des Jahres 1941 hatte es unzählige Massaker und Plünderungen gegeben. So berichtete etwa die Vertretung der „Volksdeutschen“ in Jaice Anfang Dezember 1941 nach Zagreb, dass die muslimischen, kroatischen und „volksdeutschen“ Bewohner in Jaice „in ständiger Gefahr [lebten], ihr Hab und Gut

„Handschar“ nur wenig Platz ein - das Kapitel mit dem gleichnamigen Titel ist gerade mal eine Seite lang. Vgl. Hoare, Bosnian Muslims, S. $53 \mathrm{f}$.

134 Vgl. Ferhadbegović, Vor Gericht, S. 229. Ferhadbegović, Sabina, Schuldig, im Namen des Volkes, S. 2.

135 Bürgermeister von Bukovica, Latif Moćević, an den Kommandeur der Alpinen-Division in Plevlje, 10.2.1943, PAAA, Inland IIg, R100998. Andere Berichte bestätigten solch grausame Massaker, beispielsweise in der bosnischen Gemeinde Čajniče, wo Četniks Greise gekreuzigt, Kinder auf dem Rost gebraten und Frauen auf bestialische Weise vergewaltigt und gepfählt hätten. Vgl. Muslimen-Konferenz in Prijepolje, Bericht eines „Sandschak-Muselmanen“, ca. Februar 1943, PAAA, R100998. 
in Flammen aufgehen zu sehen, oder ausgeraubt und gemordet zu werden“. ${ }^{136}$ Um den Angriffen von verschiedenen Seiten etwas entgegenzusetzen, schlossen sich Bevölkerungsgruppen zu paramilitärischen Einheiten zusammen. ${ }^{137}$ Diese wiederum strebten danach, „durch massive Gewaltanwendung gegen die Zivilbevölkerung die Kontrolle zu erlangen und ihre Macht zu sichern“. ${ }^{138}$ Korb bestätigt, dass jede Partei versuchte, die Zivilisten zur Mitarbeit zu zwingen und diese so unweigerlich in die Konflikte hineingezogen wurden. Unter dem Druck verschiedener Gewalteinflüsse, verursacht durch das Kriegsgeschehen auf nationaler Ebene und plündernder und mordender Banden auf lokaler Ebene, waren es oft Zufälle und nicht eine bestimmte politische Überzeugung, die darüber entschieden, ob sich ein Serbe den Četniks oder den Partisanen oder ein Muslim den Partisanen oder der Division „Handschar“ anschloss. Da es oft in erster Linie darum ging, das eigene Überleben zu sichern, entschied man sich entweder für die Seite, von der man sich mehr Schutz versprach, die einen bereits zur Mitarbeit „aufgefordert“ hatte oder aber für diejenige, deren Lager sich in der Nähe befand. ${ }^{139}$ Wechselnde Mitgliedschaften in verschiedenen militärischen Formationen der Region, die oft wenig mit dem ideologischen Programm einer bestimmten Bewegung zu tun hatten, waren die Folge. ${ }^{140}$

Obwohl es sich bei den Ustaše vor allem um kroatisch-katholische Kämpfer handelte, kämpften teilweise auch Muslime in ihren Reihen. ${ }^{141}$ In manchen Gebieten kam es zur Zusammenarbeit zwischen serbischen Četniks und Muslimen sogenannte muslimische Četniks entstanden. ${ }^{142}$ Doch weder das partielle Zusam-

136 Deutsche Volksgruppe in Kroatien, Ortsgruppe Jaice an Volksgruppenführung, Hauptamt für Volkswirtschaft, Agram, 3.12.1941, BarchB NS19/319, Bl. 8. Jaice stand auch später im Brennpunkt der Konflikte: Im September 1942 wurde es von Partisanen eingenommen, fiel danach wieder an deren Gegner und wurde im November 1942 ein zweites Mal von den Partisanen besetzt. Vgl. Hoare, Bosnian Muslims, S. 99.

137 Vgl. ebd., S. 45.

138 Ferhadbegović, Schuldig, im Namen des Volkes, S. 2.

139 Vgl. Korb, Im Schatten des Weltkriegs, S. 88.

140 Vgl. Emily Greble: Rezension zu Hoare, Marko Attila: Bosnian Muslims in the Second World War. A History. New York 2014, in: H-Soz-Kult,12.12.2014, www.hsozkult.de/publication review/id/rezbuecher-21507. Hoare bezeichnet die Grenzen zwischen den einzelnen Bewegungen als fließend. Vgl. Hoare, Bosnian Muslims, S. 7.

141 Ferhadbegović, Schuldig, im Namen des Volkes, S. 2.

142 Bekannte Führer von muslimischen Četniks waren Ismet Popovac, Mustafa Pašić oder Major Fehim Musakadić. Draža Mihailović ernannte letzteren, einen ehemaligen Polizeichef aus Sarajevo, schließlich zum Kommandeur aller muslimischen Četnik-Kräfte. Vgl. Hoare, Bosnian Muslims, S. 48f. Auch in der Ost-Herzegowina kam es zu einer solchen Zusammenarbeit. Der bekannteste Vertreter war der radikale Muslim Osman Đikić. Hoare geht davon aus, dass dieses Phänomen auch als Ausdruck des von den Italienern angestrebten anti-kommunisti- 
mengehen von Muslimen und der Ustaša-Bewegung noch die Kooperationen zwischen muslimischen und serbischen Četniks konnten verhindern, dass bosnische Muslime weiterhin Angriffen kroatischer Ustaša- und insbesondere serbischer Četnik-Einheiten ausgesetzt waren. Bei seinem „Marsch auf Bosnien“ im Januar 1943 etwa wollte der Četnik-Führer Draža Mihailović nicht nur die kommunistischen Partisanen in der Bihać-Region vernichten, sondern verübte mit seinen Einheiten auch zahlreiche Massaker an der muslimischen Bevölkerung Bosnien-Herzegowinas und im Sandžak. ${ }^{143}$ Gleichzeitig waren diese Zivilisten aber auch Übergriffen durch Ustaša-Angehörige ausgesetzt. Beide Parteien stellten dabei verschiedene Überlegungen an: Die Četniks beschuldigten die Muslime, an anti-orthodoxen Ausschreitungen der Ustaša teilzunehmen, und rächten sich mit Gewalt. Die Ustaše hingegen begründeten ihre Übergriffe gegen die muslimische Bevölkerung damit, dass diese mit den Kommunisten sympathisieren würde. ${ }^{144}$ Diese Anschuldigung, so al-Huseini, traf die oft anti-kommunistisch eingestellten Muslime besonders hart. ${ }^{145}$

Am 9. Juni 1942 fasste er in einem Bericht an den deutschen Staatssekretär Ernst von Weizsäcker die Situation der Muslime seit Beginn des Balkanfeldzuges 1941 zusammen:

Von 5 Millionen Einwohnern Kroatiens sind circa 800.000 Muslime. Dieselben waren die ersten, die gegen den damaligen Staat Jugoslawien revoltierten und dadurch Deutschland und den Achsenmächten geholfen haben. Aus diesem Grund sind sie besonders der Rache der Kommunisten und Serben ausgesetzt. Ihre Dörfer werden verbrannt und geplündert und viele Menschen ermordet. [...] Sie erhoffen von Deutschland eine tatkräftige Hilfe zur Besserung ihrer augenblicklichen Lage, da sie andernfalls ihrer Vernichtung entgegengehen. ${ }^{146}$

Die von al-Huseini erwähnte Parteinahme von Teilen der muslimischen Bevölkerung im Frühjahr 1941, nicht zuletzt basierend auf positiven Erinnerungen an die letzte (österreichisch-ungarische) Besatzungsmacht und der damit verbundenen Autonomie, hatte lebensbedrohliche Konsequenzen und trug zur raschen Verschlechterung der Situation der muslimischen Bevölkerung im Ustaša-Staat bei. Al-Huseini schrieb in einer Beilage im Sommer 1942, dass die Muslime gut ein Jahr nach dem deutschen Balkanfeldzug über den geringen Schutz gegen

schen Partisanenkampfs mithilfe von Hilfstruppen zu sehen ist. Vgl. Hoare, Bosnian Muslims, S. 46f. Vgl. auch Redžić, Enver, Bosnia and Herzegovina, S. 143-146.

143 Vgl. Hoare, Bosnian Muslims, S. 104.

144 Vgl. Lepre, Himmler's Bosnian Division, S. $15 \mathrm{f}$.

145 Vgl. al-Huseini an Melchers, 30.4.1943, in: Höpp, Mufti-Papiere, S. 160 f.

146 Al-Huseini an Ernst von Weizsäcker, 9.6.1942, in: Höpp, Mufti-Papiere, S. 43. Vgl. auch Korb, Im Schatten des Weltkriegs, S. 52. 
Angriffe durch Četniks und Kommunisten klagen würden. Denn bei solchen Angriffen gegen die Zivilbevölkerung seien bereits 100-150.000 Frauen, Kinder und Greise ermordet worden. Nach Massakern würden Leichen geschändet, die Dörfer geplündert und in Brand gesteckt. ${ }^{147}$ Al-Huseini forderte die Deutschen daher auf, muslimische Selbstschutzeinheiten auszurüsten: „Die Muslime fordern genügend Schutz gegen die Terrorakte der Serben und Kommunisten. Sie erbitten Waffen, um sich gegen diese Überfälle zu schützen. In allen Fällen, wo der Selbstschutz durch Waffenlieferung versucht wurde, hat sich diese Methode als überaus gut erwiesen. "148 Auch Dzemal Ibrahimović war nach dem Krieg der Meinung, dass bei der Entscheidung, sich für die Waffen-SS rekrutieren zu lassen, nicht politische Überzeugungen im Vordergrund gestanden hätten, sondern die Absicht, die Angriffe der Serben zu stoppen und „das zu retten, was in den Zonen in Bosnien an muslimischer Bevölkerung nach den Massakern von Gorazde, Foća, Zenica und in der Drina-Region übrig geblieben ist. “149

Überlebenden von Massakern blieb oft nur die Möglichkeit, in die Städte zu fliehen. ${ }^{150}$ Städte mit einem hohen Anteil an Muslimen, allen voran Sarajevo, waren deshalb mit Flüchtlingen überfüllt. ${ }^{151}$ Diese boten somit einen wichtigen Rekrutierungspool für die Vorgängereinheiten der „Handschar“ und für die Division selbst. ${ }^{152}$ Es waren folglich oft pragmatische Gründe, die zur Zusammenarbeit mit der einen (Waffen-SS) oder anderen Gruppen (beispielsweise Tito-Partisanen) führten: Das eigene Leben und das der Angehörigen sowie den eigenen Besitz zu schützen, sofern davon noch etwas übrig war, waren schlagende Argu-

147 Al-Husaini an von Weizsäcker, 9.6.1942, in: Höpp, Mufti-Papiere, S. 43. Nedim Salihbegović ging von rund 150.000 ermordeten Zivilisten in Bosnien bis Herbst 1943 aus. Vgl. Nedim Salihbegovic, „Bericht zur Lage“, 25.9.1943, BArchB, NS 19/2601, Bl. 30. Diese Zahlen müssen allerdings nach unten korrigiert werden: Siehe hierzu Robert Haydens bzw. Tomlislav Dulićs weit tiefere Angaben mit etwas mehr als 50.000 getöteten Bosniern und weit über 200.000 getöteten Serben im NDH zwischen 1941-1945. Vgl. Robert Hayden, Mass Killings and Images of Genocide in Bosnia, 1941-1945 and 1992-1995, in: Robert Hayden, From Yugoslavia to the Western Balkans, Studies of a European Disunion 1991-2011, Leiden/Boston: Brill 2013, S. 146. Tomislav Dulić, Utopia of a Nation, Uppsala: Uppsala Universitet 2005, S. 321, 323. Lepre schreibt von 100.000 getöteten Muslimen bis Ende 1943. Vgl. Lepre, Himler's Bosnian Division, S. 16. Als Vergleich: Auch auf serbischer Seite ging man bereit in den ersten Kriegsmonaten (April bis August 1941) von 100.000 bis 180.000 ermordeten Serben in den Gebieten außerhalb Serbiens aus. Zwischen 130.000 und 200.000 sollen bis Ende Juli 1941 nach Serbien geflohen sein. Radić, The Serbian Orthodox Church, S. 63 f.

148 Al-Husaini an von Weizsäcker, 9.6.1942, in: Höpp, Mufti-Papiere, S. 43.

149 Vgl. Rochas, La Handschar, S. 169.

150 Al-Husaini an von Weizsäcker, 9.6.1942, in: Höpp, Mufti-Papiere, S. 43.

151 Ebd.

152 So etwa für die „Schwarze Legion“. Vgl. Hoare, Bosnian Muslims, S. 24. 
mente. ${ }^{153}$ Dass der Beitritt zu einer bestimmten Einheit meist nichts mit politischer Überzeugung zu tun hatte, beweisen nicht zuletzt die zahlreichen Desertionen, die meist von der Waffen-SS zu den Partisanen führten. ${ }^{154}$ Selbst vor den einsetzenden Massendesertionen im Sommer 1944 habe es eine zurückhaltende Zusammenarbeit von Muslimen mit den kommunistischen Partisanen gegeben, so Hoare. Manchmal waren muslimische Milizen sogar bereit, in den Reihen der Partisanen zu kämpfen - aber auch hier nur unter der Bedingung, im eigenen Dorf bleiben zu können, um die Bevölkerung gegen Angriffe der Četniks zu schützen. ${ }^{155}$

Das Vertrauen der bosnischen Muslime in die Deutschen hatte seit 1941 aufgrund radikaler Sühnemaßnahmen auf der einen und fehlender Unterstützung auf der anderen Seite schwer gelitten, wie Salihbegović feststellte. Dennoch hofften sie immer noch auf die Hilfe Hitlers und al-Huseinis. Letzterer habe durch seine Briefe an die muslimische Bevölkerung immer „tröstend und beruhigend“ gewirkt. ${ }^{156}$ Deren „tiefe Niedergeschlagenheit und das Unvermögen, sich selbst zu helfen“, wollte sich Phleps bei den Rekrutierungen zunutze machen, und mit Sold und einer guten Ausbildung neue Rekruten gewinnen. ${ }^{157}$ In diesem Vorgehen sah er das Potenzial der Waffen-SS, nämlich dort Hilfe anzubieten, wo diese aus Sicht der Bevölkerung benötigt wurde. Er war sich sicher, dass es sich bei den Rekrutierungen der Muslime sogar um eine Notwendigkeit handelte, da diese sonst bereitwillig die Partisanen und Četniks unterstützen würden, sobald es zu schweren Kämpfen käme. ${ }^{158}$ Auch Sauberzweig riet Ende September 1943 zur raschen Rekrutierung in die Reihen der Waffen-SS, um einer Rekrutierung durch die Tito-Partisanen zuvorzukommen, denn man könne den Muslimen wohl kaum raten, sich der Ustaša-Bewegung anzuschließen, nachdem diese „muselmanische“ Dörfer geplündert und ihre Bevölkerung ausgerottet hätte. ${ }^{159}$ Ähnlich lautet die Einschätzung Hoares, der davon ausgeht, dass sich unentschlossene oder bisher neutrale muslimische Milizen durch die Situation 1943, die anhaltenden Übergriffe durch Četniks und den drohenden Kollaps des NDH-Regimes, den Partisanen anschlossen, falls die Aufstellung der „Handschar“ von ihnen als Gefahr und nicht als Nutzen wahrgenommen wurde. ${ }^{160}$

153 Vgl. Korb, Im Schatten des Weltkriegs, S. 86.

154 Vgl. ebd.

155 Vgl. Hoare, Bosnian Muslims, S. 114.

156 Vgl. Nedim Salihbegovic, „Bericht zur Lage“, 25.9.1943, BArchB, NS 19/2601, Bl. 30.

157 Vgl. Schreiben Phleps an Himmler, 5.11.1943, BArchB NS19/3893, S. 2.

158 Vgl. ebd., S. 3.

159 Vgl. Sauberzweig an Berger, 30.9.1943, BArchB, NS19/2601, Bl. 27.

160 Vgl. Hoare, Bosnian Muslims, S. 114. 
So schrieb Himmler kurz nach Aufstellungsbeginn im März 1943 denn auch folgerichtig, dass die sich in Aufstellung befindende „muselmanische Bosniaken-Division“ nach Erhalt ihrer Ausrüstung in Semlin „so rasch wie möglich in Garnisonen in Bosnien und Herzegowina zu [ver]legen [sei]. Diese Maßnahme wird die volle Beruhigung der muselmanischen Bevölkerung und ein 100\% Vertrauen dieser Bevölkerung zu uns zur Folge haben. “161 Salihbegović bestätigte, dass die bosnisch-muslimische Bevölkerung überzeugt gewesen war, ihr Leiden hätte ein Ende, als der Aufruf kam, sich freiwillig für die SS-Division zu melden. ${ }^{162}$ Entsprechend groß war die Enttäuschung, als die Bosnier entgegen den deutschen Versprechen zur Ausbildung nach Villefranche-de-Rouergue kamen. Während die geworbenen Muslime ihre Ausbildung im weit entfernten Frankreich absolvierten, kam es in Bosnien zur Katastrophe, wie Berger schrieb: Noch intensiver als vorher wüteten Četniks, Ustaše und Partisanen gegen die muslimische Zivilbevölkerung. Felder und ganze Dörfer wurden niedergebrannt, unschuldige Zivilisten massakriert. ${ }^{163}$ Die zahlreichen Opfer wären regelrecht „abgeschlachtet“ worden, während deutsche Dienststellen tatenlos zugesehen hätten, wie etwa in den Bezirken Rogatica, Čainiče, Stolac und Konjic, wo Erschießungen von Frauen, Kindern und Männern stattgefunden hätten. ${ }^{164}$ In Ostbosnien, wo Četniks, aber auch andere Partisanengruppen muslimische Dörfer angegriffen, geplündert und ihre Bewohner ermordet oder vertrieben hatten, befanden sich im November 1943 laut Bajraktarević weiterhin 50.000 Menschen auf der Flucht, die in den größeren Städten Schutz suchten. Diese hatten oft ihren ganzen Besitz verloren, und ihr Anblick hätte auf die Bewohner der Städte „einen schrecklichen Eindruck“ gemacht. ${ }^{165}$

Als Folge der verbrannten Ernten und der großen Konzentration von Flüchtlingen in den Städten traten Hungersnöte auf. Um die Not der Flüchtlinge zu lindern, befahl der Reichsführer SS Anfang Januar 1944 eine „Sammlung zur Behebung der Not der muselmanischen Bevölkerung im bosnischen Raum“. ${ }^{166}$

161 Himmler an SS-Führungshauptamt, SS-Personalhauptamt, SS-Hauptamt, SS-Gruppenführer Phleps und SS-Brigadeführer von Oberkamp, 31.3.1943, BArchB NS19/2601, Bl. 7.

162 Vgl. Nedim Salihbegovic, „Bericht zur Lage“, 25.9.1943, BArchB, NS 19/2601, Bl. 30.

163 Vgl. Betr. „Von Reichsführer-SS befohlene Sammlung zur Behebung der Not der muselmanischen Bevölkerung im bosnischen Raum“, Berger an Himmler, 12.1.1944, BArchB NS19/2601, Bl. 165 .

164 Vgl. Nedim Salihbegovic, „Bericht zur Lage“, 25.9.1943, BArchB, NS 19/2601, Bl. 31.

165 Vgl. Reisebericht SS-Hauptsturmführer Hasan Bajralitarović [Bajraktarević] an Phleps, 15.11.1943, BArchB, NS19/2601, Bl. 58.

166 Vgl. Betr. „Von Reichsführer-SS befohlene Sammlung zur Behebung der Not der muselmanischen Bevölkerung im bosnischen Raum“, Berger an Himmler, 12.1.1944, BArchB NS19/2601, Bl. 165 . 
Angehörige der 13. SS-Division spendeten daraufhin 88.590,74 Reichsmark. Diese Sammelaktion sollte propagandistisch genützt werden, indem der Großmufti von Jerusalem den Betrag genau zu jenem Zeitpunkt der muslimischen Organisation „Merhamed“ in Sarajevo überreichte, als die „Handschar“ in Bosnien einrückte. ${ }^{167}$ Eipel gibt in Kriegsgefangenschaft zu Protokoll, dass die Zivilbevölkerung Ostbosniens und angrenzenden kroatischen Gebieten, Muslime, aber auch Kroaten und „Volksdeutsche“, froh über die Ankunft der „Handschar“ im Frühjahr 1944 gewesen wären: „Das Verhältnis der Truppe zur Bevölkerung des Ortes [Gunja] wie der Umgebung wie umgekehrt war das denkbar beste, weil durch die Zusammenfassung aller am Ort liegenden Truppenangehörigen Ruhe, Sicherheit und Ordnung gewährleistet waren.“168

\subsubsection{An die k.u.k.-Zeit anschließen: Die „alten Rechte“}

Die Erinnerung an die Zeit, als Bosnien Teil der Habsburger Monarchie war, ist eng an die Wiederinstandsetzung der „alten Rechte“ geknüpft. Diese wiederum bezogen sich nicht nur auf freie Religionsausübung, sondern auch auf weitreichende Autonomie, die Bosnien zwischen 1878 und 1918 während der Zeit der österreichisch-ungarischen Besatzung genossen hatte. ${ }^{169}$ Bereits am 9 . Juni 1942 schrieb der Großmufti von Jerusalem al-Huseini: „Da die Muslime sich des guten Einvernehmens mit dem damaligen Österreich entsinnen, traten sie mit ihren Wünschen und Hoffnungen an Deutschland und die Achsenmächte heran. “170 Am 4. Dezember 1943 bat Berger den Großmufti darum, dafür zu sorgen, dass alle während der k.u.k.-Herrschaft eingesetzten bosnischen Beamten wieder in Bosnien-Herzegowina eingesetzt würden, denn diese würden das Vertrauen der lokalen muslimischen Bevölkerung genießen. ${ }^{171}$ Obwohl die Invasion österreichisch-ungarischer Truppen in Bosnien und der Herzegowina kein „Spaziergang“

167 Vgl. ebd. Interessant dabei scheint die Tatsache, dass auch das zu Teilen aus zwangsrekrutierten Polen, Weißrussen und Ukrainern bestehende Sonderregiment Dirlewanger 35.000 Reichsmark spendete und dafür drei Monate auf die Frontzulage verzichtete. Ebd.

168 Kriegsgefangenenbericht „Bericht über die 13. SS Division ,Handschar‘, ihre Aufstellung, Gliederung und 1. Einsätze im jugoslawischen Raum“, Walter Eipel, 14.11.1947, VA, HEM.OK. BOJCKA, 72-A/1-a/32, S. 9.

169 Vgl. Lepre, Himmler's Bosnian Division, S. 14.

170 Brief Nr. 17 an Ernst von Weizsäcker, 9.6.1942, al-Husaini, Muhạmmad Amin, in: Höpp, Mufti-Papiere, S. 43. Vgl. auch Korb, Im Schatten des Weltkriegs, S. 52.

171 Vgl. Berger an Himmler, „Mohamedanischer Sender/Ostafrikanische mohamedanische Divisionen“, 4.12.1943, BArchB, NS19/1896, Bl. 1f. 
gewesen war, wie Clemens Ruthner betont, ${ }^{172}$ erhielt Bosnien im Laufe der Zeit unter den Habsburgern einen Autonomiestatus, der durch den Aufbau des Ersten Jugoslawiens 1918 aufgehoben wurde und dem viele Muslime nachtrauerten. Lepre schreibt von einer Nostalgie, welche die bosnisch-muslimischen Akteure mit der österreichischen-ungarischen Herrschaft verbanden, da diese „Modellverwaltung“ auch Muslimen die Möglichkeit geboten hatte, in höchste Positionen aufzusteigen. ${ }^{173}$ Auch Nedim Salibegović schrieb in seinem „Bericht zur Lage“ im September 1943, dass man die Herrschaft Österreich-Ungarns mit „Ruhe, Sicherheit und Gerechtigkeit der damaligen Verwaltung“ sowie mit „gesicherten wirtschaftlichen Verhältnisse[n] [verband], wo jeder, der arbeitswillig war, sein Brot verdienen konnte“. ${ }^{174}$ Nach dem „Anschluss“ Österreichs 1938 an das Deutsche Reich war die slawische Bevölkerung daher überzeugt, „dass Deutschland auch das geschichtliche Erbe Österreichs angetreten und somit die Verpflichtungen gegen loyale österreichische Untertanen aus dem [Ersten] Weltkrieg übernommen hätte. Aus dieser Überzeugung sehnte die Bevölkerung den Einzug der deutschen Truppen herbei. “175

Der Vergleich zur k.u.k.-Zeit wurde nach dem Einmarsch der Deutschen im April 1941 sehr konkret: Da die neuen Besatzer Deutsch sprachen und in den Augen der Bosnier einen ähnlichen kulturellen Hintergrund pflegten, erinnerten sich letztere in vielen Bereichen des täglichen Lebens an die erst vor rund zwei Jahrzehnten abgerückten österreichisch-ungarischen Truppen. ${ }^{176}$ Die Erinnerung an die k.u.k.-Zeit wurde zusätzlich genährt durch zahlreiche in Südosteuropa stationierte Österreicher, die teilweise bereits in der österreichisch-ungarischen

172 Vgl. Ruthner, Clemens, Besetzungen und ihre Schattenseiten: Repräsentationen des Okkupationsfeldzugs 1878, in: Preljević, Ruthner, Scheer (Hgg.), Unser Bosnien - Wiener Schule, Gedächtnisorte, Wahrnehmungen, Brücken und Brechungen im Verhältnis Österreich - Bosnien und Herzegowina, Sarajevo: Universität Sarajevo 2016, S. 24-28.

173 Vgl. Lepre, Himmler's Bosnian Division, S. 16.

174 Nedim Salihbegović, „Bericht zur Lage“, 25.9.1943, BArchB, NS 19/2601, Bl. 29. Siehe zu dieser Wahrnehmung ausführlich Zaugg, Ruhe, Sicherheit und Gerechtigkeit, S. 441-448.

175 Nedim Salihbegović, „Bericht zur Lage“, 25.9.1943, BArchB, NS 19/2601, Bl. 29.

176 Al-Husaini an von Weizsäcker, 9.6.1942, Höpp, Mufti-Papiere, S. 43. Vgl. hierzu auch Zaugg, Ruhe, Sicherheit und Gerechtigkeit, S. $443 \mathrm{f}$.

Dass sich die österreichisch-ungarische Öffentlichkeit ihrerseits ein Bild über die Menschen in Bosnien und Herzegowina machte und dieses durchaus wandlungsfähig war, erläutert Imre Ress in seinem Aufsatz "Die religiöse Autonomie der Muslime in Bosnien-Herzegowina und die ungarische Politik um 1900. Wandlungen des Bosnien-Bildes in der ungarischen Öffentlichkeit“, in: Preljević, Ruthner, Scheer (Hgg.), Unser Bosnien - Wiener Schule, S. 35-46. 
Armee gedient hatten, $1938 \mathrm{zu}$ „Reichsdeutschen“ erklärt und nun in den Reihen des NS-Apparats, in Verwaltung, Wehrmacht und Waffen-SS, eingesetzt wurden. ${ }^{177}$

Phleps war der Überzeugung, dass es für die Deutschen daher wichtig wäre, die Nähe zur k.u.k.-Herrschaft zu betonen, denn

der Muselmane erinnert sich mit größter Achtung und Dankbarkeit der Verwaltung im alten Okkupationsgebiet der österreichisch-ungarischen Monarchie. Was in Bosnien und der Herzegowina geschaffen wurde, das mit Kultur und Zivilisation in Zusammenhang steht, ist das Verdienst dieser Verwaltung. ${ }^{178}$

Viele Bosnier, nicht nur bosnische Muslime, hatten ihre Dienstzeit bei der österreichisch-ungarischen Armee in guter Erinnerung behalten. Nach den ersten Rekrutierungsmonaten schrieb Phleps im November 1943 an Himmler: „Mit Stolz spricht jeder Bosniake, ${ }^{179}$ gleichgültig welcher Konfession er angehört, von seiner Dienstzeit bei b[osnisch-]h[erzegowinischen] [Regimentern der k.u.k.-Armee], wo er als tapferer Kämpfer und ganzer Mann voll bewertet und entsprechend seiner Mentalität behandelt wurde.“180

Bereits im Juni 1942 teilte al-Huseini von Weizsäcker mit, dass sich die Muslime von den Deutschen das Recht, ihre Religion frei ausüben zu dürfen, nicht zu einem Religionswechsel gedrängt zu werden, sowie die Garantie ihrer politischen Rechte erhofften. ${ }^{181}$ Himmler ging darauf ein: Er wollte den neuen Soldaten ihre „alten Rechte“ zurückgeben, die sie in der österreichisch-ungarischen Armee genossen hatten und ihnen „freie Religionsausübung“ sowie das „Tragen des Fez“ gestatten. ${ }^{182}$ Bernwalds Befragung ehemaliger Divisionsangehöriger bestätigt die Vermutung, dass keiner der Rekrutierten dem Jugoslawien von 1918 bis 1941 nachgetrauert hätte, und dass sie zwar ganz zu Beginn des NDH gleichberechtigt behandelt worden wären, danach aber rasch zu den Benachteiligten gehörten. ${ }^{183}$

177 Um einige der bekanntesten Namen zu nennen: der Sonderbeauftragte Südost Hermann Neubacher, SSPF Sandschak (Juni-November 1944), Richard Kaaserer, HSSPF Kroatien Konstantin Kammerhofer oder HSSPF Albanien Josef Fitzthum.

178 Schreiben Phleps an Himmler, 5.11.1943, BArchB NS19/3893, S. 1.

179 Bis zum Ersten Weltkrieg wurden nicht nur Muslime als Bosniaken bezeichnet. Dies war auch die Bezeichnung der Bosnier im österreichisch-ungarischen Heer.

180 Vgl. Schreiben Phleps an Himmler, 5.11.1943, BArchB NS19/3893, S. 1.

181 Al-Husaini an von Weizsäcker, 9.6.1942, Höpp, Mufti-Papiere, S. 43f.

182 Vgl. Funkspruch Himmler an Phleps, 13.2.1943, BArchB NS19/2601, Bl. 2. Siehe zu den „alten Rechten“ auch Christoph Neumayer, Erwin A. Schmidl (Hgg.), Des Kaisers Bosniaken, S. 95, 128.

183 Vgl. Bernwald, Muslime, S. 320-327. 
Auch in Albanien, im Kosovo und im Sandžak sollte die Erinnerung an die k.u.k.-Zeit rekrutierungsfördernd in Szene gesetzt werden. ${ }^{184}$ Dass die Werber der Waffen-SS nicht nur bei der Rekrutierung von Bosniern und Albanern, sondern auch bei der Aufstellung anderer Divisionen, so etwa der galizischen Division, das österreichisch-ungarische Erbe bemühten, bestätigt Leleu in seinem Aufsatz „Jenseits der Grenzen“. ${ }^{185}$

\subsubsection{Der Wunsch nach Autonomie und die Frage nach dem Antikommunismus}

Ausgehend von der Unterdrückung und Verfolgung im Ersten Jugoslawien und während der letzten Jahre sowie den Erinnerungen an die k.u.k.-Zeit bestanden in Bosnien, ähnlich wie im Kosovo oder Sandžak, starke Autonomiebestrebungen. ${ }^{186}$ Diese hatten ihren Ursprung bereits in osmanischer Zeit, als lokale Eliten Widerstand gegen die Reformen des Sultans übten, mit dem Ziel, Bosnien und Herzegowina autonom zu regieren. ${ }^{187}$ Zwar wurde dieser Wunsch auch unter Österreich-Ungarn nicht vollständig, aber immerhin $\mathrm{zu}$ Teilen umgesetzt. ${ }^{188}$ Anders als in Serbien und Kroatien, hätten die bosnischen Autonomisten nicht versucht, auch andere Bevölkerungsteile zu aktivieren, und so sei die bosnischherzegowinische Autonomiebewegung stets eine muslimisch geprägte Angelegenheit geblieben. ${ }^{189}$ Vor allem die muslimischen Eliten hofften seit der Ankunft der Deutschen im Frühjahr 1941 auf eine Möglichkeit, den Status einer autonomen Region zurückzugewinnen. ${ }^{190}$ Diese Hoffnung erklärt auch die hohe Zahl bosnischer Freiwilliger, die bereits 1941 im Krieg gegen die Sowjetunion auf deutscher Seite im Einsatz standen. ${ }^{191}$ Großmufti al-Huseini schreibt, dass die bosnischen Muslime einen ähnlichen Autonomiestatus anstreben würden, wie die Slowakei ihn genoss. Falls dies nicht möglich wäre, würden sie sich auch zufriedengeben mit einem Autonomiestatus, wie er unter österreichischer-ungarischer Herrschaft bestanden hatte, oder aber für eine ,vollständig durchzuführende Gleichberechtigung“ mit freier Religionsausübung und Vertretung

184 Vgl. Kollegger, Albaniens Wiedergeburt, Wien: Wiener Verlagsgesellschaft 1942, S. 38.

$185 \mathrm{Vgl}$. Leleu, Jenseits der Grenzen, S. 36.

186 Vgl. Schreiben betr. „Aufstellung einer SS-Legion aus bosnischen Mohammedanern“, Chef Sicherheitspolizei und SD Ernst Kaltenbrunner an Reichsführer SS Heinrich Himmler, 24.4.1943, BArchB NS19/2601, Bl. 10.

187 Vgl. Redžić, Bosnia and Hercegovina, S. 165.

188 Vgl. Zaugg, Ruhe, Sicherheit und Gerechtigkeit, S. $444 \mathrm{f}$.

189 Vgl. Redžić, Bosnia and Hercegovina, S. 165.

190 Vgl. Lepre, Himmler's Bosnian Division, S. 14. Vgl. Ferhadbegović, Vor Gericht, S. 231.

191 Vgl. Lepre, Himmler's Bosnian Division, S. 14, $16 \mathrm{f}$. 
in allen Ämtern innerhalb des NDH eintreten. ${ }^{192}$ Das langfristige Ziel der Bewegung, so ist sich Hoare sicher, war aber die Trennung Bosnien-Herzegowinas vom NDH. ${ }^{193}$ Wichtige Vertreter der Autonomiebestrebungen und gleichzeitig Unterstützer der geplanten Division „Handschar“ waren in Sarajevo Uzeir Hadžihasanović, ${ }^{194}$ Hafiz Muhamed Pandža, Leiter von „Merhamet“ (Muslimansko Dobrotvorno Družstvo, ein muslimischer Wohltätigkeitsverein) und Mitglied der Ulema medžlis, des bosnischen Gelehrtenrats, sowie Hadžihasanovićs Schwiegersohn Mustafa Softić, der zu dieser Zeit als Bürgermeister von Sarajevo amtierte. In Banja Luka unterstützte Suljaga Salihagić und in Mostar unter anderen der ehemalige Mufti Omer Džabić die Autonomiebestrebungen der bosnischen Muslime. Letzterer setzte sich sogar für einen Zusammenschluss aller muslimischen Gebiete Südosteuropas ein. ${ }^{195}$

Die bislang friedlichen bosnischen Autonomiebestrebungen, welche sich auch aus Veteranen früherer Autonomiebewegungen unter habsburgischer Herrschaft zwischen 1899 und 1909 und im Ersten Jugoslawien 1939 bis 1941 nährten, standen dem Ustaša-Staat von Anfang an kritisch gegenüber. Ein Spezifikum der Autonomisten war ihre politisch sehr breit gefächerte Ausrichtung. Das linke Ende der Autonomie-Bewegung ließ sich in der Nähe der jugoslawischen Kommunisten verorten, die rechte Seite hingegen liebäugelte zur Umsetzung ihrer Ziele auch mit der Unterstützung der deutschen Besatzer. ${ }^{196}$ Es überrascht daher nicht, dass Regierungsvertreter wie Pavle Canki oder Vjekoslav Vrančić in den deutschen Rekrutierungsanstrengungen den Versuch sahen, diese nationalbosnischen Kräfte zu fördern und durch die Aufstellung einer muslimischen Waffen-SS-Division gar eine Autonomie Bosniens erzwingen zu wollen. ${ }^{197}$ GlaiseHorstenau bemerkte zu diesen Einwänden von kroatischer Seite, dass die Muslime

192 Brief Nr. 17 al-Husaini an Ernst von Weizsäcker, 9.6.1942, Höpp, Mufti-Papiere, S. 44.

193 Hoare, Bosnian Muslims, S. 46.

194 Uzeir Hadžihasanović soll al-Huseini Anfang April 1943 sogar in seinem Haus empfangen und ihm mitgeteilt haben, dass Šuliak von den Rekrutierungen ausgeschlossen werden sollte, da die neue Waffen-SS-Division nichts mit der Ustaša zu tun haben sollte. https://handzar. jimdo.com/drugi-svjetski-rat/slike/muftija-u-posjeti-sarajevo/ (Stand: 11.7.2019).

195 Vgl. Grmek, Lambrichs, Les revoltés, S. 150. Vgl. Hoare, Bosnian Muslims, S. 46.

196 Hoare, Bosnian Muslims, S. 40, 46. Hierzu erhellend ist auch die Einschätzung von Divisionskommandeur Sauberzweig: Vgl. Sauberzweig an Berger, 30.9.1943, BArchB, NS19/ 2601, Bl. 27.

197 Vgl. „Zwischenbericht über Werbeaktion muselmanischer Freiwilliger“, Phleps an Chef des SS-Führungshauptamtes SS-Gruppenführer Jüttner, 19.4.1943, BArchB NS19/2601, Bl. 9. Schreiben betr. „Aufstellung einer SS-Legion aus bosnischen Mohammedanern“, Chef Sicherheitspolizei und SD Ernst Kaltenbrunner an Reichsführer SS Heinrich Himmler, 24.4.1943, BArchB, NS19/2601, Bl. 10. 
sich auch ohne deutsches Zutun als eigene „Volksgemeinschaft fühlen“ würden. ${ }^{198}$ Wie Canki und Vrančić richtig vermuteten, war Glaise-Horstenau daher der Meinung, dass sich genau diese Selbstwahrnehmung „militärisch ausnützen“ ließe. ${ }^{199}$ Bajraktarević sah in der Bildung eines bosnischen „Militärs unter deutscher Führung“ nicht nur die Möglichkeit, die muslimische Bevölkerung vor weiteren Übergriffen zu schützen und die Integrationskraft der Deutschen zu nutzen, indem zwar vor allem Muslime rekrutiert würden, aber auch Vertreter anderer Ethnien aufgenommen würden. Er erkannte in den Rekrutierungen für die Waffen-SS auch die Möglichkeit, den Kern einer bosnischen Armee auszubilden: „Ein so [nach deutschen Standards] ausgebildetes Militär wäre dann der Grundstock und die Garantie der öffentlichen Ordnung und des Friedens gegenüber sämtlichen inneren und äußeren Feinden.“200

Die bosnischen Unabhängigkeitsbestrebungen wurden durch die brutalen Übergriffe der Ustaša an der muslimischen Zivilbevölkerung noch verstärkt, und Sauberzweig war sich sicher, dass dieses Potenzial, wenn nicht durch die Waffen-SS genutzt, von Tito instrumentalisiert würde. ${ }^{201}$ Am 5. November 1943 meldete Phleps sich persönlich bei Himmler, um dem Anliegen der bosnischen Muslime auf einen Autonomiestatus noch einmal Nachdruck zu verleihen. ${ }^{202}$ Er wies darauf hin, dass er Himmler schon „,vor einigen Monaten“ das „Memorandum der Muselmanen“ als Abschrift überreicht hätte. „Aus dem Memorandum geht hervor, dass es das Bestreben der Muselmanen ist, einen autonomen Staat aufzubauen, in dem sie sich selbst verwalten und Herr ihrer Belange sind.“203 Phleps fand zwar die Forderung nach einem eigenen Staat „ein Unding“, war aber der Meinung, dass die Rechte der Muslime im NDH dennoch berücksichtigt werden müssten, denn

die Muselmanen sind Prellstein für alle Andern [sic]. Der katholische Kroate nennt sie falsch, verschlagen, ohne Verständnis für den kroatischen Staatsgedanken; die Ustaša mordeten im ersten Jahre der Staatsgründung Tausende dahin. Die Pravoslaven werfen dem Muselmanen wieder vor, dass er abseits steht, für einen großserbischen Staatsgedanken kein Verständnis aufbringt, daher mordet der Cetnik den Muselmanen. Der Muselmane selbst aber, so in die Enge getrieben, geht in den Wald oder schließt sich den Partisanen an. ${ }^{204}$

198 Vgl. Glaise-Horstenau an Himmler, 25.2.1943, BArchB, NS19/3523, Bl. 43 f.

199 Vgl. ebd.

200 Vgl. Reisebericht SS-Hauptsturmführer Hasan Bajralitarović [Bajraktarević] an Phleps, 15.11.1943, BArchB, NS19/2601, Bl. 59.

201 Vgl. Sauberzweig an Berger, 30.9.1943, BArchB, NS19/2601, Bl. 27.

202 Vgl. Schreiben Phleps an Himmler, 5.11.1943, BArchB NS19/3893, S. 1-3.

203 Vgl. ebd., S. 1.

204 Vgl. ebd. 
Phleps äußerte die bereits von Sauberzweig formulierten Bedenken: Würden die Deutschen die bosnischen Autonomiebestrebungen nicht unterstützen, so würden sich die bosnischen Muslime, eingeschlossen zwischen den Fronten, zur Zusammenarbeit mit den Partisanen entschließen. ${ }^{205}$ Daher wurde das Ziel einer bosnischen Autonomie ironischerweise sowohl für die Rekrutierungen in die „Handschar“-Division als auch von den kommunistischen Partisanen instrumentalisiert. $^{206}$

Die äußerst komplizierte Situation im bosnisch-herzegowinischen Raum lässt sich an folgendem Beispiel verdeutlichen. Am 17. September 1943 fand eine Besprechung zwischen Vertretern der 369. Infanterie-Division und dem „Merhamet“ statt. Anwesend waren Oberstabsintendant Langenberger und Oberzahlmeister Donner, sowie der Zweite Sekretär des „Merhamet“, Mehmed Tokić. Bei dieser Besprechung drohte „Merhamet“, der nach eigenen Angaben über eine Anhängerschaft von über 800.000 Muslimen verfügte, mit einem gewaltsamen Aufstand gegen den kroatischen Staat, wenn das Deutsche Reich die Hungerkrise unter der muslimischen Bevölkerung nicht zu lindern gedachte. ${ }^{207}$ Obwohl Tokić als Vertreter von „Merhamet“ klar zum Ausdruck brachte, dass die Muslime weder Interesse an einem Unabhängigen Staat Kroatien hätten, noch den Anschluss an Deutschland wünschten, da sie sich immer noch als Österreicher fühlen würden, wären doch aus Not „Tausende von Muselmanen in die SS eingetreten und viele Hunderte seien aus der kroatischen Wehrmacht desertiert, weil sie zur SS übertreten wollten.“ ${ }^{208}$ Alleine in Sarajevo saßen aufgrund solcher Desertionen 500 bosnische Muslime in Festungshaft. ${ }^{209}$ Tokić wollte damit aufzeigen, welche Bürden diese Muslime auf sich nehmen würden, um in der Waffen-SS zu dienen. Viele von ihnen würden der „muselmanischen nationalsozialistischen Arbeiterpartei angehören, weil sie sich als Österreicher [in einem autonomen Bosnien] und nicht als Kroaten fühlten“. ${ }^{210}$

Auf die für Januar 1944 geplanten Aufstände und Ausfuhrblockaden von Gütern der bosnischen Autonomisten reagierte Himmler ablehnend. In einem Schreiben an die Feld-Kommandostelle Persönlicher Stab Reichsführer SS, SSObersturmbannführer Brand, ließ er ausrichten, dass ihr Verhalten die ohnehin schon angespannte Situation noch verschärfen würde. Der Großmufti indes ließ

205 Vgl. Schreiben Phleps an Himmler, 5.11.1943, BArchB NS19/3893, S. 3.

206 Vgl. Hoare, Bosnian Muslims, S. 10.

207 Vgl. Abschrift Besprechung „Merhamet“, Mehmed Tokić und 369. Inf.Div., 17.9.1943, BArchB NS19/3893, Bl. 16.

208 Ebd.

209 Ebd.

210 Ebd. 
ausrichten, dass Tokić kein offizieller Vertreter, sondern nur ein Zivilist wäre, „der sich aus ganz eigensüchtigen Gründen diese Rechte angemaßt habe.“ Weder er selbst noch die muslimische Führung in Bosnien hätten ein solches Vorgehen veranlasst oder gutgeheißen. ${ }^{211}$ Mehmed Tokić war allerdings nicht nur Zivilist, sondern offizieller Vertreter des „Merhamet“ und zudem auch V-Mann der Deutschen. ${ }^{212}$

Als die Division „Handschar“ einen Monat später nach Bosnien zurückkehrte, übernahm sie bis zu ihrer partiellen Auflösung und dem darauffolgenden Rückzug im Herbst 1944 im gesamten Gebiet das Zepter. Es entstand somit praktisch ein Staat im Staat, und die Autonomiebestrebungen erreichten so für kurze Zeit ihr Ziel. ${ }^{213}$ Petke verweist auf die von der Division erlassene Landfriedensordnung, die sie in sämtlichen zivilen und militärischen Bereichen zur höchsten richterlichen Instanz erklärte, womit sie faktisch die Alleinherrschaft über Nordostbosnien ausübte. ${ }^{214}$ Gegen diese Alleinherrschaft konnte auch der Poglavnik nicht viel ausrichten, wollte aber „autonomistische“ Strömungen bei der Bildung einer zweiten SS-Division dennoch unterbinden. ${ }^{215}$ Insgesamt habe, so Berger in einem Schreiben an Himmler Anfang August 1944, die von Sauberzweig verkündete „Landfriedensordnung“ nicht nur beim kroatischen Staat, sondern auch bei deutschen Dienststellen, gemeint ist hier Kasche, für böses Blut gesorgt. $^{216}$ Sowohl Sauberzweig als auch der vor Ort eingesetzte SS-Brigadeführer Wagner hätten ,vorher fragen und politische Dinge nicht selbständig an die Hand nehmen“ sollen. ${ }^{217}$ Als schließlich die letzten noch übriggebliebenen Einheiten der „Handschar“ Mitte November 1944 die Save überquerten, um an den letzten Gefechten in der Region teilzunehmen und Bosnien anschließend für immer verließen, sei laut Lepre mit ihrem Fortgang auch der Traum auf Autonomie gestorben. ${ }^{218}$

211 Reichsführer SS an Persönlicher Stab Reichsführer SS, z.Hd. SS-Ostubaf. Brand, 11.1.1944, BArchB NS19/3893, Bl. 19.

212 Vgl. Abschrift Besprechung „Merhamet“, Mehmed Tokić und 369. Inf.Div., 17.9.1943, BArchB NS19/3893, Bl. 16. Tokić besaß die Ausweisnummer 13/42. Vgl. ebd.

213 Wolf Oschlies, Die 13. SS-Division Handschar in Bosnien und Herzegowina. Die Deutsche Armee und ihre Hilfstruppen auf dem Balkan 1941-1945, in: https://www.zukunft-braucht-erin nerung.de/die-13-ss-division-handschar-in-bosnien-und-herzegowina/ (Stand: 8.7.2019).

214 Vgl. Petke, Militärische Vergemeinschaftungsversuche, S. 251.

215 Vgl. Voelckers an Kasche, 14.8.1944, PAAA, Inland IIg/R 100998.

216 Vgl. Berger an Himmler, betr.: „Reise nach Kroatien“, 4.8.1944, BArchB, NS 19/1492, Bl. 1.

217 Berger an Himmler, betr.: „Reise nach Kroatien“, 4.8.1944, BArchB, NS 19/1492, Bl. 1.

218 Vgl. Lepre, Himmler’s Bosnian Division, S. 278. 
Eine ähnliche Ausgangslage lässt sich auch für die Region Sandžak ${ }^{219}$ nachzeichnen. Diese wurde aufgeteilt zwischen Serbien unter deutscher Militärherrschaft, und Montenegro unter italienischer Besatzung. Die Brutalität der verschiedenen Bevölkerungsteile gegeneinander fand sowohl in deutsche als auch italienische Akten Eingang. ${ }^{220}$

Der Antikommunismus spielte in bosnischen Rekrutierungsgebieten, wie in den oben zitierten Äußerungen Phleps' und Sauberzweigs zu entnehmen ist, eine untergeordnete Rolle. Obwohl er in der deutschen wie auch in al-Huseinis Propaganda einen hohen Stellenwert einnahm, ließen sich die Muslime vor Ort nicht so einfach einem ideologischen Lager zuordnen und waren je nach Ausgangslage $z u$ verschiedenen Kooperationen bereit. ${ }^{221}$ Dennoch gab es Männer wie Imam Dzemal Ibrahimović, die sich vor allem aufgrund ihrer antikommunistischen Überzeugung zur Mitarbeit in der „Handschar“ meldeten: „Und in dieser Division, muss ich ganz ehrlich sagen, sahen wir ein Bollwerk gegen den Bolschewismus“.222 Auch propagandistisch wurde die Division klar in einem antikommunistischen Zusammenhang gesehen. So schrieb al-Huseini an Wilhelm Melchers, dass der Islam den Bolschewismus bekämpfe, und die Muslime genau wissen würden, „dass ihr Schicksal mit dem Deutschlands und der Achse verbunden ist, und dass sie nur von den Serben, Kommunisten und den Alliierten bedroht sind.“ Er betonte, dass die Muslime daher bereits vor den Aushebungen für die „Handschar“ den Kommunismus aktiv bekämpft hätten, indem sie sich freiwillig für die Ostfront gemeldet hatten. ${ }^{223}$

\subsubsection{Konkrete Wünsche: Nahrung, Sold, Bewaffnung}

Neben eher abstrakten Vorstellungen wie dem Verlangen nach Autonomie, waren es mitunter sehr konkrete Bedürfnisse, welche die Bosnier in die Reihen der Waffen-SS trieben. SS-Hauptsturmführer Hasan Bajraktarević betonte, dass der „Kampf um höhere Ideale“ weitaus weniger wichtig war als sehr handfeste Wünsche nach Ausrüstung, Nahrung, Sold und der Möglichkeit, sich zu verteidigen. ${ }^{224}$

219 Unter osmanischer Herrschaft als Verwaltungseinheit „Sandžak von Novi Pazar“ zusammengefasst.

220 Vgl. Zaugg, Albanische Muslime, S. 148-177.

221 Vgl. bspw. Hoare, Bosnian Muslims, S. 39.

222 Vgl. Rochas, La Handschar, S. 169.

223 Al-Huseini an Melchers, 30.4.1943, in: Höpp, Mufti-Papiere, S. 160 f.

224 Reisebericht SS-Hauptsturmführer Hasan Bajralitarović [Bajraktarević] an Phleps, 15.11.1943, BArchB, NS19/2601, Bl. 59. 
Bereits im ersten Kriegswinter kam es im NDH aufgrund der hohen Abgaben an die Besatzer, der extremen Inflation und den zahlreichen Flüchtlingen, zu Hungersnöten. ${ }^{225}$ Ein frühes Beispiel dafür liefert der Verwaltungsbezirk Jaice in Zentralbosnien, wo die Bevölkerung schon im Dezember 1941 Hunger leiden musste und ständigen Attacken ausgesetzt war, wie die Ortsgruppe Jaice der kroatischen „Volksdeutschen“ nach Zagreb meldete:

Seit drei Monaten ist hier kein Fett mehr zu haben. Öl wird monatlich pro Kopf 1/4 Liter verteilt. Mehl ist schon seit zwei Monaten nicht mehr ausgegeben worden, Kartoffeln ebenfalls nicht, Gerste und Weizen jedoch pro Kopf und Monat 5kg. Kolbenmais, noch sehr feucht, wird entgegen allen gesetzlichen Vorschriften zum Preise von Kn. [Kuna] 12-14 verkauft. Fleisch ist seit 14 Tagen nicht mehr vorhanden. Alle Fleischerläden sind geschlossen. Milch ist nur in sehr geringen Mengen bis zu Kn. 10.- pro Liter zu haben. Bei Molkereiprodukten waren wir seit jeher auf die Zufuhr aus anderen Gebieten angewiesen, die jetzt vollständig ausbleibt. ${ }^{226}$

Das Dorf, welches vor allem von bosnischen Kroaten, Muslimen und „Volksdeutschen“ bewohnt wurde, war ständig von „Aufständischen“, wohl serbischen Četniks, umringt. In den wenigen Monaten seit dem Einmarsch der Deutschen hätten diese bereits 2.000 Häuser niedergebrannt und das Vieh weggetrieben, das von ihnen geschlachtet worden oder hilflos verendet sei. ${ }^{227}$

Ein halbes Jahr später berichtete al-Huseini von Weizsäcker, dass Städte mit einem hohen Anteil an muslimischer Bevölkerung, wie beispielsweise Sarajevo, von Flüchtlingen überfüllt seien, und die Sterberate aufgrund fehlender Nahrung und einer prekären hygienischen Situation in manchen Städten bei hundert Menschen pro Tag, in Sarajevo bei vierzig Menschen pro Tag liege. ${ }^{228}$ Auch im Folgejahr hatte sich die Lage nicht entspannt, wie einem Schreiben von SS-Hauptsturmführer Hasan Bajraktarević an Phleps von November 1943

225 Calic, Geschichte Jugoslawiens, S. 156.

226 Deutsche Volksgruppe in Kroatien, Ortsgruppe Jaice an Volksgruppenführung, Hauptamt für Volkswirtschaft, Agram, 3.12.1941, BarchB NS19/319, Bl. 8.

227 Ebd. Jaice stand auch später im Brennpunkt der Konflikte; im September 1942 wurde es von Partisanen eingenommen, fiel danach wieder an deren Gegner und wurde im November 1942 ein zweites Mal von den Partisanen besetzt. Vgl. Hoare, Bosnian Muslims, S. 99.

228 Vgl. Al-Husaini an von Weizsäcker, 9.6.1942, in: Höpp, Mufti-Papiere, S. 43. Als Vergleich: Auch auf serbischer Seite ging man bereits in den ersten Kriegsmonaten April bis August 1941 von 100.000 bis 180.000 ermordeten Serben in den Gebieten außerhalb Serbiens aus. Zwischen 130.000 und 200.000 sollen bis Ende Juli 1941 nach Serbien geflohen sein. Radić, The Serbian Orthodox Church, S. $63 \mathrm{f}$. 
zu entnehmen ist. Die Ernährungssituation der Flüchtlinge in Bosnien blieb weiterhin prekär. ${ }^{229}$

Das Versprechen auf Nahrung und Sold, der den deutschen Verhältnissen angepasst werden sollte, war somit ein wesentlicher Grund, einer deutschen Formation beizutreten. ${ }^{230}$ Die Aussicht auf „ein Stückchen Brot zu Hause“ war für einen Beitritt in die neu aufgestellte Division oft ausschlaggebend, so Bajraktarević. ${ }^{231} \mathrm{Er}$ trat dafür ein, dass die Ernährungssituation der muslimischen Bevölkerung allgemein, vor allem aber diejenige der Familien, die Freiwillige für den Dienst in der SS gestellt hatten, verbessert werden sollte. ${ }^{232}$ Auch al-Huseini betonte, dass sich die Muslime im NDH von den Deutschen Hilfe in Form von Nahrungsmitteln und sanitären Einrichtungen für die Flüchtlinge erhofften, ${ }^{233}$ und die bosnische Autonomistenbewegung um „Merhamet“ drohte mit bereits erwähntem Aufstand, falls die Deutschen nicht endlich die Nahrungskrise entschärfen würden. ${ }^{234}$

Wie wichtig genügend Nahrung, Kleidung und eine Unterkunft für die Stabilität innerhalb der „Handschar“ waren, zeigt ein Schreiben der Abteilung VI, welches die Kompanieführer aufforderte, auch über materielle Werte und körperliches Wohl auf die Soldaten einen positiven Einfluss auszuüben. ${ }^{235}$ Sold und Familienunterhalt waren ebenfalls schlagende Gründe, der Division beizutreten. ${ }^{236}$ Heimwehren litten unter Personalverlust, da viele ihrer Mitglieder aufgrund der höheren Besoldung zur Waffen-SS wechselten. ${ }^{237}$ Den Personaldossiers von Divisionsangehörigen ist zu entnehmen, welchen Stellenwert die Familienunterstüt-

229 Reisebericht SS-Hauptsturmführer Hasan Bajralitarović [Bajraktarević] an Phleps, 15.11.1943, BArchB, NS19/2601, Bl. 60.

230 Vgl. Lepre, Himmler's Bosnian Division, S. 24. Vgl. Bougarel, La division Handschar, S. 16. 231 Reisebericht SS-Hauptsturmführer Hasan Bajralitarović [Bajraktarević] an Phleps, 15.11.1943, BArchB, NS19/2601, Bl. 59.

232 Ebd., Bl. 60.

233 Al-Husaini an von Weizsäcker, 9.6.1942, Höpp, Mufti-Papiere, S. $43 \mathrm{f}$.

234 Abschrift Besprechung „Merhamet“, Mehmed Tokić und 369. Inf.Div., 17.9.1943, BArchB NS19/3893, Bl. 16.

235 13. SS-Division, Abt. VI an Kompanieführer, „Weltanschauliche und politische Ausrichtung der Truppe im besonderen Einsatz“, 2.4.1944, BArchB, NS 19/2601, Bl. 228.

236 Eipel schrieb, dass die Freiwilligen mit sofortiger Wirkung Wehrsold erhielten und die Familienangehörigen durch eine Fürsorgestelle in Zagreb mit Sitz an der Savke Cesta 77 Familienunterstützung erhielten. Vgl. Kriegsgefangenenbericht „Bericht über die 13. SS Division ,Handschar', ihre Aufstellung, Gliederung und 1. Einsätze im jugoslawischen Raum“, Walter Eipel, 14.11.1947, VA, HEM.OK.BOJCKA, 72-A/1-a/32, S. 3.

237 Vgl. Hoare, Bosnian Muslims, S. 114. 
zung hatte: Wer in der „Handschar“ Dienst tat oder einen Sohn bzw. mehrere Söhne als Rekruten stellte, erhielt Familienunterhalt und konnte so sein Überleben und dasjenige der Familie sichern. ${ }^{238}$ Wenn das Geld nicht eintraf, versuchte man mit einem Schreiben nach Belgrad oder Zemun, zu seinem Recht zu kommen, wie beispielsweise Asim Atović aus Briboj im heutigen Montenegro, dessen Vater bei der SS nachfragte, wo der Angehörigenunterhalt bleibe. ${ }^{239}$

Neben Nahrung und Sold war auch die Bewaffnung ein wichtiges Argument, sich rekrutieren zu lassen, wie der Bericht eines Muslimen aus dem Sandžak zeigt. Dieser berichtete auf der Muslimen-Konferenz in Prijepolje, die Muslime der Region hätten „weder Waffen noch irgendeine Unterstützung“, beides erhofften sie sich durch eine Zusammenarbeit mit den Deutschen. ${ }^{240}$ Auch die Tatsache, dass die Ustaša mit dem Versprechen auf mehr Sold und besseres Essen versuchte, Waffen-SS-Soldaten im Urlaub abzuwerben, um die Division „Handschar“ zu schwächen, zeigt, wie wichtig die Befriedigung elementarer Bedürfnisse war. ${ }^{241}$

\subsubsection{Konkrete Wünsche: Rache}

Neben dem Wunsch nach Schutz, Ausrüstung und Verpflegung existierte ein weiterers wichtiges Motiv, sich in der „Handschar“ einzuschreiben: Rache. Diesem Phänomen, welches die Schuld am Krieg und am begangenen Unrecht gesamthaft der gegnerischen Partei zugeschrieb, spürte Casagrande bei der Untersuchung der Schwesterdivision der „Handschar“, der „Prinz Eugen“, nach. Eine solche Einstellung lässt eigene kriegerische Handlungen als notwendige Verteidigung der eigenen Gruppe erscheinen und rechtfertigt auch Übergriffe auf die Zivilbevölkerung des gegnerischen Lagers: „Durch das selbst erlebte Unrecht wird das eigene Handeln als Notwehr oder vom Gegner verschuldete Racheaktion gesehen.“242 Bajraktarević führte aus, dass viele mit dem Beitritt in die Division nicht nur ihren geistigen Oberhäuptern gerecht werden, sondern auch ihre Heimat und die geplünderten bzw. massakrierten Verwandten und Bekannten rächen wollten:

238 Beispielsweise Uka, Jahir bzw. Fahir und Uka, Suleiman aus Rečica, Podujevo, die in die „Handschar“ eintraten, AJ, F 110 Arhiv Komizija (DK), Box F730/J782 oder Gasparitsch, Vladimir und Gasparitsch, Josef aus Slavonski Brod, AJ, F 110 Arhiv Komizija (DK), Box F702.

239 Vgl. Atović, Asim, AJ F 110 Arhiv Komizija (DK), Box F694/J746.

240 Muslimen-Konferenz in Prijepolje, Bericht eines „Sandschak-Muselmanen“, ca. Februar 1943, PAAA, R100998.

241 Vgl. Redžić, Bosnia and Herzegovina, S. 47.

242 Casagrande, Volksdeutsche SS-Division, S. 70 f. 
Auf diese Weise der Aufgabe für Glauben und Heimat bewusst, trat man in die Division mit dem Bewusstsein, dass auf diese Weise die Hoffnungen und Erwartungen der gestraften Heimat und der ausgeraubten und geplünderten Brüder erfüllt würden. Die Division ist auf diese Weise ein Symbol und die Hoffnung der Muselmanen Bosniens und der Herzegowina geworden. ${ }^{243}$

In Kriegsgefangenschaft gab SS-Standartenführer Franje Matheis zu Protokoll, dass die Soldaten ganze Dörfer plünderten, das Vieh verkauften oder unter den Muslimen verteilten, mit der Begründung, sie würden Rache für die von Četniks begangenen Verbrechen an ihren Familien üben. ${ }^{244}$ SS-Untersturmführer Günter Borkowsky gab später an, das Massaker in Čelić im Frühsommer 1944 aus Rache befohlen zu haben, da er die 35 Mann seines zurückgelassenen Halbzuges grausam verstümmelt vorgefunden hatte. ${ }^{245}$ Wie diese beiden Aussagen zeigen, bildete Rache sowohl auf Seiten bosnischer als auch deutscher Soldaten ein wichtiges Element im Divisionsalltag. Solche Racheaktionen können als ein dialektisches Konstrukt gesehen werden, denn zwischen dem Balkanfeldzug 1941 und der Aufstellung der „Handschar“ 1943 schrieb al-Huseini an von Weizsäcker, dass die bosnischen Muslime, da sie die deutschen Truppen im Balkanfeldzug unterstützt hätten, Racheaktionen von Četniks und Kommunisten ausgesetzt wären. ${ }^{246}$ Nun folgte in diesem Verständnis die Racheaktion der Muslime an ihren Rächern bzw. deren Familien. Genau diesen Umstand versuchte Sauberzweig zu instrumentalisieren, als er kurz vor der Rückkehr der bosnischen Soldaten in ihre Heimat folgende Worte an sie richtete:

Dienstliche Notwendigkeiten führten mich bereits jetzt zu einer Reise durch fast ganz Bosnien. Was ich sah, hat mich zutiefst erschüttert. Die Felder sind nicht bestellt, die Ortschaften ausgebrannt und zerstört, die wenigen übriggebliebenen Menschen wohnen in Kellern oder Erdlöchern. In den Flüchtlingslagern am Rande der Städte herrscht ein

243 Vgl. Reisebericht SS-Hauptsturmführer Hasan Bajralitarović [Bajraktarević] an Phleps, 15.11.1943, BArchB, NS19/2601, Bl. $59 \mathrm{f}$.

244 Vernehmungsprotokoll Matheis, Franje, Office of Chief of Council for War Crimes Translation of Document No. NO-4951, Landeskommission der Feststellung der Verbrechen der Okkupatoren und ihrer Helfershelfer, Inv. Nr. 35874, BArchF, Nachlass Vopersal, N 756/169a. Vgl. Matheis Franje, AJ 110, 7401, 138-329.

245 Vgl. Fall Günter Borkwosky USHMM, BArchL, B162/20812, Bl. 7. Unterstellt war Borkowsky dem Kdr. der Nachrichtenabt. SS-Standartenführer (bzw. Obersturmbannführer) Hans Hanke, Vgl. ebd. Bl. 6, 61.

246 Al-Husaini an von Weizsäcker, 9.6.1942, Höpp, Mufti-Papiere, S. 43. Vgl. auch Korb, Im Schatten des Weltkriegs, S. 88. Vgl. zur Dialektik von Gewalt auch Gerlach, Extrem gewalttätige Gesellschaften, S. 9 f., 342. 
Elend, wie ich es bisher in meinem Leben noch nie sah. Das muss durch ein schnelles und energisches Zupacken geändert werden. ${ }^{247}$

Das Motiv der Rache tauchte bei bosnischen Einheiten aber nicht erst im Zweiten Weltkrieg auf, wie folgende Zeugnisse österreichisch-ungarischer Offiziere zeigen. Pero Blašković etwa schrieb:

Meine Bosniaken, die bis zu diesem Moment so fügsam und gehorsam waren, waren plötzlich nicht mehr wiederzuerkennen. Sie wurden völlig verrückt und schlugen Tag und Nacht mit Minen und Bomben auf die Russen ein, ohne anzuhalten. In dieser Nacht griff eine Gruppe von Freiwilligen einen russischen Graben an, tötete die gesamte Besatzung und kehrte erfreut zurück, Ahmed Babić gerächt zu haben. ${ }^{248}$

\subsubsection{Die kroatische Regierung stellt sich gegen eine rein muslimische Division}

Ein größeres Problem für die Aufstellung einer kroatischen bzw. einer bosnischen Division sollte die kroatische Regierung darstellen. ${ }^{249}$ Am 13. Februar 1943 bat Reichsaußenminister von Ribbentrop den Gesandten Kasche darum, Pavelić die deutschen Pläne zur Aufstellung einer „fremdvölkischen“ WaffenSS-Division zu unterbreiten. ${ }^{250}$ Obwohl Kasche Ribbentrop bereits am 18. Februar 1943 warnte: „Kroatische Regierung möchte nicht unmittelbar Freiwilligenwerbung von deutscher Seite“, ${ }^{251}$ schien die Sache am 21. Februar geklärt und Karl Ritter schrieb: „Der Herr Reichsaußenminister hat mit besonderer Befriedigung davon Kenntnis genommen, dass der Poglavnik der Aufstellung einer SS-Division sofort zugestimmt hat.“252 Zwei Monate später äußerte aber Phleps grundsätzliche Bedenken hinsichtlich der Loyalität der Ustaša-Regierung:

Die Balkanmethoden kennend, bin ich überzeugt, dass die kroatischen Regierungsstellen zwei Gesichter zeigend, auf der einen Seite den Schein wahren, auf der anderen aber alle möglichen Mittel anwenden, um die Aufstellung zu verhindern oder zumindest empfindlich zu verzögern. ${ }^{253}$

247 Brief Nr. 8, Divisionskommandeur Sauberzweig an Mannschaft der 13. SS-Division, 25.2.1944, BArchB, NS 19/2601, Bl. 210.

248 Pero Blašković cited after: Pašić, Bosniaks in WWI, S. 90.

249 Vgl. Tessin, Verbände, Bd. 3, S. 282.

250 Vgl. Lepre, Himmler's Bosnian Division, S. 20.

251 Kasche an Ribbentrop, 18.2.1943, PAAA, Inland IIg, R100998.

252 Ritter an Gesandtschaft in Agram, 21.2.1943, PAAA Inland IIg R100998, H297631.

253 „Zwischenbericht über Werbeaktion muselmanischer Freiwilliger“, Phleps an Chef des SSFührungshauptamtes SS-Gruppenführer Jüttner, 19.4.1943, BArchB NS19/2601, Bl. 10. 
Mit dieser Einschätzung sollte Phleps Recht behalten. Zwischen 1943 und 1944 unternahm die kroatische Regierung verschiedene Versuche, die deutschen Rekrutierungsanstrengungen zu sabotieren, zu unterwandern oder zu verzögern. ${ }^{254}$

Dass die Regierung Pavelić der geplanten Aufstellung einer Waffen-SS-Division von Beginn an kritisch gegenüberstand, war vor allem den Bedenken geschuldet, „dass das Selbstbewusstsein der Mohammedaner [durch von den Deutschen aufgestellte Verbände] zu stark gehoben werde, was ihren Autonomiebestrebungen wieder Auftrieb geben könnte“, wie Kaltenbrunner im April 1943 feststellte. ${ }^{255}$ Dennoch waren die Einwände der Regierung bei den Verhandlungen nie grundsätzlicher Natur, sondern betrafen stets nur die konkrete spezifische Ausgestaltung, Benennung und personelle Zusammensetzung der Division. So war die Regierung, welche sich eng an die katholische Kirche anlehnte, nicht mit der Bildung einer rein muslimischen Waffen-SS-Division einverstanden und verlangte daher, dass auch Katholiken der Division beitreten durften. ${ }^{256}$ Zweitens sollte auch die Ustaša an der Zusammenarbeit mit einem vermeintlich nationalsozialistischen Eliteverband teilhaben dürfen. ${ }^{257}$ Dies wiederum passte ganz und gar nicht in die von Himmler angestrebte Konzeption muslimischer Verbände. Auch die Muslime selbst, die unter anderem vor den Ustaše Schutz in der Waffen-SS suchten, standen einer gemischten Division sehr skeptisch gegenüber. ${ }^{258}$

Bei den ersten Besprechungen im Februar 1943, an welchen unter anderen Kasche, der kroatische Außenminister Mladen Lorković und der Stellvertreter des Deutschen Bevollmächtigten Generals in Kroatien, Oberst Funk, anwesend waren, stellte der Poglavnik gleich einen ganzen Katalog von Forderung: Werbungen von deutscher Seite waren unerwünscht und sollten von kroatischer Seite durchgeführt, die Division sollte nicht als „muslimische“ sondern als „Ustaša“-Division bezeichnet werden, kroatische Uniformen und Dienstgradabzeichen wären zu verwenden, die Division sei auf kroatischem Boden aufzustellen und die Kommandosprache sollte Kroatisch sein. ${ }^{259}$ In diesem Falle, so das Versprechen, könnten sofort 6.000 Ustaša-Freiwillige in die neue Division eintre-

254 Vgl. Lepre, Himmler's Bosnian Division, S. 27.

255 Schreiben betr. „Aufstellung einer SS-Legion aus bosnischen Mohammedanern“, Chef Sicherheitspolizei und SD Ernst Kaltenbrunner an Reichsführer SS Heinrich Himmler, 24.4.1943, BArchB, NS19/2601, Bl. 10.

256 Letztlich dienten 2.800 Katholiken in der „Handschar“.

257 Vgl. „Zwischenbericht über Werbeaktion muselmanischer Freiwilliger“, Phleps an Chef des SS-Führungshauptamtes SS-Gruppenführer Jüttner, 19.4.1943, BArchB, NS19/2601, Bl. 9.

258 Vgl. ebd.

259 Vgl. Phleps an Himmler, BArchB, 19.2.1943, NS19/3523, Bl. 39. Vgl. auch Grmek, Lambrichs, Les revoltés, S. 152 und Lepre, Himmler's Bosnian Division, S. 22. Vgl. hierzu auch Redžić, Muslimansko autonomaštvo, S. 81. 
ten. Phleps war von diesen Forderungen befremdet und meldete, dass eine solche Division nicht als SS-Verband bezeichnet werden könne, vielmehr würde es sich um eine militärische Formation handeln, die lediglich mit Hilfe der SS aufgestellt würde. ${ }^{260}$ In einem „Blitz-Fernschreiben“ an Phleps nahm schließlich Himmler persönlich zu den Forderungen des Poglavniks Stellung: Die 6.000 Freiwilligen lehnte er zwar nicht ab, bestand aber weiterhin darauf, die Division aus Muslimen zu bilden: „Bleibe bei meiner Absicht, SS-Bosniaken-Division aus Muselmanen aufzustellen, die heute zum größten Teil nicht auf unserer Seite mitkämpfen, sondern beiseite stehen oder sogar gegen uns kämpfen.“261 Er wollte sie daher lieber in seinen Diensten wissen, weil er der Überzeugung war, dass die „Bosniaken“ an ihre Erfolge in der österreichisch-ungarischen Armee anknüpfen konnten. ${ }^{262}$

Wenige Tage späte, Ende Februar, ließ die kroatische Regierung noch einmal mitteilen, dass sie eine kroatische SS-Division begrüßen würde, allerdings nur unter der Bedingung, dass sie selbst 20.000 Freiwillige Ustaša-Mitglieder, darunter auch Muslime, stellen dürfe. ${ }^{263}$ Nicht zu Unrecht wandte Pavelić ein, dass die geplante Aufstellung außenpolitische Konsequenzen haben könnte. Er befürchtete, die Italiener würden aus Četnik-Formationen SchwarzhemdenDivisionen bilden und weiterhin Übergriffe von Četniks gegen die kroatische Bevölkerung tolerieren. ${ }^{264}$ Glaise-Horstenau konnte diese Einwände zwar nachvollziehen, war aber der Meinung, dass gewiss „die innenpolitischen Bedenken der Kroaten gegen unsere Absicht, die Freiwilligenwerbung selbst durchzuführen und auf die Bosnischen Moslims [sic] zu konzentrieren, nicht unbedingt stichhaltig“ wären, weil sich die bosnischen Muslime ohnehin als „eigene Volksgemeinschaft fühlen“ würden. ${ }^{265}$ Aufgrund der Einwände von kroatischer Seite schlug Glaise-Horstenau ein persönliches Treffen zwischen Himmler und Lorković vor. Er und auch Phleps würden sich aufgrund der „zunächst erheblich politischen

260 Aus Phleps Bericht an Himmler ist auch das unterschiedliche Verständnis zu erkennen: Die kroatische Regierung strebte wohl eher eine Legion an, also ein Verband, der lediglich mithilfe der Waffen-SS aufgestellt wurde, dann aber landeseigene Kommandeure hatte. Während die Vertreter der Waffen-SS eindeutig eine Division unter Führung der Waffen-SS anstrebten. Vgl. Phleps an Himmler, BArchB, 19.2.1943, NS19/3523, Bl. 39. Vgl. auch Grmek, Lambrichs, Les revoltés, S. 152.

261 Himmler an Phleps, „Blitz-Fernschreiben“, 20.2.1943, BArchB, NS 19/3523, Bl. $41 \mathrm{f}$.

262 Vgl. ebd.

263 Vgl. Glaise-Horstenau an Himmler, 25.2.1943, BArchB, NS 19/3523, Bl. 43.

264 Vgl. ebd.

265 Ebd., Bl. $43 \mathrm{f}$. 
Seite der Frage“ aus der Angelegenheit heraushalten. ${ }^{266}$ Himmler antwortete am 3. März 1943, dass er einem solchen Treffen sehr positiv gegenüberstehe. Allerdings kam auch für ihn die von der kroatischen Regierung mehrmals gestellte Forderung, die SS-Division als „Ustaša“-Division zu benennen, weiterhin nicht in Frage. ${ }^{267}$ Laut Vrančić soll Phleps aber, trotz der oben gemachten Angaben von Glaise-Horstenau, bei Verhandlungen zwischen Vertretern der kroatischen Regierung und einer deutschen Delegation am 4. März, angeführt von Rudolf Dengel, anwesend gewesen sein. Als Himmlers Forderung bezüglich der Aufstellung und Ausgestaltung der Division als einer muslimischen Einheit bei Vrančić weiterhin auf Ablehnung stieß, wäre Phleps wutentbrannt aus dem Raum gestürmt. Die Verhandlungen wurden tags darauf ohne ihn weitergeführt. ${ }^{268}$

In der zweiten Aprilhälfte 1943 meldete der Polizeiattaché in Zagreb, SSUntersturmführer Hans Helm, dass mit weiteren Schwierigkeiten seitens der kroatischen Regierung zu rechnen sei: Vordergründig würden sie darauf beharren, dass auch die Italiener über das Vorhaben der muslimischen SS-Division informiert werden müssten. Helm war sich aber sicher, dass die Kroaten mit diesem Vorgehen den ihnen „unwillkommenen Plan zum Scheitern“ bringen wollten. ${ }^{269}$ Einige Tage zuvor hatte Phleps Jüttner aufgrund der anhaltenden Querelen vorgeschlagen, die kroatischen Behörden ganz einfach zu übergehen, die Werbelisten beim Aufbaustab in Agram (Zagreb) unter der Leitung von SS-Standartenführer Herbert von Obwurzer durchzuarbeiten, vor allem Führer, Unterführer und „hierzu Geeignete“ festzustellen und diese einerseits durch die kroatischen Behörden, gleichzeitig aber auch durch die muslimischen Geistlichen einberufen zu lassen. ${ }^{270}$

Hinzu kam, dass die Forderungen der kroatischen Regierung über die Beitrittsmöglichkeiten von Katholiken und Mitgliedern der Ustaša in die SS-Formation hinausgingen. Bei den immer noch laufenden Verhandlungen, die zu diesem

266 Ebd., Bl. 44.

267 Himmler an Glaise-Horstenau, 3.3.1943, BArchB, NS19/3523, Bl. 44. Vgl. auch Grmek, Lambrichs, Les revoltés, S. 153.

268 Vgl. Viekolsav Vrančić, Branili smo državu, Barcelona: Knjižnica Hrvatske Revije 1985, Vol. 2, S. 357, nach: Lepre, Himmler's Bosnian Division, S. 23.

269 Schreiben betr. „Aufstellung einer SS-Legion aus bosnischen Mohammedanern“, Chef Sicherheitspolizei und SD Ernst Kaltenbrunner an Reichsführer SS Heinrich Himmler, 24.4.1943, BArchB, NS19/2601, Bl. 10.

270 Vgl. „Zwischenbericht über Werbeaktion muselmanischer Freiwilliger“, Phleps an Chef des SS-Führungshauptamtes SS-Gruppenführer Jüttner, 19.4.1943, BArchB, NS19/2601, Bl. 10. Obwurzer wird in der Quelle nur mit dem Grad eines SS-Sturmbannführers angegeben, seit Januar 1943 war er aber bereits SS-Standartenführer. Vgl. auch Kriegsgefangenenbericht „Bericht über die 13. SS Division ,Handschar‘, ihre Aufstellung, Gliederung und 1. Einsätze im jugoslawischen Raum“, Walter Eipel, 14.11.1947, VA, HEM.OK.BOJCKA, 72-A/1-a/32, S. 1. 
Zeitpunkt von Helm geführt wurden, forderten die Delegierten nun die Aufstellung einer Gendarmerie aus 6.000 Kroaten. Da Kasche es versäumt hatte, Helm über die bereits von Phleps geführten Verhandlungen zu diesem Anliegen zu unterrichten, konnte Helm keine klare Haltung gegenüber den Forderungen der kroatischen Dienststellen einnehmen. ${ }^{271}$

Bezüglich der zukünftigen Waffen-SS-Division gab die deutsche Seite letztlich in einigen Punkten nach, um das Projekt nicht zu gefährden: Die Division sollte nun aus katholischen Kroaten und kroatischen bzw. bosnischen Muslimen insbesondere aus dem Gebiet Bosnien-Herzegowinas bestehen. Angehörige der Legion Hadžiefendić sollten sich für Rekrutierungen zur Verfügung stellen. ${ }^{272}$ Von kroatischer Seite sollten Offiziere und Unteroffiziere mit deutschen Sprachkenntnissen oder „volksdeutscher“ Abstammung in die neu aufzustellende Division abkommandiert werden. Die Rekrutierungen sollten durch kroatische Dienststellen in enger Zusammenarbeit mit der SS durchgeführt werden. Die definitive Vereinbarung sollte schriftlich von der kroatischen Regierung und der deutschen Gesandtschaft in Agram, vertreten durch Kasche, bestätigt werden. $^{273}$

Zu einer weiteren Trübung des Verhältnisses führte der von der kroatischen Regierung als „unerwartet“ empfundenen Besuch von Mohammed Amin al-Huseini, dem Großmufti von Jerusalem, bei den muslimischen Eliten im NDH. ${ }^{274}$ Ganz so unerwartet kam dieser Besuch allerdings nicht, vielmehr galt der Großmufti seit Beginn der Aufstellung der bosnisch-muslimischen Division als deren Schirmherr, und sowohl seine Reise durch Bosnien als auch später zur „Handschar" nach Neuhammer wurden minutiös inszeniert, auf Bildern festgehalten und sollten auf die muslimische Welt eine Signalwirkung haben. ${ }^{275}$ Al-Huseini reiste zuerst nach Zagreb und von dort nach Banja Luka und Sarajevo. ${ }^{276}$ Die kroatische Regierung jedoch wollte den Großmufti isolieren, ihn nur mit Poglavnik-treuen Muslimen in Kontakt treten lassen und ,ihn von den Moslems der nationalen Partei und den neutralen Moslems“ fernhalten. ${ }^{277}$ Von Kremp-

271 Vgl. Schreiben betr. „Aufstellung einer SS-Legion aus bosnischen Mohammedanern“, Chef Sicherheitspolizei und SD Ernst Kaltenbrunner an Reichsführer SS Heinrich Himmler, 24.4.1943, BArchB NS19/2601, Bl. $10 \mathrm{f}$.

272 Vgl. Redžić, Muslimansko autonomaštvo, S. 81.

273 Vgl. Grmek, Lambrichs, Les revoltés, S. 154.

274 Vgl. „Zwischenbericht über Werbeaktion muselmanischer Freiwilliger“, Phleps an Chef des SS-Führungshauptamtes SS-Gruppenführer Jüttner, 19.4.1943, BArchB NS19/2601, Bl. 9.

275 Al-Husaini an Melchers, in: Höpp, Muftipapiere, 160-162.

276 Ebd., 160. Vgl auch Gensicke, Mufti von Jerusalem, S. 116-118.

277 „Zwischenbericht über Werbeaktion muselmanischer Freiwilliger“, Phleps an Chef des SSFührungshauptamtes SS-Gruppenführer Jüttner, 19.4.1943, BArchB NS19/2601, Bl. 9. 
ler umging aber diese Vorgaben und „gab den Führern der nationalen Moslems Gelegenheit zur vertraulichen Aussprache mit dem Groß-Mufti [sic], ohne Anwesenheit von Regierungsorganen oder Spitzeln.“278

Der kroatische Minister für Bosnien, Pavle Canki, sah in der deutschen Rekrutierungsstrategie das Vorhaben, Bosnien von Kroatien zu isolieren und national-bosnische Kräfte zu stärken. Auch Staatssekretär Vrančić war gegen die Aufstellung einer bosnisch-muslimischen Division, da er eine durch die Aufstellung der neuen Waffen-SS-Division „erzwungene“ Autonomie Bosniens fürchtete. Beide wussten aber, dass sich die kroatische Regierung den deutschen Wünschen nicht grundsätzlich widersetzen konnte. ${ }^{279}$ Über Informanten waren die Deutschen im Bild über Pläne, die in ihrer Abwesenheit geschmiedet wurden, denn Vertrauensmänner hatten von Krempler und Phleps Meldung gemacht, dass Canki dem Advokaten Dr. Alečković bereits den Auftrag erteilt habe, für die Regierung in Zagreb einen Bericht auszuarbeiten, „der die Lage in Bosnien so darstellen soll, als ob durch die geplante Aufstellung der Div[ision] Unruhe in die Bevölkerung gekommen sei“, und so gezielt die separatistische Bewegung der muslimischen Bevölkerungsteile vorangetrieben würde. ${ }^{280}$ Canki ging laut von Krempler so weit, „einigen Regimekreaturen“ den Auftrag zu geben, Beschwerdebriefe an ihn selbst zu richten, um seine Intervention bei der kroatischen Regierung zu legitimieren. Von Kremplers Vertrauensmann Alečković war jedoch - ohne Wissen Cankis - Mitglied der bosnischen nationalen Partei und sah sich veranlasst, von Krempler sämtliche von Cankis verfassten oder in Auftrag gegebenen Dokumente zuzuspielen. ${ }^{281}$ Als Reaktion darauf schickte Phleps den Ia der Division „Prinz Eugen“, SS-Sturmbannführer Erich Eberhardt, nach Zagreb, damit er dort mit General Glaise-Horstenau und dem Gesandten Kasche die Interventionen und Ränkespiele der kroatischen Regierung besprechen und das weitere Vorgehen definieren konnte. Kasche blieb der Sitzung jedoch fern. $^{282}$

\subsubsection{Interessen bosnisch-muslimischer Institutionen}

Der Anstoß zur Bildung einer muslimischen Division kam, ungeachtet seiner Begeisterung für den Islam, nicht von Himmler selbst. Aus einem Bericht von

278 Ebd.

279 Vgl. ebd.

280 Ebd.

281 Vgl. ebd.

282 Vgl. ebd. 
SS-Hauptsturmführer Hasan Bajraktarević an Phleps geht hervor, dass die muslimische geistliche und weltliche Führung von sich aus mit dem Vorschlag, eine muslimische Division aufzustellen, an die nationalsozialistische Führung herangetreten war. ${ }^{283}$ Grmek und Lambrichs gehen davon aus, dass die Idee einer muslimischen Division in Mostar geboren wurde. Dort liebäugelte der Mufti Omer Džabić mit einem groß angelegten muslimischen Projekt: Er wollte alle muslimischen Teile Südosteuropas, Bosnien, Sandžak und „Großalbanien“ zu einem Staat unter italienischer Herrschaft vereinen. In Rom habe sich al-Huseini nach einem Treffen mit Džabićs Delegation dazu entschlossen, den Italienern eine muslimische Armee vorzuschlagen, die gegen die Partisanen kämpfen würde. Da diese Idee von den Italienern aber nicht weiterverfolgt wurde, entschloss sich der Mufti, denselben Vorschlag den Deutschen zu unterbreiten. Um seine Idee ideologisch zu untermauern, hob er den vermeintlich germanischen Ursprung der muslimischen Bevölkerung dieser Gebiete hervor. ${ }^{284}$ Kurze Zeit später, im November 1942, meldete sich ein „Nationalkomitee“ aus Sarajevo, um in einem Memorandum dem Wunsch nach einer Aufstellung muslimischer Einheiten Nachdruck zu verleihen. ${ }^{285}$

In Zusammenhang mit den Rekrutierungen für die bosnisch-herzegowinische, später als kroatisch bezeichnete SS-Freiwilligen-Division tauchen bereits früh vier muslimische Institutionen auf. Die wichtigste scheint der Verein „Merhamet“ mit Sitz in Sarajevo gewesen zu sein, dessen langjähriger Vorsitzender Muhamed Pandža war. Der Verein „Merhamet“ hatte sich vorrangig als gemeinnützige Organisation einen Namen gemacht, da er sich um muslimische Flüchtlinge, insbesondere um Kinder, kümmerte. ${ }^{286}$ Daneben ist vor allem die bosnischmuslimische Geistlichkeit zu nennen, die sich in der „Ulema medžlis“, einem Gelehrtenrat und gleichzeitig der höchsten muslimische Verwaltungskörperschaft in Bosnien, konstituierte. Auch in der Ulema war Pandža Mitglied. ${ }^{287}$ Als dritte Organisation ist El-Hidaje zu erwähnen, welche von der Ulema bereits 1936 gegründet worden war und die muslimische Geistlichkeit im NDH vertrat. $^{288}$ An der Versammlung von El-Hidaje im August 1943 äußerten nach

283 Vgl. Reisebericht SS-Hauptsturmführer Hasan Bajralitarović [Bajraktarević] an Phleps, 15.11.1943, BArchB, NS19/2601, Bl. $59 \mathrm{f}$.

284 Vgl. Grmek, Lambrichs, Les revoltés, S. 150.

285 Ebd.

286 Vgl. Reisebericht SS-Hauptsturmführer Hasan Bajralitarović [Bajraktarević] an Phleps, 15.11.1943, BArchB, NS19/2601, Bl. 58.

287 Vgl. ebd. Vgl. Bougarel, La division Handschar, S. 49. Vgl. zur Funktion des Ulema medžlis Petke, Muslime in der Wehrmacht und Waffen-SS, S. 51.

288 Vgl. Hoare, Bosnian Muslims, S. 46. 
verschiedenen Massakern viele Vertreter ihre Besorgnis bezüglich der Situation der bosnischen Muslime. Das Massaker von Foča im August $1942^{289}$ war schließlich ausschlaggebend für die Bildung einer Schirmorganisation muslimischer Institutionen, Organisationen und Verbände in Bosnien-Herzegowina mit dem Namen „Nationale Rettung“. Die Leitung übernahmen Mehmed Handžić, Uzeir Hadžihasanović und fünf weitere Notabeln aus der Region. Der Rat der „Nationalen Rettung“ umfasste zunächst 48 Mitglieder, wurde aber nach dem Massaker in Višegrad umstrukturiert und bestand fortan aus sieben Ratsmitgliedern, darunter auch Handžić und wiederum Pandža. 290

Nach Hoare stellte diese Dachorganisation „die inoffizielle Führung der muslimischen Nation jener Zeit dar und strebte sowohl nach einer unabhängigen Außenpolitik als auch nach der Finanzierung und Bewaffnung des muslimischen Widerstands“. ${ }^{291}$ Im März 1943 trat ihr auch die extremistische Jungmuslimenorganisation bei und leitete damit die Konsolidierung zwischen der konservativen und der radikalen Fraktion der Autonomistenbewegung ein. ${ }^{292}$

Gerade in der Informationspolitik dieses Bündnisses wird die Nähe zu den arabischen Staaten deutlich, denn ihm war sehr daran gelegen, den Großmufti al-Huseini, die Könige von Saudi-Arabien und Ägypten, den Präsidenten der Türkei als auch die Alliierten von der Notlage der bosnisch-herzegowinischen Muslime zu unterrichten. ${ }^{293}$

Am 1. November 1942 richteten führende bosnische Muslime im Namen eines „National Komitees“ ein Memorandum an Hitler, in welchem sie ihre Treue zum Dritten Reich hervorhoben, ihre vermeintliche rassische Verwandtschaft $\mathrm{zu}$ den Germanen betonten und eine dezidiert antisemitische Attitüde an den Tag legten. $\mathrm{Zu}$ den Autoren dieser Denkschrift gehörten Hadžihasanović, Softić, Salihagić und möglicherweise auch Pandža. ${ }^{294}$

Diese bosnischen Institutionen hatten nicht nur bezüglich der Rekrutierungen bestimmte Bedingungen, sondern auch konkrete Vorstellungen hinsichtlich des Einsatzraumes der Division: Als sich die „Handschar“ zur Ausbildung mehrere Monate im Ausland befand, forderten die muslimischen Institutionen,

289 In der Region in und um Foča begingen Četnik-Einheiten während des Zweiten Weltkriegs drei große Massaker an der muslimischen Bevölkerung, wovon das dritte mit über 9.000 Toten das größte war.

290 Vgl. Hoare, Bosnian Muslims, S. $51 \mathrm{f}$.

291 Ebd., S. 51.

292 Vgl. ebd., S. 51 f.

293 Vgl. ebd., S. 51.

294 Vgl. ebd., S. 52. 
sie bis Ende 1943 wieder nach Bosnien zu verlegen, damit sie dort „in Aktion treten“ konnte. ${ }^{295}$

Die Propaganda für die Rekrutierung sollte ausgebaut werden, denn Bajraktarević und die muslimische Geistlichkeit waren der Meinung, dass damit die gegnerische, kommunistische Propaganda zurückgedrängt werden könnte. Dabei standen insbesondere religiöse Motive im Vordergrund, wie der folgende Satz zeigt: „Dieses wäre die Aufgabe mehrerer Imams, da diese Propaganda in erster Linie religiösen Charakter hätte und die 13. Division betreffen würde.“296 Diese Forderung trägt die Handschrift der „Ulema“, „El-Hidaje“ und „Merhamet“, die als Initiatoren eine religiöse Ausrichtung der Division wünschten. ${ }^{297}$

Außerdem forderten die bosnischen Institutionen die NS-Spitze auf, den Vorfall von Kosutica aufzuklären, wo Soldaten der Division „Prinz Eugen“ in der ersten Julihälfte 1943 aufgrund vermeintlicher Partisanenaktivitäten vierzig Menschen erschossen hatten. Da es sich um Muslime handelte, war die Sache für die Waffen-SS delikater als andere Kriegsrechtsverstöße dieses Ausmaßes. Durch die Aufklärung des Verbrechens sollte ,wenigstens formal der muselmanischen Welt eine gewisse Satisfaktion gegeben werden“ ${ }^{298}$, um diese während der laufenden Rekrutierungen für die „Handschar“ nicht zu verärgern.

\subsubsection{Interessen muslimischer Eliten im Sandžak und im serbischen Teil Kosovos}

Am Ende des 19. Jahrhunderts war der Sandžak zwar de iure immer noch unter osmanischer Herrschaft, de facto aber seit einiger Zeit von Österreich-Ungarn besetzt, da die k.u.k.-Monarchie dort nach dem Berliner Kongress von 1878 Truppen stationierte. ${ }^{299}$ In seiner Funktion als Korridor genoss der Sandžak in dieser Phase einen Status, der es den muslimischen Eliten erlaubte, auf die lokale Politik Einfluss zu nehmen. Von einem anfänglich zu großen Teilen ablehnenden Verhalten gegenüber den Repräsentanten Österreich-Ungarns war

295 Reisebericht SS-Hauptsturmführer Hasan Bajralitarović [Bajraktarević] an Phleps, 15.11.1943, BArchB, NS19/2601, Bl. 60.

296 Ebd.

297 Dies ist einer der Hauptunterschiede zur albanischen und zur „volksdeutschen“ Division, wo die treibenden Kräfte weltlich motiviert waren.

298 Reisebericht SS-Hauptsturmführer Hasan Bajralitarović [Bajraktarević] an Phleps, 15.11.1943, BArchB, NS19/2601, Bl. 60.

$299 \mathrm{Zu}$ den Verwaltungsaufgaben der Garnisonen im Sandžak vgl. Scheer, Minimale Kosten, absolut kein Blut, S. 118-133. Vgl. auch Morrison, Roberts, Sandžak, S. 61 f. 
in den dreißig Jahren eine Zuwendung zu bis hin zur Verbrüderung mit den Besatzern festzustellen. Als das Ende der österreichisch-ungarischen Verwaltung nahte, waren „die einstigen Kooperationspartner im Sandžak [...] zum Träger des alten Systems geworden, dessen Absetzung anstand“. ${ }^{300}$ Auch im Kosovo selbst zählten sich viele der Muslime zu den Gegnern der Reformen, welche in jener Zeit vom Osmanischen Reich unter dem Namen „Jungtürken“-Bewegung ausgingen. ${ }^{301}$ Zwischen 1908 und 1912 zogen die Österreicher ihre Truppen ab, und der Sandžak kam für diese vier Jahre wieder unter osmanische Herrschaft. Während des ersten Balkankriegs besetzten serbische und montenegrinische Truppen 1912 den Sandžak, der in den Londoner Verträgen 1913 zwischen diesen beiden Staaten aufgeteilt wurde. Viele Muslime, die meisten davon albanischer Abstammung, einige aber auch aus ursprünglich bosnischen Familien, begrüßten den Einmarsch österreichisch-ungarischer Truppen im November 1915, da die Invasoren insbesondere den Eliten ihr Land und ihre Privilegien zurückgaben, die ihnen drei Jahre zuvor von den Serben genommen worden waren. Montenegriner und Serben hingegen gehörten nun zu den Verfolgten. ${ }^{302}$ Für die muslimische Bevölkerung sollte die Entspannung der politischen und sozialen Situation aber nur von kurzer Dauer sein, denn mit den Friedenschlüssen von Paris wurde der Sandžak 1918 Teil des Jugoslawischen Königreichs. Für viele Muslime begann, zumindest in ihrer eigenen Wahrnehmung, eine Zeit der Unterdrückung. Diese findet auch in zahlreichen Schreiben von albanischen Notabeln aus dem Sandžak und Kosovo an den neu gegründeten Völkerbund ihren Ausdruck. $^{303}$ In der Zeit zwischen den beiden Weltkriegen kam es immer wieder zu Übergriffen an der muslimischen Bevölkerung, vor allem durch serbische Sicherheitskräfte. So töteten beispielsweise Angehörige der jugoslawischen Gendarmerie und serbische Zivilpersonen muslimische Zivilisten bei lokalen Wahlen in Mitrovica im Herbst 1924. ${ }^{304}$

Ähnlich wie die Ausgangslage bosnischer Muslime gestaltete sich nach dem Einmarsch der Deutschen die Situation muslimischer Eliten im Sandžak und in dem bei Serbien verbliebenen Teil Kosovos unter deutscher Militärherrschaft. Die-

300 Scheer, Minimale Kosten, absolut kein Blut, S. 57, 59, 61. Vgl. Morrison, Roberts, Sandžak, S. 65 .

301 Vgl. Schmidt, Kosovo, S. 81-84.

302 Vgl. Morrison, Roberts, Sandžak, S. 93.

303 Vgl. beispielsweise M. Midhat Frashëri to the Peace Conference, "Albanian Minorities in the Serb-Croat-Slovene State”, 29 April 1921, UN Archive Geneva, C.29. M.13 oder “Question albanaise”, Rapport de M. A.J. Balfour, représentant de la Grande-Bretagne, UN Archive Geneva, S 363/1/4.

304 Annex 5 Albanian Minorities in the Serb-Croat-Slovene Kingdom, Note by the Secretary General, 11 November 1924, UN Archive Geneva, C.29. M.13. 
ses Gebiet umfasste die Bezirke Mitrovica, Vushtrri/Vučitrn, Podujevo und Novi Pazar. ${ }^{305}$ Albanische Freischärler hatten bereits 1941 die deutsch-italienische Invasion unterstützt, in der Hoffnung, die Achsenmächte würden alle hauptsächlich albanisch bewohnten Gebiete vom „serbischen Joch“ befreien. ${ }^{306}$

Vor die Schwierigkeit gestellt, serbische und albanische Interessen gleichzeitig zu befriedigen, versuchten die Deutschen bereits in der zweiten Jahreshälfte 1941 beide Bevölkerungsteile in administrative Vorgänge einzubeziehen:

Um zu verhindern, dass die alten Gegensätze zwischen albanischer und serbischer Bevölkerung unter der derzeitigen Aufstandspsychose zu gewaltsamen Auseinandersetzungen führen, werden im Mitrovitza-Gebiet [sic] auch Angehörige der ortsangesessenen arnautischen ${ }^{307}$ Bevölkerung zur Verwaltung herangezogen. ${ }^{308}$

Als die Auseinandersetzungen zwischen Serben und Albanern anhielten, diskutierten die Deutschen sogar über eine Aussiedlung albanischer Bevölkerungsteile aus dem Gebiet um Mitrovica in den italienischen Teil Kosovos. ${ }^{309}$ Der Diplomat Peter Pfeiffer riet jedoch dringend davon ab, da eine solche Umsiedlung ,bei Albanern noch tiefere Erbitterung auslösen [würde] als alle serbischen Kolonisierungsversuche der letzten Jahrzehnte“ und somit dem deutschen Ansehen in der albanischen Bevölkerung schaden würde. ${ }^{310}$ Die Region erhielt schließlich von deutscher Seite einen Autonomiestatus zugesprochen und konnte so bestimmte Entscheidungen losgelöst von der Regierung in Belgrad treffen. ${ }^{311}$

305 Vgl. Bericht ,über die Reise in das Arnautengebiet von Kosovska Mitrovica und Novi Pazar“ des Volkstumsreferenten Dr. Feninger beim Bevollmächtigten des AA in Belgrad, 15.26.10.1941, PAAA, R261153, Bl. 33.

306 Vgl. Kollegger, Albaniens Wiedergeburt, S. 66. Vgl. auch Avni Gjilani an Jacomoni, 16.4.1941, A.Q.SH., F.161, 1941, D 1078, S. 7.

307 Arnauten: Aus dem Türkischen stammende Bezeichnung für Albaner, in den hier zitierten Quellen verwendet zur näheren Definition von albanischen Muslimen.

308 Abschrift von Referent Geheimrat von Bülow an Reichaußenminister Ribbentrop zur Vorlage, 20.11.1941, PAAA R101024, Bl. 4.

309 Vorgeschlagen wurde die Aussiedlung von rund 100.000 Albanern aus Südwestserbien nach Albanien. Vgl. Auswärtiges Amt, Otto von Erdmannsdorff an Generalkonsulat Tirana, 15.11.1941, PAAA, Altes Amt, Tirana 4/3.

310 Telegramm Generalkonsulat Tirana, Peter Pfeiffer an AA, 17.11.1941, PAAA, R261153, Bl. 81. Auch im Süden Albaniens waren Umsiedlungen vorgesehen: So bestanden Umsiedlungspläne für 20.000 albanische Flüchtlinge aus der griechisch-albanischen Grenzregion Tsamouriá/Çamëria, die in Filiates versammelt waren. Diese sollten nach Südalbanien umgesiedelt und umgekehrt die dortige orthodoxe griechische Bevölkerung nach „Tschamurien“ überführt werden. Vgl. Junker an Schliep, 21.8.1944, PAAA, R27305.

311 Vgl. Bericht an das italienische Außenministerium, ohne Namensangabe, 19.4.1944, ASD, RSI, Aff. Pol., Busta 51, fasc. Alb. 1/1, S. 1. 
Bereits kurz nach dem Balkanfeldzug 1941 formierte sich innerhalb der albanischen Bevölkerung aufgrund der angespannten Lage eine Serbien- und Italien-feindliche Bewegung mit dem Zentrum in Mitrovica, welche jede Zusammenarbeit mit den Italienern ablehnte. ${ }^{312}$ Eine wichtige Rolle spielte dabei der aus Mitrovica stammende Ferhat Draga, der einerseits als persönlicher Berater des in Albanien eingesetzten italienischen Generalstatthalters Francesco Jacomoni di San Savino fungierte, andererseits aber als Vater des in Serbisch-Kosovo eingesetzten albanischen „Volksgruppenführers“ Ali Draga auch über die Autonomiebestrebungen der Muslime und Rekrutierungsabsichten der Deutschen im Nordkosovo und Sandžak informiert war. ${ }^{313}$ Sein Sohn Ali Draga spielte, zusammen mit Xhafer Deva, Ibrahim Lufti, Rexhep Mitrovica und Bedri Pejani, die alle im bei Serbien verbliebenen Teil Kosovos bzw. im Sandzak beheimatet waren, als „Volksgruppenführer“ eine zentrale Rolle bei den Rekrutierungen von Albanern in verschiedene „Selbstschutzeinheiten“, die „albanisch muselmanische Freiwilligenlegion“, die „Handschar“ und später die „Skanderbeg“. Draga, Deva, Mitrovica und Lufti stammten aus Mitrovica, Pejani aus Vushtrri/Vučitern. Sie alle waren nicht erst während der deutschen Besatzung, sondern bereits seit Jahrzehnten wichtige politische Akteure in der Region und Mitglieder des „Komitee für die Verteidigung des Kosovo“ (Komiteti KONARE), welches 1918 in Shkodër gegründet und von Kadri Prishtina geleitet wurde. Zwischenzeitlich wurde es durch verschiedene Exilorganisationen unterstützt, war seit April 1941 aktiv bei der Rekrutierung lokaler Soldaten für deutsche Einheiten und ging im Herbst 1943 in der „Zweiten Liga von Prizren“ auf. Beide Organisationen legten eine dezidierte Kollaborationswilligkeit an den Tag, mit dem Ziel, Autonomie bzw. einen Anschluss an „Großalbanien“ und die Bewaffnung der Bevölkerung zu erreichen. ${ }^{314}$ Dass die Gegner der Muslime im Sandžak und Nordkosovo ähnlich wie in Bosnien auch vor extremer Gewalt nicht Halt machten, zeigt etwa der Wahlspruch einer Četnik-Bande aus der Region: „NICHT EIN MUSELMANE WIRD UNTER UNS BLEIBEN“. Nach der Säuberung des Sandžak „,von muselmani-

312 Vgl. Telegramm Bevollmächtigter des AA beim Militärbefehlshaber Serbien Benzler an AA, 30.10.1941, PAAA, R261153.

$313 \mathrm{Vgl}$. Bericht an das italienische Außenministerium, ohne Namensangabe, 19.4.1944, ASD, RSI, Aff. Pol., Busta 51, fasc. Alb.

314 In Fiume wurde 1920 ein irredentistisches Komitee gegründet, welches Mitglieder aus Kosovo, Mazedonien, Kroatien, Montenegro und Ungarn hatte. Vertreter aus Kosovo waren Hasan Bey Prishtina, Dervish Bey Mitrovitza, Bajram Curri und Avni Bey Gjilani. Vgl. Avni Gjilani an Jacomoni, 16.4.1941, A.Q.SH., F.161, 1941, D 1078, S. 7. Vgl. auch Zaugg, Albanische Muslime, S. 140, 143. 
schen und katholischen Elementen“, sollten dort Montenegriner und Serben angesiedelt werden. ${ }^{315}$

Aufgrund anhaltender Spannungen zwischen Serben und Albanern fand im Februar eine Muslimen-Konferenz in Prijepolje statt, und im Frühjahr 1943 wurden im SS-Hauptamt verschiedene Möglichkeiten zur Erhaltung von Ruhe und Ordnung und die „Heranziehung der muslimischen Bevölkerung zu militärischen Zwecken“ diskutiert. Gegebenenfalls sollte mit Vorschlägen an das Auswärtige Amt herangetreten werden, berichtete Reichel. ${ }^{316}$ Aus genannten Gründen rechnete Berger mit großem Zulauf der albanischen Bevölkerung aus dem SandžakGebiet und angrenzenden Gebieten. ${ }^{317}$

\subsection{Werbung und Aufstellung}

Als Aufstellungsbeginn der Division „Handschar“ wurde der 1. März 1943 festgelegt. ${ }^{318}$ Die Werbungen sollten in den Gebieten Bosnien-Herzegowinas als auch im Sandžak und in dem Teil Kosovos, der bei Serbien unter deutscher Militärherrschaft verbliebenen war, durchgeführt werden. Im Folgenden werden sowohl Vorgängereinheiten erläutert, die schließlich ganz oder in Teilen in der Division „Handschar“ aufgingen, als auch das konkrete Vorgehen von WaffenSS und affiliierten Stellen vor Ort.

\subsubsection{Vorgängereinheiten}

Für ihre Rekrutierungen bosnischer Muslime konnten die deutschen Besatzer auf ihre Erfahrungen beim Aufbau der Schwesterdivision „Prinz Eugen“ zurückgreifen, wie es in einem Schreiben der Abteilung D des Auswärtigen Amtes an das OKW und Berger zu lesen ist: „In Ausführung eines Führerlasses hatte die deutsche Gesandtschaft in Agram die Weisung erhalten, sofort das Einverständnis der kroatischen Regierung dazu herbeizuführen, dass die Waffen-SS-Division

315 Kommandant des Ozrener Korps, Hauptmann I. Kl., Miloš M. Jovanović an Kommandanten der Zepaer Militärischen Freischärlerabteilung Golub Mitrović, 13.2.1943, PAAA, R100998. Hervorhebung im Original. Zaugg, Albanische Muslime, S. 165.

316 Vgl. Muslimen-Konferenz in Prijepolje, ca. Februar 1943, PAAA, R100998. Vgl. Bericht Reichel, AA Inland IIc, 12.4.1943, PAAA, Inland IIg R,100998.

317 Berger an Auswärtiges Amt, Abt. D VIII, 9.4.1943, PAAA, Inland IIg, R100998.

318 Vgl. Jüttner an Sonderverteiler/70 Ausfertigungen, betr. „Aufstellung der Kroatischen SSFreiwilligen-Division“, 30.4.1943, BArchB, NS19/3523, Bl. 34. 
„Prinz Eugen“ durch Werbung eine neue Division aus kroatischen Freiwilligen aufstellt."319

In der Region hatten sich in den letzten zwei Jahren seit dem Balkanfeldzug eine Vielzahl von Milizen und kleineren Einheiten formiert, die in der Division „Handschar“ aufgingen, und deren Kommandeure bei der Werbung unterstützend wirkten. ${ }^{320}$ Schon im September 1941 unterstützte der Präfekt in Tuzla, Ragib Čapljić, die Bildung autonomer muslimischer Verbände innerhalb dieses Gebiets. ${ }^{321}$ Im November begann eine weitere wichtige Schlüsselfigur damit, bewaffnete Einheiten aufzustellen. Muhamed Hadžiefendić hatte im Rang eines Leutnants in der österreichisch-ungarischen und als Major in der jugoslawischen Armee gedient. Die Initialzündung für den Aufbau dieser lokalen Milizverbände war die erfolgreiche Vereitelung eines Angriffs auf das muslimische Dorf Puračić. Ende Dezember erhielt Hadžiefendić von offizieller Seite aus Zagreb die Erlaubnis, zusammen mit Vorstehern städtischer und dörflicher Eliten eine muslimische Legion zu bilden. Bereits am 22. Dezember 1941 wurde in Tuzla schließlich offiziell die „Freiwilligen Sektion des Volksaufstands von Major Hadžiefendić“ gegründet. $^{322}$ Im Frühjahr 1942 befehligte Hadžiefendić ungefähr 5.000 Mann, welche in der Region von Gračanica im Westen, Orašje und Bosanski Šamac im Norden, Zvornik und Bijeljina im Osten, und Kladanj im Süden im Einsatz waren. Dieses „Freiwilligen-Heim-Garde-Regiment“/Domobransko Dobrovoljačka Pukovnija“, kurz „Domdo“, bestand Ende 1942 aus sechs Bataillonsstäben in Bijeljina, Brčko, Gračanica, Puračić, Živinice und Tojšice. Das Oberkommando lag weiterhin in Tuzla bei Hadžiefendić. ${ }^{323}$ Dieser war bekannt für seine anti-kroatische Einstellung und hoffte, mit seiner Legion den Kern einer bosnisch-herzegowinischen Armee zu bilden, die fähig sein würde, die Region in die Autonomie zu führen. ${ }^{324}$ Ein Abkommen vom 5. März 1943 legte zudem fest, dass die neu aufzustellende Waffen-SS-Division durch Personal der Hadžiefendić-Legion unterstützt würde ${ }^{325}$, die etwa über 4.000-7.000 Mann verfügte. ${ }^{326}$

319 Abteilung VIII 110g an OKW/Abt. Ausland/Abwehr und an Berger, 17.2.1943, PAAA Inland IIg R100998.

320 Vgl. Lepre, Himmler's Bosnian Division, S. 23.

321 Čapljić stand später unter Anklage, bei der Vergabe von Ämtern Muslime bevorzugt zu haben. Vgl. Redžić, Bosnia and Herzegovina, S. 171.

322 Hoare, Bosnian Muslims, S. 46.

323 Vgl. Hoare, Bosnian Muslims, S. 46.

324 Vgl. ebd., S. 114. Vgl. auch Adnan Jahić, Muslimanske formacije. Tuzlanskog kraja u Drugom svjetskom ratu, Tuzla: Znaj u Bosne/Preoporod 1995, S. 42.

325 Vgl. Lepre, Himmler's Bosnian Division, S. 23.

326 Vgl. hierzu auch Redžić, Muslimansko autonomaštvo, S. 81. 


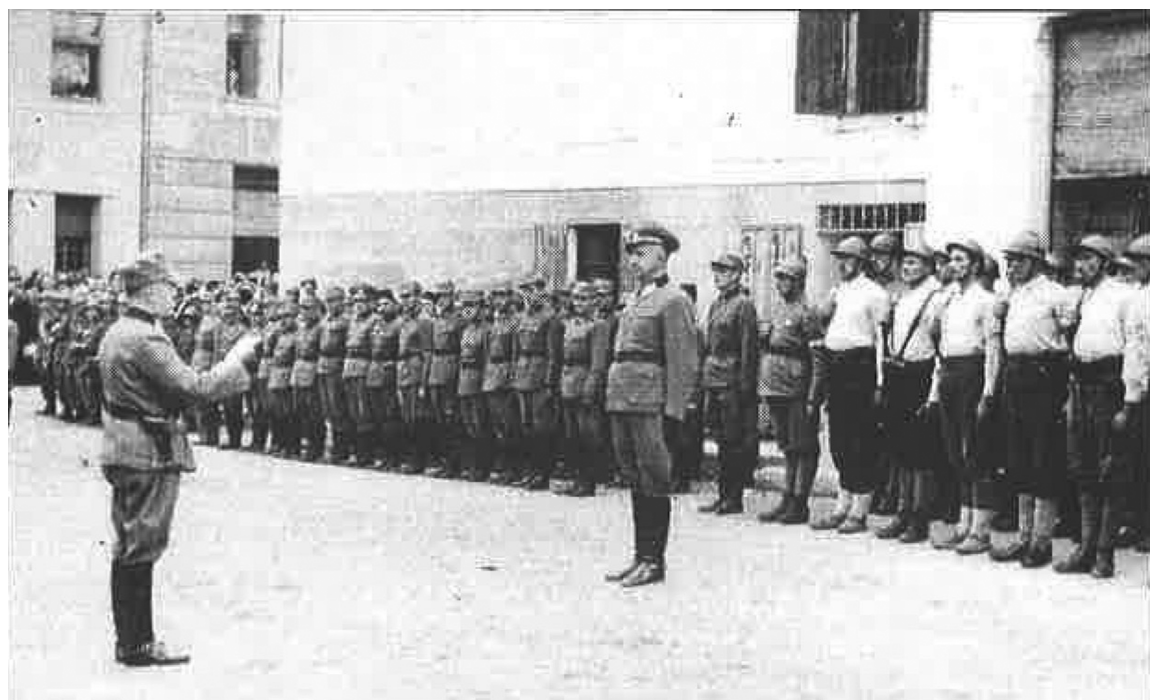

Abb. 18: Hadžiefendić mit seinen Soldaten bei einer Ehrung in Tuzla, 22.9.1942.327

Auch Jure Francetić, Ustaša-Kommandeur für Bosnien-Herzegowina, organisierte unter dem Namen „Schwarze Legion“ bewaffnete Einheiten, die er vor allem aus muslimischen Flüchtlingen aus Ostbosnien rekrutierte. Hoare geht davon aus, dass in dieser Formation bereits im Frühjahr 1942 1.000-1.500 Mann gegen kommunistische Partisanen und Četniks kämpften. ${ }^{328}$ In Bijeljina hatte Murat Bey Pašić, ein lokaler Ustaša-Kommandeur mit Sympathien für die muslimische Unabhängigkeitsbewegung ebenfalls damit begonnen, bewaffnete Verbände aus bosnischen Muslimen aufzubauen. Obwohl ein Ustaša-Kommandeur, soll er sich dafür eingesetzt haben, dass Bosnien unter deutsche Verwaltung kam, um das Gebiet auf diese Weise dem Einfluss des NDH zu entziehen. ${ }^{329}$ Im Vorfeld der Aufstellungen nannte Glaise-Horstenau als weiteren möglichen Rekrutierungspool für die „Handschar“ die Legion von Hadij Effendić. Diese bestand ebenfalls aus muslimischen Bosniaken und war nach seinen Angaben zwischen 4.000 und 7.000 Mann stark. ${ }^{330}$ Weitere muslimische Milizen existierten beispielsweise in

327 Adnan Jahić, Muslimanske formacije, ohne Seitenangabe.

328 Vgl. Hoare, Bosnian Muslims, S. 24.

329 Vgl. ebd., S. 44.

330 Vgl. Botschafter Ritter an Gesandtschaft in Agram 21.02.1943, PAAA, Inland IIg, R100998, H297632. 


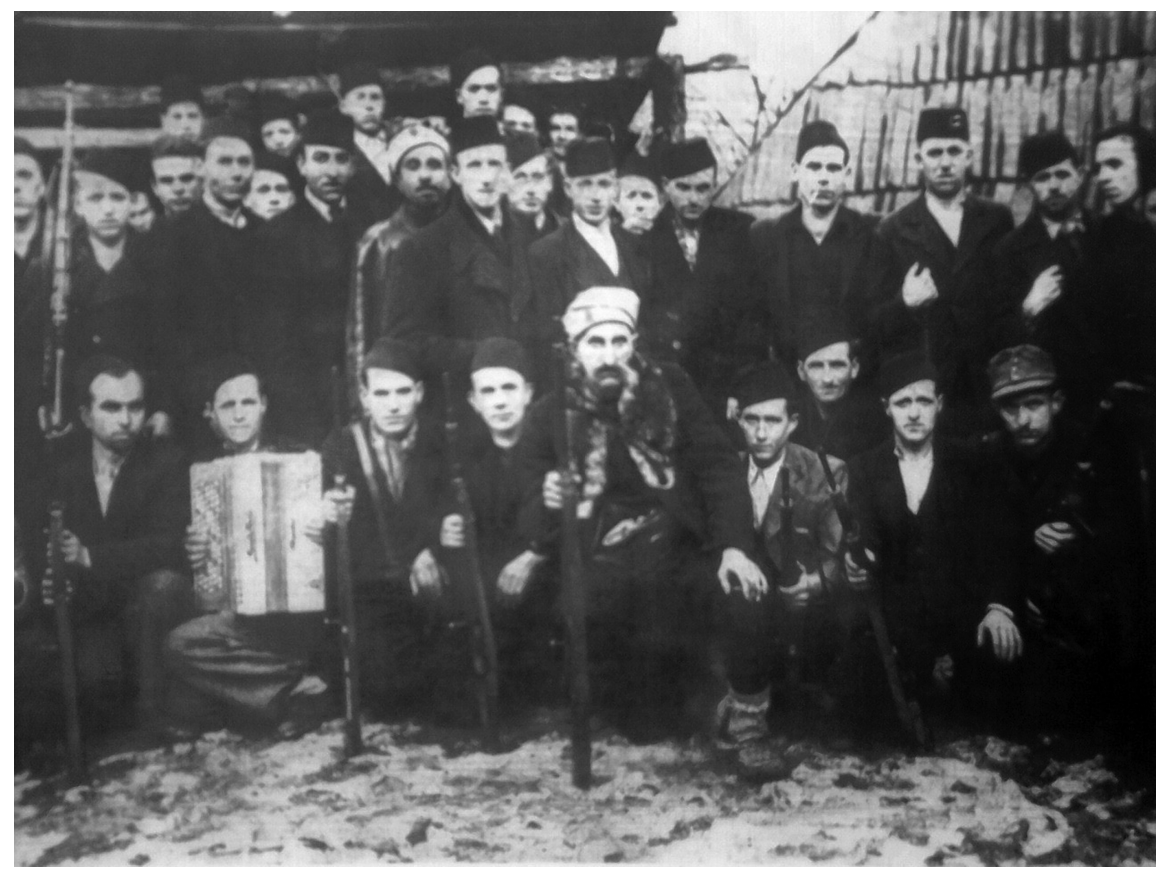

Abb. 19: Muslimische Miliz von Fadil Imamović in Janjići. ${ }^{331}$

Foča, Goražde, Janjići, Travnik (Salko Ćatić) oder in Fazlagica Kula bei Gacko (Džemal Tanović). ${ }^{332}$

Nach Hoare wurden die Männer dieser Milizen oft willkürlich aus der Bauernschaft des nordöstlichen Bosniens rekrutiert, und er betont, dass ihre Disziplin und ihr Verhalten gegenüber Zivilisten demjenigen der Banden ähnelte, die sie bekämpften: Sie plünderten serbische Dörfer und misshandelten oder töteten deren Einwohner. Der regulären Armee des NDH wie auch der Polizei lehnten sie ab. Doch auch kroatischen Zivilisten standen sie feindlich gegenüber, da sie ihr Einsatzgebiet als muslimisches Territorium betrachteten. ${ }^{333}$ Muslime desertierten aber auch aus der regulären Armee im NDH, um in einer der lokalen Milizeinheiten zu dienen und so Haus und Hof verteidigen zu können. Da viele Muslime die neu aufgestellte reguläre Armee des NDH, die „Kroatische Heim-

331 https://handzar.jimdo.com/drugi-svjetski-rat/od-1941-do-1945/muslimanske-milicije-ubosni-i-herzegovini/ (Stand: 3.3.2020).

332 Vgl. https://handzar.jimdo.com/drugi-svjetski-rat/od-1941-do-1945/muslimanske-milicijeu-bosni-i-herzegovini/ (Stand: 18.7.2019).

333 Vgl. Hoare, Bosnian Muslims, S. 46. 
wehr“ (Hrvatsko Domobranstvo), die Ustaša und vor allem Četniks als feindliche Kräfte wahrnahmen, versuchten sie auf diese Weise, sich selbst und die hauptsächlich von Muslimen bewohnten Gebiete zu schützen. ${ }^{334}$

Hoare nennt allein für Sarajevo fünf muslimischen Milizen, die bereits kurz nach Einmarsch der Deutschen 1941 in den Stadtteilen Vratnik, Hrasnica, Nahorevo, Jarčedol und Kotarac gebildet worden waren. ${ }^{335}$ Indem sie ihre Milizen dem Befehl Hadžiefendićs unterstellten, versuchten die frühen muslimischen Autonomiebewegungen in Sarajevo außerdem, den Wirkungsradius seiner Legion auf ihre Gebiete auszudehnen. ${ }^{336}$ Im Oktober 1942 verfolgte die Dachorganisation „Nationale Rettung“ die von Hadžiefendić 1941 begonnene Aufstellung von bosnischen Milizen weiter. Zu diesem Zweck stattete Pandža Pavelić einen Besuch ab, bei welchem er die Aufstellung einer Miliz vorschlug, die das gesamte Gebiet Bosnien-Herzegowina abdecken sollte. Er schlug Hadžiefendić, Sulejman Filipović oder Šefket Hasadedić als mögliche Kommandeure vor. Verständlicherweise zeigte der Poglavnik wenig Interesse an einer bosnischen Armee mit autonomistischem Charakter und beschränkte die Aufstellung der Miliz auf den Raum Tuzla. ${ }^{337}$

Frühe Rekrutierungen von Muslimen im Sandžak unterstanden der Aufsicht des HSSPF Serbien, SS-Gruppenführer August Meyszner. Murat Bayrević, Jurist und seit seiner Schulzeit überzeugter Antikommunist, war als Ustaša-Kommissar für den Sandžak bereits seit 1941 für die Werbung Freiwilliger für die Ostfront zuständig. ${ }^{338}$ Noch wichtiger als Bayrević waren drei weitere Männer, die zum Zeitpunkt der Aufstellung der „Handschar“ 1943 bereits über zwei Jahre Erfahrung in der Werbung von Freiwilligen verfügten: Xhafer Deva, Ali Draga und Ibrahim Lufti. ${ }^{339}$ Als V-Mann, der bereits seit dem Balkanfeldzug im Dienst der deutschen Wehrmacht stand, beteiligte sich Xhafer Deva an allen frühen Rekrutierungen muslimischer Albaner in deutsche Verbände und war, zusammen mit Ali Draga und dem Kreisvorsteher von Mitrovica Ibrahim Lufti, in der Werbung von Freiwilligen für die deutsche Wehrmacht aktiv. ${ }^{340}$

\footnotetext{
334 Vgl. ebd., S. 45.

335 Vgl. ebd., S. 46.

336 Vgl. ebd., S. 52.

337 Vgl. ebd., S. 52. Vgl. auch Jahić, Muslimanske formacije, S. 43-55.

338 Aufzeichnung, „Lebenslauf des Murat Bayrević“, PAAA Inland IIg R100998.

339 Vgl. Bevollmächtigter des AA beim Militärbefehlshaber Serbien Benzler an AA, „Italienische Beschwerde über die Betätigung Xhafer Devas im Mitrovica-Gebiet“, 31.3.1943, PAAA, R100998 H297622. Vgl. Bevollmächtigter des AA beim Militärbefehlshaber Serbien Benzler an AA, „Aufstellung eines muselmanischen Freiwilligenkorps“, 13.4.1943, PAAA, R100998.

340 Vgl. ebd. Vgl. auch Bevollmächtigter des AA beim Militärbefehlshaber Serbien Benzler, an AA, 31.3.1943, PAAA Inland IIg R100998, H297622. Vgl. zum Stellenwert der „V-Männer“ für die Vorbereitung des deutschen Einmarschs auch Stamm, Deutsche Besetzung Albaniens, S. 100.
} 
Im März 1943 setzte er sich bei der Werbung für ein „Muselmanisches Freiwilligenkorps“ im serbischen Kosovska Mitrovica und Novi Pazar ein. ${ }^{341}$ Diese Idee wurde von Berger aufgegriffen, der gegenüber dem Auswärtigen Amt im Frühjahr 1943 die Meinung vertrat, dass die Aufstellung von „Selbstschutzeinheiten“ in dieser Region notwendig sei, „um der zurückbleibenden Bevölkerung ein Gefühl der Sicherheit gegenüber den serbischen Banden zu geben“. ${ }^{342} \mathrm{Zu}$ diesem Zweck sollte zunächst ein Regiment aus Freiwilligen aus den Gebieten Kosovska Mitrovica und Novipazar aufgestellt werden. Die Deutschen gingen von 10.000-12.000 Freiwilligen aus. ${ }^{343}$ Draga hingegen rechnete mit nur ungefähr 4.000 Freiwilligen für solche Einheiten. ${ }^{344}$

Als Draga Deva aufgrund „alter persönlicher Gegensätze“ bei den Italienern anschwärzte und seine Funktion als „Vertrauensmann der Abwehrstelle in Belgrad“ daraufhin öffentlich wurde, forderten die Italiener ihre Verbündeten auf, Deva aufgrund seiner ,ausgesprochenen italienfeindlichen Haltung“ zurückzupfeifen. ${ }^{345}$ Doch Deva und Draga, einer deutschfreundlich und der andere eher als italienfreundlich zu bezeichnen, hegten beide ein großes Interesse, die Freiwilligenwerbung sowohl für die Wehrmacht als auch für die Waffen-SS weiterzuführen. Draga stimmte daher schließlich zu, dass Deva trotz persönlicher Differenzen gemeinsam mit Lufti auch weiterhin an der Werbung beteiligt bleiben sollte. Allerdings wurde ihm zunächst jede Einflussnahme auf die weitere Verwendung der rekrutierten Einheiten untersagt. ${ }^{346}$ Dies sollte sich jedoch bald ändern: Nach der Kapitulation Italiens setzten die Deutschen Deva als Innenminister Albaniens ein. Gemeinsam mit Bedri Pejani und dem späteren Mi-

341 Vgl. Schreiben „Aufstellung eines muselmanischen Freiwilligenkorps“ Bevollmächtigter des AA beim Militärbefehlshaber Serbien Benzler an AA, 13.4.1943, PAAA, R100998.

342 Berger an das AA, „Betreff: Freiwillige für die 13. (kroatische) SS-Division aus dem Sandžakgebiet“, 9.4.1943, PAAA, R100998, H297616.

343 Diese hätten eigentlich für Wehrmachteinheiten genutzt werden sollen, konnten aber jetzt für die Waffen-SS rekrutiert werden. Vgl. Bevollmächtigter des AA beim Militärbefehlshaber Serbien Benzler an AA, 13.4.1943, PAAA, Inland IIg, R100998. Vgl. Dienststelle des AA beim Militärbefehlshaber Serbien, Gehart Feine an AA, „Werbung unter der muselmanischen Bevölkerung“, 18.5.1943, PAAA, R100998.

344 Vgl. Dienststelle des AA beim Militärbefehlshaber Serbien, Gehart Feine an AA, 18.5.1943, PAAA, R100998.

345 Vgl. Schreiben „Italienische Beschwerde über die Betätigung Xhafer Devas im MitrovicaGebiet“ Bevollmächtigter des AA beim Militärbefehlshaber Serbien Benzler an AA, 31.3.1943, PAAA, R100998 H297621.

346 Vgl. ebd. 
nisterpräsidenten Rexhep Mitrovica sollte er bei den Rekrutierungen für die Division „Skanderbeg“ eine zentrale Rolle spielen. ${ }^{347}$

\subsubsection{Rekrutierungen in Bosnien-Herzegowina}

Mitte Februar 1943 erhielt Phleps von Himmler die Anweisung, keine Zeit zu verlieren und „heute schon“ mit der „Werbung der Freiwilligen“ zu beginnen. ${ }^{348}$ Himmler war sich sicher, dass Phleps seine Sache gut machen würde: „Ich habe dem Führer gemeldet, dass der Auftrag bei Ihnen in der besten Hand ist. “349 Auch die Werbung für die „Handschar“ verlief nicht unbedingt auf freiwilliger Basis: ${ }^{350}$ Selbst wenn kein Befehl zur Einführung einer allgemeinen Wehrpflicht erlassen wurde, wie dies 1942 für die Aufstellung der „Prinz Eugen“ der Fall gewesen war, kam die Praxis von Zwangsaushebungen und Abgabequoten einer solchen sehr nahe. ${ }^{351}$ Phleps schrieb in einer Weisung an Jüttner sogar ausdrücklich von Einberufungen. ${ }^{352}$ Offener Rekrutierungszwang deutscher Dienststellen ist in mehreren Fällen dokumentiert; so wurden etwa im bosnischen Travnik die wehrfähigen Männer während des Gebets aus der Moschee abgeführt und für die Division gemustert. ${ }^{353}$

Dennoch tritt das Prinzip der „Freiwilligkeit“ in zahlreichen Akten in den Vordergrund, denn Himmler war davon überzeugt, dass die Muslime Südosteuropas nur darauf warten würden, in seiner nationalsozialistischen Elite-Armee zu dienen. ${ }^{354}$ Insbesondere die Ausstattung mit den „alten Rechten“, die sie in der österreichisch-ungarischen Armee genossen hatten, sowie die „freie Religionsausübung“ schienen ihm dafür geeignete Lockmittel zu sein. ${ }^{355}$ Berger hingegen

347 OB Südost, Bericht „Entwicklung der militärischen Lage in Albanien im Herbst 1944“, undatiert, BArchF, RW 40/116a, Bl. 14f. Vgl. auch Zaugg, Albanische Muslime, S. 92.

348 Vgl. Funkspruch Himmler an Phleps, 13.2.1943, BArchB NS19/2601, Bl. 2.

349 Ebd.

350 Vgl. Schmidhuber, Kriegsgefangenenbericht II, 19.8.1945, VA HEM.OK.BOJCKA, 72/1/2/3.

351 Vgl. Sundhaussen, Waffen-SS in Kroatien, S. 189. Vgl. Stein, Geschichte der Waffen-

SS, S. 154 f. Petke kritisiert, dass Stein und Longerich von einer allgemeinen Wehrpflicht schreiben, ohne aber dafür eine Quelle zu nennen. Vgl. Stein, Geschichte der Waffen-SS, S. 162f. Vgl. Longerich, Heinrich Himmler, S. 695. Vgl. Petke, Muslime in der Waffen-SS, S. 77.

352 Vgl. „Zwischenbericht über Werbeaktion muselmanischer Freiwilliger“, Phleps an Chef des SS-Führungshauptamtes SS-Gruppenführer Jüttner, 19.4.1943, BArchB, NS19/2601, Bl. 10.

353 Vgl. Salihbegovic, „Bericht zur Lage“, 25.9.1943, BAB, NS 19/2601, Bl. 32.

354 Vgl. Funkspruch Himmler an Phleps, 13.2.1943, BArchB NS19/2601, Bl. 2.

355 Vgl. ebd. Zu den Rechten, welche die Bosniaken in der k.u.k.-Armee genossen hatten, vgl. auch Neumayer, Schmidl, Des Kaisers Bosniaken, S. 95 f., 99, 103. Bereits bei der Besetzung 
kannte noch andere Methoden, um die Rekrutierungen in Gang zu halten: So bat er etwa darum, man möge ihm einige Flaschen Alkohol zukommen lassen, um die Rekrutierungsverhandlungen mit lokalen Clanchefs voranzutreiben. ${ }^{356}$ Die zu Rekrutierenden selbst waren oft Analphabeten, wie etwa untenstehendes Dokument zeigt, und konnten sich somit kaum vergewissern, auf was sie sich einließen. ${ }^{357}$

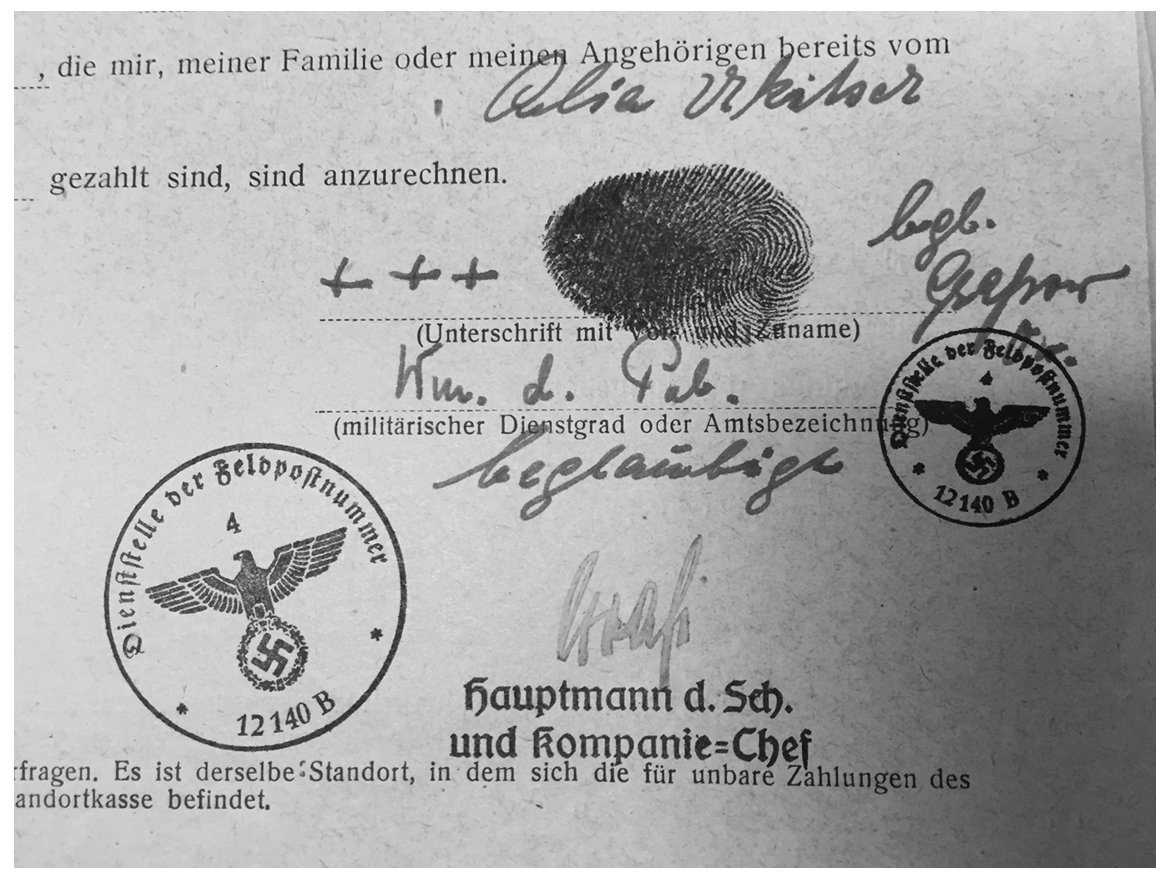

Abb. 20: Ukić, Alija unterschreibt mit drei Kreuzen und Fingerabdruck. ${ }^{358}$

Im Februar 1943 wurde SS-Standartenführer Dengel damit beauftragt, in Agram beim Stab des Bevollmächtigten Generals Glaise-Horstenau ,alle Aufstellungsfra-

1878 proklamierte Franz Joseph I.: „Eure Gesetze und Einrichtungen sollen nicht willkürlich umgestoßen, Eure Sitten und Gebräuche sollen geschont werden. “ Die Proclamation in: Sammlung I (1880), S. 3f., entnommen der Wiener Zeitung Nr. 172 vom 28. Juli 1878, zitiert nach Džaja, Srećko M.: Bosnien-Herzegowina in der österreichisch-ungarischen Epoche (1878-1918). München: Oldenbourg 1994, S. 58.

356 Vgl. Rittmeister i. A. von Kremplers an von Grolmann, 21.10.1943, NARA, T313/Roll847, F. 000858.

357 Vgl. Rochas, La Handschar, S. 169.

358 Ukić, Alija, AJ, F 110, DK, Box F730/J782. 
gen noch vorher zu klären und dann die Stammrollen mit Hilfe kroatischer Dienststellen anzulegen“. ${ }^{359}$ Wie Karl Ritter, Diplomat und Verbindungsmann zwischen dem Auswärtigen Amt und dem OKW, dem Gesandten Kasche in Zagreb schrieb, sollten die Rekrutierungen nicht nur in Absprache mit der kroatischen Regierung, sondern auch „,in enger Fühlung mit der Wehrmacht“ erfolgen; er meldete außerdem, dass das OKW deshalb bereits über die Rekrutierungsabsichten für die „Handschar" unterrichtet worden war. ${ }^{360}$

Die Aufstellung sollte, bis andere Befehle erfolgten, dem SS-Führungshaupamt unterstehen. Phleps, dem die Aufstellung oblag, erhielt Verstärkung durch den von SS-Standartenführer von Obwurzer geleiteten Aufstellungsstab. ${ }^{361}$ Dieser war bereits am 9. März 1943 in Berlin gebildet worden, bezog aber erst Anfang April Quartier in Zagreb. ${ }^{362}$ In dieser Zeit wurde in Zagreb, wie bereits erläutert, heftig über die Ausgestaltung der zukünftigen Division diskutiert. ${ }^{363}$

Am 5. März 1943 hatte der Stab Phleps gemeinsam mit Vertretern der kroatischen Regierung folgendes Vorgehen festgelegt: Die „kroatische SS FreiwilligenDivision“ sollte aus Muslimen und Katholiken aufgestellt werden, die in erster Linie aus Bosnien-Herzegowina stammten. Die Hadžiefendić-Legion würde dabei der Division Personal zur Verfügung stellen. Von kroatischer Seite wurden zweisprachige Offiziere und Unteroffiziere, darunter auch „Volksdeutsche“, für die Division freigegeben. Geplant war, die Rekrutierungen in enger Zusammenarbeit mit der Waffen-SS unter deutscher Kontrolle durch die kroatische Regierung umzusetzen, und die Einberufung der Freiwilligen durch die Ergänzungsstelle Südost auszuführen. ${ }^{364}$ Die kroatische Sprache war als Umgangs- und Ausbildungssprache vorgesehen, Deutsch würde jedoch als Kommandosprache eingesetzt werden. Sold und andere Leistungen sollten den deutschen Verhältnissen angepasst und auf religiöse Bräuche größte Rücksicht gemommen werden. Das endgültige Abkommen wurde im Austausch von Anweisungen zwischen der kroatischen Regierung und der deutschen Legation ausgearbeitet. ${ }^{365}$

Um die Rekrutierungen zu beschleunigen und verstecktem Widerstand sowie beabsichtigten Verzögerungen und Unterlassungen seitens der kroatischen Regie-

359 Vgl. Phleps an Himmler, 20.2.1943, BArchB, NS19/3523, Bl. 39.

360 Botschafter Ritter an Gesandtschaft in Agram 21.2.1943, PAAA, Inland IIg, R100998 H297634f. 361 Vgl. Jüttner an Sonderverteiler/70 Ausfertigungen, betr. „Aufstellung der Kroatischen SSFreiwilligen-Division“, 30.4.1943, BArchB, NS19/3523, Bl. 35.

362 Vgl. Lepre, Himmler's Bosnian Division, S. 25-27.

363 Vgl. Kapitel: Die kroatische Regierung stellt sich gegen eine rein muslimische Division.

364 Vgl. Lepre, Himmler's Bosnian Division, S. $23 \mathrm{f}$.

365 Vgl. ebd., Lorković hatte noch im Februar 1943 gefordert, dass auch die Kommandosprache Kroatisch sein sollte. Vgl. Lepre, Himmler's Bosnian Division, S. 22. 
rung vorzubeugen, wollte Phleps, ohne die kroatischen Behörden zu informieren, bereits Führer, Unterführer und Führeranwärter durch SS-Standartenführer Herbert von Obwurzer beim Aufstellungsstab in Zagreb auswählen lassen. Erst danach sollten die kroatischen Dienststellen und, falls diese die Arbeit der SS behinderten, parallel dazu die muslimische Geistlichkeit mit der Einberufung beauftragt werden. ${ }^{366}$ Der Aufstellungsstab wurde angewiesen, bereits Standeslisten anzulegen und die Rekrutierten auf die Einheiten der bosnischen Division, des Südostkorps und auf Polizeieinheiten zu verteilen. ${ }^{367}$ Die Einberufungsbefehle wurden individuell ausgefertigt, damit dann Einberufungen zu gegebenem Zeitpunkt durchgeführt werden konnten. Zur „Handschar“ sollten die muslimischen, zum Korps und den Polizeieinheiten auch christliche Bosnier und Herzegowiner zugelassen werden. ${ }^{368}$

Aufgrund der Abmachung, dass sowohl kroatische als auch deutsche Dienststellen bei den Aushebungen vertreten waren, brachen der von Himmler als Werbeleiter eingesetzte von Krempler und Alija Šuljak als Vertreter der kroatischen Regierung am 20. März 1943 zu einer 18tägigen Rekrutierungstour durch elf bosnische Bezirke auf, darunter Tuzla, Živinice und Gračanica. ${ }^{369}$ So genannte „Freiwilligen“-Sammelstellen bzw. Rekrutierungszentren wurden in Zemun/Semlin, Tuzla, Sarajevo, Banja Luka und Zagreb eingerichtet. ${ }^{370}$ Walter Eipel nennt zusätzlich noch die Werbestellen in Brod und Šid. ${ }^{371}$ Die rekrutierten Soldaten kamen in sogenannte Auffanglager, welche alle dem Ersatzkommando Südost in Zagreb unterstellt waren. Eipel selbst war zuerst als Leiter des Auffanglagers Agram (Zagreb)-Cernomereć mit Platz für ungefähr 2.000 und später in Zemun/Semlin, welches Platz für 5.000 Mann bot, eingesetzt. Ein drittes solches Lager existierte in Osijek/Esseg. ${ }^{372}$

Eipel und die Mitarbeiter dieser drei Lager hatten folgende Aufgaben:

1) Aufnahme und wirtschaftliche Betreuung der Freiwilligen nach ärztlicher Untersuchung,

366 Vgl. „Zwischenbericht über Werbeaktion muselmanischer Freiwilliger“, Phleps an Chef des SS-Führungshauptamtes SS-Gruppenführer Jüttner, 19.4.1943, BArchB NS19/2601, Bl. 10.

367 Vgl. ebd.

368 Vgl. ebd.

369 Vgl. Hoare, Bosnian Muslims, S. 53. Vgl. Lepre, Himmler's Bosnian Division, S. 24.

370 Vgl. Bernwald, Muslime, S. 117. Vgl. „Zwischenbericht über Werbeaktion muselmanischer Freiwilliger“, Phleps an Chef des SS-Führungshauptamtes, SS-Gruppenführer Jüttner, 19.4.1943, BArchB NS19/2601, Bl. 8.

371 Vgl. Kriegsgefangenenbericht „Bericht über die 13. SS-Division ,Handschar‘, ihre Aufstellung, Gliederung“, Walter Eipel, 14.11.1947, VA, HEM.OK.BOJCKA, 72-A/1-a/32, S. 2.

372 Vgl. ebd. Noch im März 1943 war nur ein Sammellager bei der „volksdeutschen“ Mittelstelle in Zemun vorgesehen gewesen, wie aus einem Schreiben von Himmler hervorgeht. Vgl. Himmler an SS-Führungshauptamt, SS-Personalhauptamt, SS-Hauptamt, SS-Gruppenführer Phleps und SS-Brigadeführer von Oberkamp, 31.3.1943, BArchB NS19/2601, Bl. 6. 
2) Einkleidung der tauglich befundenen Freiwilligen,

3) Abtransport der Freiwilligen nach dem Truppenübungsplatz Wildflecken (Rhön) nach Weisung der Div.Ia.

4) Stärkemeldungsabgabe täglich an Ia Division. ${ }^{373}$

Von Krempler meldete Phleps am 19. April 1943 „gute Erfolge“ bei den Rekrutierungen. Alleine in den Räumen Sarajevo und Tuzla hätten bereits 20.000 bis 25.000 Mann geworben werden können. ${ }^{374}$ In einem Schreiben vom 29. April rapportierte Berger schließlich Himmler genauere Zahlen, nämlich, dass bis zu diesem Stichtag 12.000 Bosniaken, davon tauglich etwa 8.000-9.000, 8.000 Westbosniaken, sowie 8.000-10.000 freiwillige albanische Muslime aus dem Sandžak-Gebiet geworben werden konnten. ${ }^{375}$ Dort und für angrenzende Gebiete, war sich Benzler sicher, würde die vorangegangene Aufstellung eines „muselmanischen Freikorps bei der albanischen und muselmanischen Bevölkerung voraussichtlich Befriedigung und einen bedeutenden Zustrom auslösen.“ Aufgrund der bedrängten Lage, in der sich die Muslime in ganz Südosteuropa befanden, war er der Meinung, dass auch muslimische Freiwillige aus anderen Grenzregionen, die dem ehemaligen jugoslawischen Staat angehört hatten, in die Division eintreten würden. ${ }^{376}$ Zwei Wochen später, am 30. April 1943, war aber immer noch nicht klar, welche Gebiete insgesamt als Rekrutierungsräume für die „Handschar“ infrage kamen. ${ }^{377}$ Zudem waren, wie sich herausstellte, die oben genannten Zahlen zu optimistisch. Dass vermehrt Kroaten in die Division aufgenommen wurden, war nicht nur Ausdruck des Abkommens mit der kroatischen Regierung, sondern auch eine Folge der als mäßig zu bezeichnenden Rekrutierungsfreudigkeit von Muslimen. ${ }^{378}$ Jüttner hatte bereits im April verlau-

373 Vgl. Kriegsgefangenenbericht „Bericht über die 13. SS-Division ,Handschar‘, ihre Aufstellung, Gliederung“, Walter Eipel, 14.11.1947, VA, HEM.OK.BOJCKA, 72-A/1-a/32, S. 2 f.

374 Vgl. Phleps an Chef des SS-Führungshauptamt, SS-Gruppenführer Jüttner, „Zwischenbericht über Werbeaktion muselmanischer Freiwilliger“, 19.4.1943, BAB, NS 19/2601, Bl. 8. Auch Petke bezeichnet die von von Krempler gemachten Angaben als übertrieben. Vgl. Petke, Muslime in der Wehrmacht und Waffen-SS, S. $303 \mathrm{f}$.

375 Vgl. Berger an Himmler, „Betr.: Bosniaken-Division“, 29.4.1943, BArchB, NS 19/2601, Bl. 11. 376 Bevollmächtigter des AA beim Militärbefehlshaber Serbien Felix Benzler an AA, „Aufstellung eines muselmanischen Freiwilligenkorps“, 13.4.1943, PAAA, R100998.

377 Vgl. Jüttner an Sonderverteiler, betr. „Aufstellung der Kroatischen SS-Freiwilligen-Division“, 30.4.1943, BArchB, NS19/3523, Bl. 34.

378 „Der in den Vorbesprechungen aufgetauchte Gedanke, die Division als ,grüne Division` zu bezeichnen und ihr grüne Spiegel zu geben, wurde fallengelassen, weil sie auf kroatischen Wunsch nicht nur aus Muselmanen, sondern auch aus katholischen Kroaten bestehen soll. Nach den letzten Berichten aus Agram ist das auch tatsächlich immer mehr der Fall, da sich 
ten lassen, dass auch Deutsche und „Volksdeutsche“ eingesetzt werden könnten, wenn sich zu wenig Freiwillige melden würden. ${ }^{379}$ Auch Abklärungen, ob muslimische Inder und bestimmte KZ-Insassen aus der Haft entlassen und rekrutiert werden könnten, deuten auf personelle Engpässe hin. ${ }^{380}$ Dennoch beharrte Himmler darauf, dass die Muslime sich nur nicht rekrutieren ließen, weil „Obwurzer in seiner Eitelkeit wie ein Elefant im Porzellanladen wirkt. Völlig gegen meinen Befehl richtet er sich in seiner Propaganda vor allem an die Kroaten.“ Obwohl Obwurzer aus heutiger Sicht nur bedingt eine Schuld traf, etwa weil auf den Werbeplakaten das kroatische Wappen prangte, ließ ihn Himmler auf August 1943 versetzen. ${ }^{381}$

Dennoch erwartete Himmler bis zum 1. August 1943 Meldung über die volle Aufstellung der Division von rund 26.000 Mann. Kammerhofer erteilte er die wenig dankbare Aufgabe, den Gesandten Kasche, den Deutschen Bevollmächtigten General Glaise-Horstenau sowie die relevanten kroatischen Stellen über dieses Vorhaben zu informieren. ${ }^{382}$ Zwei Tage später genehmigte Himmler zwei Millionen Reichsmark, um Kammerhofer bei der Werbung für die kroatische SSFreiwilligen-Division zu unterstützen. ${ }^{383}$

Nachdem Šuljak auf Druck der Deutschen nicht mehr an den Werbemaßnahmen teilnehmen durfte, war von Krempler allein für die Rekrutierungen im Raum Ostbosnien und Sandžak-Region zuständig: „Vorläufig arbeitet SS-O[ber] stu[rm]f[ührer] v[on] Krempler selbständig, damit die ganze Aktion nicht leidet [,] und schafft in der muselmanischen Bevölkerung jene Vertrauensatmosphäre, die nötig ist, um die ganze Aktion der Ausstellung der muselmanischen Division zu festigen. “384 Berger war überzeugt, mit von Krempler die richtige Wahl getroffen $\mathrm{zu}$ haben, da dieser Bosnisch verstand und, wie es Berger nannte, „mit den Leuten tadellos zurande“ kam. Berger bestätigte Himmler, von Krempler ermutigt zu haben, „in der bisher großzügigen Art weiterzumachen“, um

nicht genügend Muselmanen als Freiwillige melden.“ Wagner an Reichel, 3.6.1943, PAAA, R100998. Vgl. Grmek, Lambrichs, Les revoltés, S. 147.

379 Jüttner an Sonderverteiler, betr. „Aufstellung der Kroatischen SS-Freiwilligen-Division“, 30.4.1943, BArchB, NS19/3523, Bl. 34.

380 Berger an Himmler, Betr. „Indische Mohamedaner, 13.11.1943, BArchB NS 19/ 2601, Bl. 37, nach Petke, Muslime in der Waffen-SS, S. $77 \mathrm{f}$.

381 Helmut Heiber (Hg.), Reichsführer! ... Briefe an und von Himmler, Stuttgart: Deutsche Verlags-Anstalt 1968, S. 213.

382 Vgl. Himmler an Kammerhofer, 1.7.1943, BArchB, NS19/3523, Bl. 59.

383 Vgl. Himmler an Berger, 3.7.1943, BArchB, NS19/3523, Bl. 73.

384 „Zwischenbericht über Werbeaktion muselmanischer Freiwilliger“, Phleps an Chef des SS-Führungshauptamtes, SS-Gruppenführer Jüttner, 19.4.1943, BArchB NS19/2601, Bl. 10 f. 
den Aufbau der Division zu beschleunigen. ${ }^{385}$ Mit dieser positiven Umschreibung meinte Berger den von Kasche, aber auch von der kroatischen Regierung vehement kritisierten Umgang Kremplers mit der lokalen Bevölkerung. ${ }^{386}$ Von Krempler verschwieg nämlich, dass Männer während des Gebets aus Moscheen gezerrt und zum Dienst verpflichtet, ${ }^{387}$ und Schüler direkt von den Gymnasien geworben wurden. ${ }^{388}$

Nebst der Freiwilligenwerbung in Städten und Dörfern forderte Himmler Anfang Juli 1943, dass Angehörigen der Ergänzungsstellen in denjenigen Truppenteilen der kroatischen Wehrmacht, in welchen „vorwiegend Muselmanen“ dienen würden, auch Werbeabende erlaubt sein sollten. ${ }^{389}$ Diesen Werbeabenden musste seiner Ansicht nach ,die sofortige Freigabe und der sofortige Abmarsch der Freiwilligen, die sich gemeldet haben“, folgen. Der Reichsführer SS stellte weiter fest: „Ich muss diese Forderung stellen, da mein Vertrauen in die loyale Durchführung der getroffenen Abmachungen sehr stark geschwunden ist.“390

Obwohl Himmler noch im März 1943 an das SS-Führungshauptamt, das SSPersonalhauptamt, das SS-Hauptamt, SS-Gruppenführer Phleps und SS-Brigadeführer von Oberkamp schrieb, dass die Rekruten „,so rasch wie möglich“ von den Auffanglagern nach Bosnien-Herzegowina zurückverlegt werden sollten, blieb die Division nicht lange in Bosnien, sondern wurde nach Frankreich in die Départements Haute Loire, Lozère und Aveyron verlegt. ${ }^{391}$ Die Hauptmotivation vieler „Freiwilliger“, nämlich ihre Angehörigen vor Übergriffen durch die Četniks und Ustaša zu schützen, löste sich in Luft auf. Ein anderer Grund, weshalb sich nicht mehr Freiwillige für die Waffen-SS-Division meldeten, lag für den Deutschen Bevollmächtigten General in Kroatien, General der Infanterie Edmund Glaise-Horstenau darin, dass sich die Situation in Bosnien und im übrigen Südosteuropa seit 1941 stark verändert und das Vertrauen in die deutsche Besatzungsmacht gelitten hatte. Nach Schätzungen einflussreicher bosnischer Muslime hätten sich im Jahr 1941 nicht 20.000, sondern 100.000 freiwillig ge-

385 Berger an Himmler, „Betr.: Bosniaken-Division“, 29.4.1943, BArchB, NS 19/2601, Bl. 11.

386 Vgl. Gesandter Kasche an AA, 15.9.1943, PAAA, Inland IIg R100998.

387 Vgl. „Bericht zur Lage“, Nedim Salihbegovic 25.9.1943, BArchB, NS 19/2601, Bl. 32. Vgl. zu Rekrutierungspraktiken für die „Handschar“ Schmider, Der jugoslawische Kriegsschauplatz, S. 1029.

388 Bernwald, Muslime, S. 36.

389 Vgl. Himmler an Kammerhofer, 1.7.1943, BArchB, NS19/3523, Bl. 59.

390 Ebd.

391 Vgl. Himmler an SS-Führungshauptamt, SS-Personalhauptamt, SS-Hauptamt, SS-Gruppenführer Phleps und SS-Brigadeführer von Oberkamp, 31.3.1943, BArchB NS19/2601, Bl. 6. 
meldet; nun wäre es ein Bruchteil davon, ließ Vize-Ministerpräsident Osman Kulenović ausrichten. ${ }^{392}$

\subsubsection{Rekrutierungen im Sandžak und Kosovo-Gebiet}

Wie in den bosnischen Teilen des NDH setzte auch in den bei Serbien verbliebenen Gebieten, Nordkosovo und Sandžak, im März 1943 die Rekrutierung muslimischer Albaner und bosnischer Muslime für die 13. Waffen-Gebirgs-Division ein. Berger war der Überzeugung, dass gerade die Bevölkerung aus dem Sandžak-Gebiet gerne bereit wäre, an der Seite der Deutschen zu kämpfen. Im April 1943 frohlockte er in einem Schreiben an das Auswärtige Amt: „Wie aus einer Meldung des Aufbauamtes der 13. (kroatischen) SS-Division hervorgeht, besteht unter den Mohammedanern des Sandžak-Gebietes große Bereitschaft, freiwillig in diese Division einzutreten. “393 Ganz in Karl-May-Manier war er sich sicher, „dass die Urkraft dieser Bevölkerung, die eine ausgezeichnete soldatische Anlage hat, unbedingt im Rahmen dieser Division zu verwenden" sei. ${ }^{394}$

Berger wollte es aber nicht bei den Rekrutierungen im Sandžak und Nordkosovo belassen, sondern diese auf das als „Neualbanien“ bezeichnete italienische Gebiet Mittel- und Südkosovo sowie auf montenegrinische Grenzgebiete ausdehnen. Da er Diskussionen mit Kasche fürchtete, hatte er vor, den Gesandten in Zagreb dieses Mal zu übergehen:

Diese Bereitschaft besteht außerdem auch noch bei der benachbarten arnautischen Bevölkerung. [...] Da jedoch ein Teil dieser Bevölkerung in der unter italienischer Verwaltung stehenden Zone liegt, schlägt das SS-Hauptamt - um politische Unzuträglichkeiten zu vermeiden - folgende Regelung vor: Die Werbung und Einstellung dieser Freiwilligen wird zuständigkeitshalber nicht mit der deutschen Gesandtschaft in Agram, sondern mit dem Beauftragten des Auswärtigen Amtes in Belgrad, dem Herrn Gesandten Benzler, abgesprochen. ${ }^{395}$

Auch Eberhard Reichel war überzeugt, dass gerade die „Muselmanen im italienischen Okkupationsgebiet glänzende Soldateneigenschaften“ hätten. ${ }^{396}$

392 Vgl. Edmund Glaise-Horstenau an Himmler, 25.2.1943, BArchB, NS19/3523, Bl. 44.

393 Berger an das AA, „Betreff: Freiwillige für die 13. (kroatische) SS-Division aus dem Sandžakgebiet“", 9.4.1943, PAAA, R100998, H297616.

394 Ebd.

395 Ebd.

396 Bericht Reichel, AA Inland IIc, 12.4.1943, PAAA Inland IIg R100998. 
Bereits am 25. April 1943 meldete Berger, dass aus dem Sandžak schon 8.000-10.000 Freiwillige für die „Handschar“ rekrutiert worden waren. ${ }^{397} \mathrm{Al}$ lerdings waren laut späteren Berichten maximal 4.000 Albaner aus dem Sandžak in der „Handschar“ eingesetzt. ${ }^{398}$ Ein Schreiben Reichels von Anfang Mai 1943 legte fest, dass die jüngeren Jahrgänge „zum freiwilligen Eintritt in die Waffen-SS aufgefordert, die älteren jedoch dem Dienst in Polizeiformationen zugeführt werden sollten“. ${ }^{399}$ Ob die Freiwilligeneinheiten aus diesem Raum geschlossen zum Einsatz kommen würden, stand zu diesem Zeitpunkt noch nicht fest. ${ }^{400}$ Aus heutiger Perspektive lässt sich sagen, dass die Bezeichnung „Albanerbataillon“ für das Bataillon I/28 der „Handschar“ zwar seine Berechtigung hatte, dass aber auch in anderen Einheiten, beispielsweise im II/27 und III/27 oder im II/28 Albaner aus der Sandžak-Region und angrenzenden Gebieten eingesetzt waren. ${ }^{401}$ Als Kommandeur des Albaner-Bataillons sollte SS-Hauptsturmführer Bormann eingesetzt werden, der später zur „Skanderbeg“ versetzt wurde. ${ }^{402}$ Zur Unterscheidung von ihren bosnischen Mitsoldaten trugen die Albaner in Bormanns Bataillon einen albanischen Hut, keinen Fez. Himmler schien, dass gerade diese „Äußerlichkeiten [...] für die Festigung der Division ungeheuer viel“ bedeuten würden. ${ }^{403}$

Kurz nach der Kapitulation Italiens im September 1943 gelang es Neubacher, die Rekrutierungen der Waffen-SS im Sandžak zu stoppen: „Als ich meinen Albanien-Auftrag übernahm, befanden sich auch Werber für die muselmanische Waffen-SS-Division ,Handschar', die in Bosnien aufgestellt wurde, in dem damals albanischen Kosovo-Gebiet. Es ist mir mit Hilfe Kaltenbrunners gelungen, Himmler zu veranlassen, diese Werbungen, die nicht gut zu unserer Neutralitätspolitik

397 Separat aufgeführt: 12.000 Bosniaken (davon 8.000 Westbosniaken), davon tauglich etwa 8.000-9.000. Vgl. Berger an Himmler, „Betr.: Bosniaken-Division“, 29.4.1943, BAB, NS 19/ 2601, Bl. 11.

398 Vgl. Neubacher an AA, mit Bitte an Himmler um Rückführung schon ausgebildeter Albaner, 25.9.1943, PAAA, R100998.

399 Reichel an die Dienststelle des Bevollmächtigten des AA in Belgrad, 5.5.1943, PAAA, Inland IIg R100998.

400 Ebd.

401 Vgl. Kriegsgefangenenprotokoll SS-Sturmbannführer Willi Hempel, nach Ferhadbegović, Vor Gericht, S. 239. Vgl. beispielsweise Hali, Agoš aus Palatna, Podujevo, der im 2/SS-Geb.Jäg. Rgt. 28 eingesetzt war. AJ F 110 Arhiv Komizija (DK), Box F704/J756.

402 Vernehmungsprotokoll Matheis, Franje, Office of Chief of Council for War Crimes Translation of Document No. NO-4951, Landeskommission der Feststellung der Verbrechen der Okkupatoren und ihrer Helfershelfer, Inv. Nr. 35874, BArchF, Nachlass Vopersal, N 756/169a. Siehe zu Bormann ausführlich: Gerichtsbeschluss „Bormann“, AJ F 110, Fh. 27647/1810.

403 Schreiben Himmlers an Oswald Pohl, Leiter des SS-Wirtschafts- und Verwaltungshauptamtes (SS-WVHA), 26.11.1943, BAB, NS 19/2601, Bl. 44. 
passten, einzustellen. “404 Gleichzeitig versuchte er aber Ende September, die rund 4.000 bereits rekrutierten Albaner der „Handschar“ von ihren Ausbildungsorten in Frankreich bzw. Schlesien nach Albanien zu holen, da die instabile innenpolitische Situation ihre Rückkehr erforderlich machen würde. ${ }^{405}$ Berger schlug diese Bitte mit der Begründung aus, ihre Ausbildung sei für eine Verlegung nach Albanien noch zu wenig fortgeschritten. ${ }^{406}$

Anfang Dezember 1943 intervenierte dann auch Berger bei Himmler, da er der Meinung war, dass der Sandžak als personeller Ausgleich in der Region für die nach Frankreich bzw. Schlesien versetzten Kontingente als zusätzliche Rekrutierungsregion in Frage käme. Der Sandžak würde, wahrscheinlich auf Druck Nedićs, den Serben zugesprochen werden. Obwohl die Wehrmacht zu diesem Zeitpunkt in Waffenstillstandsverhandlungen mit den Četniks und ihrem obersten Führer, General Mihailović war, schien es Berger wichtig, die außerordentliche Stellung der Sandžak-Region für Rekrutierungen zu nutzen. Er informierte Himmler, dass

Der Sandzak [sic] [...] eine gewisse Schlüsselstellung als Korridor zwischen den mohamedanischen Gebieten in Bosnien, Herzegowina und Albanien einerseits und den katholischen bzw. orthodoxen Gebieten in Serbien und Montenegro andererseits ein[nimmt]. Der Sandzak stellte schon zur Türkenzeit die Verbindung der mohamedanischen Welt zwischen Bosnien und der Türkei über Bulgarien dar (Korridor) und wurde auch schon unter der alten K.u.K.-Regierung mit besonderer Sorgfalt bearbeitet. ${ }^{407}$

\subsubsection{Werbung durch Flugblätter und Radio}

Die Werbung für die „Handschar“ sollte über Rundfunk, Presse und Flugblattpropaganda erfolgen. Als Hauptverantwortlichen für diese Aufgabe setzte Himmler den Großmufti ein, der für die Verbreitung der Werbereden und Werbeschriften unter den Muslimen sorgen sollte. ${ }^{408}$ Pünktlich zum Rekrutierungsbeginn für die Division „Handschar“ machte al-Huseini in seiner Rede zum Geburtstag des Pro-

404 Neubacher, Sonderauftrag Südost, S. 115f.

405 Vgl. Neubacher an AA, mit Bitte an Himmler um Rückführung schon ausgebildeter Albaner, 25.9.1943, PAAA, R100998.

406 Vgl. Berger an das AA, z.Hd. Reichel, Betrifft: Albaner, 11.10.1943, PAAA, R100998, H297594.

407 Berger an Himmler, betr. „Mohamedanischer Sender/Ostafrikanische mohamedanische Divisionen“, 4.12.1943, BArchB, NS19/1896, Bl. 3.

408 Reichsführer SS, SS-Hauptamt A I/M, Vermerk betr. „Mobilisierung des Islam“, 28.2.1944, BArchB, NS 31/42, Bl. 6. 
pheten Mohamed am 19. März 1943 auf das Schicksal der bosnischen Muslime aufmerksam, indem er dieses in einen größeren Zusammenhang von globaler Politik zu stellen versuchte:

Die Herzen aller Muslime müssen heute an die muslimischen Brüder in Bosnien denken, die ein sehr schweres Schicksal zu erdulden haben, da sie von den serbischen und kommunistischen Banden verfolgt werden, die von England und der Sowjetunion unterstützt werden, wie dieses von Eden persönlich im Unterhaus erklärt wurde. Sie werden ermordet, ihrer Güter beraubt, und ihre Dörfer werden verbrannt. Damit trägt [sic] England und seine Verbündeten wieder eine sehr schwere Verantwortung vor der Geschichte, weil sie die Muslime in Europa misshandeln und ermorden, wie sie es ja in den arabischen Ländern und in Indien schon getan haben. ${ }^{409}$

Ähnlich aufgebaut wie al-Huseinis Rede waren auch Propagandaschriften, wie „Dogu ve Bati“ (Ost und West), die von der „kroatisch-muselmanischen Verlagsanstalt“ für den türkischen Markt gedruckt wurden. Sie hatten zum Ziel, durch die Schilderung der Situation der Muslime in Bosnien und der Schuldzuweisung für diese Umstände an Briten und Russen, die Türken für die Aufstellung muslimischer Waffen-SS-Verbände zu sensibilisieren. Außerdem sollte dieser Verlag zu einem späteren Zeitpunkt auch „zur Betreuung der Angehörigen der SS-Division und der muselmanischen Arbeiter im Reich“ herangezogen werden. ${ }^{410}$ Für die Einflussnahme und Sensibilisierung für Verbände der Waffen-SS in Nahost war eine „illegale arabische Korrespondenz“ geplant, welche ihre Empfänger „auf dem Schmuggelweg“ erreichen sollte. Zu diesem Zweck sollte eine Vertretung der „kroatisch-muselmanischen Verlagsanstalt“ in der Türkei eingerichtet werden. ${ }^{411}$ Bei diesem Unterfangen wird der Versuch Himmlers und Bergers sichtbar, über die Grenzen Bosniens hinaus potentielle Rekruten für die Verbände der Waffen-SS zu erreichen.

Da Bosnien-Herzegowina vor allem aber aus ländlichen Gebieten bestand, gründete die Werbung in der Region selbst auf wesentlich einfacheren Fundamenten: Flugblätter, welche die wesentlichen Gründe, die für einen Beitritt in die Division sprachen, umschrieben, wurden unter der Bevölkerung verteilt und sollten die Werbeleiter vor Ort unterstützen. SS-Hauptsturmführer Hasan Bajraktarević beschwor in einem solchen Flugblatt vor allem den Autonomiegedanken als Beitrittsgrund für die Waffen-SS:

409 Al-Huseini, Rede zum Maulid, 19.3.1943, in: Höpp, Mufti-Papiere, S. 155.

410 Anlage 1, „Propagandamöglichkeiten im bosnisch-muselmanischen Raum“, ohne Datum, PAAA, R100998.

411 Ebd. 
Muslimische Bosniaken! Bosnien und die Herzegowina haben jahrhundertelang ihr Eigenleben geführt. Das Volk ohne Unterschied der Religion hat in Eintracht und brüderlichem Frieden gelebt. Kehren wir daher zurück zu unserer glänzenden Vergangenheit, in welcher sich das Leben in Frieden und Tolleranz [sic] entwickelte. Das uns aufgezwungene Ustascha-Regime hat Bosnien und die [sic] Herzegowina das größte Unglück gebracht. Unser geschichtlicher Wunsch durch alle Jahrhunderte war ein autonomes Bosnien, wo alle Bosniaken ohne Unterschied der Religion ob Moslems, Orthodoxen [sic] und Katholiken die gleichen Rechte genießen. ${ }^{412}$

Auch Flugblätter von „geläuterten“ Partisanen, welche die Vorzüge der WaffenSS-Division im Vergleich zum Dienst in einer Partisaneneinheit anpriesen, machten die Runde. So etwa das Flugblatt Nr. 3 der Division „Handschar“, in welchem Halid Komić aus Bosnanski Novi, der sich als ehemaliger Kommandeur der 8. Grenzer-Brigade vorgestellte, von den Vorteilen der „Handschar“ spricht:

Es gibt keine bessere Kameradschaft, [sic] als die in unserer Division. Vor dem Gesetz sind alle gleich, vom gemeinen Soldaten bis zum höchsten Offizier. Auch unter der Zivilbevölkerung Deutschlands gibt es keine Unterschiede. Zur Arbeitszeit sind alle Arbeiter, in der freien Zeit sind alle Herren. [...] Unsere bosnisch-hercegowinische [sic] SS-Division wird Frieden, Ordnung und Gerechtigkeit in unserer Heimat schaffen. [...] Verbunden mit unseren deutschen Kameraden kämpfen wir in der Freiwilligen bosnisch-hercegowinischen [sic] SS-Division, [sic] für den Frieden in unserer geliebten Heimat. Für Ruhe und Arbeit und Sicherheit aller Bewohner dieser Heimat! Es grüßt Euch Euer aufrichtiger Freund, der ehemalige Partisane und Kommandant der 8. Grenzer-Brigade, der jetzige SS-Mann Halid Komić. ${ }^{413}$

Dem Bericht Bajraktarevićs an Phleps vom 15. November 1943 ist ein weiterer Aufruf angehängt, der die propagandistische Ausschlachtung der Situation der bosnischen Muslime für die Waffen-SS aufzeigt:

Brüder Mohamedaner! In den letzten 2 Jahren überlebten wir die schrecklichsten Tage unseres tausendjährigen Bestehens in unserem schönen Vaterland Bosnien. In unserem guten und friedfertigen Volk haben die hinzugekommenen Elemente die höllische und verbrecherische Fackel des Hasses hineingeworfen aus dem der Brand entstand[,] der die Höfe der Leute vernichtete, Ustaschaungeheuer, die in unsere Gegenden im stolzen Bosnien die Fahne verbrecherischen Chauvinismus hissten und dem Lande den kroatischen Stempel aufdrücken wollten, in dem kaum 1/5 Kroaten sind. Diese Ustaschaverbrecher fingen feige an[,] unter moslemischen Namen und in moslemischer Tracht grausam Serben hinzuschlachten und in Gruben zu werfen. Es fand sich freilich hier und da ein Bosniake, ein Abtrünniger, der den Ustaschen Körper und Seele verschrieben hatte. Dieses Ustaschawüten führte zum grausamen und schrecklichen Blutbad nicht an den Ustaschen[,] sondern an der unschuldigen moslemischen Bevölkerung. So ist [sic] durch das

412 Flugblatt angehängt an Reisebericht SS-Hauptsturmführer Hasan Bajralitarović [Bajraktarević] an Phleps, 15.11.1943, BArchB, NS19/2601, Bl. 61.

413 13. SS-Division / Flugblatt-Entwurf Nr. 3, BArchB, NS 19/2601, Bl. 171. 
Wirken des Ustascha-Cetnikvandalismus 150.000 Bosniaken muslimischer Konfession getötet oder hingeschlachtet und zu gleicher Zeit tausende von unseren Söhnen in den kroatischen Konzentrationslagern auf die grausamste Weise gefoltert und gemordet worden. 250.000 unserer Brüder sind obdachlos geblieben und unerhörter Not und Martern ausgeliefert [...].

Treten wir in feste Reihen, um das schreckliche Ungeheuer des Blutbades und der Vernichtung zu beseitigen. Nehmen wir alle Waffen in die Hand und treten in den Kampf, nicht um zu töten, hinzuschlachten und zu vernichten und zu brennen, sondern damit wir uns gegen jeden verteidigen, der versucht uns anzugreifen und zu vernichten. Treten wir in feste Reihen, um unsere Familien und unser Heim zu verteidigen. Vergessen wir die Rache und streben wir als Moslems dahin uns mit allen zu versöhnen. Kämpfen wir für die Sicherheit nicht nur unserer Familien und Heime[,] sondern auch für diejenigen unserer orthodoxen und katholischen Menschen. ${ }^{414}$

Wer nicht lesen konnte, für den ließen Himmler und Berger Plakate drucken, die als Sinnbild für den gemeinsamen Kampf von Deutschen und Muslimen gegen den „Bolschewismus“ verstanden werden wollten, aber mit den Anfangssätzen des oben genannten Flugblatts versehen waren: „Der große Führer Adolf Hitler und der Poglavnik Ante Pavelić fordern euch auf zur Verteidigung Eures Herdes. Reihet Euch ein in die Reihen der Freiwilligen Kroatischen WaffenSS““ ${ }^{415}$ Dieses Werbeplakat verfehlte jedoch die Interessen des Zielpublikums und wirkte abschreckend, denn es zeigt einen deutschen und einen kroatischen bzw. bosnisch-herzegowinischen Waffen-SS-Soldaten, darüber prangen die SS Runen und das kroatische Wappen. Dieses Bildprogramm wirkte auf wehrfähige Männer in Bosnien und der Herzegowina eher rekrutierungshemmend, da der Verband klar als kroatische Division vorgestellt wird und nicht als eine Miliz, welche die muslimischen Interessen und Autonomiebestrebungen in Bosnien-Herzegowina unterstützen würde.

414 Flugblatt angehängt an Reisebericht SS-Hauptsturmführer Hasan Bajralitarović [Bajraktarević] an Phleps, 15.11.1943, BArchB, NS19/2601, Bl. 61.

415 Anlage 2, Übersetzung des Werbeplakats und eines Aufrufs Adolf Hitlers an die „Kroaten Herzeg-Bosnas“, ohne Datum, PAAA, R100998. 


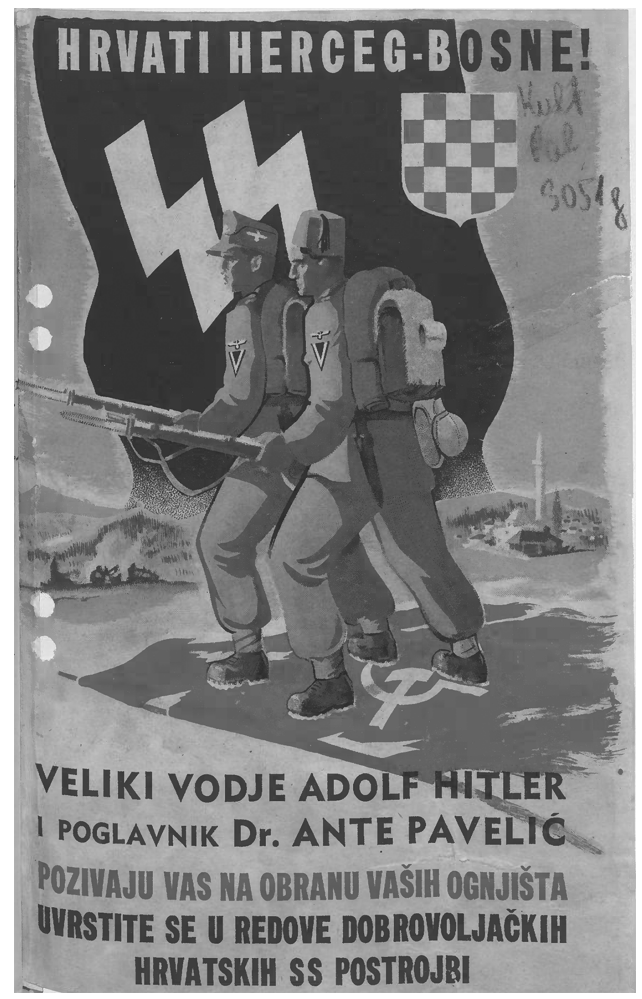

Abb. 21: Kroatisches Werbeplakat für die Division „Handschar“. ${ }^{416}$

Das dem Plakat beigefügte Flugblatt hingegen ist wieder in der herkömmlichen pro-bosnischen Sprache verfasst und fokussiert als Zweck der Division die Selbstverteidigung der Menschen in Bosnien-Herzegowina:

Die Opfer, die Ihr in der Verteidigung Eurer Herdstätten, Eures Staates gebracht habt, sind groß und beispiellos. Ihr alle habt durch diese Opfer gezeigt, wo Euer Platz ist. Ihr wie auch die übrigen Völker und an deren Spitze das deutsche Volk nehmt heute teil an der Verteidigung all dessen, was Euch das Liebste ist, und das ist die Verteidigung Eurer Heimstätten, Eures Besitzes und Eures Glaubens. Der Kommunismus, das Partisanentum, der Bolschewismus, das sind jene Feinde, die Euch diese Heiligtümer zerstören wollen.

Eure heldenhaften Söhne stehen gegen den Feind, der schon jetzt in Todeszuckungen liegt. So, wie man auf den großen russischen Komplexen alles vernichtet, was bolschewistisch ist, ganz so muss auch in Eurer Heimat alles vernichtet werden, was bolschewistisch oder tätig ist.

416 Kroatisches Werbeplakat für die Division „Handschar“, PAAA 100998. 
Seid versichert, dass sich das, was Bihac [sic], Priedor, Kljuc [sic], Glamoc [sic] und andere Städte, Dörfer und Ansiedlungen erduldeten, nicht wiederholen wird, denn es ist nun zu dem gekommen, was ihr Euch Monate lang gewünscht und erwartet habt:

Adolf Hitler wird Euch helfen! ${ }^{417}$

Ein ähnliches Flugblatt ist bei Casagrande zu finden. Im Gegensatz zu oben genanntem ist hier jedoch eine Stoßrichtung zu finden, die ausschließlich auf den Kommunismus zielt. Im ersten Teil sind identische Formulierungen wie in dem oben gezeigten Flugblatt zu finden, und auch der Satz, welcher das Vorgehen auf den „großen russischen Komplexen“ mit demjenigen in Südosteuropa gleichsetzt, bleibt unverändert. ${ }^{418}$ Welche Rolle die Soldaten der „Handschar“ in den Reihen der Vielvölkerarmee und im neuen Europa einnehmen sollten, wird gegen Ende des Flugblatts ersichtlich:

Auf Wunsch des Führers des deutschen Volkes seid Ihr auserwählt und berufen, als erstes nicht-germanisches Volk in die Reihen der besten Soldaten, der berühmten SS-Abteilungen, aufgenommen zu werden. Ihr werdet die besten Waffen, die das deutsche Volk besitzt, erhalten und mit diesen auch die Übermacht über den Feind. [...]. Kroaten, Muselmanen und Katholiken, [...] kommet und tretet den Reihen der Freiwilligen Kroatischen SS-Division bei! ${ }^{419}$

\subsubsection{Probleme bei der Werbung}

Nachdem die kroatischen Behörden bereits bei den Vorbereitungen hemmend gewirkt und für Auseinandersetzungen gesorgt hatten, behinderten sie nun auch die Rekrutierungen, indem der Poglavnik einen seiner größten Anhänger, Alija Šuljak, als Werbeleiter von kroatischer Seite einsetzte. ${ }^{420}$ Phleps beschreibt ihn als einen radikalen Muslim, der selbst in der muslimischen Bevölkerung als ,ausgesprochener Renegat und Hetzer gegen das muselmanische Volkstum und Anstifter zahlreicher Gemetzel gegen Serben bekannt [war].“421 Die Spitze der Unverschämtheit erreichte Šuljak, als er in Ustaša-Uniform bei den Werbestellen erschien, just bei jenen Muslimen also, die unter anderem in die Waffen-SS eintraten, um Übergriffen durch Ustaša zu entkommen. ${ }^{422}$ Allein das Erschei-

417 Kroatisches Flugblatt für die Division „Handschar“, PAAA 100998.

418 PAAA Inland IIg 310/2574 Dok. J23-24, nach: Casagrande, Volksdeutsche SS-Division, S. 331 .

419 Ebd.

$420 \mathrm{Zu}$ Šuljak vgl. Redžić, Bosnia and Herzegovina, S. 166.

421 „Zwischenbericht über Werbeaktion muselmanischer Freiwilliger“, Phleps an Chef des SSFührungshauptamtes, SS-Gruppenführer Jüttner, 19.4.1943, BArchB NS19/2601, Bl. 8.

422 Vgl. ebd. 
nen Šuljaks in den Rekrutierungsstellen hätte die muslimische Bevölkerung bereits verunsichert, da sie daraufhin annahmen, die Aufstellung der Division „wäre eine reine Ustascha-Angelegenheit“ - und auch die bosnischen Serben fürchteten daher neue Übergriffe. ${ }^{423}$

Als von Krempler Šuljak aufgrund solcher Auftritte unlauterer Werbemethoden bezichtigte, forderte die kroatische Regierung die sofortige Absetzung von Kremplers. ${ }^{424}$ Der Streit um die Werbemaßnahmen eskalierte schließlich, so dass Phleps am 6. April 1943 persönlich bei Vrančić vorsprechen musste, diesen über Šuljaks unkorrektes Verhalten aufklärte und ebenfalls seine Abberufung verlangte. An Šuljaks Stelle versprach Vrančić nun zwei kroatische Offiziere einzusetzen, die allerdings nie erschienen. Daraufhin führte von Krempler die weiteren Werbeaktionen ohne Unterstützung von kroatischer Seite durch. ${ }^{425}$ Phleps war überzeugt, dass sich die Rekrutierungserfolge erst durch die Absenz kroatischer Werbeleiter einstellte: „Bereits nach wenigen Tagen zeigten sich sehr gute Werbeerfolge, da mein Werbeleiter nun unbeeinflusst von kroatischen Regierungsvertretern die Werbung rein von SS-mäßiger Basis aus starten konnte.“426

Auch beim Druck von Werbeplakaten kam es zu Problemen: Vrančić hatte ohne Rücksprache mit deutschen Dienststellen neue Werbeplakate mit einem Aufruf an alle Kroaten und Bosnier, unabhängig welcher Religion sie angehörten, drucken lassen. Darauf reiste von Krempler nach Tuzla, um Hadžiefendić darüber zu informieren, dass der Befehl aus Berlin laute, eine muslimische Division aufzustellen. Zusammen begaben sie sich schließlich nach Sarajevo, um dort neue Aufrufe drucken zu lassen, die sich explizit an junge Muslime zwischen 17 bis 35 Jahren im NDH wandten. ${ }^{427}$

Dies war allerdings nur die Spitze des Eisbergs: Am 1. Juli 1943 schrieb Himmler Kammerhofer, er sei mit der bisherigen Unterstützung der Rekrutierungen durch die kroatische Regierung „absolut unzufrieden“. Insbesondere störte ihn, dass in Gebieten, in welchen sich Männer freiwillig zur Waffen-SS gemeldet hatten, „über Nacht wilde Rekrutierungen“ stattgefunden hätten. Junge Männer seien mitten in der Nacht aus ihren Betten geholt und ,angeblich in Kasernen der kroatischen Wehrmacht“ gebracht worden. Himmler, der nicht glauben wollte, dass die kroatische Regierung selbst diese Aktionen in die Wege geleitet hatte, vermutete, dass sie von Kommunisten oder Četniks durchgeführt und von der kroatischen Regierung toleriert worden wären. Er wies Kammerhofer an, in den Gebieten, wo es

423 Vgl. ebd., Bl. 9.

424 Vgl. ebd.

425 Vgl. ebd.

426 Ebd.

427 Vgl. Grmek, Lambrichs, Les revoltés, S. 155. 
zu solchen nächtlichen Zwangsrekrutierungen gekommen war, „sofort polizeilich durchzugreifen“. 428

Außerdem hegte er den Verdacht, dass junge Kroaten, die sich freiwillig zur Waffen-SS gemeldet hatten, nicht nur in Kasernen, sondern in kroatische Konzentrationslager verschleppt worden wären. Kammerhofer sollte daher alle Insassen der KZ Novogradiška und Jasenovac überprüfen. ${ }^{429}$ Auch hier vertrat Himmler - zumindest offiziell - die Meinung, dass es sich bei den Urhebern dieser Vorgänge um Feinde des kroatischen Staates handeln müsste, die die Rekrutierungen und die Zusammenarbeit zwischen dem NDH und der SS auf diese Weise unterwandern wollten. Aus diesem Grund befahl er Kammerhofer, die Verantwortlichen ausfindig zu machen, in $\mathrm{KZ}$ zu deportieren und nötigenfalls die Todesstrafe zu verhängen. ${ }^{430}$

Himmler war aber noch mit weiteren Punkten sehr unzufrieden, die direkt das Versagen der kroatischen Regierung betrafen. Von deren Seite waren per Stichtag, dem 15. Mai 1943, keine Listen der Freiwilligenwerbung eingereicht worden. Auch hier schien ihm, dass Sabotage gegen den Poglavnik betrieben wurde - oder zumindest verpackte er seinen Vorwurf in diese Worte, denn die kroatische Regierung fand immer wieder neue Möglichkeiten, um die Aufstellung zu verzögern, wie bereits im Kapitel „Die kroatische Regierung stellt sich gegen eine rein muslimische Division“ gezeigt wurde.

Kasche, der im Wesentlichen die Meinung der kroatischen Regierung teilte, meldete dem Auswärtigen Amt nach wenigen Monaten noch andere Missstände, diesmal auf Seiten der Waffen-SS: Von Krempler wäre wegen ,äußerst nachteiliger Methoden bei der Werbung “ für die bosnische SS-Division aufgefallen. ${ }^{431}$ So sprach von Krempler bei seinen Werbefahrten durch Bosnien nur Serbisch („Ekavisch“) $)^{432}$ und ließ wehrfähige Männer sogar aus dem Freitagsgebet abführen. ${ }^{433}$

Spätestens im September 1943 war die Rekrutierungseuphorie auf dem Balkan verflogen. Divisionskommandeur Sauberzweig beklagte sich darüber bei SS-Obersturmbannführer Brandt und Berger, denn er fand es tief bedauerlich,

428 Himmler an Beauftragten des Reichsführer SS in Kroatien, SS-Brigadeführer und Generalmajor der Polizei Konstantin Kammerhofer, 1.7.1943, BArchB, NS19/3523, Bl. 58.

429 Vgl. Himmler an Beauftragten des Reichsführer SS in Kroatien, SS-Brigadeführer und Generalmajor der Polizei Konstantin Kammerhofer, 1.7.1943, BArchB, NS19/3523, Bl. 58. Vgl. hierzu auch Tessin, Verbände, Bd. 3, S. $282 \mathrm{f}$.

430 Vgl. Kammerhofer, 1.7.1943, BArchB, NS19/3523, Bl. 59.

431 Vgl. Gesandter Kasche an AA, 15.9.1943, PAAA, Inland IIg R100998.

432 Vgl. Lepre, Himmler's Bosnian Division, S. $27 \mathrm{f}$.

433 Vgl. Salihbegovic, „Bericht zur Lage“, 25.9.1943, BArchB, NS 19/2601, Bl. 32. 
dass „seine Division [Handschar]“ trotz „der politischen Lage auf dem Balkan [...] noch lange nicht steht und man den Termin ihrer Einsatzbereitschaft unter den gegebenen Umständen überhaupt nicht vorausbestimmen kann.“434 Man nahm an, dass die Rekrutierungsquoten in Bosnien so stark zurückgegangen waren, weil die Kommunisten nach der Verlegung der „Handschar“ ins Ausland die Bevölkerung gewarnt hatten,

dass Deutschland in diesem Moment die [13. Waffen-Gebirgs-] Division [der SS] aufstellt, weil es an allen Fronten Rückschläge erhalten hätte und Kanonenfutter brauchte, [und] dass die SS-Freiwilligen niemals in ihre Heimat zurückkehren würden, sondern dass sie ihr Leben in den weiten Ebenen Russlands oder im besten Falle in Frankreich verlieren würden. ${ }^{435}$

Auch SS-Hauptsturmführer Hasan Bajraktarević schreibt, dass sich das Gerücht verbreitete, die „Handschar“ würde nicht nach Bosnien zurückkehren, sondern auf „irgendeinen anderen Kriegsschauplatz“ verlegt. ${ }^{436}$ Obwohl offiziell zurückgewiesen, hatte diese Vermutung durchaus Berechtigung, denn in einem Memorandum vom 30. März 1944 heisst es, dass gerade durch solche Rekrutierungen „deutsches Blut“ geschont werden sollte; denn „für jeden Fremdländischen, der fällt, weint keine deutsche Mutter.“437

Hinderlich für die Aufstellung erwies sich auch das Zugeständnis an die kroatische Regierung, Katholiken in die Division aufzunehmen und die Formation als „kroatische Division“ zu bezeichnen. Die bosnischen Muslime hatten Mühe, sich damit zu identifizieren, da eine ihrer Hauptmotivationen gerade die Loslösung vom kroatischen Staat war. Andererseits fühlten sich auch die katholischen Kroaten in der Division durch deren innere muslimische Ausrichtung benachteiligt. ${ }^{438}$ Kasche schien außerdem die Ausdehnung der SS-Werbung auf katholische Kroaten der kroatischen Wehrmacht fragwürdig und hinsichtlich des deutsch-kroatischen Verhältnisses kontraproduktiv. ${ }^{439}$ Selbst die Rekrutierung albanischer Muslime aus dem Sandžak sollte letztlich zu Problemen führen, da sich Albaner

434 Sauberzweig an Brandt, 30.9.1943, BArchB, NS 19/2601, Bl. 25.

435 „Bericht zur Lage“, Salihbegovic, 25.9.1943, BArchB, NS 19/2601, Bl. 31.

436 Vgl. Reisebericht SS-Hauptsturmführer Hasan Bajralitarović [Bajraktarević] an Phleps, 15.11.1943, BArchB, NS19/2601, Bl. 59.

437 Memorandum vom 30.3.1944 (möglicherweise vom Leiter der Germanischen Leitstelle, SSObersturmbannführer Franz Riedweg) BArchB, NS 19/3647, Bl. 34 und SS-HA/Be/We, VS-Tgb. Nr.106/44 g.Kdos., an den HSSPF beim Militärbefehlshaber in Frankreich, Betr.: Zusammenschluss der Rechtsverbände in Frankreich, 8.2.1944, BArchB, NS 19/1504, Bl. 1, zitiert nach: Leleu, Jenseits der Grenzen, S. 35.

438 Vgl. bspw. Hoare, Bosnian Muslims, S. 117.

439 Vgl. Kasche Telegramm, 14.5.1943, PAAA, Inland IIg R100998. 
und Bosnier nicht vertrugen. ${ }^{440}$ Nach der Kapitulation Italiens und der Neuorganisation des albanischen Staates wurden die Rekrutierungen im Sandžak und Nordkosovo auf Neubachers Wunsch offiziell eingestellt. ${ }^{441}$

\subsubsection{Die Rolle Pandžas und die Einsetzung von Imamen für die Werbung}

Pandža, der in allen wichtigen muslimischen Gremien vertreten war, welche die Rekrutierungen unterstützten, galt für die bosnischen Muslime als Integrationsfigur. Unermüdlich schlug er die Werbetrommel für die Division „Handschar“:

Und tatsächlich haben sich dank der Empfehlung der Kirchenbehörden, insbesondere Pandžas selbst, in unsere Division Alt und Jung, Verheiratete und Ledige, Kaufleute und Gewerbetreibende, Besitzer und Beamte gemeldet, da jeder wusste, dass das, was von Pandža empfohlen und geführt wird, etwas wirklich Islamisches und Heimatliebendes darstellt. Wir, die wir tatsächlich wissen, was Pandža für die Schaffung und Gründung unserer Division getan hat, fragen uns, ob man überhaupt und auf welche Weise so schnell und leicht die Anzahl Freiwilliger hätte sammeln können, wenn nicht Pandža, sein Einsatz, Empfehlung und Propaganda gewesen wären. ${ }^{442}$

Pandžas Einstellung führte dazu, dass er von den Deutschen als ihr größter „Freund, Sympathiseur und Mitarbeiter“ erkannt, von der kroatischen Regierung hingegen als „anational“ eingestuft wurde. ${ }^{443}$ Zum Ustaša-Regime hatte er immer eine gewisse Distanz gewahrt und sah nun mit der Rückendeckung der Deutschen den Moment gekommen, sich öffentlich für die Autonomie Bosniens einzusetzen. ${ }^{444}$ Diese beiden Merkmale, ein anti-kroatisches und pro-bosnisches Verhalten führten, so die Meinung Bajraktarevićs, dazu, dass Pandža in der „muselmanischen Welt solche herrlichen Erfolge in bezug [sic] auf die B.H.Division“ erzielen konnte. Pandžas Involvierung in die frühen Rekrutierungen für die „Handschar“ gingen sogar so weit, dass jeder Rekrut, noch bevor er sich beim Ersatzkommando der SS-Division meldete, persönlich bei Pandža vorsprechen musste, der ihn auf die Division und ihre Aufgaben einschwor. ${ }^{445}$

440 Vgl. Deutsches Konsulat Sarajevo Erich Gördes an Deutsche Gesandtschaft Agram, 23.8.1943, PAAA Inland IIg R100998.

441 Vgl. Neubacher, Sonderauftrag Südost, S. 115f.

442 Reisebericht SS-Hauptsturmführer Hasan Bajralitarović [Bajraktarević] an Phleps, 15.11.1943, BArchB, NS19/2601, Bl. 58.

443 Vgl. Reisebericht SS-Hauptsturmführer Hasan Bajralitarović [Bajraktarević] an Phleps, 15.11.1943, BArchB, NS19/2601, Bl. 58.

444 Vgl. Motadel, Islam and the Nazi Germany’s War, S. 206.

445 Vgl. Reisebericht SS-Hauptsturmführer Hasan Bajralitarović [Bajraktarević] an Phleps, 15.11.1943, BArchB, NS19/2601, Bl. 58. Vgl. Motadel, Islam and the Nazi Germany's War, S. 249. 
Pandža war es auch, der die Unterstützung der bosnischen Geistlichkeit sicherte, indem er sie vom Nutzen der Division überzeugte. ${ }^{446}$

Sauberzweig warnte Berger, dass die Rekrutierung zurzeit in den Händen derer liege, welche die Division sabotieren würden - damit meinte er die kroatische Regierung und ihren Verbündeten Kasche. ${ }^{447}$ Viel besser schien ihm die von Berger von Anfang an angestrebte Lösung, nämlich die Rekrutierungen allesamt in die Hände der Imame zu legen. Sauberzweig meinte hier vor allem die lokalen Imame, versprach aber, dass er bei größeren Werbeaktionen auch Imame aus der Division zur Verfügung stellen könne. ${ }^{448}$ Hinzu kam, dass Pandža im Herbst plötzlich verschwand. Er war in einen Hinterhalt der Partisanen geraten und schlug diesen daraufhin eine Kooperation vor. Allerdings wurde er kurz darauf von deutschen Einheiten befreit und zurückgebracht. ${ }^{449}$ Motadel hingegen führt an, Pandža habe sich selbst in die Wälder begeben, um dort die Muslimische Befreiungsbewegung (Muslimanski Oslobodilački Pokret) zu gründen. ${ }^{450}$ Welche der beiden Varianten den tatsächlichen Vorgängen entsprach, lässt sich heute nicht mehr mit letzter Sicherheit feststellen. Die Behauptung der feindlichen (kommunistischen) Propaganda, Pandža habe die Seiten gewechselt, indem er den Kommunisten - freiwillig oder notgedrungen - eine Zusammenarbeit angeboten hatte, kam den eigentlichen Ereignissen sehr nahe und verunsicherte selbst Divisionsangehörige in höheren Rängen. ${ }^{451}$

Himmler ging schließlich auf Sauberzweigs Vorschlag ein. Im November 1943 schickte er zur Werbung von Muslimen drei Imame der 13. SS-FreiwilligenDivision durch Kroatien und Bosnien. Einer davon war SS-Hauptsturmführer und Imam Hasan Bajraktarević. Dieser schrieb in seinem Reisebericht, dass sie zuerst „Möglichkeiten und Bedingungen für die Arbeit“ überprüften. Da sie als Imame bereits vorher eng mit der kirchlichen und weltlichen Führung der bosnischen Muslime zusammengearbeitet hatten - Bajraktarević selbst war vor seinem Dienst in der „Handschar“ Imam in Mostar gewesen - hatten sie bei diesen Abklärungen keine Schwierigkeiten. Die Werbeaktionen wurden vor allem in Sarajevo und Mostar durchgeführt.

446 Vgl. ebd., S. 248.

447 Vgl. zum Verhältnis der kroatischen Regierung zu Kasche auch Korb, Im Schatten des Weltkriegs, S. 111.

448 Vgl. Sauberzweig an Berger, 30.9.1943, BArchB, NS 19/2601, Bl. 28.

449 Vgl. Redžić, Bosnia and Herzegovina, S. 224.

450 Vgl. Motadel, Islam and the Nazi Germany's War, S. 207. Vgl. zum Muslimanski Oslobodilački Pokret ausführlich Tomasevich, War and Revolution in Yugoslavia, S. $503 \mathrm{f}$.

451 Vgl. Reisebericht SS-Hauptsturmführer Hasan Bajralitarović [Bajraktarević] an Phleps, 15.11.1943, BArchB, NS19/2601, Bl. 59. 
Bajraktarević und die beiden anderen Werbeimame schätzten jedoch die Lage überall als schwierig für weitere Rekrutierungsmaßnahmen ein. Denn die feindliche Propaganda hatte Bosnien längst erreicht und die bosnischen Muslime über die Verluste des Dritten Reichs im Osten und seine falschen Versprechungen unterrichtet. Somit sah Bajraktarević eine einzige Möglichkeit, die Bevölkerung mit einer positiven Darstellung der SS-Freiwilligen-Division zu überzeugen: Um potentielle Anwärter positiv zu stimmen, überbrachten die Werbeimame bei ihrer Ankunft Grüße der bereits rekrutierten Soldaten, die in jener Zeit zur Ausbildung im Ausland weilten. ${ }^{452}$ Hinderlich für zukünftige Rekrutierungen schienen ihm allerdings die Lage vor Ort, vor allem in Ostbosnien, die Abwesenheit der Division, die somit die lokale Bevölkerung nicht schützen konnte und das plötzliche Verschwinden Pandžas. ${ }^{453}$

\subsection{Ausbildung}

Um das Vertrauen der Bevölkerung wiederzugewinnen, hatte Himmler im März 1943 versprochen, die Divisionsangehörigen, nachdem sie in Zagreb, Osijek oder Zemun ausgerüstet worden waren, sofort wieder nach Bosnien-Herzegowina zurückzuverlegen. ${ }^{454}$ Es ist bereits mehrmals ausgeführt worden, dass ein wesentliches Lockmittel bzw. eine wesentliche Motivation für einen Beitritt in die „Handschar“ die Verteidigung der heimischen Höfe und Dörfer war. ${ }^{455}$ Entsprechend ging die Bevölkerung davon aus, dass die Soldaten in Bosnien ausgebildet würden. Aus dem Kriegsgefangenenbericht Eipels geht jedoch hervor, dass die Soldaten von den drei Auffanglagern direkt auf den Truppenübungsplatz Wildflecken (Rhön) in Deutschland geschickt wurden, von dort im Sommer zur weiteren Ausbildung nach Frankreich und Anfang Oktober 1943 nach Neuhammer kamen. ${ }^{456}$ Auch Führer und Unterführer sollten zu einer Vorschulung ins Reich geschickt werden. So schreibt etwa Bernwald in seinen Memoiren von

452 Vgl. ebd., Bl. 57.

453 Vgl. ebd., Bl. 58.

454 Himmler an SS-Führungshauptamt, SS-Personalhauptamt, SS-Hauptamt, SS-Gruppenführer Phleps und SS-Brigadeführer von Oberkamp, 31.3.1943, BArchB NS19/2601, Bl. 6.

455 Vgl. Casagrande, Volkdeutsche Division, S. 332.

456 Vgl. Kriegsgefangenenbericht „Bericht über die 13. SS Division ,Handschar', ihre Aufstellung, Gliederung“, Walter Eipel, 14.11.1947, VA, HEM.OK.BOJCKA, 72-A/1-a/32, S. 2-4. 
der Ausbildung in Berlin-Lichterfelde und dem Besuch der Dolmetscherschule in Berlin-Oranienburg. ${ }^{457}$

\subsubsection{Militärische Schulung}

Anfang Juli 1943 wurde die Division für mehrere Monate zur Ausbildung nach Le Puy und Villefranche-de-Rouergue in Frankreich verlegt, wo sie neu gegliedert und in „Kroatische SS-Freiwilligen-Gebirgs-Division“ umbenannt wurde. Indem die Division ins Ausland verlegt wurde, hofften Himmler und Berger, sie der Einflussnahme konkurrierender Institutionen, namentlich der kroatischen Regierung, der Wehrmacht und des Auswärtigen Amts zu entziehen. ${ }^{458}$

Die militärische Ausbildung der Geworbenen fand in drei Regionen statt. Einen ersten Teil absolvierten die Rekruten bereits im NDH. Danach wurden sie im Sommer nach Frankreich und im Herbst 1943 nach Schlesien geschickt.

Auffallend ist, dass die fast einjährige Ausbildung der 13. Waffen-GebirgsDivision der SS, im Vergleich zu anderen „fremdvölkischen“ Divisionen, etwa der „Skanderbeg“, wesentlich länger dauerte. ${ }^{459}$ Doch gerade die Verlegung zu Ausbildungszwecken ins Ausland brachte Probleme mit sich: Die bosnisch-muslimische Zivilbevölkerung, oft Angehörige der Rekrutierten, blieb ungeschützt in der Heimat zurück und war Übergriffen durch Ustaša und Četniks noch hilfloser ausgeliefert als zuvor - die Soldaten der „Handschar“, die von diesen Massakern wussten, fühlten sich durch die Verlegung ins Ausland betrogen.

In Frankreich, wohin die „Handschar“ im Sommer $1943 \mathrm{zu}$ Ausbildungszwecken verlegt wurde, waren die einzelnen Einheiten der „Handschar“ in verschiedenen Kleinstädten untergebracht. Der Divisionsstab bezog in Mende Quartier, wurde aber am 21. August nach Le Rozier verlegt.

457 Vgl. Bernwald, Muslime in der Waffen-SS, S. 39-41, 43f. Vgl. auch „Zwischenbericht über Werbeaktion muselmanischer Freiwilliger“, Phleps an Chef des SS-Führungshauptamtes, SSGruppenführer Jüttner, 19.4.1943, BArchB NS19/2601, Bl. 10.

458 Vgl. SSFHA „Betr.: Aufstellung der Kroat. SS-Freiw. Div.“, 2.7.1943, WNA, T 175, Roll 111, Bl. 2635376-2635384 nach Petke, Muslime in der Waffen-SS, S. 78. Vgl. Petke, Militärische Vergemeinschaftungsversuche, S. 249.

459 Im Vergleich dazu wurden die Angehörigen der 21. Waffen-Gebirgs-Division der SS nur rund sechs Wochen ausgebildet. Bernwald hatte 1942 als einer der frühen „volksdeutscher“ Rekruten und späterer Angehöriger der „Handschar“ ebenfalls eine nur zweimonatige militärische Ausbildung absolviert. Bernwald, Muslime in der Waffen-SS, S. 39. 
Die Division war wie folgt auf die verschiedenen Ortschaften in Südfrankreich verteilt ${ }^{460}$ :

\begin{tabular}{ll}
\hline Regimenter & Bataillone \\
\hline SS-Geb.Jg.Rgt. 1: Rodez & I/1: Rodez \\
\hline & II/1: Espalion \\
\hline III/1: Decazeville \\
\hline IV/Rodez \\
\hline I/2: Champ du Larzac \\
\hline II/2: Champ du Larzac \\
\hline III/2: Millau \\
\hline IV/2: Millau \\
\hline I/AR 13: Aubin \\
\hline II/AR 13: Champ du Larzac \\
\hline III/AR 13: Champ du Larzac \\
\hline IV/AR 13: St. Affrique
\end{tabular}

Weitere Bataillone/Abteilungen:

SS-Geb.Pi.Btl. 13: Villefranche-de-Rouergue

SS-Flak-Abt. 13: Le Puy

SS-Pz.Jg.Abt. 13: Le Puy

SS-Div.Nachsch.Tr. 13: Marvejols

SS-Geb.Nachr.Abt. 13: Mende

SS-Aufkl.Abt. 13: Langogne

SS-Sanitäts-Abt. 13: Le Puy

$460 \mathrm{Vgl}$. George Lepre, comment: https://forum.axishistory.com/viewtopic.php?t=81382 (1.2.2020). 
(fortgesetzt)

SS-Wirtschafts-Btl. 13: Langogne

1. \& 2. SS-Vet.Kp. 13: Marvejols

1. \& 2. Reiter-Schwadron 13: Severac le Chateau

Nach einer gescheiterten Meuterei in Villefranche, der standrechtlichen Erschießung der Hauptschuldigen und der Deportation weiterer 800 Soldaten in Lager, gelangte die Division schließlich nach Neuhammer in Schlesien, ${ }^{461}$ „wo Aufstellung und Ausbildung vervollständigt wurden“, wie Günter Borkwoski später zu Protokoll gab. ${ }^{462}$ Dort endete die Grundausbildung am 30. November 1943. Darauf folgten bis Weihnachten verschiedene Übungen im Verband. Die Ausbildung innerhalb kleinster Einheiten, Kampfgruppen, endete am 9. Januar 1944 und wurde von abschließenden Übungen in Kompaniestärke abgerundet, bis die Division Mitte Februar 1944 ihre Heimreise antrat. ${ }^{463}$

Die Gliederung der „Handschar“ in Neuhammer sah nach Aussagen Alfred Schraders wie folgt aus. Er bestätigt, dass weiterhin Personalknappheit herrschte:

1) Divisionskommandeur SS-Brigadeführer Sauberzweig mit Divisionsstab; Jägerregiment 27 Obersturmbannführer Hampel, Artillerieregiment, Sanitätsund Nachrichtenabteilung, Pionierbataillon

2) Jägerregiment 28 Obersturmbannführer Reithel, Artillerieregiment, -Aufklärungsabteilung, Panzerjägerabteilung

3) Jedes Regiment hatte auf dem Papier 4 Bataillone mit je 6 Kompanien. Tatsächlich gab es aber nur 3 Bataillone mit 5 bzw. 4 Kompanien.

4) Das Regiment 28 gliederte sich in Kommandeur, Regimentsstab, Nachrichtenund Radfahrzug. Das I. Bataillon kommandierte Hauptsturmführer Bormann, das II. Sturmbannführer Zill mit Stab, Adjutant, Ordonanz-Offizier, Arzt, Veterinär, Nachrichtenzug, Meldestaffel, je fünf Kompanien (drei Jäger-, eine Maschinengewehr-, eine schwere Kompanie)

461 Vgl. Lepre, Himmler’s Bosnian Division, S. 47, 81, 117. Vgl. auch Mallmann, Cüppers, Halbmond und Hakenkreuz: Das „Dritte Reich“, die Araber und Palästina, 2. Aufl. Darmstadt: Wissenschaftliche Buchgesellschaft 2007 S. 228. Ausführlich vgl. Lepre, Himmler's Bosnian Division, S. 81-108.

462 Vgl. Fall Günter Borkwoski, Aussage Erich Schäfer, 23.4.1964, USHMM, BArchL, B162/ 20812, Bl. 70.

463 Vgl. Lepre, Himmler’s Bosnian Division, S. 117. 
5) Eine Jägerkompanie bestand aus: Kompanieführer, Kompanietrupp, drei Zügen, eine SMG-Gruppe. ${ }^{464}$

Mehner gibt eine abweichende Gliederung an. ${ }^{465}$

Per Bahn gelangte die Division bis nach Kroatien und von dort schließlich nach Bosnien. ${ }^{466}$

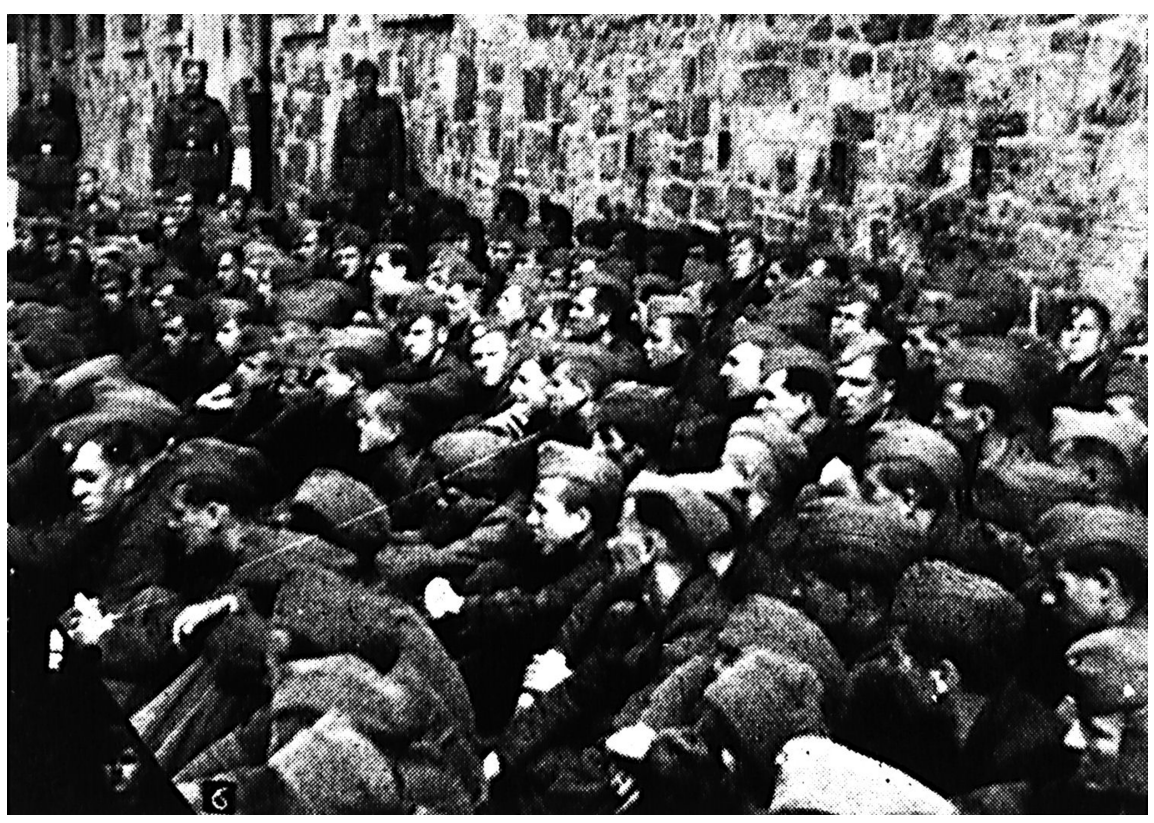

Abb. 22: Bildunterschrift „Kompanieunterricht im Freien bei einer Einheit der Division ,Handschar““. 467

\subsubsection{Hand in Hand: „Weltanschauliche Schulung“ und Religion}

Wie bereits im Einleitungsteil dieser Studie erörtert, fand ab 1943 mit der Erweiterung der Waffen-SS auf muslimische südosteuropäische Divisionen auch eine

464 Vgl. Kriegsgefangenenbericht, Alfred Schrader, 31.10.1947, VA HEM.OK.BOJCKA, 72A/1a/ 34, S. $1 \mathrm{f}$.

465 Vgl. Gliederung bei Mehner, Waffen-SS, Bd. S. $221 \mathrm{f}$.

466 Vgl. Fall Günter Borkwoski, Aussage Erich Schäfer, 23.4.1964, USHMM, BArchL, B162/ 20812, Bl. 70. Vgl. Petke, Militärische Vergemeinschaftungsversuche, S. 251.

467 BArchF, Nachlass Vopersal, N756 168a. 
Anpassung der „ideologischen Schulung“ an diese Region statt. ${ }^{468}$ Der größte Unterschied zwischen der bisherigen ,ideologischen Schulung“ und der ideologischen Ausbildung innerhalb der „Handschar“ bestand darin, dass zwar eine Abteilung VI (,Weltanschauliche Erziehung“) bestand, diese aber die Schulung zu großen Teilen den Imamen der Division übertrugen, die insgesamt „die weltanschaulich geistige Erziehung“ der Truppe übernehmen sollten. Denn „der Imam ist der Treuhänder des Islam in der Division. Er hat die Kräfte der Religion für die Erziehung der Div[isions]-Angehörigen zu guten SS-Männern und Soldaten wachzurufen und zu entfalten.“469

Der Großmufti von Jerusalem, Mohammed Amin al-Huseini, war nicht nur in die Werbung für die 13. Waffen-Gebirgs-Division involviert, sondern zeichnete auch verantwortlich für die spezifische Ausbildung geworbener Imame ${ }^{470}$ und war gemeinsam mit dem SS-Hauptamt für die Herausgabe übergeordneter Richtlinien zuständig. ${ }^{471}$ Mit dem Aufbau einer Abteilung VI war Studienrat Heinrich Gaese betraut, der auch die Schulungen in Babelsberg leitete. ${ }^{472}$ Der spätere Führer der Abteilung VI der 13. Waffen-Gebirgs-Division, SS-Hauptsturmführer Ekkehard Wangemann, war als „weltanschaulicher und politischer Referent“ für die Weitergabe der „weltanschaulichen Erziehung“ durch die Imame an die Truppe verantwortlich. ${ }^{473}$ Letzter Leiter der Abteilung VI wurde schließlich der „volksdeutsche“ Rumäne SS-Obersturmbannführer Georg Floritsch, der bereits vorher in dieser Abteilung gedient hatte. Daneben bestand die Abteilung aus SS-Oberscharführer Albert Bauer, SS-Untersturmführer Julius Kaesdorf, ein „Volksdeutscher“ aus Kroatien, sowie Erich Wiegandt, der bereits zuvor u. a. als Kreisschulungsredner der NSDAP in Erscheinung getreten war. ${ }^{474}$ Der Leiter der Abteilung VI war direkt dem Divisionskommandeur unterstellt und sollte seine

468 Vgl. hierzu auch Daniel Kuppel, „Das Echo unserer Taten“. Die Praxis der weltanschaulichen Erziehung in der SS, Paderborn: Schöningh 2019, S. 198-208.

469 Abteilung VI, „Dienstanweisung für Imame der 13. SS-Freiwilligen b.h.Geb.Div. (Kroatien)“, 15.3.1944, BAB, NS 19/2601, Bl. 248.

470 Vgl. Mallmann, Cüppers, Halbmond und Hakenkreuz, S. 231.

471 SS-Hauptsturmführer, Unterschrift nicht lesbar, Abschrift „Mündlicher Befehl Chef SSHauptamt“, 19.5.1943, BArchB, NS 19/2601, Bl. 245.

472 Vgl. Harten, Himmlers Lehrer, S. 416.

473 Sauberzweig, Divisions-Sonderbefehl „Betr: Stellung der Imame innerhalb der Division“, 13. SS-Division, Abt. VI Tgb.Nr. 21/44 geh., 8.3.1944, BArchB, NS 19/2601, Bl. 247. Ähnlich organisiert waren bereits seit 1942 muslimische Legionen der Wehrmacht; so auch die Einhaltung von muslimischen Speisevorschriften. Vgl. auch Mallmann/Cüppers, Halbmond und Hakenkreuz, S. 223.

474 Vgl. Harten, Himmlers Lehrer, S. 416. Detaillierte Angaben zu den einzelnen Imamen neben Muhasilović, Đozo und Malkoć bietet Bernwald, Muslime in der Waffen-SS, S. 73-83. 
Aufgabe im Einverständnis mit dem Divisions-Imam ausführen. Die Imame waren bis hinunter zur Bataillonsebene auf die Division verteilt. In disziplinärer Hinsicht waren sie dem Divisionskommandeur direkt unterstellt, bei „religiös rituellen Fragen“ aber dem Divisions-Imam. ${ }^{475}$ Als solche waren SS-Sturmbannführer Abdullah Muhasilović, SS-Hauptsturmführer Husein Đozo sowie SS-Hauptsturmführer Halim Malkoć eingesetzt. Sie befehligten die in jedem Bataillon eingesetzten Imame. ${ }^{476}$

Dass die versprochene muslimische Ausgestaltung der Division nicht nur leere Worte waren, davon zeugt beispielsweise die Einrichtung einer Großküche und etwa 15-20 Feldküchen, die speziell auf eine Verpflegung unter „Einhaltung der muslimischen Riten“ ausgerichtet waren. ${ }^{477}$ Himmler ließ im Juli 1943 über Berger beim Großmufti Informationen über die muslimischen Ernährungsvorschriften einholen. ${ }^{478}$ Schweinefleisch, Wurst, die unter anderem Schweinefleisch enthielt, und Alkohol sollten den muslimischen Soldaten erspart bleiben, und Himmler betonte, dass ,alle Kommandeure, Kompaniechefs und sonstigen SS-Führer, besonders aber die zuständigen Wirtschafts-Verwaltungsführer und -unterführer für die treueste und loyalste Wahrung dieses Sonderrechtes verantwortlich“ waren. Er wollte sicherstellen, dass sämtliche muslimische Angehörige der Waffen-SS und Polizei diese Sonderrechte in Anspruch nehmen durften. ${ }^{479}$ Die Abteilung VI hatte auf sechs Seiten die religiösen Feiertage und Zeremonien aufgelistet und das Vorgehen bei den einzelnen Anlässen für die Kommandeure erläutert. Die Tage, auf welche jene Feiertage im Jahre 1944 fielen, waren vermerkt, damit sie in der Truppe auch entsprechend begangen werden konnten. Bei hohen Feiertagen sollte, falls die Einheit nicht im Einsatz stand, eine Feier durchgeführt werden. ${ }^{480}$ Am einschneidendsten für die Truppe war der Fastenmonat Ramadan. ${ }^{481}$ Begräbnisse waren nach muslimischen Sitten durchzuführen: Wenn ein Soldat seinen Verwundungen erlag, ohne die Augen noch einmal

475 Sauberzweig, Divisions-Sonderbefehl „Betr: Stellung der Imame innerhalb der Division“, 13. SS-Division, Abt. VI Tgb.Nr. 21/44 geh., 8.3.1944, BArchB, NS 19/2601, Bl. 247. Dies war bereits 1942 bei den ersten muslimischen Legionen der Wehrmacht so eingeführt worden. So auch die Einhaltung von muslimischen Speisevorschriften. Vgl. auch Mallmann/Cüppers, Halbmond und Hakenkreuz, S. 223.

476 Vgl. Harten, Himmlers Lehrer, S. 416.

477 Vgl. Kriegsgefangenenbericht „Bericht über die 13. SS Division ,Handschar', ihre Aufstellung, Gliederung und 1. Einsätze im jugoslawischen Raum“, Walter Eipel, 14.11.1947, VA, HEM. OK.BOJCKA, 72-A/1-a/32, S. 3.

478 Vgl. Himmler an Berger, 22.7.1943, BArchB, NS 19/2601, Bl. 142.

479 Vgl. Entwurf Himmler, August 1943, BArchB, NS 19/2601, Bl. 148.

480 Vgl. Abteilung VI, „Dienstanweisung für Imame der 13. SS-Freiwilligen b.h.Geb.Div. (Kroatien)“, 15.3.1944, BArchB, NS 19/2601, Bl. 248.

481 Vgl. ebd. Vgl. auch von Pistor an Vorpersal, undatiert, BArchF, N 756/182b. 
zu öffnen, wurde er in der Uniform begraben; aß oder trank er noch einmal, sollte er gebadet und in Leinen gewickelt werden. ${ }^{482}$ Dass bereits in dieser Zeit teilweise auch eine säkularisierte Form islamischen Glaubens praktiziert wurde, blendete Himmler in seiner orientalistischen Denkweise komplett aus. Immerhin ist der von Sauberzweig herausgegebenen „Dienstanweisung für Imame“ zu entnehmen, dass die Teilnahme der Muslime an sämtlichen religiösen Feiern freiwillig sei. ${ }^{483}$

Die Nähe zum Islam war eine der grundlegenden Charaktereigenschaften der „Handschar“. Modellhaft sollten die angehenden Feldimame nicht nur in religiöser Hinsicht, sondern auch ideologisch auf die Mannschaften einwirken. Es waren vor allem Schullehrer, die speziell für die Aufgabe als Divisionsgeistliche von der Ulema in Sarajevo angeworben wurden. Einige unter ihnen hatten ihre Ausbildungen an namhaften Universitäten in Alexandria oder Kairo absolviert. ${ }^{484}$ Die Imame wurden in Sarajevo gesammelt und von dort zur Uniformierung und Einführung nach Zagreb in die Savska Cesta 77 geschickt, ${ }^{485}$ die bereits damals als Institut zur Lehrerausbildung diente. Von dort kamen sie nach Babelsberg in einen dreiwöchigen „Ausbildungskurs für Imame“, ${ }^{486}$ der von Berger organisiert und von Gaese geleitet wurde. ${ }^{487}$

Nach Angaben Bernwalds gegenüber Lepre aus dem Jahr 1993, wurden die Lektionen in einer großen Villa abgehalten. Sie beinhalteten „Die Waffen-SS: Organisation und Ränge“, „Die Geschichte des Nationalismus“ sowie verschiedene Deutschkurse. Divisions-Imam Džemal Ibrahimović hingegen gab an, dass die Ausbildung zusätzlich zu den Vorlesungen auch in der Ausbildung an Handfeuerwaffen bestanden hätte. ${ }^{488}$ Um die angehenden Imame der Division bei Laune zu halten, wurde zuweilen auf weltliche Genüsse zurückgegriffen, zum Beispiel indem man unter ihnen Zigaretten verteilte. ${ }^{489}$

Schließlich sollte al-Huseini im brandenburgischen Guben ein ehemaliges Hotel überschrieben werden, damit er dort eine Imamschule einrichten konnte ${ }^{490}$ und, wie Himmler an Berger schrieb, „eine Imamenschaft heran[ziehen], um

482 Vgl. Abteilung VI, „Dienstanweisung für Imame der 13. SS-Freiwilligen b.h.Geb.Div. (Kroatien)“, 15.3.1944, BArchB, NS 19/2601, Bl. 248.

483 Vgl. ebd.

484 Vgl. Lepre, Himmler's Bosnian Division, S. 71.

485 Ebd.

486 Vgl. Harten, Himmlers Lehrer, S. 416.

487 Vgl. Lepre, Himmler’s Bosnian Division, S. 71f. Vgl. Harten, Himmlers Lehrer, S. 416.

488 Vgl. Lepre, Himmler's Bosnian Division, S. $71 \mathrm{f}$.

489 Vgl. ebd. Vgl. hierzu auch „Zuverfügungstellung von Zigaretten für die Abteilung Osttürken und Kaukasus“, 30.9.1944, NS 31/170, Bl. 52.

490 Vgl. Mallmann, Cüppers, Halbmond und Hakenkreuz, S. 231. 
damit auch ein Korps von Priestern zu bekommen, die auf ihn [al-Huseini] persönlich ausgerichtet und zugleich politisch in einer entsprechenden Weise gebildet sind“. ${ }^{491}$ Am 21. April 1944 richtete al-Huseini in der Eröffnungsrede der Imamschule folgende Worte an Berger und an seine Kameraden:

Die Moslime, die schwere Angriffe und Unterdrückungen durch ihre Feinde zu erleiden haben, werden niemals einen besseren Verbündeten als das Großdeutsche Reich haben. Aber auch das nationalsozialistische Deutschland wird unter allen seinen Freunden niemals einen besseren und treueren für die Zusammenarbeit finden als die Moslime. ${ }^{492}$

Begeistert stellte al-Huseini fest, dass die „bosnisch herzegowinische Division“ für diese Zusammenarbeit ein „tatkräftiges Beispiel“ darstelle und er sich besonders darüber freue, Geistliche aus dieser Division zur Ausbildung in Guben begrüßen zu dürfen. ${ }^{493}$ Auch Himmler war der Meinung, dass die Imamstudenten der Division sowie geeignete junge Muslime so rasch wie möglich zur Ausbildung in das Imaminstitut geschickt werden müssten, um noch mehr Imame für muslimische Divisionen zur Verfügung zu haben. ${ }^{494}$ Am 26. November 1944 fand die Eröffnung einer weiteren muslimischen Institution im Deutschen Reich statt: die osttürkische Mullahschule in Dresden. ${ }^{495}$ Tags darauf bedankte sich al-Huseini bei Himmler:

Anlässlich der Eröffnung des Imam-Institutes der Osttürken in Dresden, das als weiteres Zeichen für Ihr großes Interesse an der islamisch-deutschen Zusammenarbeit zu betrachten ist, übermittle ich Ihnen den aufrichtigen Dank und die besten Grüße der Muslimen [sic]. Ich versichere Sie [sic], das [sic] die Zusammenarbeit in dem gemeinsamen Kampf immer enger, größer werden und bis zum Endsieg andauern wird. ${ }^{496}$

Zur „Vertiefung der weltanschaulich geistigen Erziehung“ sollte ein spezielles Leitheft herausgegeben werden, das später auch für andere muslimische Divi-

491 Himmler an Berger, 24.11.1944, BAB, NS 19/2601, Bl. 42.

492 Höpp, Mufti-Papiere, S. 212.

493 Vgl. ebd., S. 212.

494 Vgl. Schreiben Himmler an Berger, 24.11.1944, BAB, NS 19/2601, Bl. 42. Auch die Wehrmacht bot Imamkurse an, Leiter dieser Kurse war Bertold Spuler. Dieser stellte genaue Bedingungen auf, unter welchen die Imamkurse durchgeführt werden sollten. Vgl. Peter Heine: Die Imam-Kurse der deutschen Wehrmacht im Jahre 1944, in: Gerhard Höpp (Hg.): Fremde Erfahrungen. Asiaten und Afrikaner in Deutschland, Österreich und in der Schweiz bis 1945, Berlin 1997. S. 229-232.

495 Vgl. „Entwurf für Ansprache zur Eröffnung der Osttürkischen Mullah-Schule in Dresden am 26. November 1944“, ohne Namensangabe, ohne Datum, BArchB, NS 31/60, Bl. 2-4.

496 Vgl. Höpp, Mufti-Papiere, S. 229. Schreibweise im Original. 
sionen zum Einsatz kommen sollte - so war zumindest der Plan. ${ }^{497}$ Eine Zeitschrift, ebenfalls „Handžar“ genannt, erschien in Deutsch und Kroatisch bzw. Bosnisch. Für die elf Ausgaben zwischen Juli 1943 und Oktober 1944 waren zuerst Gaese und später sein Mitarbeiter SS-Oberscharführer Albert Bauer verantwortlich. ${ }^{498}$

Jede Woche sollten die Divisions-Imame mindestens einen Vortrag pro Kompanie halten und zudem bei jeder sich bietenden Gelegenheit, „,belehrend und erziehend auf die Truppe ein[...]wirken: In Marschpausen, in den Quartieren, vor allem im Einsatz, wo sich sehr oft der Unterschied zwischen unserem Wollen und des Gegners Zerstörungswahnsinn zeigt. “499 Nicht nur während seiner Arbeitszeiten sollte der Imam seinen Erziehungsaufgaben nachgehen, sondern auch seine Freizeit mit der Mannschaft verbringen. Besondere Aufmerksamkeit galt dem Wohl der Angehörigen der Soldaten in der Heimat. In Absprache mit dem Fürsorgeleiter war der Imam verpflichtet, Fürsorgemaßnahmen für diese Familien zu überprüfen und falls notwendig in die Wege zu leiten. ${ }^{500}$

Ähnlich Vorgaben galten für die weltlichen Vorgesetzten, die ebenfalls jede Gelegenheit zur „weltanschaulichen“ Beeinflussung der Soldaten nutzen sollten: Der Kompanieführer hatte bei Marschpausen, beim Rasten, bei Lagebesprechungen, in den Bunkern, am Abend am Biwakfeuer oder „bei der Zigarette nach dem Abendessen“ belehrend auf die Mannschaft einzuwirken. ${ }^{501}$ Sowohl über immaterielle Anteilnahme, wie aktives Zuhören bei Sorgen, als auch über dem körperlichen Wohl dienende Werte wie Nahrung, Kleidung oder Unterkunft sollte der Führer zur Mannschaft Vertrauen aufbauen. Wangemann war überzeugt, dass „eine so zusammengewachsene, verschworene Gemeinschaft (Bunkergemeinschaft, Grabengemeinschaft) zwischen Kompanieführer und Männern [...] jede Krise und Spannung im Kampfverlauf“ überstehen würde. ${ }^{502}$

Nach einer Besprechung mit Kommandeuren und Imamen am 8. April 1944 hielt Wangemann fest, in Zukunft den Fokus nicht mehr so sehr auf die weltanschauliche, sondern in Übereinkunft mit dem SS-Hauptamt und dem Großmufti

497 Vgl. Abschrift „Mündlicher Befehl Chef SS-Hauptamt“, SS-Hauptsturmführer, Unterschrift nicht lesbar, 19.5.1943, BArchB, NS 19/2601, Bl. 245.

498 Vgl. Harten, Himmlers Lehrer, S. 416. Siehe abgedruckte Exemplare der Divisionszeitung Folge 1-9 in: Bernwald, Muslime in der Waffen-SS, S. 329-412.

499 Abteilung VI, „Dienstanweisung für Imame der 13. SS-Freiwilligen b.h.Geb.Div. (Kroatien)“, 15.3.1944, BArchB, NS 19/2601, Bl. 250.

500 Vgl. ebd.

501 13. SS-Division, Abt. VI an Kompanieführer, „Weltanschauliche und politische Ausrichtung der Truppe im besonderen Einsatz“, 2.4.1944, BArchB, NS 19/2601, Bl. 228.

502 Ebd. 
von Jerusalem eher auf eine politische Schulung zu richten ${ }^{503}$, um anhand konkreter Beispiele eine Fanatisierung der Soldaten zu erreichen. So sollte der Kompanieführer die „weltanschauliche Schulung“ mithilfe anschaulicher Beispiele präsentieren, beispielsweise am amerikanischen Soldaten demonstrieren, „dass [dieser] für die Interessen der Wallstreet-Juden kämpft“. ${ }^{504}$

Wangemann war überzeugt, dass es vor allem „die innere Überzeugung, gegebenenfalls die Fanatisierung [war], die den einzelnen Mann vorwärtstreiben, die Truppe den Sieg erringen lassen."505 Er betonte, nicht emotionale Gründe hätten zur Aufstellung der „Handschar“ geführt, sondern die Erkenntnis, dass ein gemeinsamer Kampf gegen gemeinsame Feinde im Interesse beider, sowohl des Nationalsozialismus als auch des Islam, lag: „Also rein zweckmäßige Gründe auf beiden Seiten, untermauert durch viel gemeinsames in den beiden Weltanschauungen“. ${ }^{506}$ Daraus ergab sich, dass „das Erziehungsziel [...] also für beide [nationalsozialistische Kommandeure und muslimische Imame] das Gleiche [ist] ... der willensstarke und tatenfrohe Kämpfer, der bereit ist, für eine neue und bessere europäische Ordnung sein Leben einzusetzen. “507 So verwundert es nicht, dass im 6. „Weltanschauliche Erziehung“-Kurzlehrgang, den Angehörige der 13. SS-Division vom 29. März bis am 1. April 1944 absolvierten, die Antwort auf die Frage „Aus welchem Grund kämpfen Nationalsozialismus und Islam zusammen?“ lautete: ${ }^{508}$ „Islam und Nationalsozialismus haben dieselben Feinde und haben auch im Glauben Berührungspunkte. (Islam hat auch die Bestrebung, sich auf andere Völker zu verbreiten.)‘509

Obwohl Wangemann die Hauptaufgabe der Imame darin sah, „die Mannschaft zu guten Muselmanen zu erziehen“, sprach er in diesem späten Schreiben

503 Vgl. Führer der Abteilung VI, SS-Hauptsturmführer Ekkehard Wangemann, Gedächtnisaufzeichnung der „Dienstbesprechung der Kommandeure und Imame“, 8.4.1944, BArchB, NS 19/2601, Bl. 187.

504 Vgl. 13. SS-Division, Abt. VI an Kompanieführer, „Weltanschauliche und politische Ausrichtung der Truppe im besonderen Einsatz“, 2.4.1944, BArchB, NS 19/2601, Bl. 229.

505 Ebd.

506 Vgl. Führer der Abteilung VI, SS-Hauptsturmführer Ekkehard Wangemann, Gedächtnisaufzeichnung der „Dienstbesprechung der Kommandeure und Imame“, 8.4.1944, BArchB, NS 19/2601, Bl. 186.

507 Abteilung VI, „Dienstanweisung für Imame der 13. SS-Freiwilligen b.h.Geb.Div. (Kroatien)“, 15.3.1944, BArchB, NS 19/2601, Bl. 248.

508 13. SS-Division, Abt. VI, Fragebogen „für schriftliche Arbeit des 6. We-Kurzlehrganges vom 29.3.-1.4.1944“, 1.4.1944, BArchB, NS 19/2601, Bl. 232.

509 Antworten von SS-Sturmmann Stefan Windisch, 3./SS-Flak Abt. $13 \mathrm{zu}$ „Schriftliche Arbeit 6. We-Kurzlehrgang“, 1.4.1944, BArchB, NS 19/2601, Bl. 233. Vgl. hierzu auch Mallmann, Cüppers, Halbmond und Hakenkreuz, S. 231. 
noch einmal die übergeordnete Zielsetzung an, in welcher auch die Weiterführung von Rekrutierungen muslimischer Soldaten sichtbar wird: „über ihren Selbstzweck, als bosnisch-herzegowinische Division in diesem Raum hinaus, hat diese Division den ihnen allen bekannte[n] höheren politischen Zweck, die Brücke von Europa zum Weltislam zu schlagen. “510 Wichtig schien ihm aber, dass es nicht zu einer Synthese zwischen Islam und Nationalsozialismus kommen und nicht versucht werden sollte, muslimischen Soldaten den Nationalsozialismus aufzuzwingen. Vielmehr sollte in der Ausbildung auf die gemeinsamen Feinde, namentlich Judentum, Anglo-Amerikanismus, Kommunismus, Freimaurerei und Katholizismus (Vatikan) fokussiert und entsprechend „der gemeinsamen positiven Linie: a) Kämpferische Grundeinstellung, b) ethisch-sittliche Auffassung, c) völkische Erziehung“ auf die Soldaten eingewirkt werden. ${ }^{511}$ Als wesentliche Voraussetzung galt somit: „unbedingte gegenseitige Achtung der beiden Weltanschauungen (Nationalsozialismus - Islam).“512

Eine Schulung in lokalen religiösen und kulturellen Belangen erhielt auch das aus dem Ausland nach Bosnien zurückkehrende deutsche bzw. „volksdeutsche“ Rahmenpersonal im Frühjahr 1943. Divisionskommandeur Sauberzweig befahl den Divisions-Imamen, den deutschen Unterführern und Männern „einen ausführlichen Vortrag [...] über die religiösen $u[n d]$ familiären Sitten und Gebräuche in unserem Einsatzraum“ zu halten. So hoffte er, Gesetzesverstößen aus Unkenntnis vorzubeugen; denn für ihn stellte das Überqueren der Save letztlich auch das Überschreiten einer Kulturgrenze dar. ${ }^{513}$ Sofort nach dem Überschreiten dieser Grenze sollten bei Vernehmungen grundsätzlich ein Imam beigezogen werden, um die Ermittlungsdauer zu verkürzen und ihre Ansicht bei Fällen mit muslimischen Angeklagten anzuhören. ${ }^{514}$

510 Führer der Abteilung VI, SS-Hauptsturmführer Wangemann, Gedächtnisaufzeichnung der „Dienstbesprechung der Kommandeure und Imame“, 8.4.1944, BArchB, NS 19/2601, Bl. 186.

511 SS-Hauptsturmführer, Unterschrift nicht lesbar, „Betr. Weltanschaulich geistige Erziehung der muselmanischen SS-Division. Bez: Mündlicher Befehl Chef SS-Hauptamt“, 19.5.1943, BArchB, NS 19/2601, Bl. 245.

512 Ebd. Hervorhebung im Original.

513 „Aus der Erwägung heraus, dass wir beim Überschreiten der Save eine ganz andere Welt betreten, als wir sie kennen, weise ich ganz besonders auf die strenge Einhaltung dieses Befehles hin.“ Divisions-Sonderbefehl „Betr: Stellung der Imame innerhalb der Division“, Sauberzweig, 13. SS-Division, Abt. VI Tgb.Nr. 21/44 geh., 8.3.1944, BArchB, NS 19/2601, Bl. 247.

514 Vgl. ebd. 


\subsection{Aufbau, Struktur und Zusammensetzung}

Die „Handschar“ bildete zwar den ersten Großverband, der aus „Fremdvölkischen" bestand, doch dies soll nicht darüber hinwegtäuschen, dass schon seit dem Balkanfeldzug 1941 Bosnier, Herzegowiner, Kroaten, Serben und Albaner für den Dienst in der Wehrmacht, der Waffen-SS und Polizei herangezogen, auf verschiedene Einheiten verteilt und teilweise auch an der Ostfront eingesetzt waren. ${ }^{515}$ Multikultur war dabei ein wesentliches Merkmal solcher Verbände und somit kein Novum der frisch ausgehobenen „Handschar“. Dass aber jenes „fremdvölkische“ ethnische Element bewusst hervorgehoben und propagandistisch genutzt wurde, war neu. ${ }^{516}$

\subsubsection{Rahmenpersonal}

Nicht nur die Mannschaftsebene, auch diejenige der Unterführer und Führer wies eine Vielfalt an Nationalitäten und Migrationshintergründen auf. Wie vorher die „Prinz Eugen“ und ein Jahr später die „Skanderbeg“, konnte die „Handschar“ nicht ohne Hilfe von deutschem Rahmenpersonal und sogar Mannschaften aufgestellt werden. ${ }^{517}$ „Deutsch“ bzw. „reichsdeutsch“ bezeichnete jedoch in diesem Zusammenhang nicht nur Personal aus Deutschland, sondern auch aus Österreich stammende Soldaten. Casagrande stellte in seinen Untersuchungen fest, dass auch „eingedeutschte“ Südtiroler, frühere italienische Staatsbürger, die vorher als Führeranwärter in Divisionen wie der „Totenkopf“, der „Leibstandarte“ oder „Das Reich“ gedient hatten, später als Ausbildungspersonal zur „Handschar“ versetzt wurden. ${ }^{518}$ In einem Rundschreiben Jüttners wurde festgelegt, dass die Führerstellen aber zunächst mit „volksdeutschen“ aktiven und Reserve-Offizieren sowie muslimischen aktiven und Reserve-Offizieren besetzt werden sollten. ${ }^{519}$ Die kroatische Regierung sollte zweisprachige kroatische Führer und Unterführer sowie „volksdeutsches“ Rahmenpersonal stellen. ${ }^{520}$

515 Vgl. Generalstatthalter Albanien, Gabinetto Diplomatico an das Ministero degli Affari Esteri zur Situation in Serbien, 7.12.1942, ASD, Archivio del Gabinetto, 1923-1943, Busta 1492 (AG Serbia 54). Vgl. Dienststelle des AA beim Militärbefehlshaber Serbien Gehart Feine an AA, „Werbung unter der muselmanischen Bevölkerung“, 18.5.1943, PAAA, R100998.

516 Vgl. zu dieser Entwicklung Casagrande, Volksdeutsche SS-Division, S. $334 \mathrm{f}$.

517 Vgl. Schreiben Phleps an Himmler, 7.5.1944, BArchB, NS 19/2601, Bl. 95.

518 Vgl. Casagrande, Südtiroler, S. 104.

519 Vgl. Jüttner an Sonderverteiler/70 Ausfertigungen, betr. „Aufstellung der Kroatischen SSFreiwilligen-Division“, 30.4.1943, BArchB, NS19/3523, Bl. 34.

520 Vgl. Lepre, Himmler's Bosnian Division, S. 24. 
Betreffend der Unterführer stellte Jüttner folgende Forderungen: Die Unterführer sollten, wenn möglich, „freiwillig“ auf dem Gebiet des NDH geworben werden und dem muslimischen Glauben angehören. Falls die Unterführerstellen nicht mit solchen Freiwilligen besetzt werden konnten, sollten „ausschließlich Reichsdeutsche bzw. Volksdeutsche zu dieser Division“ versetzt werden. ${ }^{521}$ Außerdem betonte Jüttner, dass schließlich auch innerhalb der Division „für die rasche Heranbildung eines muselmanischen Führernachwuchses“ zu sorgen sei. ${ }^{522}$ In der Anklageschrift gegen Walter Bormann, Kommandeur des I. Bataillons des Regiments 28 der „Handschar“ sind Belege zu finden, dass auf Führungsebene, wenn auch selten, Muslime eingesetzt waren. ${ }^{523}$

Die Einstufung „reichsdeutscher“, „volksdeutscher“, kroatischer (katholischer) und muslimischer Führer sollten auf Anweisung Jüttners so erfolgen, dass sie gemäß dem aktuellen Dienstgrad, den sie im kroatischen Heer innegehabt hatten, behandelt, eingestuft und besoldet wurden. Dienstältere Führer sollten um einen Dienstgrad zurückgestuft werden. Die Probezeit betrug sechs Monate, danach sollten sie als „Führer auf Kriegsdauer“ übernommen werden. ${ }^{524}$ Wer vom ausgehobenen oder versetzten Rahmenpersonal körperlich oder aufgrund seiner Leistung als ungenügend eingestuft wurde, sollte zuerst zur Polizei versetzt und, falls auch da ungeeignet, entlassen werden.

Führer der Sanitäts- und Verwaltungsdienste hatte das Führungshauptamt, Amtsgruppe D bzw. das Personalamt des SS-Wirtschafts- und Verwaltungshauptamtes zu stellen. Das Hauptamt SS-Gericht sollte das Gericht der kroatischen SSFreiwilligen-Division stellen. Die Nachrichtenabteilung der „Handschar“ war auf Verfügung des Führungshauptamtes, Kommandoamt der Waffen-SS, am 27. April 1943 befohlen worden und wurde in Goslar aufgestellt. ${ }^{525}$

\subsubsection{Zu den Divisionskommandeuren}

Im Folgenden soll anhand von Kurzbiographien ein Einblick in die soziale Struktur der Divisionskommandeure sowie einiger Kommandeure auf unteren Ebenen gegeben werden. Die meisten der hier vorgestellten Personen hatten bereits im Ersten Weltkrieg, viele von ihnen in der k.u.k.-Armee gedient. Einige von ihnen

521 Vgl. Jüttner an Sonderverteiler/70 Ausfertigungen, betr. „Aufstellung der Kroatischen SSFreiwilligen-Division“, 30.4.1943, BArchB, NS19/3523, Bl. 34.

522 Jüttner an Sonderverteiler/70 Ausfertigungen, betr. „Aufstellung der Kroatischen SS-Freiwilligen-Division“, 30.4.1943, BArchB, NS19/3523, Bl. 34.

523 Vgl. Anklageschrift gegen Bormann, 13.10.1947, AJ, 110, kutja 25647/1810, S. 1.

$524 \mathrm{Vgl}$. (auch für das Folgende) Jüttner an Sonderverteiler/70 Ausfertigungen, betr. „Aufstellung der Kroatischen SS-Freiwilligen-Division“, 30.4.1943, BArchB, NS19/3523, Bl. 34.

525 Vgl. Tessin, Verbände, Bd. 3, S. 283. 
konnten in den 1940er Jahren durch sich ständig ändernde nationalstaatliche Gebilde bereits auf Karrieren in mehreren Armeen zurückblicken. Die meisten von ihnen waren „Volksdeutsche“ oder Österreicher.

\section{April bis 9. August 1943: SS-Standartenführer Herbert von Obwurzer (1888-1945)}

Herbert von Obwurzer wurde am 23. Juni 1888 in Innsbruck-Wilten geboren. Das Adelsprädikat „von“ erhielt die Familie, nachdem Herberts Vater im Ersten Weltkrieg gefallen war. Auch er selbst kämpfte bereits im Ersten Weltkrieg in der k.u.k.-Armee, zuletzt in der Funktion als Hauptmann beim 1. Regiment der „Tiroler Kaiserjäger“. Braun, der gemeinsam mit Obwurzer dem Aufstellungsstab für die Division „Handschar“ angehörte, betonte insbesondere Obwurzers Dienstzeit in der österreichisch-ungarischen Armee und gab an, letzterer sei von Kopf bis Fuß ein Offizier gewesen. ${ }^{526}$

Nach dem Ersten Weltkrieg war Obwurzer Angehöriger des Freikorps „Eiserne Division“ und 1919 in die Kämpfe im Baltikum involviert. Seit 1920 zeichnete er verantwortlich für den Aufbau der „Tiroler Heimwehr“ und trat bereits 1930 der NSDAP bei. Dem Beitritt zur Partei folgte ein Umzug ins Deutsche Reich, wo er ab 1937 den Rang eines Majors innehatte. 1942 erfolgte der Wechsel zur Waffen-SS im Rang eines Obersturmbannführers. Ab Sommer 1942 diente er in der 6. SS-Gebirgs-Division „Nord“ und wurde von dort zur „Handschar“ versetzt. Er war nicht nur mit der Aufstellung der Division betraut, sondern diente vom 1. April bis 9. August 1943 auch als ihr erster Kommandeur. Von dort wechselte er im September 1943 zur 1. SS-Infanterie-Brigade, die in der Sowjetunion zahlreiche Morde an Zivilisten begangen hatte. Im Juli 1944 wurde er Kommandeur der lettischen 15. Waffen-Grenadier-Division der SS. Seit einer Aufklärungsfahrt am 26. Januar 1945 galt er als vermisst und wurde danach für tot erklärt. ${ }^{527}$

\section{August 1943 bis Juni 1944 SS-Brigadeführer Karl-Gustav Sauberzweig (1899-1945)}

Karl-Gustav Sauberzweig stammte aus dem polnischen Wysoka (Wissek). Er war bereits im Ersten Weltkrieg Soldat und wurde mit dem Eisernen Kreuz Ers-

526 Tagebuch von Erich Braun, Eintrag vom 10.3.1943, zitiert nach Lepre, Himmler's Bosnian Division, S. 27.

527 Vgl. https://handzar.jimdo.com/drugi-svjetski-rat/ukratko-o-diviziji/herbert-von-obwur zer/ (19.6.2019). Die Einträge im Biographischen Lexikon Österreichs erweisen sich für die Zeit des Zweiten Weltkriegs als sehr lückenhaft. https://www.biographien.ac.at/oebl/oebl_O/Ob wurzer_Herbert_1888_1945.xml (Stand: 19.6.2019). 
ter und Zweiter Klasse und dem Verwundetenabzeichen in Schwarz ausgezeichnet. Wysoka gehörte nach den Wiener Verträgen zu Preußen, wurde aber nach dem Ersten Weltkrieg Polen zugeschlagen. Nach dem Weltkrieg entschied sich Sauberzweig, weiterhin in der stark verkleinerten Reichswehr zu dienen - ab 1925 im Dienstgrad eines Oberleutnants. ${ }^{528}$ Von August 1940 bis August 1941 war er Generalstabsoffizier im XI. Armeekorps. Sauberzweig hatte mehrere unbedeutende Posten innerhalb der Wehrmacht, was ihn Anfang August 1943 dazu bewog, zur Waffen-SS zu wechseln, um seine Karrierechancen zu erhöhen. Im Rang eines SS-Brigadeführers und Generalmajors wurde er kurz danach, am 9. August 1943, als Kommandeur der 13. Waffen-Gebirgs-Division der SS eingesetzt. Er blieb Divisionskommandeur bis Juni 1944. Danach war er Amtschef des Führungshauptamtes und stellte das XIII. SS-Armeekorps auf. Im Spätherbst 1944 zerstritt er sich schließlich mit Hitler, wurde daraufhin festgenommen und blieb bis zur Befreiung inhaftiert. Anderen Aussagen zufolge ließ Himmler ihn in Begleitung eines Arztes in eine Berliner psychiatrische Klinik einsperren. ${ }^{529}$ Nach dem Krieg beging er im Lager Neuengamme Suizid, als die Briten ihn an Jugoslawien ausliefern wollten. ${ }^{530}$

\section{Juni 1944 bis 8. Mai 1945 SS-Brigadeführer Desiderius Hampel (1895-1981)}

Auch Desiderius Hampel war ein „Volksdeutscher“. Er wurde am 20. Januar 1895 in Sisak im heutigen Kroatien geboren. Nach Ausbruch des Ersten Weltkriegs kam Hampel im österreichisch-ungarischen Heer zuerst als Fähnrich zum ungarisch-kroatischen Infanterie-Regiment „Freiherr von Giesl“ (Nr. 16). ${ }^{531} \mathrm{Er}$ stieg bis zum Offizier auf und erhielt verschiedene Auszeichnungen. Gemeinsam mit anderen Offizieren schloss er sich nach dem Ersten Weltkrieg in einem Freikorps gegen die Serben zusammen, die ihn schließlich internierten. Zwischen 1925 und 1928 studierte er Forstwirtschaft an der Universität München. Im Dezember 1937 trat er in die ungarische Armee ein. Dort diente er bis März 1941 und trat danach im November desselben Jahres als Major in die kroatische Armee über, wo er als Nachrichtenoffizier beim IV. Armeekorps eingesetzt wurde. 1942 ließ er sich als SS-Sturmbannführer für die Waffen-SS rekrutieren und kommandierte ab 25. Mai 1942 das III. Bataillon des SS-Gebirgsjäger-Regiments 1 der SS-Freiwilligen-Ge-

528 Vgl. Schulz, Wegmann, Zinke, Die Generale der Waffen-SS und der Polizei, Bd. 4, S. 415 f. 529 Vgl. Vernehmungsprotokoll Matheis, Franje, Office of Chief of Council for War Crimes Translation of Document No. NO-4951, Landeskommission der Feststellung der Verbrechen der Okkupatoren und ihrer Helfershelfer, Inv. Nr. 35874, BArchF, Nachlass Vopersal, N 756/169a. 530 Vgl. Schulz, Wegmann, Zinke, Die Generale der Waffen-SS und der Polizei, Bd. 4, S. $422 \mathrm{f}$. 531 Schulz, Wegmann, Zinke, Die Generale der Waffen-SS und der Polizei, Bd. 2, S. 18. 
birgs-Division „Prinz Eugen“. ${ }^{532}$ Am 11. Juni 1943 wurde ihm das Kommando des Feldersatz-Bataillons der „Prinz Eugen“ übertragen. Am 28. September 1943 wurde er zum Kommandeur des SS-Gebirgsjäger-Regiments 27 der „Handschar“ ernannt. In dieser Funktion diente er mit einer kurzen Unterbrechung von fünf Wochen, die er beim Stab des V. SS-Gebirgskorps verbrachte. Von Juni 1944 bis zum Kriegsende kommandierte Hampel schließlich die Division „Handschar“, wobei er am 9. November 1944 zum SS-Oberführer befördert wurde. 1939 wurde er mit dem Eisernen Kreuz Erster und Zweiter Klasse und 1945 mit dem Ritterkreuz ausgezeichnet. Am 12. Mai 1945 geriet er in britische Kriegsgefangenschaft, wurde aber bereits am 11. Dezember 1946 entlassen. Nach dem Krieg lebte er bis zu seinem Tod in Graz. ${ }^{533}$

\subsubsection{Kurzbiographien weiterer Kommandeure}

Für das deutsche Rahmenpersonal sollen hier stellvertretend einige Beispiele angeführt werden, um einen Einblick in die sozialen Milieus und den militärischen Werdegang zu ermöglichen. Die Biographien verdeutlichen, wie heterogen das Führungspersonal hinsichtlich Alter, Herkunft und Bildungsniveau war.

\section{Beispiel 1: Heinrich Wilhelm Schüßler}

Heinrich Wilhelm Schüßler wurde am 16. April 1915 in Elm als Sohn des Reichbahnarbeiters Johann Peter Schüßler geboren. Ursprünglich war Schüßler Schlachterlehrling, wechselte dann aber in den Beruf des Kriminalbeamten, wohl durch die sich ihm bietenden Möglichkeiten nach dem Beitritt zur Waffen-SS. Bei Religionszugehörigkeit schrieb er „gottgläubig“, was auf seine innere Nähe zur SS und ihrer Haltung zur Religion hindeutet. ${ }^{534}$ Am 28. Mai 1933 trat er in den „Freiwilligen Arbeitsdienst“, ein Programm für junge Arbeitslose, ein. Im Juli 1934 erfolgte der Übertritt vom Arbeitsdienst in die „Leibstandarte SS Adolf Hitler“. Schließlich wechselte er Ende 1938 zur Grenzpolizei. Kurz vor Kriegsbeginn, am 27. August 1939, wurde er wieder zur „Leibstandarte“ versetzt. ${ }^{535}$ In die Division „Handschar“ trat er mit dem Dienstgrad eines SS-Rottenführers ein. Am 1. September 1943 wurde Schüßler zum SS-Untersturmführer befördert und am 9. November 1944 schließlich zum SS-Obersturmführer. ${ }^{536}$

532 Vgl. ebd., S. 19.

533 Vgl. ebd., S. 19-20. Vgl. zu Hampel auch SS-Personalakte Desiderius Hampel, USHMM, BArchL B 162/20814, Bl. 54-65.

534 Vgl. SS-Personalakte Heinrich Wilhelm Schüßler, USHMM, BArchL B 162/20815, Bl 4.

535 Vgl. ebd., 5.

536 Vgl. ebd., Bl. 2. 


\section{Beispiel 2: Albert Stenwedel}

Ein bemerkenswerter Fall ist Albert Stenwedel, der am 10. September 1908 in Hamburg Altona als Sohn eines Telegrapheninspektors geboren wurde. ${ }^{537}$ Er gilt als einer der Begründer der „Leibstandarte SS Adolf Hitler“. ${ }^{538}$ Stenwedel war SS-Mitglied der ersten Stunde: Bereits 1925 trat er in den SS-Sturm 1/III/4 ein. Im Juli 1932 nahm er am Unterführerlehrgang der 4. SS-Standarte teil, am 12. März 1933 wurde er bereits zum SS-Scharführer befördert. Im Mai 1933 erfolgte die Versetzung zur „Leibstandarte SS Adolf Hitler“, in welcher er ab Oktober desselben Jahres die 3. Kompanie im Rang eines SS-Stabsscharführers befehligte. Die Beförderung zum SS-Untersturmführer erfolgte im März 1935, zum SS-Obersturmführer im April 1936. ${ }^{539}$ Im Januar 1941 wurde er zum SS-Hauptsturmführer befördert. $^{540}$ Ab 7. Juni 1943 tat Stenwedel Dienst in Zagreb in dem von der 13. Waffen-Gebirgsdivision geführten Auffanglager, war im Aufstellungsstab und kommandierte in der „Handschar“ schließlich das II. Bataillon des Waffen-Gebirgsjäger-Regiments 27. ${ }^{541}$ Stenwedels letzte Beförderung, zum SS-Sturmbannführer, erfolgte im Januar 1945..$^{542}$ Noch Anfang Mai 1945 wurde er angeblich mit dem Ritterkreuz ausgezeichnet, doch ein Nachweis für die Verleihung dieses Ordens an Stenwedel liegt nicht vor. ${ }^{543}$ Dass er auch in späteren Jahren in EhemaligenKreisen aktiv war, beweist seine Erwähnung in Kalteneggers einschlägiger Publikation „Totenkopf und Edelweiß“ von 2008. Kaltenegger dankte Stenwedel für dessen Unterstützung bei der Fertigstellung seines Buches. ${ }^{544}$

\section{Beispiel 3: Gerd Jordt}

Gerd Jordt wurde am 3. Dezember 1918 in Burg auf Fehmarn geboren. Bereits mit knapp 19 Jahren, im November 1937, schrieb sich Jordt bei der Waffen-SS, in die SS-Standarte „Germania“ ein. ${ }^{545}$ Er erwähnte in seinem handgeschriebenen Lebenslauf den frühen Verlust seiner Mutter. Sie starb, als er erst vier Jahre alt

537 Vgl. SS-Personalakte Albert Stenwedel, USHMM, BArchL B 162/20815, Bl. 20.

538 Vgl. Kaltenegger, Totenkopf und Edelweiß, S. 341.

539 Vgl. ebd., Bl. 21, 25.

540 Vgl. ebd., Bl. 21.

541 Vgl. ebd., Bl. 20, 24. Vgl. auch Vernehmung Stenwedels im Fall Borkowsky, 23.4.1964, USHMM, BArchL B 162/20812, Bl. 131.

542 Vgl. ebd., Bl. 21.

543 Vgl. Kaltenegger, Totenkopf und Edelweiß, S. 341 mit Scherzer, Veit, Die Ritterkreuzträger. Die Inhaber des Ritterkreuzes des Eisernen Kreuzes 1939 von Heer, Luftwaffe, Kriegsmarine, Waffen-SS, Volkssturm sowie mit Deutschland verbündeter Streitkräfte nach den Unterlagen des Bundesarchivs, 2. Aufl., Ranis: Scherzers Militaer-Verlag 2007, S. 177.

544 Vgl. Kaltenegger, Totenkopf und Edelweiß, S. 15.

545 Vgl. SS Personalakte Gerd Jordt, USHMM, BArchL B 162/20815, Bl. 47 f. 
war. Sein Vater heiratete wieder und Jordt wurde in Burg auf Fehmarn eingeschult. Von Herbst 1935 bis Ostern 1937 besuchte er eine nationalsozialistische Erziehungsanstalt, eine Internatsoberschule. ${ }^{546}$ Zwischen 1940 und 1943 tat er in verschiedenen Formationen Dienst, darunter auch in der Division „Reich“. Am 13. Juli 1943 kam er zur „Handschar“, diente dort im Rang eines SS-Obersturmführers und fiel am 13. November 1944 kurz vor seinem 26. Geburtstag. ${ }^{547}$

\section{Beispiel 4: Franje Matheis}

Franje Matheis wurde am 17. Januar 1889 in Sremska Mitrovica geboren. Zu den familiären Hintergründen ist nichts weiter bekannt. Er war „Volksdeutscher“, war verheiratet und hatte zwei Kinder. Im Ersten Weltkrieg hatte er in der österreichischungarischen Armee als Offizier gedient. In der Zwischenkriegszeit war er Privatangestellter und wurde nach eigenen Angaben „,in Kriegszeiten reaktiviert“. ${ }^{548}$ Im Rang eines SS-Standartenführers kommandierte er das Waffen-Gebirgsjäger-Regiment 28 der „Handschar“, in welchem auch das so genannte Albaner-Bataillon diente. ${ }^{549}$

\subsubsection{Imame innerhalb der Division}

Die Imame rekrutierten sich in erster Linie aus der Gruppe der Religionslehrer Bosniens. Oft hatten diese angehenden Armee-Imame in namhaften Universitäten in Kairo oder Alexandria Religion studiert. Sie wurden durch die UlemaMedžlis rekrutiert. ${ }^{550}$

Als Divisions-Imam der „Handschar“ wurde zuerst Abdulah Muhasilović eingesetzt. Husein Đozo löste ihn Ende 1944 ab. Bernwald widmet den Imamen seiner ehemaligen Division in seinen Memoiren ein ganzes Kapitel. ${ }^{551} \mathrm{Ob}$ wohl er als „Volksdeutscher“ nicht dem muslimischen Glauben angehörte, widerspiegeln seine Erinnerungen die Relevanz, welche die Imame für die gesamte Division besaßen. Als Beweggründe, weshalb sich die jungen Religionsstudenten

546 Vgl. ebd., Bl. 48.

547 Vgl. ebd. Bl. 44.

548 Vernehmungsprotokoll Matheis, Franje, Office of Chief of Council for War Crimes Translation of Document No. NO-4951, Landeskommission der Feststellung der Verbrechen der Okkupatoren und ihrer Helfershelfer, Inv. Nr. 35874, BArchF, Nachlass Vopersal, N 756/169a.

549 Vernehmungsprotokoll Matheis, Franje, Office of Chief of Council for War Crimes Translation of Document No. NO-4951, Landeskommission der Feststellung der Verbrechen der Okkupatoren und ihrer Helfershelfer, Inv. Nr. 35874, BArchF, Nachlass Vopersal, N 756/169a. Vgl. auch Verhörprotokoll Matheis, 4.10.1945, AJ 110/60552 und Vernehmung Matheis, 6.3.1947, AJ 110/ 60552.

550 Vgl. Lepre, Himmler's Bosnian Division, S. $71 \mathrm{f}$.

551 Vgl. Bernwald, Muslime in der Waffen-SS, S. 71-86. 
für den Dienst in der „Handschar“ rekrutieren ließen, gibt Bernwald an, dass sie oft selbst Zeuge von Massakern an der muslimischen Bevölkerung in Bosnien geworden wären. Da sie mehrheitlich aus Ostbosnien stammten, hätten sie „den Mord an ihren Landsleuten hautnah erlebt“. ${ }^{552}$

Namentlich erwähnt werden folgende Imame der Division „Handschar“: 553

\begin{tabular}{ll}
\hline Abdulah Muhasilović & Selejman Alinajstrović \\
Husejin Đozo & Muhamed Mujakić \\
Haris Krkut & Halim Malkoć \\
Džemal Ibrahimović & Kasim Mašić \\
Hasan Bajraktarević & Hasim Torlić \\
Salih Šabanović & Osman Delić \\
Fikret Mehmedagić & \\
\hline
\end{tabular}

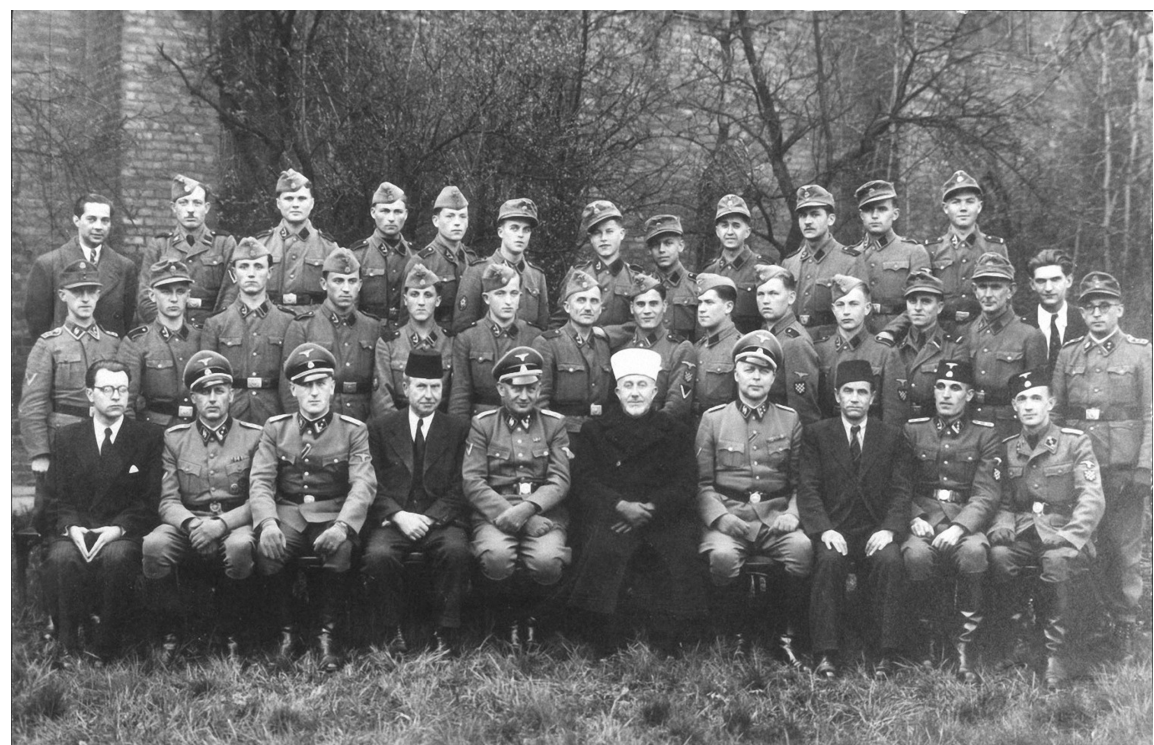

Abb. 23: Imamen-Lehrgang in Guben. ${ }^{554}$

552 Vgl. ebd., S. 71.

553 Vgl. Lepre, Himmler's Bosnian Division, S. 73.

554 Vgl. Bernwald, Muslime in der Waffen-SS, S. 85. Vgl. auch Lepre, Himmler's Bosnian Division, S. 73. 


\subsubsection{Truppe}

Obwohl Himmler sich dafür eingesetzt hatte, dass sich die Division nur aus muslimischen Freiwilligen rekrutieren sollte, ${ }^{555}$ wurden schließlich sowohl Muslime als auch Katholiken, vor allem aus Bosnien-Herzegowina, in die „Handschar“ aufgenommen. ${ }^{556}$ Denn die kroatische Regierung hatte sich gegenüber einer rein muslimischen Division ablehnend geäußert. ${ }^{557}$ Auf Mannschaftsebene wies die Division schließlich einen Anteil von über 90 Prozent Muslimen auf. ${ }^{558}$ Den Soldaten wurde, wie bereits erwähnt, freie Religionsausübung zugesagt, und die Vorgesetzten sollten darauf bedacht sein, die ,notwendige Rücksicht auf die besonderen Gewohnheiten der Mohammedaner“ zu nehmen. ${ }^{559}$

Neben bosnischen Muslimen waren 2.800 kroatische Katholiken und rund 4.000 Albaner, die meisten davon Muslime, aber auch einige albanische Katholiken, in der Division eingesetzt. ${ }^{560}$ Einblicke in die Zusammensetzung des Verbandes und wie unterschiedlich sie Divisionsangehörige wahrnahmen, zeigen folgende Beispiele. Erich Plappert sprach bei seiner Vernehmung am 9. Januar 1964 von einer Division mit rund 27.000 Mann, von welchen rund 24-25.000 „fremdländische, nämlich bosniakische Muselmanen waren. Ein einziges Bataillon der Division setzte sich allerdings aus Albanern zusammen. “561 Günter Borkowsky hingegen beschrieb bei seiner Vernehmung die Zusammensetzung der „Handschar“ differenzierter: „Diese Division setzte sich überwiegend aus Volksdeutschen, Bosniaken, Slowenen, Albanern, Muselmanen [gemeint sind hier Muslime aus weiteren Staaten] usw. zusammen. “562 Auch Erich Schäfer sagte aus,

555 Vgl. Jüttner an Sonderverteiler/70 Ausfertigungen, betr. „Aufstellung der Kroatischen SSFreiwilligen-Division“, 30.4.1943, BArchB, NS19/3523, Bl. 34.

556 Vgl. Lepre, Himmler's Bosnian Division, S. 23. Vgl. auch Casagrande, Volksdeutsche SS-Division, S. 331.

557 Vgl. Lepre, Himmler's Bosnian Division, S. 23.

558 Vgl. Sauberzweig an Berger, Schreiben „Betreff: 3. Reichsstraßensammlung für das WHW am 20. und 21.11.43“, 5.11.1943, BArchB, NS 19/2601, Bl. 153.

559 Botschafter Ritter an Gesandtschaft Agram, 21.2.1943, PAAA, Inland IIg R100998, H297632f. 560 Vgl. Neubacher an AA, 25.9.1943, PAAA, R100998.

561 Vgl. Fall Günter Borkowsky, Aussage Erich Plappert, 9.1.1964, USHMM, BArchL, B162/ 20812, Bl. 58. Vgl. die hiervon abweichenden Zahlen in den untenstehenden Tabellen mit einer Sollstärke von knapp 22.000 Mann.

562 Vgl. Fall Günter Borkowsky, Aussage Günter Borkowsky, 26.8.1963, USHMM, BArchL, B162/20812, Bl. 6. 
dass sich die „Handschar“ zu einem großen Teil aus „Bosniaken, Kroaten, Serben, Muselmanen, Albanern und anderen“ zusammengesetzt hätte. ${ }^{563}$

Als Kommandosprache wurde Deutsch festgelegt, als Ausbildungs- und Umgangssprache sollte aber Kroatisch bzw. Bosnisch gesprochen werden. ${ }^{564}$ Auch die Divisionszeitschrift „Handžar“ erschien zweisprachig in Deutsch und Bosnisch. ${ }^{565}$ Als Übersetzer dienten einerseits „Volksdeutsche“ wie Bernwald, oder aber ältere Bosniaken, die bereits in der österreichisch-ungarischen Armee gedient hatten. ${ }^{566}$ Der Bezug zu den österreichisch-ungarischen Bosniaken-Regimentern

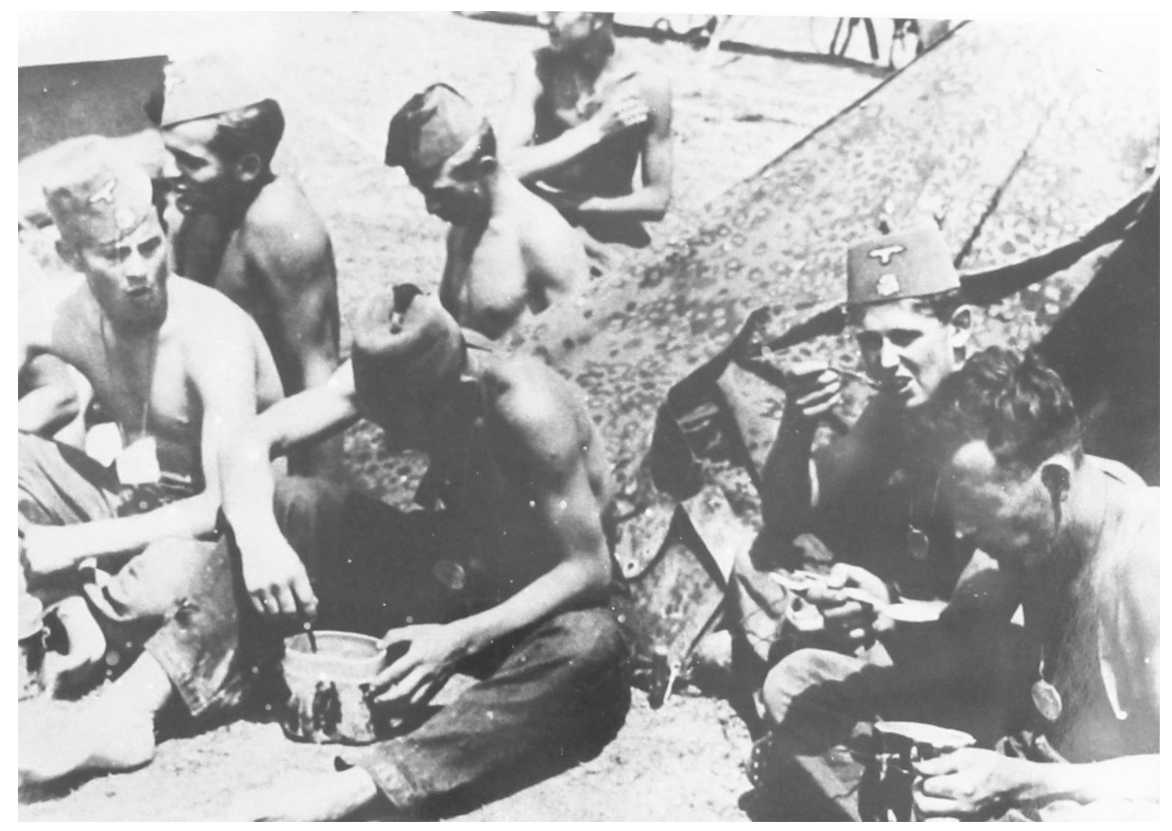

Abb. 24: Bildunterschrift „Nach anstrengendem Dienst unter fröhlichen Kameraden schmeckt den SS-Freiwilligen das Mitagessen noch einmal so gut.“567

563 Vgl. ebd., Bl. 69.

564 Vgl. Jüttner an Sonderverteiler/70 Ausfertigungen, betr. „Aufstellung der Kroatischen SSFreiwilligen-Division“, 30.4.1943, BArchB, NS19/3523, Bl. 35.

565 Vgl. zahlreiche Abdrucke der Divisionszeitung in: Bernwald, Muslime in der Waffen-SS, S. 329-412.

566 Bernwald war zuerst Dolmetscher bei der Wehrmacht und wurde im Herbst 1942 von der Waffen-SS wie andere seiner Klasse am Gymnasium geworben. Er besuchte von März bis April 1943 eine Dolmetscherschule der Waffen-SS in Oranienburg. Vgl. Bernwald, Muslime in der Waffen-SS, S. 34, 36, 43f. Lepre, Himmler's Bosnian Division, S. 61.

567 BArchF, Nachlass Vopersal, N756 168a. 
war auf verschiedenen Ebenen sichtbar, so etwa, wie bereits gezeigt, bei der Zusicherung der „alten Rechte“, darunter die freie Religionsausübung, wie sie die bosnischen Soldaten in der k.u.k.-Armee genossen hatten. Am deutlichsten kommt dieser Rückbezug zum Vorschein, wenn man Biographien älterer Soldaten und Vorgesetzter betrachtet, die als Bosnier, Kroaten, „Volksdeutsche“ oder Österreicher (seit 1938 deutsche Staatsbürger) bereits im Ersten Weltkrieg in der habsburgischen Armee gedient hatten. Dieser enge Bezug zur k.u.k.-Zeit zeigt sich auch in den Worten Himmlers: „In diesem Jahr [1944] wird die Division die Probe ihrer Bewährung ablegen und ich bin überzeugt, sie wird diese Prüfung in bedingungsloser Treue zu unserem großen Führer Adolf Hitler ebenso ruhmreich bestehen wie die Väter der heutigen Generation sie in langen Kriegsjahren bestanden.“568

\subsubsection{Zusammenarbeit mit Hilfstruppen}

Bereits vor den anlaufenden Rekrutierungen hatten die Deutschen mit der Legion „Hadžiefendićc“ und anderen ähnlichen Milizen zusammengearbeitet. Als die Rekrutierungen für die „Handschar“ anliefen, gingen große Teile dieser Legion darin auf. ${ }^{569}$ Weitere Zusammenarbeit mit unterschiedlichsten Gruppierungen ist belegt: Da die „Handschar“ in Ostbosnien zwar die Zentren zumindest zeitweise zu kontrollieren vermochte, aber nicht in der Lage war, auch sämtliche ländlichen Gebiete zu kontrollieren, war die Division auf Hilfstruppen angewiesen. Diese setzten sich einerseits aus Einheiten der muslimischen „Grünen Kader“, benannt nach den Deserteuren der k.u.k.-Armee im Ersten Weltkrieg, zusammen, andererseits teilweise aber auch aus serbischen Četnik-Einheiten, was nicht ohne Spannungen blieb. ${ }^{570}$

\subsubsection{Gliederung und Unterstellung}

Einblicke in die Gliederung und Aufstellung der Division „Handschar“ geben neben einschlägigen Werken wie Tessins Publikationen zu Verbänden von Wehr-

568 Himmler an Sauberzweig, 26.12.1943, BArchB, NS19/2601, Bl. 52.

569 Vgl. Notiz Kommandeur SS-Freiw.Geb.Div. „Prinz Eugen“ von Oberkamp, Ia Tgb.Nr. 196/ 43 g Kdos., BArchB, NS19/3504, Bl. 34.

570 Vgl. Redzić, Bosnia and Herzegovina, S. 187. Vgl. auch Bougarel, Korb, Petke, Zaugg, Muslim SS Units, S. 261. 
macht und Waffen-SS auch Kriegsgefangenenberichte wie etwa der „Bericht über die 13. SS Division ,Handschar‘, ihre Aufstellung, Gliederung“ von Walter Eipel oder ein ähnlicher Bericht von Alfred Schrader. ${ }^{571}$

\subsubsection{Aufbaustab in Zagreb}

SS-Standartenführer Obwurzer leitete den in Zagreb (Agram) im Frühjahr 1943 eingerichteten Aufbaustab. Als Ia war SS-Hauptsturmführer (später Sturmbannführer) Erich Braun eingesetzt, der zwei Mitarbeiter, SS-Hauptsturmführer Emil [?] Kuhler und SS-Untersturmführer Herbert Schack, hatte. IIa war SS-Hauptsturmführer Götz Berens von Rautenfeld. Ib wurde erst nach dem Eintreffen des planmäßigen Dienststellenleiters, SS-Hauptsturmführer Karl Liecke, durch SSUntersturmführer Herbert Richter besetzt, während IIb zunächst vakant blieb. Das Divisionskriegsgericht (III) blieb vorerst ebenfalls unbesetzt. Als Divisionsintendant (IVa) waren SS-Hauptsturmführer Johann [?] Küster und dessen Vertreter SS-Hauptsturmführer Lange im Einsatz. Divisionsingenieur (V) war SS-Hauptsturmführer Heinrich [?] Christiansen. Auch die Stelle „Weltanschauliche Schulung“ (VI) wurde vorerst nicht besetzt. ${ }^{572}$ Der Aufbaustab stand von Anfang an in engem Kontakt zum Ersatzkommando Südost, welches Kammerhofer unterstellt war. SS-Obersturmbannführer Hauser, späterer Bataillonskommandeur in der Division „Skanderbeg“, leitete das Ersatzkommando Südost und erhielt Weisungen aus der Hauptstelle Wien (Glovietgasse). Diese wiederum stand in direktem Kontakt zum SS-Führungshauptamt. ${ }^{573}$

\subsubsection{Verbindungsstab in Zagreb}

Der Verbindungsstab wurde Mitte Juli 1943 in Zagreb aufgebaut. Mit dem Aufbau betraute Obwurzer Eipel, der von fünf größeren Aufgabenfeldern berichtete, mit welchen sich der Verbindungsstab zu befassen hatte. Er war zuständig für

a) Wahrnehmung der Interessen der Freiwilligen und ihrer Angehörigen in Zusammenarbeit mit der Fürsorgestelle Kroatien.

571 Vgl. Tessin, Verbände, Bd. 3, S. 283-285. Vgl. Kriegsgefangenenbericht „Bericht über die 13. SS Division ,Handschar‘, ihre Aufstellung, Gliederung“, Walter Eipel, 14.11.1947, VA, HEM.OK. BOJCKA, 72-A/1-a/32. Vgl. hierzu beide Kriegsgefangenenberichte, Alfred Schrader, 31.10.1947, VA HEM.OK.BOJCKA, 72A/1/34 (handschriftlich) und 72A/1a/34 (mit Schreibmaschine abgetippt).

572 Vgl. Kriegsgefangenenbericht „Bericht über die 13. SS Division ,Handschar‘, ihre Aufstellung, Gliederung“, Walter Eipel, 14.11.1947, VA, HEM.OK.BOJCKA, 72-A/1-a/32.

573 Ebd., S.1f. 
b) Aufrechterhaltung der Verbindung zum Ersatzkommando Südost, Agram, wegen der Erfassung Freiwilliger unter Innehaltung über den Höh. SS. u. Polizeiführer sowie

c) Aufrechterhaltung der Verbindung zum Kroat. Kriegsministerium - Deutsche Abteilung - und Erfassung der volksdeutschen Teile unter Einhaltung der Erfassungsstelle beim Ersatzkommando Südost Agram.

d) Überwachung der Auffanglager hinsichtlich der Durchführung der Befehle der Division; zugleich Zusammenarbeit mit diesen Lagern.

e) Durchführung geschlossener Sammeltransporte aus den Lagern nach dem Tr[uppen]üb[ungs]platz Wildflecken (Rhoen) nach Maßgabe der Transportbestimmungen der Transport-Kommandantur Agram. [...]. ${ }^{574}$

\subsubsection{Gliederung}

Die Nähe zur Division „Prinz Eugen“ wird bereits in der Aufbauphase deutlich: Innerhalb der „Handschar“ war dieselbe Gliederung vorgesehen wie bei der „Prinz Eugen“. ${ }^{575}$ Himmler plante, beide südosteuropäischen Divisionen, die „Prinz Eugen“ und die neue „muselmanische Bosniaken-Division“ in ein von Phleps kommandiertes Armeekorps, schließlich V. SS Freiwilligen-Gebirgskorps genannt, $\mathrm{zu}$ integrieren. ${ }^{576}$

Waffen-Gebirgs-Jäger-Regiment der SS $27^{577}$

Waffen-Gebirgs-Jäger-Regiment der SS $28^{578}$

SS-Waffen-Artillerie-Regiment 13

SS-Gebirgs-Panzerjäger-Abteilung 13

Kroatische SS-Panzer-Abteilung

Kroatisches SS-Kradschützen-Bataillon

574 Ebd., S. 3 f.

575 Vgl. Funkspruch Himmler an Phleps, 13.2.1943, BArchB NS19/2601. Vgl auch Phleps an Himmler, BArchB, NS19/3523, Bl. 39.

576 Vgl. Himmler an SS-Führungshauptamt, SS-Personalhauptamt, SS-Hauptamt, SS-Gruppenführer Phleps und SS-Brigadeführer von Oberkamp, 31.3.1943, BArchB NS19/2601, Bl. 6.

577 Zuerst als kroat. Nr. 1 bezeichnet.

578 Zuerst als kroat. Nr. 2 bezeichnet. 
(fortgesetzt)

\begin{tabular}{ll}
\hline Kroatische SS-Kavallerie-Abteilung \\
\hline & Kroatisches SS-Radfahr-Bataillon \\
\hline SS-Gebirgs-Aufklärungs-Abteilung 13 \\
\hline SS-Panzer-Aufklärungszug \\
\hline SS-Gebirgs-Pionier-Bataillon 13 \\
\hline SS-Flak-Abteilung 13 \\
\hline SS-Gebirgs-Nachrichten-Abteilung 13 \\
\hline SS-Divisions-Nachschubführer 13 \\
\hline SS-Gebirgs-Panzerjäger-Abteilung 13 \\
\hline SS-Divisions-Nachschubtruppen \\
\hline SS-Verwaltungs-Bataillon 13 \\
\hline SS-Wirtschafts-Bataillon 13 \\
\hline SS-Sanitätsabteilung 13 \\
SS-Gebirgs-Veterinär-Kompanie 13
\end{tabular}

Eipel gab in Kriegsgefangenschaft aus dem Gedächtnis folgende Aufstellung und jeweilige Ist-Stärken zu Protokoll:

Kommandeur der Division: SS-Brigadeführer und Generalmajor der Waffen-SS Karl-Gustav Sauberzweig,

Ia: SS-Sturmbannführer Erich Braun; Gehilfe: SS-Hauptsturmführer Hans Lösch Ib (Qu): SS-Hauptsturmführer Karl Liecke, Gehilfe: SS-Untersturmführer Herbert Richter

Zuständig für Waffen und Munition: SS-Hauptsturmführer Waldemar Könnemann Ic: SS-Hauptsturmführer Karl Rachor; Gehilfe: SS-Obersturmführer Artur Fiechtner O1: SS-Hauptsturmführer Heinrich Brichze

IIa: SS-Sturmbannführer Götz Berens von Rautenfeld

IIb: SS-Obersturmführer Alexander Egersdorfer

III: SS-Hauptsturmführer Franz von Kocevar

IVa: SS-Sturmbannführer Otto Küster; Mitarbeiter: SS-Hauptsturmführer Wilhelm Langer

579 Tessin gibt eine abweichende Gliederung an: Vgl. Tessin, Verbände, Bd. 3, S. 283. 
IVb: SS-Sturmbannführer Dr. Otto Kloes

IVc: SS-Sturmbannführer Dr. Hans Voigt

Vmot: SS-Sturmbannführer Heinrich Christiansen

VI: SS-Obersturmführer Heinrich Gaese

Kommandant Divisionsstabsquartier: SS-Obersturmführer Friedrich Recknagel ${ }^{580}$

\begin{tabular}{|c|c|c|c|}
\hline Anzahl & Regiment/Abteilung & $\begin{array}{l}\text { Ungefähre } \\
\text { Stärke }\end{array}$ & Kommandeur \\
\hline \multirow[t]{2}{*}{2} & $\begin{array}{l}\text { Geb.Jäg.Rgt. mit je } 3 \mathrm{Btl} . \mathrm{Zu} \\
\text { 4-5 Kp. }\end{array}$ & 7.600 Mann & $\begin{array}{l}\text { Rgt. } 27 \text { SS-Ostubaf. Desiderius } \\
\text { Hampel }\end{array}$ \\
\hline & & & $\begin{array}{l}\text { Rgt. } 28 \text { SS-Ostubaf. Helmuth } \\
\text { Raithel }\end{array}$ \\
\hline 1 & Art.Rgt. mit 4 Abt. zu 9 Battr. & 2.000 Mann & SS-Ostubaf. Ernst Schmedding \\
\hline 1 & Aufklär. Abt. & 2.500 Mann & $\begin{array}{l}\text { SS-Hstf. (später Stubaf) Emil } \\
\text { Kuhler }\end{array}$ \\
\hline 1 & Panzerjäg. Abt. & 1.000 Mann & SS-Hstf. Gerhard Dierich \\
\hline 1 & Div.Nachr.Abt. & 600 Mann & SS-Stubaf. Hans Hanke \\
\hline 1 & Pion.Abt. & 1.200 Mann & SS-Stubaf. Heinz Knoll \\
\hline 1 & Flak-Abt. & 800 Mann & unbekannt \\
\hline 1 & Wirtschafts-Btl. & 400 Mann & SS-Stubaf. Otto Küster \\
\hline 1 & $\begin{array}{l}\text { Sanitätsabt. Mit } 3 \text { Kp. und Entl. } \\
\text { Zug }\end{array}$ & 600 Mann & unbekannt \\
\hline 1 & Veterinär-Kp. & 500 Mann & unbekannt \\
\hline 1 & Pferdelazarett & 100 Mann & unbekannt \\
\hline 1 & Divisionsnachschub & 1.000 Mann & SS-Stubaf. Albert Faßbender \\
\hline 1 & Feldgendarmerie & 100 Mann & unbekannt \\
\hline 1 & Stabskp.Feldpost, Div.Stb. & 600 Mann & unbekannt $^{581}$ \\
\hline
\end{tabular}

$\overline{580}$ Vgl. Kriegsgefangenenbericht „Bericht über die 13. SS Division ,Handschar‘, ihre Aufstellung, Gliederung“, Walter Eipel, 14.11.1947, VA, HEM.OK.BOJCKA, 72-A/1-a/32, S. 4 f. Vgl. dazu auch Gliederung bei Tessin, Verbände, Bd. 3, S.

581 Ebd., S. 5. 


\subsubsection{Stärke}

In oben aufgeführter Aufzeichnung ging Eipel von einer Ist-Gesamtstärke von etwa 19.000 Mann aus, ${ }^{582}$ was in etwa den Angaben bei Lepre entspricht. Diese nahm im Laufe des Jahres 1944 stetig ab. Für den Februar 1944 gibt Lepre eine Gesamtstärke von 18.563 Mann bei einem Soll von 18.697 Mann an, davon 377 Führer und 2.078 Unterführer. Die Verteilung auf die einzelnen Einheiten wird in folgender Grafik deutlich. ${ }^{583}$

582 Vgl. Kriegsgefangenenbericht „Bericht über die 13. SS Division ,Handschar‘, ihre Aufstellung, Gliederung“, Walter Eipel, 14.11.1947, VA, HEM.OK.BOJCKA, 72-A/1-a/32, S. 5.

583 Lepre, Himmler's Bosnian Division, S. 138. 
Stand ros 15.2.194.

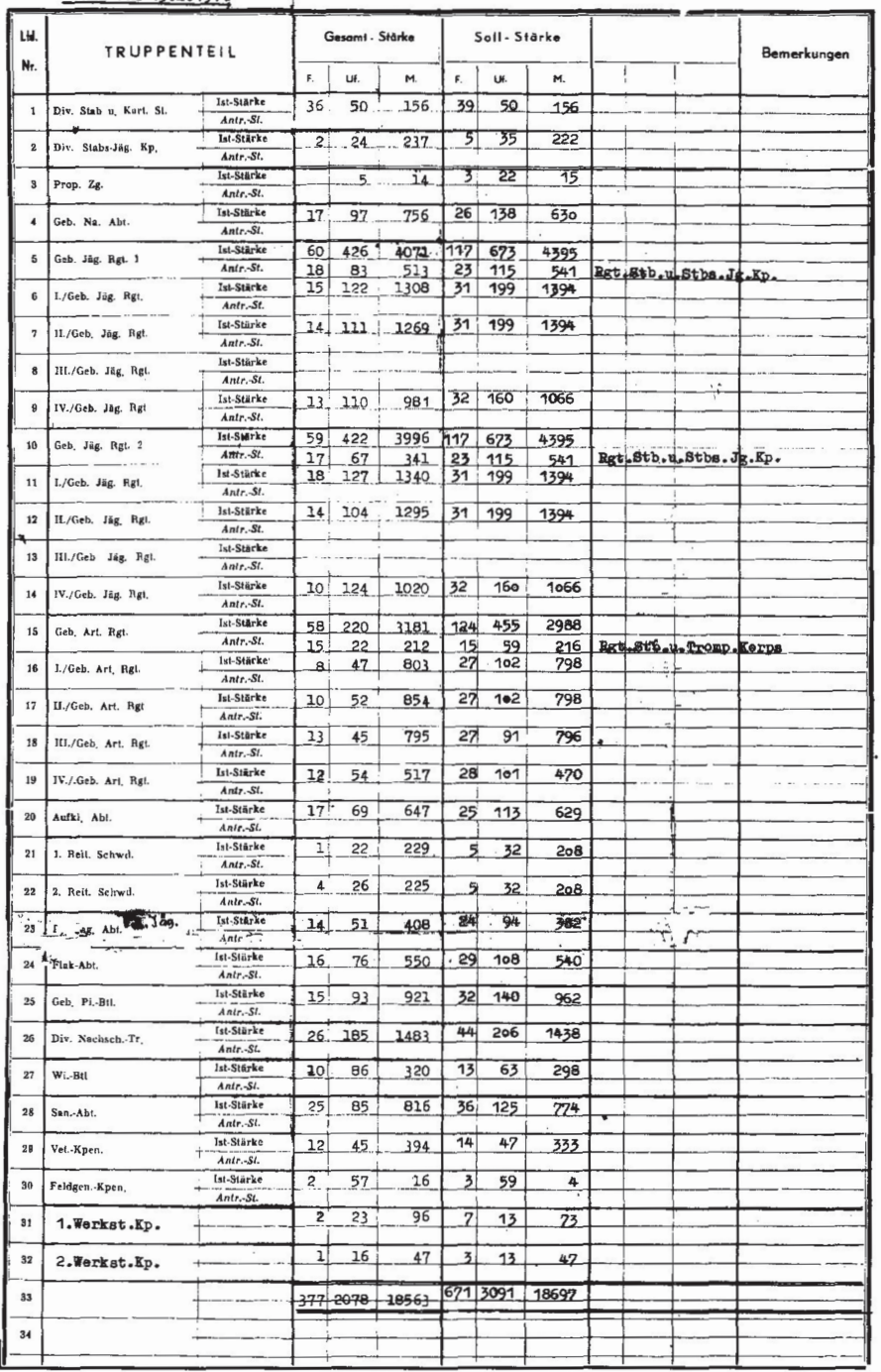

Division strength report dated 15 February 1944. Gesamt-Stärke = Total Strength, Soll-Stärke $=$ Prescribed Strength, F = Officers, Uf. $=$ NCOs, M. = enlisted men. The shortages of officers and NCOs are obvious.

Abb. 25: Divisionsstärke per 15. Februar 1944. 
Im April 1944 verzeichnete die „Handschar“ folgende Stärke: ${ }^{584}$

\begin{tabular}{llllll}
\hline & Führer & Unterführer & Mannschaften & Davon Hilfswillige & Gesamt \\
Soll & 658 & 3.006 & 17.968 & 2.087 & 21.632 \\
Ist (per 31.3.1944) & 400 & 2.262 & 18.396 & - & 21.058 \\
\hline
\end{tabular}

Am 5. September 1944 sahen die Zahlen schlechter aus: ${ }^{585}$

\begin{tabular}{llllll}
\hline & Führer & Unterführer & Mannschaften & Davon Hilfswillige & Gesamt \\
Soll & 491 & 2.737 & 15.811 & 2.782 & 19.039 \\
Ist (per 31.8.1944) & 335 & 1.818 & 16.829 & - & 18.982 \\
\hline
\end{tabular}

Die Zahlen vom 10. September 1944 zeigen einen Rückgang von 703 Mann innerhalb von fünf Tagen, was auf massive Erosionserscheinungen bzw. Massendesertionen hinweist: ${ }^{586}$

\begin{tabular}{llllll}
\hline & Führer & Unterführer & Mannschaften & Davon Hilfswillige & Gesamt \\
Soll & 514 & 2.737 & 15.811 & 2.782 & 19.062 \\
Ist (per 31.8.1944) & 344 & 1.924 & 16.002 & - & 18.279 \\
\hline
\end{tabular}

\subsection{Ausrüstung und Besoldung}

Ihre Ausrüstung sollten die frisch ausgehobenen „muselmanischen Bosniaken“ je nach Rekrutierungsort in den Barackenlagern der „Volksdeutschen Mittelstelle“

bei Zemun/Semlin, heute ein Stadtteil Belgrads, in Zagreb oder Osijek in Empfang nehmen, danach sollten die Rekruten möglichst rasch in die Garnisonen in Bosnien und Herzegowina verlegt werden. ${ }^{587}$ Da Zemun vom vorgesehenen Einsatzgebiet 150 Kilometer und mehr entfernt lag, beklagte sich Sauberzweig, dass „die Division sich alles selbst abholen muss und in dieser Ewigkeit wertvollste reichsdeutsche Unterführer beschäftigt werden, die in der Ausbildung besseren Dienst leisten würden. “588 Er schlug deshalb vor, kriegs-

584 Stärkemeldung „Handschar“, 17.4.1944, BArchB, NS19/1475, Bl. 6.

585 Stärkemeldung „Handschar“, 5.9.1944, BArchB, NS19/1475, Bl. 12.

586 Stärkemeldung „Handschar“, 10.9.1944, BArchB, NS19/1475, Bl. 18.

587 Vgl. Himmler an SS-Führungshauptamt, SS-Personalhauptamt, SS-Hauptamt, SS-Gruppenführer Phleps und SS-Brigadeführer von Oberkamp, 31.3.1943, BArchB NS19/2601, Bl. 7. Vgl. Kriegsgefangenenbericht „Bericht über die 13. SS Division, Handschar‘, ihre Aufstellung, Gliederung“, Walter Eipel, 14.11.1947, VA, HEM.OK.BOJCKA, 72-A/1-a/32, S. 2.

588 Sauberzweig an Berger, 30.9.1943, BArchB, NS19/2601, Bl. 27. 
versehrte Führer und Unterführer für die Beschaffung von Bewaffnung und Material einzusetzen, um sicherzustellen, dass die muslimische Division so rasch wie möglich einsatzfähig würde. Nach seinen Berechnungen würde er nach vollständiger Bewaffnung und Eintreffen des gesamten Ersatzes vier Monate benötigen, bis seine Division einsatzbereit wäre. Ende September 1943 schien ihm aber die Einsatzfähigkeit der Soldaten immer noch weit entfernt. ${ }^{589}$

Bereits Ende Februar 1943 ließ Botschafter Ritter gegenüber der Gesandtschaft in Zagreb verlauten, dass die Besoldung sowie Fürsorgeleistungen ebenso hoch angesetzt werden sollten wie bei „reichsdeutschem“ Personal. ${ }^{590}$ Jüttner passte diese Verordnung zwei Monate später an, indem er angab, dass die Besoldung, Versorgung und Fürsorge entsprechend den bereits existierenden, der Waffen-SS angegliederten SS-Freiwilligen-Legionen und den übrigen kroatischen Legionstruppen der Wehrmacht erfolgen sollte. ${ }^{591}$ Auch Walter Eipel gibt in Kriegsgefangenschaft zu Protokoll, dass der „Wehrsold“ ab sofort und „nach den mit der Fürsorgestelle Kroatien vereinbarten Wehrsoldsätzen“ bezahlt wurde. ${ }^{592}$ Grmek und Lambrichs hingegen erwähnen, dass die Besoldung dieselbe sein sollte, die auch „reichs-“ und „volksdeutsche“ Waffen-SS-Soldaten für ihren Dienst erhielten. ${ }^{593}$

Die Zuweisung von Waffen, Gerät und Bespannfahrzeugen (die Bezeichnung für Pferdewagen) sollte auf Sonderbefehl des SS-Führungshauptamtes, Abteilung Ib erfolgen. ${ }^{594}$ Auch die Zuteilung von Kraftfahrzeugen sollte auf Sonderbefehl des Führungshauptamtes Amt X erfolgen, dementsprechend von Pferden für die Bespannfahrezeuge durch das Amt VI. ${ }^{595}$

589 Vgl. ebd.

590 Vgl. Botschafter Ritter an Gesandtschaft in Agram, 21.02.1943, PAAA, Inland IIg, R100998, H297634. Dass die Familienunterstützung wichtig war, wird auch in den Aussagen Eipels ersichtlich. Die zuständige Fürsorgestelle war in der Savka Cesta 77 in Zagreb untergebracht. Vgl. Kriegsgefangenenbericht „Bericht über die 13. SS Division ,Handschar', ihre Aufstellung, Gliederung“, Walter Eipel, 14.11.1947, VA, HEM.OK.BOJCKA, 72-A/1-a/32, S. 3.

591 Vgl. Jüttner an Sonderverteiler/70 Ausfertigungen, betr. „Aufstellung der Kroatischen SSFreiwilligen-Division“, 30.4.1943, BArchB, NS19/3523, Bl. 35.

592 Kriegsgefangenenbericht „Bericht über die 13. SS Division ,Handschar“, ihre Aufstellung, Gliederung“, Walter Eipel, 14.11.1947, VA, HEM.OK.BOJCKA, 72-A/1-a/32, S. 3.

$593 \mathrm{Vgl}$. Grmek/Lambrichs, Les revoltés, S. 154.

594 Vgl. Jüttner an Sonderverteiler/70 Ausfertigungen, betr. „Aufstellung der Kroatischen SSFreiwilligen-Division“, 30.4.1943, BArchB, NS19/3523, Bl. 34.

595 Vgl. ebd., Bl. 35. 
Die Uniformierung entsprach derjenigen von bereits aufgestellten Gebirgsdivisionen. Da es sich aber um „fremdvölkische“ Einheiten handelte, wurden folgende Abweichungen angeordnet:

a) Abzeichen der Kragenspiegel wird noch befohlen. [Hier wurde schließlich der Krummdolch gewählt.]

b) Zum Dienstanzug wird ein feldgrauer Fez getragen.

c) Ein roter Fez steht als Parade- und Ausgehkopfbedeckung jedem Mann zu.

d) Den Führern ist das Tragen der Bergmütze zum Ausgehanzug gestattet.

e) SS-Angehörige [gemeint sind hier „germanische“ Soldaten, die als „ordensfähig“ galten] tragen auf der linken [sic!] Brustseite die Sigrunen. Jeder Mann der Division trägt am rechten Oberarm ein rot-weißes Abzeichen [die kroatische Flagge] nach dem von Reichsführer-SS genehmigten Muster. ${ }^{596}$

Alles in allem, so schreibt Petke, könne davon ausgegangen werden, dass die Ausstattung der Division mit Uniformen zumindest zum Zeitpunkt ihrer Aufstellung ausreichend gewesen sei. Die Versorgung mit Waffen, schwerem Gerät und Ausbildungspersonal hingegen wäre von Anfang an prekär gewesen. ${ }^{597}$ Die Ausrüstungsfrage schien umso wichtiger, als die Ausrüstung bei den bereits bestehenden Ostlegionen der Wehrmacht zu Missstimmungen geführt hatte. Die Soldaten der Ostlegionen waren oft mit sowjetischen Beutewaffen und geflickten deutschen und sowjetischen Uniformen ausgerüstet worden. Die Division „Handschar“ sollte nun der Waffen-SS als positives Gegenstück dienen. ${ }^{598}$ Durch die folkloreske Ausstattung und das kroatische Wappen am rechten Ärmel wollte Himmler visuell unterstreichen, dass „reichsdeutsche“ und „fremdvölkische“ Soldaten gemeinsam und vereint in dieser neuen Division kämpfen würden. ${ }^{599}$ In Wirklichkeit machten aber bereits die Sigrunen am Kragenspiegel auf das Gefälle innerhalb der Division aufmerksam: „Fremdvölkischen“ Verbänden war das Tragen der Sigrunen verboten. ${ }^{600}$ Eine weitere Unterscheidung schien Himmler ebenfalls wichtig, wie er dem Leiter des SS-Wirtschafts- und Verwaltungshauptamtes Oswald Pohl mitteilte:

Für die Albaner im Rahmen der Bosniaken-Division sind andere Mützen notwendig, und zwar Mützen in der weißen Art und Form, wie die beiliegenden. Ich bitte[,] dass die Bearbei-

596 Jüttner an Sonderverteiler/70 Ausfertigungen, betr. „Aufstellung der Kroatischen SS-Freiwilligen-Division“, 30.4.1943, BArchB, NS19/3523, Bl. 35. Die Sigrunen wurden am rechten Kragenspiegel getragen.

597 Vgl. Petke, Militärische Vergemeinschaftungsversuche, S. 253.

598 Ebd., S. 252.

599 Ebd., S. 253.

600 Vgl. Casagrande, Volksdeutsche SS-Division, S. 325. 
ter Ihres Hauptamtes sich mit der Division selbst an Ort und Stelle in Neuhammer in Verbindung setzen. Die Feze, die jetzt geliefert worden sind, sind nicht richtig. Sie haben die Farbe der Marokkaner-Feze, außerdem ist auch die Form die der Marokkaner[-]Feze. Die Feze müssen umgefärbt und etwas abgeschnitten werden. Ich bitte Sie, die Lieferung der nunmehr richtigen Feze und der neuen Albaner-Kopfbedeckungen [...] zu beschleunigen, denn diese Äußerlichkeiten bedeuten für die Festigung der Division ungeheuer viel. ${ }^{601}$

Die Kopfbedeckung zwischen Bosniaken und Albanern sollte sich seiner Meinung nach unterschieden, um die besondere Stellung der Albaner in dieser neu aufgestellten „muselmanischen Division“ $\mathrm{zu}$ unterstreichen. ${ }^{602}$

\subsection{Stationierung und Einsatzräume}

Ihren Schwerpunkt hatte die Division „Handschar“ in Ostbosnien. Nachdem sie im Frühjahr 1943 aus dem Ausland zurückkehrte, übernahm sie in diesem Gebiet de facto die Kontrolle. ${ }^{603}$ Die Division hielt die wichtigsten Städte wie auch einige strategische Punkte unter direkter Kontrolle und teilte sich die Macht mit lokalen kollaborierenden Stellen. In ländlichen Gebieten delegierte sie die Herrschaft an serbische Četniks und den muslimischen „Grünen Kader“. ${ }^{604}$ Kasche empörte sich am 26. Juli 1944: „Die Division hat einen hoch-politischen Schritt unternommen, den engeren Raum Brčko-Tuzla-Bijeljina unter eigene Sonderverwaltung unter völliger Nichtanerkennung der kroatischen Gegebenheiten zu nehmen. “605 Obwohl die kroatische Regierung mit diesem Vorgehen nicht einverstanden war und der Poglavnik und weitere Regierungsvertreter sich bei einer Besprechung vom 13. August 1944 mit Berger, Glaise-Horstenau und Kammerhofer beschwerten, konnten sie wenig ausrichten. ${ }^{606}$

Versuche der Division, neben der militärischen auch die wirtschaftliche Kontrolle über die Region zu übernehmen und die landwirtschaftlichen Erträge der Region zu steigern, scheiterten ${ }^{607}$, obwohl, wie Eipel betont, den „kroatischen

601 Schreiben Himmlers an Oswald Pohl, Leiter des SS-Wirtschafts- und Verwaltungshauptamtes (SS-WVHA), 26.11.1943, BArchB, NS 19/2601, Bl. 44.

602 Vgl. ebd.

603 Vgl. Petke, Militärische Vergemeinschaftungsversuche, S. 251. Vgl. auch Birn, Höhere SSund Polizeiführer, S. 272.

604 Vgl. Redzić, Bosnia and Herzegovina, S. 187. Vgl. auch Bougarel, Korb, Petke, Zaugg, Muslim SS Units, S. 261.

605 Vgl. Kasche an AA, 26.7.1944, PAAA, Inland IIg/R 100998.

606 Vgl. Voelckers an Kasche, 14.8.1944, PAAA, Inland IIg/R 100998.

607 Vgl. u. a. Zeugenaussagen von Ibrahim Muminović, Asim Bajramović and Alaga Čoralić in AJ, Collection DKUZ, box 544, file 5540. 
[bosnischen] und ,volksdeutschen` Bauern kostenlos ganztägig - aber auch wöchentlich - je nach Größe der [zu] bestellenden Äcker, Gespanne sowie Mannschaften zur Frühjahrbestellung zur Verfügung “ gestellt wurden. ${ }^{608}$ Die Futterlage für Tiere war in diesem Gebiet zeitweise so schlecht, dass ein großer Teil der Pferde der Division in den rückwärtigen Raum Mitrovica-Priština/ Prishtina-Uroševac verlegt werden musste. ${ }^{609}$

Stationierung einzelner Truppenteile der Division „Handschar“610

\begin{tabular}{ll}
\hline Divisionsstab & Vinkovci \\
\hline Rgt. 27 (Stab) & Šid \\
\hline I/27 & Kukujevci \\
\hline II/27 & Mlasica \\
\hline III/27 & Adaševci \\
\hline Rgt. 28 (Stab) & Taradišt \\
\hline I/28 & Županja \\
II/28 & Gocovci \\
\hline III/28 & Cerna \\
\hline SS-Geb.Art.Rgt. 13 (Stab) & Vinkovci \\
\hline I/AR 13 & Tovarnik \\
\hline II/AR 13 & Županja \\
\hline III/AR 13 & Taradišt \\
\hline IV/AR 13 & Orolik \\
\hline
\end{tabular}

608 Kriegsgefangenenbericht „Bericht über die 13. SS Division ,Handschar‘, ihre Aufstellung, Gliederung“, Walter Eipel, 14.11.1947, VA, HEM.OK.BOJCKA, 72-A/1-a/32, S. 9.

609 Kriegstagebuch Nr. 3, 181. Inf.Div. Abt. Ia, 1.11.1943-31.12.1943, Generalleutnant und Div. Kdr. (unterzeichnet am: 10.12.1943), Kriegstagebuch geführt durch Oblt. Lösche, 30.11.1943, BArchF RH26-181/30, S. 12.

610 Vgl. Lepre, Himmler's Bosnian Division, S. 142. Vgl. hierzu auch Michaelis, Gebirgs-Divisionen der Waffen-SS, S. 119. Viele dieser Orte gehören heute zu Kroatien oder Serbien und liegen im bosnich-kroatisch-serbischen Grenzgebiet. 
(fortgesetzt)

\begin{tabular}{lc}
\hline SS-Aufkl.Abt. 13 & Bojagaci \\
\hline SS-Nachr.Abt. 13 & Jarmina \\
\hline SS-Geb.Pionier Bt. 13 & Barcinci \\
\hline SS-Veterinär Dienste & Novo Selo \\
\hline SS-Dinatru 13 & Vinkovci \\
\hline SS-Wirtschaft Bt. 13 & Vinkovci \\
\hline SS-Flak Abt. 13 & Vinkovci \\
\hline SS-Panzerjäger Abt. 13 & Jankovci \\
\hline
\end{tabular}

Schrader gibt weitere Auskünfte: Die Mannschaften seien zuerst nach Brčko gebracht worden, das I. Bataillon seines Regiments nach Sremska Mitrovica, II. nach Čelić, das IV. Bataillon nach Koraj. Er widerspricht den oben gemachten Angaben bei Lepre und gibt an, der Regimentsstab hätte in Čelić sein Quartier aufgeschlagen ${ }^{611}$ Auch Eipel erwähnt neben Brčko und Čelić auch Vinkovci sowie die Ortskommandantur Gunja, der er zugeteilt war. ${ }^{612}$

Anfang September 1944 wurde die Division nach schweren Verlusten zur Auffrischung in den Raum Vukovice-Osmaci-Srebrenica verlegt. Allerdings kämpften die deutschen Vorgesetzten mit rasant zunehmenden Massendesertionen: In dieser Zeit verließen über 2.000 Mann die „Handschar“. Aus diesem Grund sollten Soldaten aus der Division „Kama“, die nach kurzem und sehr eingeschränktem Bestehen wieder aufgelöst wurde, übernommen werden. ${ }^{613}$ Trotz dieser Auflösungserscheinungen dauerte der Fortbestand der „Handschar“ noch an: Ein Teil der verbliebenen Soldaten kam nach Zagreb und sollte dort zur Entlastung des LXIX. Armeekorps eingesetzt werden. Noch vor ihrem Abmarsch desertierten jedoch weitere 1.000 Mann. ${ }^{614}$

611 Vgl. Kriegsgefangenenbericht, Alfred Schrader, 31.10.1947, VA HEM.OK.BOJCKA, 72A/1a/ 34, S. 2. Vgl. auch Lepre, Himmler's Bosnian Division, S. 142.

612 Vgl. Kriegsgefangenenbericht „Bericht über die 13. SS Division ,Handschar‘, ihre Aufstellung, Gliederung“, Walter Eipel, 14.11.1947, VA, HEM.OK.BOJCKA, 72-A/1-a/32, S. 9.

613 Vgl. Michaelis, Gebirgs-Divisionen der Waffen-SS, S. 177.

614 Vgl. ebd., S. 128. 
Die Division hatte ihre schweren Waffen bereits an die 1. Gebirgs-Division abgegeben und zog sich, nur noch in Resten vorhanden, nach Apatin/Batina zurück. Bei Fünfkirchen (Pecs)/Batina sollten diese Reste als Kampfgruppe eingesetzt werden. Am 6. März 1945 nahm die Kampfgruppe an der Offensive „Frühlingserwachen“ teil, die aber bereits am 7. März aufgrund der Wetterverhältnisse stockte und schließlich zum Erliegen kam. ${ }^{615}$

\subsubsection{Aufgabenbereiche und Einsätze}

Nach ihrer Rückkehr aus Schlesien war die Division zwischen Februar 1944 und 1945 ausschließlich in Südosteuropa eingesetzt. ${ }^{616}$ In Ostbosnien wurde sie in erster Linie zur Bekämpfung der immer stärker werdenden Partisaneneinheiten verwendet. ${ }^{617}$ Dabei standen die Sicherung von Straßen und wehrwirtschaftlich relevanten Objekten wie Minen oder Fabriken im Zentrum, die bei Partisanen beliebte Sabotageziele darstellten. Ein weiteres Betätigungsfeld waren Aufbauund Bewachungsaufgaben in Konzentrations- bzw. Anhaltelagern. Allerdings unterstanden viele Lager in der Region der Kontrolle der Ustaša. ${ }^{618}$

Der Division oblag die Sicherung des Raumes zwischen den beiden Flüssen Bosut und Save, welches heute zu Serbien gehört. Doch auch in den Gebieten südlich davon wurde die „Handschar“ eingesetzt, etwa gegen Tito-Einheiten in Bijeljina, Koraj, im Raum Čelić, bei Rahić, Ratković und Mitrovica. Schließlich war die Division auch im Raum Janja im Einsatz, hier insbesondere bei der Sicherung des Bergbaugebietes von Ugljević. Danach kämpfte sie im Partisanenkrieg südostwärts Tuzla, in der Region Zvornik, bei Gornja und Derventa. ${ }^{619} \mathrm{Im}$ Frühjahr 1944 nahm die Division Janja und Ugljevik ein und war auch bei Pripoj eingesetzt. Von Ende April bis Mai kämpfte die Division „Handschar“ in der Majevica geschlossen gegen die von Tito in Nordostbosnien konzentrierten Kräfte. ${ }^{620}$

\footnotetext{
615 Vgl. ebd., S. 134.

616 Vgl. Kaltenegger, Totenkopf und Edelweiss, S. 63.

617 Vgl. Fall Günter Borkwosky USHMM, BArchL, B162/20812, Bl. 6.

618 Vgl. Marija Vulesica, Kroatien, in: Wolfgang Benz, Barbara Dister, Der Ort des Terrors. Geschichte der nationalsozialitischen Konzentrationslager, Bd. 9, München: C.H. Beck 2009, S. 314. 619 Vgl. Kaltenegger, Totenkopf und Edelweiss, S. 63.

620 Ebd., S. 63, 223.
} 


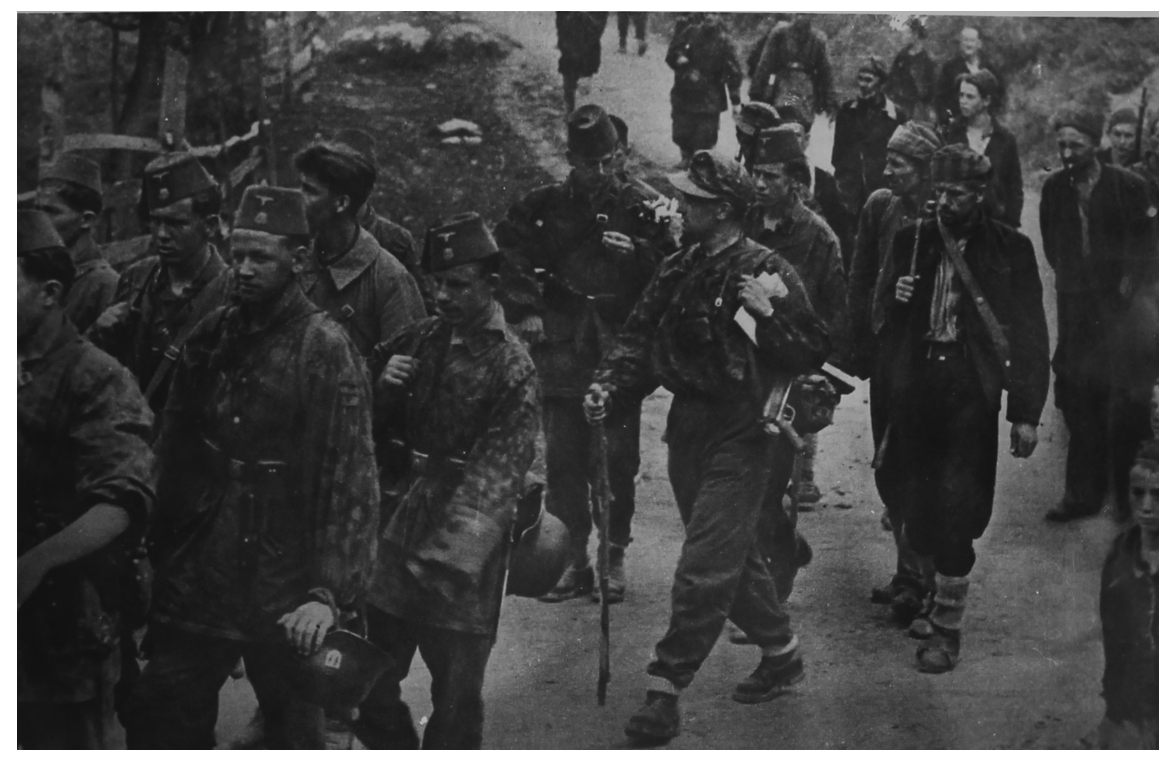

Abb. 26: Soldaten der „Handschar“ mit Hilfstruppen. ${ }^{621}$

\subsection{Kriegsverbrechen}

Obwohl die Rückkehr der Division nach Bosnien von den klerikalen und weltlichen bosnischen Eliten bereits bis Ende des Jahres gefordert worden war, ${ }^{622}$ kehrte sie erst im Februar 1944 dorthin zurück. Den Rückkehrern bot sich ein Bild des Grauens: In ihrer Abwesenheit waren zahlreiche bosniakische Dörfer von Ustaša und Četniks überfallen und geplündert und ihre Bewohner niedergemetzelt worden. Vieh weidete verlassen auf den Feldern. Selbst für Divisionskommandeur Sauberzweig scheinen die Bilder so erschütternd gewesen $\mathrm{zu}$ sein, dass er sie in seinen Berichten festhielt. ${ }^{623}$

621 Notiz Vopersals zum Bild: „Reproduktion eines Fotos aus der Sammlung Eyns/Brüssel“, BArchF, Nachlass Vopersal, N756 168a.

622 Vgl. Reisebericht SS-Hauptsturmführer Hasan Bajralitarović [Bajraktarevićc] an Phleps, 15.11.1943, BArchB, NS19/2601, Bl. 60.

623 Vgl. Divisionskommandeur Sauberzweig an Mannschaft der 13. SS-Division, Brief Nr. 8, 25.2.1944, BArchB, NS 19/2601, Bl. 210. Vgl. Nedim Salihbegovic, „Bericht zur Lage“, 25.9.1943, BArchB, NS 19/2601, Bl. 31. 


\subsubsection{Massaker, Vergewaltigungen und Plünderungen}

Die im Folgenden untersuchten Einsätze der „Handschar“ in Nord- und Nordostbosnien, die keinen Anspruch auf Vollständigkeit haben, waren dementsprechend geprägt von Rachegelüsten. ${ }^{624}$ Am brutalsten gingen die Soldaten der „Handschar“ gegen die - oft wehrlose - serbische Bevölkerung in diesen Gebieten vor. Sie begründeten ihr Verhalten damit, dass ihre eigenen Familien von serbischen Četniks umgebracht worden wären. ${ }^{625}$ Die genaue Zahl der Opfer ist bis heute nicht bekannt; auch die im Folgenden genannten Opferzahlen können nicht mit letzter Sicherheit verifiziert werden. Nachgewiesen werden kann aber eine Anzahl von Kriegsverbrechen, die von Angehörigen der „Handschar“ begangen wurden sowie Konzentrations- und Internierungslager („Anhaltelager“), an deren Aufbau und Überwachung sie beteiligt waren.

Auf ihre Rückkehr aus Schlesien im Februar 1944 folgte eine der ersten militärischen Aktionen der „Handschar“ in Westsyrmien, wo sie versuchte, die Partisanen aus der Region um Bosut zu vertreiben. Dabei begingen die Angehörigen der Division zahlreiche Massaker: In Sremska Rača ermordeten sie 360, in Bosut 160 und in Jamena 70 Zivilisten. Nach der Überquerung der Save im März/April 1944 stellte die „Handschar“ zwischen den Flüssen Drina, Spreča und Bosna in Ostbosnien einen „Befriedungsraum“ unter eigener Herrschaft auf. Es folgten weitere Massaker in diesem Gebiet: In Zabrđe waren es 260 Ermordete, in Lopare 220 und in Trnovo 70. Obwohl sich die „Handschar“ vor allem in dem von ihr kontrollierten Raum aufhielt, nahm sie auch an Einsätzen außerhalb teil, so etwa in Šekovići und Vlasenica. ${ }^{626}$ De facto hatte sie nämlich seit Frühjahr die Macht in Ostbosnien übernommen, wo sie unter anderem bei der Operation „Kugelblitz“ ein Blutbad anrichtete. ${ }^{627}$ Zahlreiche weitere Dörfer und Weiler werden in der Anklageschrift gegen Bormann, den ehemaligen Kommandeur des I. Bataillons des Regiments 28 vorgebracht. Seine Einheit soll in insgesamt 23 Ortschaften, teilweise bereits oben genannt, und in folgenden Dörfern und Weilern Massaker be-

624 Vgl. Casagrande, Volkdeutsche Division, S. 69.

625 Korb schreibt, dass sich die Einsätze der Ustaša und der Angehörigen von SS-Formationen in Südosteuropa gegen Zivilisten in Brutalität kaum unterschieden hätten. Vgl. Korb, Im Schatten des Weltkriegs, S. 116.

626 Vgl. u. a. Zeugenaussagen von Ibrahim Muminović, Asim Bajramović und Alaga Čoralić, AJ, Collection DKUZ, box 544, file 5540. Zum Hergang verschiedener hier genannter Massaker vgl. auch Anklageschrift gegen Bormann (Kdr. des Albaner-Btl.), 13.10.1947, AJ, fond 110, 25647/1810, S. 2-6.

627 Wolf Oschlies, Die 13. SS-Division Handschar in Bosnien und Herzegowina. Die Deutsche Armee und ihre Hilfstruppen auf dem Balkan 1941-1945, in: https://www.zukunft-braucht-erin nerung.de/die-13-ss-division-handschar-in-bosnien-und-herzegowina/ (Stand: 8.7.2019). 
gangen haben: Grk (15 Vergewaltigungsopfer, danach umgebracht), Batrovce (26 Opfer), Morovići (240 Opfer), Vršane (40 Opfer), Gornje, Donje, Srednje Dragaljevce (in diesen beiden Dörfern zusammen 55 Opfer) Čadjavice (einige Opfer), Srednjem Zabrdju (92 Opfer), Bačinci (17 Opfer), Berkasovo (170 Opfer), Ugljevik (7 Opfer), Tutnjevac (30 Opfer), Lopare, Jablanica, Mačkovca,Vukasvaca (in diesen vier insgesamt 218 Opfer). ${ }^{628}$ Weitere betroffene Dörfer waren Koraj (14 Opfer), Mirosavci, Ratkovići (27 Opfer), Donja Trnova (141 Opfer), Modran (ohne Angaben der Opferzahlen), Glogovac (ohne Angaben der Opferzahlen), Tobut (18 Opfer), Bukovica Donja (40 Opfer). ${ }^{629}$

In Nachkriegsprozessen wiesen angeklagte Offiziere der „Handschar“ die Verantwortung an in Bosnien begangenen Massakern oft von sich, indem sie betonten, dass die „wilden“ Muslime so ihrem „Wunsch nach Rache“ nachgekommen seien. Insbesondere das blutrünstige Vorgehen des albanischen Bataillons wurde dabei hervorgehoben. Allerdings hätten zahlreiche Dörfer, deren Bewohner massakriert wurden, in Austausch mit den Partisanen gestanden, und es habe sich dabei sowohl um serbische als auch muslimische Dörfer gehandelt. Aus heutiger Perspektive lässt sich schwer eruieren, welche Massaker befohlen und welche aus eigenem Antrieb begangen wurden. Feststellen lässt sich, dass Massaker vor allem im östlichen Europa ein integrativer Bestandteil der deutschen Kriegführung im Partisanenkampf waren. Einige Soldaten hatten bei Verhören vor jugoslawischen Gerichten ausgesagt, dass die Massaker auf Befehl deutscher Führer begangen worden waren und man ihnen bei Verweigerung des Befehls mit schweren Strafen (Körperstrafe bis Exekution) gedroht hätte. ${ }^{630}$ Wenn man das Verhalten von Wehrmacht und Waffen-SS im Partisanenkampf in

628 Vgl. zu Albanern auch Anklageschrift gegen Bormann (Kdr. des Albaner-Btl.), 13.10.1947, AJ, 110, kutja 25647, broj. 1810, S. 2-6.

629 Anklageschriften gegen SS-Hstuf. Ulisperger Ludwig, AJ, 110, broj 14041, SS-Oscha. Wiegel Fritz, AJ, 110, broj 23693, SS-Oscha. Wink Hans, AJ, 110, broj 23694, SS-Oscha. Winking Heinrich, AJ, 110, broj 23695, SS-Hstuf. Schinke Gerhard, AJ, 110, broj 23702, SS-Uscha. Schmidt Willi, AJ, 110, broj 23705, SS-Ostuf. Schreer Willi, AJ, 110, broj 23707, SS-Hscha. Schwerin Erwin, AJ, 110, broj 23708, SS-Oscha. Sentker Friedrich, AJ, 110, broj 23709, SSOscha. Srtansky Robert, AJ, 110, broj 23710, SS-Oscha. Tegtmeier Walter, AJ, 110, broj 23712, SSOscha. Guenther Walter, AJ, 110, broj 23714, SS-Uscha. Runge Harry, AJ, 110, broj 23731, SSUstuf. Weber Kurt, AJ, 110, broj 26391, SS-Ostuf. Schrader Alfred, AJ, 110, broj. 23706, SSUscha. Heinek Johann, AJ, 110, broj 25072, SS-Hstuf. Gunther Servaci, AJ, 110, broj 25634, SSHstuf. Weichsel, AJ, 110, broj 25637, SS-Ostuf. Wegemann Josip, AJ, 110, broj 25639, SS-Ustuf. Tot, AJ, 110, broj 25642, SS-Staf. Schmeding Ernst, AJ, 110, broj 26629, SS-Ustuf. Winkel, AJ, 110, broj 26634, SS-Oscha. Strattmann Heinz, AJ, 110, broj 23711.

630 Vgl., inter alia, Aussagen von Ibrahim Muminović, Asim Bajramović und Alaga Čoralić in AJ, 110, kutja 544, broj 5540. Zitiert nach Bougarel, Korb, Petke, Zaugg, Muslim SS Units, S. 265. 
anderen Gegenden Europas vergleicht, kann ein solches Vorgehen durchaus den Tatsachen entsprechen. Allerdings ist in gewissen Fällen Rache als Motiv ebenfalls glaubwürdig. Wesentlich erscheint hier, dass sowohl Offiziere als auch einfache Soldaten versucht haben, die Schuld an den Massakern auf andere Akteure zu schieben. So verwiesen, ähnlich wie ihre Vorgesetzten, zahlreiche angeklagte ehemalige bosnische „Handschar“-Angehörige auf die noch brutalere Vorgehensweise ihrer albanischen Kameraden in der Division. ${ }^{631}$ Es ist heute schwierig festzustellen, in welchem Maße diese Wahrnehmung durch kulturelle Vorurteile und individuelle Erfahrungen bedingt war, einen Ablenkungsversuch von eigenen Vergehen darstellte oder aber einen objektiven Blick wiedergab. ${ }^{632}$

Im Folgenden werden zur Verdeutlichung solcher Vorwürfe Auszüge aus dem Kriegsgefangenenprotokoll des Kommandeurs des Gebirgs-Jäger-Regiments 28 der Division „Handschar“, Franz (Franje) Matheis, einem „Volksdeutschen“ aus Sremska Mitrovica, wiedergegeben:

Im Regiment war auch ein Batl. von Schiftaren (Skipetaren) die aus Albanien und Kosovo stammten. Dieses Bataillon sollte als Kern zur Aufstellung einer albanischen Div. genannt ,Skenderbeg' [sic], dienen.

\section{$[\ldots]$}

Am 12. März 1944 begann der Vormarsch der Division aus der Umgebung von Vinkovci. Die Bewegung wurde in zwei Kolonnen durchgeführt. Eine Kolonne über Brčko auf Celik [sic], die zweite über Sremske Race [Sremska Rača] auf Bjeljina. Vorher aber wurde die ganze Div[ision] bei einer Säuberungsaktion um Morovice [Morović] in Srem verwendet, wo im Rahmen dieser Aktion durch die Zerstörung des Staudammes der Bosut dieses ganze Gebiet überschwemmt wurde. Es wurde angenommen, dass sich hier eine Base der NOV (Volksbefreiungs-Armee) befindet, von wo aus die Truppen auf Rajevica bis Tuzla verteilt werden. In dieser Aktion hat das Schiftaren Bataillon unglaubliche Greueltaten [sic] ausgeführt. In Srem. Raca [Sremska Rača] wurde jede angetroffene Person umgebracht. Auf ihrem Marsch haben diese Menschen jeden geschlachtet, den sie angetroffen haben und der keinen „Fes“ trug. Es gab Fälle, dass der Offizier, der sich an der Spitze der Kolonne befand, im Feld arbeitende Menschen sah. Als er sich später wieder nach ihnen umschaute, konnte er sehen, dass sich diese friedlich arbeitenden Menschen nicht mehr am Leben befanden. Die Schiftari (Skipatari) sind[,] als sie jene bemerkten[,] einfach aus der Reihe getreten und haben sie abgeschlachtet. Was wir den Soldaten gelegentlich [in] ihrer Schulzeit in Deutschland besonders unterstrichen - man muss unter das bis jetzt Vorgefallene einen dicken Strich ziehen und dass wir jedem Feind unserer Division zeigen

631 Vgl. Ferhadbegović, Vor Gericht, S. 238.

632 Wie in der Einleitung zu dieser Arbeit gezeigt, werden alle südosteuropäischen WaffenSS-Divisionen bis heute für nationalistische Zwecke instrumentalisiert: Entweder werden ihre Veteranen als bosnische, kroatische und kosovarische Nationalhelden stilisiert oder aber als Verbrecher am serbischen Volk charakterisiert. 
müssen, dass wir wirklich ein Herr der Ordnung und der Ruhe sind, - wurde verdorben durch den Befehl zur Säuberung des Gebietes um BOSUT. Bei dieser Gelegenheit hat der Div[isions-]Kommandant [sic] General SAUBERZWEIG den Befehl gegeben, dass es nördlich der Save keine Gefangenen gibt. Dies wirkte besonders deprimierend auf viele Offiziere, da es im Gegensatz zu dem stand, was sie den Soldaten beibrachten und sie in eine sehr schwere Situation versetzte. Besonders der Kommandant des 27. Reg. Oberst [Desiderius] Hampel war sehr bedrückt[,] und soweit mir bekannt ist, hat er jede Tötung, wo es immer nur möglich war, verhindert. Die Schiftaren konnte man aber nicht zügeln, erst recht nicht, wenn sie schon Blut gesehen hatten.

Da man mit so einer Arbeit auch auf der anderen Seite der Save fortfuhr, entstand eine ernste Bewegung[,] dieses Bataillon zu beseitigen. Die Greueltaten [sic] wurden auch jenseits der Save auf die grausamste Art ausgeführt. Eine Frau wurde getötet und ihr das Herz herausgenommen, herumgetragen und dann in einen Graben geworfen. Es gab keine Zurückhaltung, denn die Schiftari behaupteten[,] sie müssen so handeln, da ihre Familien von den Tschetniks umgebracht worden sind.

Diese Greueltaten [sic] zwangen selbst den Div. Kommandanten SAUBERZWEIG einzusehen, dass dies politisch unmöglich ist[,] und dass er selbst die Entfernung der Schiftaren verlangte. Sie wurden aus der Div[ision] entfernt und nach Albanien geschickt, wo sie als Grundlage bei der Schaffung der ,Skenderbeg‘ [sic] Division dienten. Der Kommandant des Schiftaren Bataillons war der Hauptsturmführer BORMANN. ${ }^{633}$

Am wichtigsten für die gewaltaffinen Strukturen innerhalb der Division scheint jedoch Matheis Fazit, dass auch nach der Entfernung des Albanerbataillons keine Ordnung in der Division hergestellt werden konnte. Er bezeichnete die verbliebenen bosnischen und „volksdeutschen“ Soldaten als „zügellos“. Sie hätten sich ständig betrunken, ihre Ausrüstung verkauft, ganze Dörfer geplündert, das gestohlene Vieh verkauft oder es an Muslime verschenkt. Ihr wichtigstes Motiv dabei sei die Rache für die an ihren Familien verübten Massaker durch Četniks gewesen. Schließlich wären sie sogar fahnenflüchtig geworden. Matheis kam zum Schluss, dass Sauberzweig aufgrund seines Versagens als Divisionskommandeur sowie bei den Meutereien in der „Handschar“ und der Division „Kama“ zuerst von Himmler ermahnt und schließlich in eine psychiatrische Klinik gebracht worden sei. ${ }^{634}$

Aus dem oben zitierten Dokument lassen sich beide genannten Vorgehensweisen, Befehl und Eigeninitiative, erkennen: ${ }^{635}$ einerseits befohlene Kriegsverbrechen, wie die erwähnte „Säuberungsaktion um Morovice [Morović] in Srem“,

633 Vernehmungsprotokoll Matheis, Franje, Office of Chief of Council for War Crimes Translation of Document No. NO-4951, Landeskommission der Feststellung der Verbrechen der Okkupatoren und ihrer Helfershelfer, Inv. Nr. 35874, BArchF, Nachlass Vopersal, N 756/169a.

634 Ebd.

635 Bougarel, Korb, Petke, Zaugg, Muslim SS Units, S. 265. 
die einen Freipass für Massaker darstellte, oder der Befehl Sauberzweigs, nördlich der Save keine Gefangenen zu machen. Hinzu kommt die Tatsache, dass dieser Befehl auch südlich der Save fortsetzt wurde und somit der Kontrolle der Vorgesetzten entglitt. Die Verbrechen südlich der Save wurden aus einer Eigeninitiative heraus begangen und ließen sich nach Aussagen Matheis' nur schwer kontrollieren. Dass die Vorgesetzten weder eingriffen noch die unerlaubte Entfernung von der Truppe ahndeten, legt den Schluss nahe, dass die Deutschen trotz solch eigenmächtiger Aktionen im Frühjahr 1944 auf jeden Soldaten angewiesen waren. Matheis stellt schließlich die Entfernung der Albaner aus der „Handschar“ zur Division „Skanderbeg“ als Befreiungsschlag dar. Allerdings widerspricht diese Aussage Sauberzweigs Divisionsbrief Nr. 9, in welchem er die Albaner für ihr Vorgehen lobte. ${ }^{636}$

Im Folgenden sollen hier einige der Verbrechen ausführlicher erläutert werden, wobei die angegebenen Opferzahlen nicht verifiziert werden konnten. Allein in der Anklageschrift gegen Zvonimir Bernwald werden acht Ortschaften genannt, über die die Divisionsangehörigen hergefallen waren. Die Anklage lautete einerseits auf Zerstörung und Plünderung der Dörfer sowie auf Vergewaltigung von Mädchen und Frauen und der Ermordung zahlreicher Dorfbewohner. ${ }^{637}$ In der Anklageschrift gegen den Bataillonskommandeur im Regiment 28 der „Handschar“, Bormann, der das erwähnte Albanerbataillon kommandierte, werden 23 Dörfer und Weiler genannt und teilweise sehr detailliert Kriegsverbrechen geschildert. ${ }^{638}$

Ein weiterer hier besprochener Fall deckte drei Verbrechen auf und offenbart gleichzeitig die Gratwanderung zwischen Anklage und Reinwaschen ehemaliger Täter in der Bundesrepublik Deutschland der frühen 1960er Jahre und der Pathologisierung des Zeugen und Täters, dem man mit Verweis auf seine Unzurechnungsfähigkeit jegliches Urteilsvermögen absprach: In einer Selbstanzeige gab Günter Borkowsky am 26. August 1963 zu Protokoll, als Kommandeur einer Einheit der „Handschar“ im Sommer bzw. Herbst 1944 den Befehl für Massentötungen in den drei Dörfern Čelić, Vinkovci und Brčko gegeben zu haben, wobei er die Verbrechen und ihre Vorgeschichte detailliert schilderte. ${ }^{639}$ Diese drei Dörfer lagen im Divisionsgebiet und waren von der „Handschar“ bereits im März 1944, bei ihrer Rückkehr aus Frankreich bzw. Schlesien heimgesucht

636 Vgl. Divisionskommandeur Sauberzweig an Mannschaft der 13. SS-Division, Brief Nr. 9, 27.3.1944, BArchB, NS 19/2601, Bl. 216.

637 Vgl. Bernwald, Muslime in der Waffen-SS, S. 311-320.

638 Vgl. Anklageschrift gegen Bormann, 13. Oktober 1947, AJ, fond 110, kutja 25647, broj. 1810, S. 2-6.

639 Vgl. Fall Günter Borkwoski USHMM, BArchL, B162/20812, Bl. 6-9. 
worden. ${ }^{640}$ Bei seiner Vernehmung hatte Matheis gegen den ehemaligen Divisionskommandeur Sauberzweig ausgesagt, dieser hätte den Befehl erteilt, beim Rückmarsch nach Bosnien im Frühjahr 1943 in Vinkovci keine Gefangenen zu machen. ${ }^{641}$ Am 29. Februar 1944 wies Sauberzweig die Division für die bevorstehende Operation „Wegweiser“ an, „das Waldgebiet zwischen Hauptbahn, Save, Straße Brčko- Zupanja-Vinkovci vom Feinde restlos durch seine Vernichtung zu säubern“. Sauberzweig hob hervor, dass vor allem bei Grk mit stärkerem Widerstand zu rechnen sei, erwähnte aber unter anderen auch Batrovci, Rača und Jamena. Da diese Gebiete nicht von Muslimen bewohnt seien, müsse nur auf die „volksdeutsche“ Bevölkerung Rücksicht genommen werden. Dies kam einem Freipass zur Ermordung der serbischen Bevölkerung gleich. ${ }^{642}$

Die von Borkowsky gemachten Aussagen sind detailliert und entsprechen auch in ihrer geografischen Beschreibung realen Gegebenheiten; beispielsweise nennt er für Brčko einen flachen Abhang zum Ufer der Save hin. Auch der zuständige Kriminalkommisar befand, dass „die Angaben des Beschuldigten [...] glaubhaft“ klangen, und obwohl letzterer „,sich für die Selbstanzeige Mut habe antrinken müssen“, hätte er keineswegs so stark unter Alkoholeinfluss gestanden, „als dass er nicht mehr Herr seiner geistigen Kräfte [gewesen wäre]. “643 Die über 70 Zeugen, die zu allen drei von Borkowsky zu Protokoll gegebenen Fällen befragt wurden, wiesen mit wenigen Ausnahmen sämtliche Vorwürfe von sich. Einige bezeichneten Borkowsky als Lügner. ${ }^{644}$ Borkowskys Vorgesetzter Hanke gab als Zeuge zu Protokoll, sein einstiger Untergebener hätte alles frei erfunden. Zum Zeitpunkt der angegeben Massaker, die nie stattgefunden hätten, sei die Division nördlich der Save bei Gunja stationiert gewesen. Gleichzeitig gibt Hanke aber an, dass Buschenhagen ,über die Dinge, die Borkowsky hier erlebt

640 Vernehmungsprotokoll Matheis, Franje, Office of Chief of Council for War Crimes Translation of Document No. NO-4951, Landeskommission der Feststellung der Verbrechen der Okkupatoren und ihrer Helfershelfer, Inv. Nr. 35874, Nachlass Vopersal, BArchF, N 756/169a.

641 Vgl. Schulz, Wegmann, Zinke, Die Generale der Waffen-SS und der Polizei, Bd. 4, S. 422 (vgl. auch Fußnote).

642 Sauberzweig, Divisionsbefehl Operation „Wegweiser“, 29.2.1944, zur Verfügung gestellt durch George Lepre, S. 1f.

643 Vgl. Kriminalkommissar Barden, „Schlussvermerk“, 26.8.1963, USHMM, BArchL, B162/ 20812, Bl. 13.

644 Insgesamt wurden über 50 Zeugen vorgeladen. Vgl. USHMM, BArchL, B162/20812. Vgl. bspw. Zeugenaussage Günter Falkhof im Fall Günter Borkowsky, 16.3.1964, USHMM, BArchL, B162/ 20812, Bl. 150. 
haben will, vielleicht Auskunft geben“ könne. ${ }^{645}$ Die Aussage, dass die Division zu diesem Zeitpunkt in Gunja stationiert gewesen sei und daher nicht in diesem Raum operiert haben könne, wie Hanke betonte, widerlegen jedoch die Aussagen des ehemaligen „Handschar“-Angehörigen Zvonimir Bernwald. Er bestätigt, dass die Division im Oktober in Brčko lag und am 16. Oktober, außer dem Regiment 28, größtenteils nach Nordkroatien verlegt wurde. Vinkovci ist ebenfalls als eine der nächsten Stationen genannt u. a. in Bezug auf die AufklärungsAbteilung $13 .{ }^{646}$

Borkowsky hingegen wurde zuerst zu einer Abschwächung seines Geständnisses - vom Befehlsgeber zum Zuschauer - und schließlich zum Dementi bewogen; das Verfahren schließlich eingestellt. ${ }^{647}$

Bei den vorgeladenen Zeugen handelte es sich nicht etwa um Zivilisten aus diesen Gebieten, sondern, mit Ausnahme der Ehefrau, allesamt um ehemalige Waffen-SS-Angehörige der „Handschar“, die sich mit Aussagen selbst belastet hätten. ${ }^{648}$ Am 3. Juni 1964 zog schließlich auch Borkowsky seine Aussage zurück und erklärte, dass er zum Zeitpunkt der Selbstanzeige betrunken gewesen sei, die Verbrechen reine Phantasie wären und er nur mit ihnen hätte angeben wollen. ${ }^{649}$

\subsubsection{Das Dorf Kuzmin}

In den frühen Morgenstunden des 17. Februar 1944 umzingelten Einheiten der Division „Handschar“ das Dorf Kuzmin. Kein Dorfbewohner konnte das Dorf mehr verlassen. 11 Personen wurden verhaftet, neun davon mussten nach $\mathrm{Ku}$ kujevci mitgehen, die zwei anderen kamen nach Šid. In Kukujevci mussten sich diese Personen vor dem Rathaus aufstellen und zwei Stunden lang ausharren. Während dieser zwei Stunden wurde mit Gewehren auf sie gezielt und die Angehörigen der Division „Handschar“ anscheinend von „Volksdeutschen“ mit Rufen dazu aufgefordert, diese Menschen zu erschießen. ${ }^{650}$

645 Sonderkommission Z, Zeuge Kommandeur Rgt. Handschar Hanke, 24.1.1964, USHMM, BArchL, B162/20812, Bl. 60.

646 Vgl. Bernwald, Muslime in der Waffen-SS, S. 218.

647 Vgl. Fall Günter Borkowsky, Aussagen Borkowskys zu seinen Angaben vom 26.8.1963, 3.6.1964 und Einstellung des Verfahrens, 30.10.1964, USHMM, BArchL, B162/20812, Bl. 153-156, 296-301.

648 Vgl. bspw. Zeugenaussage Hans Hanke, im Fall Günter Borkowsky USHMM, BArchL, B162/20812, Bl. 60-64.

649 Vgl. Fall Günter Borkowsky, 26.8.1963, USHMM, BArchL, B162/20812, Bl. 153 f.

650 Vgl. Bernwald, Muslime in der Waffen-SS, S. 316. 


\subsubsection{Grk}

Das Dorf Grk wurde Anfang März 1944 von den „Handschar“-Angehörigen heimgesucht. Das Dorf wurde geplündert, die SS-Soldaten sollen fünfzehn Mädchen bis zur Bewusstlosigkeit vergewaltigt haben, anschließend wurden die Frauen umgebracht und in einem kleinen Wald begraben. ${ }^{651}$

\subsubsection{Batrovci}

Beim Eintreffen im Dorf Batrovci am 10. März 1944 sollen „Handschar“-Angehörige alle Menschen, auf die sie trafen, egal welchen Alters, getötet haben. Insgesamt handelt es sich um 26 Opfer, darunter auch ein dreijähriges Kind. ${ }^{652}$

\subsubsection{Bačinci}

Die „Handschar“ hielt sich nach Angaben von Zeugen 17 Tage in Bačinci auf. 17 Personen wurden in dieser Zeit verhaftet und nach Ruma gebracht. Weitere vier wurden in das Lager Vinkovci deportiert und später ,auf der Eisenbahnstrecke bei Garčin erhängt aufgefunden“. ${ }^{653}$

\subsubsection{Berkasovo}

In Berkasovo verhafteten Angehörige der „Handschar“ sieben Personen, davon zwei Frauen. Diese wurden in das Lager Vinkovci deportiert. Zwei der Gefangenen kehrten nicht zurück. ${ }^{654}$

\subsubsection{Bosut}

In Bosut wurden 160 Personen umgebracht, teilweise auf bestialische Art und Weise. 30 der Opfer waren Kinder, eine ungenannte Anzahl Frauen, einige davon schwanger. Auf ihrem Rückweg nach Bosnien kehrten die Soldaten der „Handschar“ (nun ohne ihre albanischen Kameraden, diese waren in der Zwischenzeit zur „Skanderbeg“ abkommandiert worden) in das Dorf zurück. Die Bevölkerung war gewarnt worden und konnte fliehen. Aus Rache darüber brannten die Soldaten das ganze Dorf nieder. ${ }^{655}$

651 Vgl. ebd. Vgl. identischer Anklagepunkt in Anklageschrift gegen Bormann (Kdr. des Albaner-Btl.), 13.10.1947, AJ, fond 110, kutja 25647, broj. 1810, S. 2.

652 Vgl. Bernwald, Muslime in der Waffen-SS, S. 316.

653 Vgl. ebd. Vgl. auch Anklageschrift gegen Bormann (Kdr. des Albaner-Btl.), 13.10.1947, AJ, 110, kutja 25647, broj. 1810, S. 2-6.

654 Vgl. Bernwald, Muslime in der Waffen-SS, S. $316 \mathrm{f}$.

655 Vgl. ebd. 


\subsubsection{Jamena}

In Jamena fanden 70 Menschen durch die „Handschar“ den Tod. 30 weitere Personen wurden in das Lager Vinkovci deportiert. Eine nicht genannte Anzahl junger Frauen kam zur Zwangsarbeit nach Deutschland. Das Dorf wurde niedergebrannt. Anscheinend blieb die örtliche Bevölkerung dem Dorf fern, da die „Handschar“-Soldaten mehrmals zurückkamen, um weiter zu plündern. Nach Aussagen von Zeugen wurden sogar Fenster, Türen und Zäune mitgenommen. Außerdem mähten sie 1.000 Morgen $\left(25.000 \mathrm{~m}^{2}\right)$ Weizen ab und brachten die Ernte nach Drenovci. ${ }^{656}$

\subsubsection{Sremska Laze}

Hier wurden die Menschen des Dorfes im Kirchhof zusammengetrieben, allerdings konnte ihre Hinrichtung durch eine Intervention „der Männer aus der Gemeinde" verhindert werden. ${ }^{657}$

\subsubsection{Dobrinjce}

Dobrinjce wurde im Juli 1944 durch die Einheit von Sepp Mor aus Putinci verwüstet. Die Bevölkerung hatte sich versteckt. Fünf Personen wurden entdeckt und erschossen. ${ }^{658}$

\subsubsection{0 Čelić}

SS-Untersturmführer Willi Günter Borkowsky gab am 26. August 1963 bei seiner Selbstanzeige an, dass er Befehl gegeben habe, in Čelić im Frühjahr/Frühsommer 194457 Männer, Frauen und Kinder zu erschießen. Ein Halbzug hatte tags zuvor vom Kompaniechef SS-Untersturmführer Otto Kien den Befehl erhalten, zur Feindaufklärung zurückzubleiben und bei Feindberührung Bericht zu erstatten. Die letzte Meldung dieses 35 Mann starken Halbzugs erhielt die Division aus Čelić. ${ }^{659}$ Als weitere Meldungen ausblieben, erhielt Borkowsky von Kien den Befehl, zur Aufklärung mit seiner Einheit von 120 Mann bis Čelić vorzugehen und nachzusehen, was geschehen war. Nahe der Dorfkirche fand Borkowsky die Männer, die laut seiner Aussage „regelrecht niedergemetzelt“ worden waren, die

\footnotetext{
656 Vgl. ebd., S. 317.

657 Vgl. ebd.

658 Vgl. ebd., S. $317 \mathrm{f}$.

659 Vgl. Fall Günter Borkowsky, 26.8.1963, USHMM, BArchL,B162/20812, Bl. 6. Siehe hierzu: Kämpfe im Raum Čelić-Koraj-Bijeljina, mit Beginn 1.4.1944, http://znaci.net/arhiv/dogadjaj/ 1267 (Stand: 1.2.2019).
} 
Augen waren teilweise ausgestochen, die Ohren und Zunge abgeschnitten und ein Kainsmal auf die Stirn geschnitten worden. ${ }^{600}$ „Der Anblick der Ermordeten rief in mir ein derartiges Gefühl von Rache hervor, dass ich meinen Leuten den Befehl gab, alle Zivilpersonen zu greifen, derer sie habhaft werden [konnten], um sie standrechtlich zu erschießen.“661 Für die 35 ermordeten „Handschar“-Soldaten ließ Borkowsky 57 Zivilisten erschießen. 1963 gibt er zu Protokoll: „Wenn ich heute noch an den Anblick der toten SS-Kameraden denke, so überkommt mich wohl ein ganz trauriges Gefühl. Die Männer kämpften aus Überzeugung. Die Zivilisten, die auf meinen Befehl hin erschossen wurden, kämpften aber für ihre Heimat, und sie waren wehrlos. “662 Borkowskys detaillierte Angaben lassen ein genaues Bild zum Hergang der Tötungen zu. In diesem Fall wurden die Erschießungen durch ihn selbst, sowie die Gruppenführer Heinrich Wagner und Paul Dieterle vorgenommen. „Nachdem die Leute aufgegriffen und auf dem Marktplatz festgehalten wurden, mussten sie vor der Kirche in Celic [sic] eine Grube ausheben. Als diese fertig war [durchgestrichen im Original: mussten sie sich alle davor auf] die Grube war gar nicht fertig, denn die Geiseln wurden von uns [durchgestrichen im Original] während des Aushebens der Grube von uns niedergeschossen, und zwar wurden die Erschießungen vorgenommen von mir und den beiden Gruppenführern Heinrich Wagner und Paul Dieterle. [...] Als Waffen benutzten wir unsere Maschinenpistolen. Ich kann mich noch erinnern, dass Heinrich Wagner auf Verletzte [sic] aber noch nicht tote Jugoslawen mit seiner Pistole Fangschüsse abgegeben hat.“663 Die 35 toten „Handschar“-Angehörigen wurden mitgenommen und auf dem Friedhof in Gunja beerdigt. ${ }^{664}$ Anfang der 1960er Jahre verneinten einige infolge der Aussagen Borkowskys vorgeladene ehemalige „Handschar“-Angehörige die Vorfälle in Čelić - Heinz Gerlach gab jedoch zu Protokoll „dass mir vom Hörensagen [bekannt] und gerüchteweise im Sommer 1944 im Raum Zelitsch [Čelić] ein Gefecht abgespielt haben soll, bei dem Partisanen in größerer Anzahl eine Einheit des Artillerieregimentes überfiel [en].“665 Er nahm daher an, dass sich Borkowsky zum Zeitpunkt des Gefechts in Čelić aufgehalten haben könnte. ${ }^{666}$

660 Vgl. Fall Günter Borkowsky USHMM, BArchL, B162/20812, Bl. 7.

661 Ebd.

662 Ebd.

663 Ebd.

664 Ebd., Bl. 8.

665 Fall Günter Borkowsky, Aussage Heinz Gerlach, 20.4.1963 [1964?], USHMM, BArchL, B162/20812, Bl. 107.

666 Ebd. 
Čelić war mit großer Wahrscheinlichkeit bereits nach der Überquerung der Save von Divisionsangehörigen heimgesucht worden, denn das Regiment 28, dem auch das bereits erwähnte Albanerbataillon angehörte, sollte südlich der Save auf der Straße Richtung Brčko/Čelić vorrücken, wie Eipel in Kriegsgefangenschaft aussagte. Obwohl er sich genau erinnerte, dass das Tagesziel „Čelić“ erreicht und dort ein Gefechtsstand errichtet worden war, wies er im nächsten Satz jegliche Verantwortung für Einsätze von sich: „Ob und inwieweit Verluste eingetreten waren, wie stark hier die gegnerischen Kräfte angesetzt waren, entzieht sich meiner Kenntnis, da ich aus vorerwähnten Gründen selbst an diesem Einsatz niemals teilgenommen habe, auch irgendwelche Einsatzbefehle nicht erhielt.“667 Matheis machte zwar auch keine konkreten Angaben, gab aber zu Protokoll, dass der von Sauberzweig ausgegebene Divisionsbefehl, nördlich der Save keine Gefangenen zu machen, auch südlich der Save, im Raum Čelić und Brčko, insbesondere durch das Albanerbataillon weiter ausgeführt wurde. ${ }^{668}$

Im Herbst 1944 kam es in und um Čelić und Brčko zu erneuten Zusammenstößen zwischen Partisanen und Angehörigen der Division „Handschar“. Doch jetzt waren die Partisanen im Vorteil. Sie erbeuteten 100 Waffen und machten 45 Gefangene. Ob es dabei zu Massakern kam, bleibt offen. ${ }^{669}$ Als Borkowsky schließlich am 3. Juni 1964 seine Aussage zurückzog, machte er nun zum Kriegsverbrechen in Čelić folgende Aussage: „Einen solchen Vorfall habe ich nie erlebt. Ich habe heute auch gar keine Einzelheiten dieser Angaben in meinem Gedächtnis gehabt. Ich kann heute über mein Verhalten nur selbst den Kopf schütteln. Es ist geradezu sagenhaft, welche Phantasie ich entwickelt habe. “670

\subsubsection{Brčko}

Das Massaker in Brčko kann wohl in Zusammenhang mit der Stationierung der Division in Čelić und Brčko im Frühjahr und den Rückzugskämpfen im Herbst 1944 gesehen werden: Am 5. oder 6. Oktober 1944 erreichte Borkowskys Einheit Brčko und bezog dort Quartier. Da die Soldaten mit einem nächtlichen Angriff durch Partisaneneinheiten rechneten, stellten sie an neuralgischen Punkten des

667 Kriegsgefangenenbericht „Bericht über die 13. SS Division ,Handschar‘, ihre Aufstellung, Gliederung“, Walter Eipel, 14.11.1947, VA, HEM.OK.BOJCKA, 72-A/1-a/32, S. 7 f.

668 Vernehmungsprotokoll Matheis, Franje, Office of Chief of Council for War Crimes Translation of Document No. NO-4951, Landeskommission der Feststellung der Verbrechen der Okkupatoren und ihrer Helfershelfer, Inv. Nr. 35874, Nachlass Vopersal, BArchF, N 756/169a.

669 Vgl. Stojan Nikolić et al., Hronologija narodnooslobodilačkog rata i revolucije na jugu Srbije, Leskovac: 1966, S. 946.

670 Vgl. Fall Günter Borkowsky, 26.8.1963, USHMM, BArchL, B162/20812, Bl. 154. 
Ortes Wachposten auf. Als die Wachposten um 22 Uhr abgelöst werden sollten, fand die Ablösung sie mit durchgeschnittenen Kehlen. In derselben Nacht ereignete sich ab Mitternacht bis zum Morgengrauen „ein regelrechter Feuerüberfall“ auf die Einheiten der Division „Handschar“. Die „Handschar“ verlor dabei 78 Mann. ${ }^{671}$ Borkowsky, der an diesem Tag die alleinige Befehlsgewalt über die Einheiten in Brčko hatte, da SS-Untersturmführer Kien nach Belgrad gereist war, befahl, alle Zivilisten, die aufgefunden werden konnten, zu erschießen. 160-170 Männer, Frauen und Kinder wurden zumeist in ihren Häusern erschossen und „am Ort ihres Todes“ liegengelassen. ${ }^{672}$ Obwohl Günter Falkhof bei seiner Vernehmung deutlich zum Ausdruck brachte, was er von Borkowsky Selbstanzeige hielt: „der Tatbestand der von Borkowsky vorgetragenen Geschehnisse in Yugoslavien [sic] ist erlogen. Das möchte ich einmal ganz deutlich zu Anbeginn meiner Vernehmung sagen“, ${ }^{673}$ fiel ihm später während der Vernehmung ein, dass gefangene Partisanen in einem Schuppen bei Brčko festgehalten und dort von Feldgendarmen misshandelt worden wären. Er hätte das selbst gesehen. Er fährt fort: „Es gingen dann später Gerüchte herum, wonach einige dieser gefangenen Partisanen erschossen worden sein sollen. Das soll außerhalb Brčko’s [sic] geschehen sein. Das ist aber auch der einzigste [sic] Fall der mir in Erinnerung ist und der von Erschießungen handelt. “674 Harry Bensel, ebenfalls als Zeuge aufgerufen, gab zu Protokoll, Borkowsky habe möglicherweise „diese Dinge bei der ,Prinz Eugen“ erlebt“ und versuchte so, der Schwesterdivision die Schuld zu zuschieben. ${ }^{675}$

\subsubsection{Vinkovci}

Zwei bis vier Tage vorher, am 3. oder 4. Oktober 1944, ließ Borkowsky 45 Männer, Frauen und Kinder ermorden. Kurz zuvor war eine Nachhut der Division von 11 Mann „fürchterlich zerstümmelt“ in Vinkovci aufgefunden worden. Ihnen waren Ohren, Zungen und zum Teil die Geschlechtsteile abgeschnitten worden. Drei Nachrichtenhelferinnen waren mit Gewehren Handgranaten in die Vagina gesteckt und gezündet worden. Borkowsky gibt an, dass diese „am Unterleib fürchterlich zerrissen“ waren. ${ }^{676}$ Daraufhin gab Borkowsky seiner Einheit den Be-

671 Vgl. Fall Günter Borkowsky USHMM, BArchL, B162/20812, Bl. 9.

672 Vgl. ebd., Bl. 9.

673 Vgl. Zeugenaussage Günter Falkhof im Fall Günter Borkowsky, 16.3.1964, USHMM, BArchL, B162/20812, Bl. 150.

674 Vgl. Zeugenaussage Günter Falkhof im Fall Günter Borkowsky, 16.3.1964, USHMM, BArchL, B162/20812, Bl. 151.

675 Vgl. Zeugenaussage Harry Bensel im Fall Günter Borkowsky, 16.3.1964, USHMM, BArchL, B162/20812, Bl. 129.

676 Fall ebd., Bl. 8. 
fehl, so viele Zivilisten wie möglich einzufangen. 45 Männer, Frauen und Kinder wurden schließlich erschossen, in große Weinfässer geworfen und einen Hang zur Save hinuntergerollt, teilweise fielen sie bereits beim Hinunterrollen oder aber im Fluss aus den Fässern. Borkowsky gibt zu Protokoll:

Wenn ich heute daran zurückdenke, dass wir die Leichen auf diese Weise beseitigten, so überkommt mich das Grauen; aber man muss die Situation berücksichtigen, in der ich mich damals befand. In der bestialischen Tötung der Nachrichtenhelferinnen und der Kameraden glaubte ich, mein Tun rechtfertigen zu können. ${ }^{677}$

Auch hier verneinten Zeugen die Vorfälle: Günter Falkhof sagte aus, die ganze Geschichte sei erlogen, bosnische Frauen seien nie als Nachrichtenhelferinnen in der Division eingesetzt gewesen. ${ }^{678}$ Harry Bensel hingegen sagt nur aus, dass er bei der Abteilung nie welche gesehen habe. ${ }^{679}$

\subsubsection{Lager}

Neben ihren Einsätzen im Partisanenkrieg und bei der Sicherung wehrwirtschaftlich relevanter Infrastruktur war die Division auch bei der Bewachung von Lagern eingesetzt. Allerdings ist die Geschichte der Lager auf dem Territorium des NDH noch kaum erforscht. Immerhin scheint in den letzten Jahrzehnten zumindest ein Forschungsinteresse erwacht $\mathrm{zu}$ sein. Auffallend ist bei der wenigen Literatur, die dazu exisiert, dass der Fokus nur auf die von den Ustaša kontrollierten Lager gelegt wird und somit die durch die Waffen-SS bewachten Lager gänzlich in den Hintergrund rücken. ${ }^{680}$ Insgesamt werden in der heutigen Forschung zu Lagern auf dem Gebiet des ehemaligen NDH über 50 Einrichtungen verschiedenen Typs gezählt. Grob wird zwischen Lagern, die unter kroatischer, deutscher oder italienischer Kontrolle standen, unterschieden. ${ }^{681}$ Obwohl Zeitzeugen sämtliche Lager im NDH als Konzentrationslager bezeichneten, entsprachen viele nicht

677 Ebd., Bl. 7.

678 Vgl. Zeugenaussage Günter Falkhof im Fall Günter Borkowsky, 16.3.1964, USHMM, BArchL, B162/20812, Bl. 151. Es lässt sich zwar nicht überprüfen, ob die Division auch bosnische Nachrichtenhelferinnen anheuerte. Belegt ist aber, dass für solche Aufgaben auch bei der Gegenseite Frauen und zuweilen auch Kinder eingesetzt wurden. Vgl. bspw. Casagrande, Volksdeutsche SS-Division, S. 225.

679 Vgl. Zeugenaussage Harry Bensel im Fall Günter Borkowsky, 16.3.1964, USHMM, BArchL, B162/20812, Bl. 130.

680 Vulesica nennt vor allem zwei wichtige Autoren: die kroatischen Historiker Zrdavko Dizdar und Narcisa Lengel-Krizman. Vgl. Vulesica, Kroatien, S. 331.

681 Vgl. Vulesica, Kroatien, S. 314. 
der Definition eines deutschen KZ. ${ }^{62}$ Der Kontrolle der „Handschar“ unterstanden verschiedene Lager, so etwa das Lager von Ruma, das Lager von Vinkovci sowie das Lager von Kruščica. Nach Dizdar sollen zwei weitere Lager, diejenigen von Jankomir und Sisak, unter direkter deutscher Leitung gestanden haben. ${ }^{683}$ Daneben existierten der Lagerkomplex Jasenovac und Novo Gradiška und weitere Nebenlager sowie zahlreiche weitere Lager unter Kontrolle der kroatischen Ustaša. ${ }^{684}$ In Jasenovac und Novo Gradiška hielt die Ustaša sogar potentielle Rekruten, Befürworter der SS, die sich hatten rekrutieren lassen wollen, fest. Himmler beauftragte Kammerhofer damit, die Insassen in beiden Lagern zwecks Überführung in die „Handschar“-Division zu überprüfen. ${ }^{685}$ Im Folgenden soll kurz auf die durch Angehörige der „Handschar“ beaufsichtigten Lager eingegangen werden, soweit Informationen zugänglich sind; die Lager unter kroatischer Führung werden im Rahmen dieser Untersuchung nicht weiter besprochen.

\subsubsection{Das Lager von Vinkovci und Ruma}

In Bernwalds Anklageschrift ist zu lesen, dass Verhaftete aus Kuzmin nach den Verhören in das Lager Vincovci gebracht wurden. Auch sieben Verhaftete aus Berkasovo, darunter zwei Frauen, wurden in dieses Lager eingeliefert. ${ }^{686} \mathrm{Zu}$ Vinkovci sind aber leider auch bei Vulesica keine weiteren Informationen zu finden. ${ }^{687} \mathrm{Im}$ Zusammenhang mit Festnahmen wird lediglich erwähnt, dass die Gefangenen nach Ruma gebracht wurden. Weitere Anhaltspunkte gibt es nicht. ${ }^{688}$

\subsubsection{Das Konzentrationslager Kruščica}

Separat erwähnt werden muss das Konzentrationslager Kruščica südlich von Vitez in Zentralbosnien. Teile der Division „Handschar“ sollen mit der Bewachung des Lagers beauftragt gewesen sein. Darin festgehalten wurden vor allem

\footnotetext{
682 Vgl. ebd., S. 315.

683 Vgl. ebd.

684 Vgl. für Jasenovac Berger, Egon, Jasenovac. Un camp de la mort en Croatie, Genf: Éditions des Syrtes 2015. Vgl. hierzu auch Korb, Im Schatten des Weltkriegs, S. 390-413. Vgl. Vulesica, Kroatien, S. 227-230. Novo Gradiška wie auch Gospić wurden nach dem Krieg von Tito in Gefängnisse für politische Gefangene umgewandelt und existierten bis zur Auflösung Jugoslawiens. Vgl. Vortragsskript „Tretiranje albanskih političkih zatvorenika u gospićkom zatvoru“, Privatarchiv, Ibish Neziraj.

685 Vgl. Himmler an Beauftragten des Reichsführer SS in Kroatien, SS-Brigadeführer und Generalmajor der Polizei Konstantin Kammerhofer, 1.7.1943, BArchB, NS19/3523, Bl. 58.

686 Vgl. Bernwald, Muslime in der Waffen-SS, S. 316.

687 Vgl. Vulesica, Kroatien, S. 317.

688 Vgl. Bernwald, Muslime in der Waffen-SS, S. 316.
} 
SerbInnen, JüdInnen und Roma. Bei den Insassen handelte es sich vor allem um Frauen und Kinder. ${ }^{689}$

\subsubsection{Das Anhaltelager Semlin/Sajmište}

Aufgebaut wurde das als „Judenlager“ wie auch als „Anhaltelager“ bekannte Konzentrationslager in Semlin/Sajmište in der Genmeinde von Zemun/Semlin bereits im Herbst 1941. Dort wurden auch zahlreiche Jüdinnen und Juden in so genannten Gaswagen umgebracht. ${ }^{690}$ Ab 1943 wurde es zum Sammelpunkt und zur Drehscheibe für den Weitertransport von Gefangenen, vor allem auch Juden aus ganz Südosteuropa. ${ }^{61}$ Das Lager lag auf kroatischem Hoheitsgebiet und wurde nach Angaben Emanuel Schäfers von Angehörigen der deutschen Schutzpolizei bewacht. ${ }^{692}$ Inwieweit auch Angehörige der „Handschar“ bzw. solche, die später zur „Handschar“ vesrsetzt wurden, dort Dienst taten, bleibt unklar.

\subsection{Schwierigkeiten}

\subsubsection{Chancen und Grenzen von Multikultur in der Truppe und ein anderes Verständnis von Kriegführung}

In seinem Brief Nr. 9 an die Soldaten der „Handschar“ beschwor Sauberzweig interkulturelle Freundschaften innerhalb seiner Division, die in seinen Augen einem höheren Ziel dienten: „Ich habe Beispiele von Kameradschaft zwischen Deutschen und Muselmanen, zwischen Deutschen aus Ungarn [„Volksdeutschen“] und Bosniaken gehört, die ein wahres Heldenlied sind. So muss es sein. Wir alle gehören zusammen und sind auf Gedeih und Verderb unserer Idee verschrieben. “693 Ende Dezember 1943 gratulierte Himmler in einem Schreiben an Sauberzweig den „braven Führern, Unterführern und Mannschaften“ der muslimischen SS-Freiwilligendivision. ${ }^{694}$ Sauberzweigs Anstrengungen und Himmlers Glückwünschen zum Trotz kann indes nicht davon ausgegangen werden, dass es sich bei der „Handschar“ um eine „große brüderliche Gemeinschaft“ gehandelt hat. Vielmehr standen die verschiedenen Ethnien und Religionen in einem Spannungsverhältnis

689 Vgl. Vulesica, Kroatien, S. 315.

690 Vgl. auch Manoschek, Serbien ist judenfrei, S. 169-184.

691 Vgl. Sundhaussen, Serbien, S. 344.

692 Vgl. auch Manoschek, Serbien ist judenfrei, S. 174.

693 Divisionskommandeur Sauberzweig an Mannschaft der 13. SS-Division, Brief Nr. 9, 27.3.1944, BArchB, NS 19/2601, Bl. 214.

694 Vgl. Himmler an Sauberzweig, 26.12.1943, BArchB, NS19/2601, Bl. 52. 
zueinander, das von Eifersucht und Missgunst geprägt war. ${ }^{695}$ In einem anonymen Leserbrief an die Redaktion der Divisionszeitung „Handžar“ wird die angespannte Situation deutlich: Ein katholischer Kroate warf der Redaktion vor, dass nie von Kroatien die Rede sei, obwohl doch zahlreiche Kroaten in der „Handschar“ dienen würden. Und obwohl die Bosnier den größten Teil der Division ausmachten, würde Bosnien immer Teil Kroatiens bleiben. Alle Divisionsangehörigen würden für Hitlers Ziel kämpfen, aber nicht für die zweideutigen Absichten - gemeint sind die bosnischen Autonomiebestrebungen - welche in der Divisionszeitung geäußert würden. ${ }^{696}$ Auch die dezidiert muslimische Ausrichtung und folkloreske Ausstattung der Division stieß bei vielen Katholiken auf Ablehnung. ${ }^{697}$

Auf der anderen Seite konnten sich die bosnischen Muslime nicht mit der Namensgebung „Kroatische SS-Freiwilligen-Gebirgsdivision“ identifizieren. Aus diesem Grund veranlassten Phleps und Sauberzweig im Herbst 1943 eine Namensänderung. Nun hieß die Division “13. SS-Freiwilligen b[osnisch]h[erzegowinischen] Division (Kroatien)“. ${ }^{698}$ Das Verhältnis zwischen den Kulturen gestaltete sich aber nicht nur auf Divisionsebene schwierig - auch im Alltag kamen gerade auf Mannschaftsebene kulturelle Unterschiede zum Vorschein: Viele Bosnier vom Lande sahen zum ersten Mal geschlossene Toiletten oder elektrisches Licht. Ohne militärische Vorbildung mussten die jungen Soldaten von ihren meist „volksdeutschen“ und österreichischen Vorgesetzten von Grund auf ausgebildet werden. ${ }^{699}$ Auch die Sprache bildete oft eine Barriere zwischen den bosnischen Soldaten und Imamen und den deutschsprachigen Vorgesetzten. Hier waren „volksdeutsche“ Divisionsangehörige als Brückenbauer und Übersetzer oft unerlässlich. Sie waren, wie Bernwald später schrieb, auch Anlaufstelle für Anliegen und Fragen, welche die Bosnier nicht mit den deutschen Kommandeuren besprechen wollten. ${ }^{700}$

Letztere hatten oft einen kolonialistischen Blick auf ihre bosnischen Untergebenen, wie folgende Aussagen Sauberzweigs zeigen: Der Bosniake wäre ein guter Soldat; seine Stärken verortete Sauberzweig vor allem in der Nutzung des Geländes und im Nahkampf. ${ }^{701}$ Beim Rückzug allerdings müsse er streng ge-

695 Vgl. Rochas, La Handschar, S. $76 \mathrm{f}$.

696 Vgl. Anonymer Brief an die Herausgeber der „Handžar“, 4.9.1943, nach: Lepre, Himmler’s Bosnian Division, S. 59.

697 Vgl. Rochas, La Handschar, S. 77.

698 Vgl. Lepre, Himmler's Bosnian Division, S. 60. Vgl. Rochas, La Handschar, S. 78.

699 Vgl. Lepre, Himmler's Bosnian Division, S. 60.

$700 \mathrm{Vg}$. Bernwald, Muslime in der Waffen-SS, S. 71.

701 Vgl. 13. SS-Division, Ia/G, Tgb. Nr.: Ia 83/43, 24.8.1943, nach: Lepre, Himmler's Bosnian Division, S. 61. 
führt werden. Dasselbe galt seiner Ansicht nach auch bei Artilleriebeschuss. Der Bosnier würde dem Offizier, der sein Vertrauen gewinnt, mit einer fast kindlichen Loyalität begegnen, und er habe einen extremen Sinn für Gerechtigkeit und Ehre. Da er seine bosnische Heimat über alles liebe, sei mit der Motivation einer raschen Verlegung zurück in die Heimat auch in der Ausbildung zu arbeiten: Die Vorgesetzten sollten bei jeder Gelegenheit betonen, dass diese Verlegung nicht zuletzt von den persönlichen Fortschritten des Einzelnen abhinge. ${ }^{702}$ Die unterschiedlichen Vorstellungen, wie Krieg geführt werden sollte, überforderte die deutschen Vorgesetzten zuweilen. Der Verbindungsoffizier Himmlers, Hermann Fegelein, wies bei einer Lagebesprechung mit Hitler darauf hin, dass Angehörige der „Handschar“, nicht nur gefangene Partisanen mit dem Messer umbringen sondern manchen gar das Herz herausschneiden würden. ${ }^{703}$ Einer hätte, obwohl er am rechten Arm verletzt und dieser eingebunden war, mit dem Messer in seiner linken Hand 17 Gefangene umgebracht. ${ }^{704}$

Ähnlich fremd wirkten auch die Albaner auf ihre Vorgesetzten - entsprechend ähneln sich die Berichte über ihr Verhalten: Die Albaner schienen trotz der bereits mehrmonatigen Ausbildung wenig diszipliniert. Sie entfernten sich unerlaubt von der Truppe, sei es, wie im Kapitel „Kriegsverbrechen“ erwähnt, um Zivilisten zu massakrieren, sei es, um sich in Häusern „Wasser und Proviant zu besorgen“. ${ }^{705}$ Kaesdorf betonte, dass die Marschdisziplin im Albanerbataillon der „Handschar“ schwer zu halten sei, da sich die Albaner „verplauschen und ohne bösen Willen von der Truppe entfernen.“"706

Um den Disziplinierungsschwierigkeiten zu begegnen, schlug Sauberzweig vor, an „den Wetteifer zwischen den einzelnen Gruppen“ zu appellieren, denn

der Albaner gehorcht nicht gern aus jener selbstverständlichen Unterordnung und Disziplin, an die der Deutsche gewöhnt ist, sondern erwartet neben der durch persönliche Leistung erworbenen Autorität seines Führers für sich selbst die Möglichkeit, sich hervorzutun. Ein lebhaftes Auszeichnungsbedürfnis kann dazu führen, dass [sic] einzelne Kämpfertum zu demonstrieren und sich der Anerkennung der anderen zu vergewissern. ${ }^{707}$

Problematisch war insbesondere der Umgang zwischen den einzelnen ethnischen Gruppen: Die albanischen Muslime vertrugen sich nicht mit den bosni-

702 Vgl. ebd.

703 Vgl. Sundhaussen, Waffen-SS in Kroatien, S. 194.

704 Vgl. Helmut Heiber (Hg.), Hitlers Lagebesprechungen: Die Protokollfragmente seiner militärischen Konferenzen 1942-1945, Stuttgart: Deutsche Verlagsanstalt 1962, S. 560. Vgl. hierzu auch Casagrande, Volksdeutsche SS-Division, S. 334.

705 „Erfahrungen mit albanischen Soldaten“, Kaesdorf, undatiert, BArchB, NS 31/444, S. 26.

706 Ebd. Vgl. Zaugg, Albanische Muslime, S. 309.

707 „Erfahrungen mit albanischen Soldaten“, Kaesdorf, undatiert, BArchB, NS 31/444, S. 27. 
schen Muslimen. In den Baracken zählten Messerstechereien zum Alltag. Erich Gördes meldete nach Zagreb, dass die Albaner auf ihn einen besseren Eindruck machen würden, die Bosniaken hingegen schienen ihm streitsüchtig und diebisch. Unter den deutschen Vorgesetzten herrschte die Meinung, die Bosniaken „seien faul, hätten sich zwar freiwillig gemeldet, drückten sich aber ebenso freiwillig vom Dienst; um wenigstens auf einige Stunden los zu kommen[,] rieben sie sich die Körperteile mit Sand wund oder schlügen sich die Haut mit der Bürste wund“. ${ }^{708}$ Dass Selbstverstümmelung in der „Handschar“ vorkam, beweist etwa der Fall von Muhamed Dmećević, der sich beim Waffenreinigen am 28. Juli 1944 in drei Zehen seines linken Fußes schoss. ${ }^{709}$ Sauberzweig war der Meinung, dass die Muslime allgemein ein unstetes Element in der Division darstellten und immer zu der Seite wechseln würden, die ihnen stärker schien. ${ }^{710}$

$\mathrm{Zu}$ den Albanern in seiner Division schien er jedoch eine enge Beziehung gepflegt $\mathrm{zu}$ haben. In einem seiner Divisionsbriefe richtete er das Wort direkt an sie, indem er dem kommunistischen Konzept einer panslawistischen Bewegung dasjenige des balkanischen Islams entgegensetzte:

Für Euch, meine lieben Albaner[,] ist dieser Marsch der Weg zur Heimat. Wenn Ihr, meine lieben Albaner, die bosnische Grenze überschreitet, so tretet ihr ein in den Ring der $\mathrm{Mu}-$ selmanen, der sich als Brücke von der Sava zu Euren Bergen hinzieht. [...] Heil der Heimat, durch Bosnien bis zu den Bergen Albaniens. ${ }^{711}$

Auch in seinem letzten Divisionsbrief an die Albaner der „Handschar“ schrieb Sauberzweig:

Ich möchte nicht schließen, ohne besonders die Tapferkeit der Albaner anzuerkennen, die eingeschlossen vom überlegenen Feind, sich freikämpften und ein Soldatentum ohnegleichen zeigten. Sie sind die Vorboten einer Heimat, zu der wir die Verbindung auch suchen und finden werden. ${ }^{712}$

708 Vgl. Deutsches Konsulat Sarajevo, Erich Gördes an Deutsche Gesandtschaft Agram, 23.8.1943, PAAA Inland IIg R100998.

709 Vgl. 1./SS-San.Abt. „H“, Truppenarzt, Betr. Selbstverletzung des SS-Schützen Dmećević, Muhamed, 9.8.1944, VHA, Řada N.13. SS-Fr-Geb. Div. "H”. 7.

710 Vgl. Redžić, Bosnia and Herzegovina, S. 47.

711 Divisionskommandeur Sauberzweig an Mannschaft der 13. SS-Division, Brief Nr. 8, 25.2.1944, BArchB, NS 19/2601, Bl. 210.Vgl. Lepre, Himmler's Bosnian Division, S. 151 f.

712 Divisionskommandeur Sauberzweig an Mannschaft der 13. SS-Division, Brief Nr. 9, 27.3.1944, BArchB, NS 19/2601, Bl. 216. Er spricht hier auch von den „vielen Heldentaten“ seiner Division. Ähnliches berichtet Kaesdorf: Die Albaner seien besonders geübt im „Nahkampf“ und in der Anwendung von Kriegslisten, Kaesdorf, „Erfahrungen mit albanischen Soldaten“, undatiert, BArchB, NS 31/444, S. $26 \mathrm{f}$. 
Ob dieses Lob lediglich den Zweck hatte, die Truppe zu motivieren, muss offen bleiben.

Das von Sauberzweig als „Soldatentum ohnegleichen“ bezeichnete Vorgehen äußerte sich vor allem darin, auf dem Marsch Richtung Save auf unbewaffnete Zivilisten zu schießen, wie SS-Sturmbannführer Willi Hempel in Kriegsgefangenschaft zu Protokoll gab. ${ }^{713}$ Auch bosnische Kriegsgefangene der „Handschar“ lasteten den Albanern aus dem Sandžak und Nordkosovo Gewaltexzesse und Massaker an, wie in den vorangehenden Kapiteln erläutert wurde. ${ }^{714}$ Kaesdorf beschreibt jenes fremdartige Verhalten der albanischen Soldaten innerhalb der „Handschar“ mit folgenden Worten:

Sein [des muslimischen Albaners] Einsatzwille ist unbedingt und total. Er kennt in seiner Heimat nur den Vernichtungskrieg, der auch Weib und Kind nicht schont und hat unter diesen Lebensbedingungen eine Widerstandskraft und Zähigkeit entwickelt, die nicht leicht zu überbieten sind. ${ }^{715}$

Matheis war der Meinung, dass gerade diese Unkontrollierbarkeit der durch die Albaner begangenen Gräueltaten letztlich zu deren Versetzung in die sich in Aufstellung befindende Division „Skanderbeg“ geführt habe. ${ }^{716}$

Obwohl die deutsche Führung durch die Versetzung der Albaner gehofft hatte, die Disziplin in der Division wiederherstellen zu können, trat dieser Fall nicht ein: „Unterdessen, trotz der Entfernung der Schiftaren[,] wurde keine Ordnung in die Div[ision] gebracht. Die Soldaten waren zügellos, betranken sich und verkauften ihre Ausrüstung und wurden auch flüchtig. “717 Auch Casagrande stellte in seiner Untersuchung fest, dass nicht nur die Albaner sondern auch die bosnischen Divisionsangehörigen „mit ungeheurer Grausamkeit“ gegen feindliche Četnik- und Partisanenverbände vorgingen, nachdem sie in ihre Heimatgebiete zurückgekehrt waren. ${ }^{718}$

713 Vgl. Ferhadbegović, Vor Gericht, S. 239. Zum „Unternehmen Save“ und dem letzten Einsatz des albanischen Bataillons innerhalb der „Handschar“ vgl. Lepre, Himmler’s Bosnian Division, S. 151-169.

714 Vgl. ebd., S. 238.

715 Kaesdorf, „Erfahrungen mit albanischen Soldaten“, undatiert, BArchB, NS 31/444, S. 28.

716 Vgl. Vernehmungsprotokoll Matheis, Franje, Office of Chief of Council for War Crimes Translation of Document No. NO-4951, Landeskommission der Feststellung der Verbrechen der Okkupatoren und ihrer Helfershelfer, Inv. Nr. 35874, Nachlass Vopersal, BArchF, N 756/169a. Vgl. zu Albanern auch Anklageschrift gegen Bormann (Kdr. Albaner-Btl.), 13. 10. 1947, AJ, fond 110, kutja 25647, broj. 1810, S. 3, 5.

717 Vgl. Vgl. Vernehmungsprotokoll Matheis, Franje, Office of Chief of Council for War Crimes Translation of Document No. NO-4951, Landeskommission der Feststellung der Verbrechen der Okkupatoren und ihrer Helfershelfer, Inv. Nr. 35874, Nachlass Vopersal, BArchF, N 756/169a.

718 Vgl. Casagrande, Volksdeutsche SS-Division, S. 334. 


\subsubsection{Zwei Meutereien und Massendesertionen}

Die Division „Handschar“ bildete noch in anderer Hinsicht eine Ausnahme. Sie ist eine der wenigen Waffen-SS-Divisionen, in welcher zwei Meutereien geplant und umgesetzt wurden. Die erste fand im September 1943 in Villefranche-deRouergue, die zweite im Oktober 1944 innerhalb der Divisions-Stabsjäger-Kompanie statt. Da es sich bei der zweiten eher um eine organisierte Massendesertion handelte, soll hier die Meuterei in Frankreich im Vordergrund stehen. ${ }^{719}$ Diese Meuterei wird in verschiedenen Werken erwähnt: Mirko Grmek und Louise Lambrichs haben ihr ein ganzes Buch gewidmet und zeichnen detailliert die Umstände und Hintergründe nach, die zur Meuterei führten. ${ }^{720}$ Bernwald beschreibt sie in seinen Memoiren auf ganzen 55 Seiten. ${ }^{721}$ Auch Lepre und Hoare gehen ausführlich darauf ein. ${ }^{722}$

In Villefranche-de-Rouergue, fern ihrer Heimat, entschlossen sich Bosnier aus der unteren Führungsebene, das deutsche Rahmenpersonal gefangen zu nehmen und zu erschießen. Die Meuterei war geplant für den 17. September 1943. Quellen über die genauen Abläufe und Hintergründe der Meuterei sind kaum vorhanden, einige Befragungsprotokolle von Angehörigen der „Handschar" bilden die Basis für die Untersuchungen. ${ }^{723}$ Zvonimir Bernwald gibt zwar als Zeitzeuge Auskunft über Planung, Umsetzung und das Scheitern des Aufstandes, ${ }^{724}$ übernimmt dabei aber die Diktion der Nationalsozialisten und schreibt von den deutschen Vorgesetzten als „Opfern“ und von den Aufständischen als „Rädelsführern“. ${ }^{725}$ Dennoch helfen die von ihm recherchierten Biographien, den Werdegang der jungen Meuterer nachzuzeichnen. ${ }^{726}$

Auffallend ist, dass es sich bei den jungen Männern nicht um klassische Antifaschisten handelte. Die vier Hauptschuldigen handelten wohl weder in der Überlegung, den Nationalsozialismus zu besiegen noch in Koordination oder Zusammenarbeit mit lokalen französischen Widerstandkämpfern, wie in einigen Werken angegeben wird. Lepre betont zwar in seinem Buch die kommunis-

719 Vgl. Lepre, Himmler’s Bosnian Division, S. 266.

720 Vgl. Grmek, Lambrichs, Les révoltés.

721 Vgl. Bernwald, Muslime in der Waffen-SS, S. 117-171.

722 Vgl. Lepre, Himmler's Bosnian Division, S. 81-108. Vgl. Hoare, Bosnian Muslims, S. $117 \mathrm{f}$.

723 Vgl. beispielsweise Bericht Halim Malkoć, September 1943, in: Kaltenegger, Totenkopf und Edelweiss, S. 54.

724 Vgl. Bernwald, Muslime in der Waffen-SS, S. 117-171.

725 Vgl. ebd., S. 148.

726 „Eine wesentliche Aufgabe im Rahmen der Klärung der Hintergründe der Meuterei bestand in der Aufbereitung der Lebensläufe der Rädelsführer des Aufstandes." Bernwald, Muslime in der Waffen-SS, S. 139. 
tische Überzeugung von mindestens einem der Hauptverantwortlichen, Ferid Džanić. Auch erwähnt er, dass Džanić und seine Mitstreiter Božo Jelenek und Nikola Vukelić den Kontakt zur französischen Resistance gesucht hätten - in der Hoffnung, die Meuterei würde durch sie oder britische Verbindungsoffiziere unterstützt. Dazu fehlen allerdings konkrete Hinweise. ${ }^{727}$ Grmek und Lambrichs hingegen sind vorsichtiger: So analysieren sie im Falle Ferid Džanićs aus Bosanski Novi, einem der Anführer des späteren Aufstandes, sehr genau, inwiefern er mit den französischen Partisanen in Verbindung stand oder ob er sogar für die Gestapo arbeitete. ${ }^{728}$ Liest man die von Bernwald zusammengestellten Kurzbiographien der Meuterer, scheint die Hoffnung, bald in ihre Heimat zurückzukehren, eine der treibenden Kräfte gewesen zu sein. ${ }^{729}$ Bernwald selbst schreibt, die wirklichen Hintergründe der Meuterei würden wohl immer im Dunkeln bleiben. ${ }^{730}$ In der Tat ist heute schwierig nachzuvollziehen, ob alle Beteiligten mit den Kommunisten sympathisierten oder ob pragamatische Gründe, wie die Rückkehr in die Heimat, die ausschlaggebenden Motive waren.

Auffallend ist auch, dass alle Anführer im jugoslawischen bzw. im kroatischen Heer gedient und dort bereits den Status von Offiziersanwärtern erreicht hatten. Bernwald schreibt richtig, dass sie sich somit alle bewusst gewesen seien, was ihnen im Fall eines Scheiterns drohte. In Bezug auf die Anführer bestehen Unklarheiten. Bernwald bezeichnet Luftja Dizdarević als Hauptanführer; ${ }^{731}$ Lepre hingegen nennt Ferid Džanić, einen bosnischen Muslim, als Hauptanführer der Meuterei. ${ }^{732}$ Nach Lepre war Božo (Božidar) Jelenek aka Eduard Matutinović, ein katholischer Kroate aus Kutina, sein engster Verbündeter. Als vierte Anführer gilt Nikola Vukelić. ${ }^{733}$

Džanić selbst stammte aus einer muslimischen Familie aus Bihać, studierte an der technischen Universität in Belgrad. 1941, noch im Königreich Jugoslawien, wurde er eingezogen und war Offiziersanwärter. Džanić diente zuerst in einer bosnischen Heimwehr, schloss sich 1942 der 8. Krajina Brigade der kommunistischen Partisanen an, um einer Verhaftung im NDH zu entgehen, und geriet schließlich Anfang 1943 in deutsche Kriegsgefangenschaft. Er kam in ein Ge-

727 Vgl. Lepre, Himmler's Bosnian Division, S. 82f.

728 Grmek, Lambrichs, Les révoltés, S. 197-207. Vgl. hierzu auch Petke, Militärische Vergemeinschaftungsversuche, S. 251.

729 Vgl. auch Bernwald, Muslime in der Waffen-SS, S. 149-157.

730 Vgl. ebd. 157.

731 Vgl. ebd., S. 139. Über Dizdarević ist wenig zu erfahren. Er wurde 1921 in Sarajevo geboren und von den Deutschen als militärisch nicht leistungsfähig eingestuft. Vgl. Lepre, Himmler's Bosnian Division, S. 82.

732 Vgl. ebd.

733 Vgl. ebd. 
fangenenlager bei Sarajevo. Er wurde vor die Wahl gestellt, der neu aufgestellten Division „Handschar“ beizutreten oder weiterhin in Gefangenschaft zu bleiben. ${ }^{734}$ In der „Handschar“ hatte er den Rang eines Untersturmführers. Am 1. August 1943 trat er als „Freiwilliger“ in die neu aufgestellte 13. WaffenGebirgs-Division der SS ein. Auch sein engster Vertrauter Jelenek war Kommunist und saß deswegen acht Monate in einem kroatischen Gefängnis. Er trat unter dem Pseudonym „Eduard Matutinovic““ in die Division ein und wollte gemäß Lepre Kontakte zu anderen Kommunisten innerhalb der Division aufbauen. Im Sommer 1943 wurde er von Zemun nach Dresden geschickt. Vukelić trat der Division in Brčko bei. Auch er kam zur Ausbildung nach Dresden. ${ }^{735}$ $\mathrm{Zu}$ Jelenek schreiben auch Grmek und Lambrichs ausführlich. Im Kapitel „Jelenek, un maquisard examplaire“ zeigen sie exemplarisch den Werdegang Božo Jeleneks auf, der sich als Kommunist in die „Handschar“ einschrieb, dort die Meuterei mitorganisierte und schließlich den Weg zu den französischen Partisanen fand. ${ }^{736}$

Aus diesen Hintergründen ergibt sich eine weitere Besonderheit der Meuterei von Villefranche, nämlich ihre Ausrichtung: Sie war nicht unbedingt politisch motiviert. Zwar wird in der einschlägigen Militaria-Literatur den Aufständischen eine Verbindung zur französischen Résistance, der NOP und den Westalliierten nachgesagt, ${ }^{737}$ doch zwei Gründe könnten wichtiger gewesen sein: einerseits der Wille, so rasch wie möglich zurück in die Heimat zu gelangen, andererseits die Unzufriedenheit der katholischen Divisionsangehörigen mit der starken Ausrichtung auf die muslimische Autonomisten-Bewegung. ${ }^{738}$

In den frühen Morgenstunden des 17. Septembers stürmten die Aufständischen die Quartiere der zwei Pionierbataillone und entwaffneten die deutschen Vorgesetzten sowie die Mannschaften. Nach Angaben ehemaliger Divisionsangehöriger rechneten die Verschwörer mit der Unterstützung durch die Briten bzw. den französischen Widerstand. Sie begannen dann damit, die deutschen Führer, darunter SS-Obersturmbannführer Oskar Kirchbaum, SS-Hauptsturmführer Heinrich Kuntz, SS-Obersturmführer Gerhard Kretschmer und SS-Obersturmführer Julius Galatha zu erschießen. SS-Obersturmführer Anton Wolf sei

734 Vgl. ebd. Hoare hingegen schreibt, Džanić habe fliehen können und sich danach freiwillig zur „Handschar“ gemeldet. Vgl. Hoare, Bosnian Muslims, S. 117.

735 Vgl. Lepre, Himmler's Bosnian Division, S. 82.

736 Vgl. Grmek, Lambrichs, Les revoltés, S. 235-253.

737 Vgl. Kaltenegger, Totenkopf und Edelweiß, S. 53.

738 Vgl. Hoare, Bosnian Muslims, S. 117. Auch die Bewohner Villefranches nahmen die Soldaten in erster Linie als Muslime wahr, die sich mit andern Muslimen aus dem Senegal unterhielten und durch ihre Anwesenheit und Unterkunft in öffentlichen Gebäuden die Stadt veränderten. Vgl. Grmek/Lambrichs, Les revoltés, S. 20-22. 
zwar zuerst in den Raum im Stabsgebäude, wo die Erschießungen stattfanden, gerufen worden, kurz darauf aber wieder herausgebracht worden. SS-Obersturmführer Alexander Michawetz gelang die Flucht. ${ }^{739}$ Bataillons-Imam Halim Malkoć gelang es, die involvierten Mannschaften schließlich gegen die Anführer der Meuterei aufzubringen, indem er den Aufstand als einen kommunistischen darstellte, den es zu bekämpfen galt. Unterstützt wurde er bei der Niederschlagung der Meuterei durch den Truppenarzt Dr. Willfried Schweiger. Für diese Tat wurde Malkoć später mit dem Eisernen Kreuz ausgezeichnet. ${ }^{740}$

Durch das Militärgericht der 13. Waffen-SS-Division unter Vorsitz von Franz von Kocevar wurden folgende Personen zum Tod verurteilt:

\section{Stammpersonal}

- SS-Unterscharführer Karamanović,

- SS-Unterscharführer Ivan Jurković,

- SS-Rottenführer Alija Beganović,

- SS-Rottenführer Mustafa Morić,

- SS-Sturmann Jusup Vučjak,

\section{Soldaten}

- Meha Memišević,

- Muja Alispahić,

- Ismet Ćefović,

- Uzeir Mehičić,

- Filip Njimc,

- Sulejman Silajdžić (in Abwesenheit),

- Zemk Banjić,

- Efraim Bašić.

\section{Drei weitere Soldaten wurden später noch zum Tode verurteilt}

- Klaus Tilly,

- Hasan Novkinić,

- Suljo Suljčić. ${ }^{741}$

739 Vgl. Lepre, Himmler's Bosnian Division, S. 83-86. Bernwald, Muslime in der Waffen-SS, S. $122 \mathrm{f}$.

740 Vgl. Lepre, Himmler’s Bosnian Division, S. 90. Vgl. Bernwald, Muslime in der Waffen-SS, S. $122-124$.

741 Vgl. https://handzar.jimdo.com/2015/09/01/hanžar-divizija-istine-i-laži/ (8.7.2018). Allerdings, so schreibt Bernwald, habe es sich beim Todesurteil von Tilly nicht um die Teilnahme an der Meuterei, sondern um unerlaubtes Entfernen von der Truppe aufgrund einer Beziehung 
Diejenigen Verdächtigen, die nicht in Villefranche erschossen wurden, je nach Quelle zwischen 825 und 830 Mann, wurden in Le Puy gesammelt und Ende September nach Deutschland deportiert. ${ }^{742}$ Milan Blažeković schrieb 1979 in einem Brief an Vopersal, dass es sich bei den Deportierten um einige hundert Bosniaken und Albaner gehandelt habe. ${ }^{743}$ Sauberzweig betonte Anfang Dezember 1943, dass diese Unterführer und Mannschaften so schnell wie möglich von der Division entfernt werden mussten,

da sie nur einen Unruheherd für die Division darstellten, umso mehr, als sie keinen geregelten Dienst versehen konnten und die Gefahr augenscheinlich war, dass dunkle Elemente, insbesondere ehemalige jugoslawische Emigranten, versuchten, sich an diese Leute heranzumachen. ${ }^{744}$

Vom Konzentrationslager Dachau kamen sie nach Berlin, wo sie zu Zwangsarbeit verurteilt wurden. Lepre gibt an, dass sie vor die Wahl gestellt worden wären, „freiwillig“ in den Arbeitsdienst einzutreten oder aber ohne Nahrung zu bleiben. Die Männer weigerten sich zuerst mit der Begründung, sie seien ausschließlich zur Bekämpfung des Kommunismus in ihrer Heimat rekrutiert worden - was auf eine antikommunistische Einstellung weiterer involvierter Personenkreise außerhalb des Kerns der Anführer hindeutet. Nach einigen Tagen ohne Essen waren 536 bereit, für die Deutschen zu arbeiten, und wurden der Organisation Todt überstellt. 265 weigerten sich weiterhin und kamen daraufhin in das Konzentrationslager Neuengamme. Das Schicksal der restlichen 24 ist nicht bekannt. ${ }^{745}$

Sofort wurde von deutscher Seite der Vorwurf laut, diese Meuterei habe nur angezettelt werden können, weil man nachgegeben, und auch Katholiken in die „Handschar“ aufgenommen habe. Bernwald erwähnt aber sowohl die Teil-

zu einer Französin gehandelt. Er war bei der Nachrichtenabteilung in Mende und nicht beim Pionier-Bataillon in Villefranche eingesetzt. Sein Todesurteil wurde schließlich aufgehoben und in eine Strafversetzung umgewandelt. Vgl. Bernwald, Muslime in der Waffen-SS, S. 140-142.

742 Vgl. Brief Milan Blažeković an Vopersal, 11.3.1979, Nachlass Vopersal, BArchF, N 756/ 168b. Vgl. hierzu ausführlich Lepre, Himmler's Bosnian Division, S. 81-108. Vgl. Bernwald, Muslime in der Waffen-SS, S. 141 und Hoare, Bosnian Muslims, S. 118.

743 Vgl. Milan Blažeković an Vopersal, 11.3.1979, Nachlass Vopersal, BArchF, N 756/168b. Vgl. hierzu ausführlich Lepre, Himmler's Bosnian Division, S. 81-108.

744 Sauberzweig an SS-Führungshauptamt, 4.12.1943, in: Bernwald, Muslime in der WaffenSS, S. 141.

745 Vgl. Lepre, Himmler's Bosnian Division, S. 47, 81, $106 \mathrm{f}$. Vgl. auch Mallmann, Cüppers, Halbmond und Hakenkreuz, S. 228. Hoare schreibt, die Gefangenen wären in das KZ Dachau transportiert worden. Vgl. Hoare, Bosnian Muslims, S. 118. Auch die Angehörigen der „Prinz Eugen“, welche im August 1943 einen Befehl verweigert hatten, wurden nach Dachau deportiert. Vgl. Schulz, Wegmann, Zinke, Die Generale der Waffen-SS und der Polizei, Bd. 3, S. 510. 
nahme von Bosniaken als auch katholischer Kroaten am Aufstand. ${ }^{746}$ Berger forderte in einem Geheimvermerk an Neubacher, dass die „Handschar“ von den „verseuchten Katholiken“ [sic] gesäubert werden sollte. ${ }^{747}$ Laut einem Schreiben Milan Blažekovićs an den HIAG-Archivar Wolfgang Vopersal aus dem Jahr 1979 fanden sich unter den Meuterern aber auch Albaner. Diese Albaner baten später darum, aus dem Lager in Deutschland nach Albanien zurückgeholt zu werden. $^{748}$

Die Aussage der deportierten Divisionsangehörigen deutet einmal mehr darauf hin, dass sich die Motivation, in der Waffen-SS zu kämpfen, verflüchtigte, sobald sie außerhalb ihrer Heimat stationiert waren, ihre Familie zurücklassen mussten und nicht darüber informiert wurden, wo sie nach ihrer Ausbildung in Frankreich eingesetzt würden bzw. wann sie nach Hause zurückkehren durften.

Dass die Bosnier nicht mit ihrer Versetzung nach Villefranche-de-Rouergue und Neuhammer einverstanden gewesen waren, zeigte sich, als sofort nach dem Überschreiten der bosnischen Grenze Anfang 1944 Desertionen einsetzten. Um nicht aufzufallen, versuchten die Soldaten ihre Blutgruppentätowierung durch das Ausdrücken von Zigaretten auf der Innenseite des Oberarms oder das Aufritzen der Haut an dieser Stelle unkenntlich zu machen. ${ }^{749}$ Anfang Mai 1944 schrieb Phleps an Hitler über die ihm unterstellten Waffen-SS-Divisionen, dass sich „der Karren ganz im Dreck verrenne“ und die Desertion als Ausweg von immer zahlreicheren Soldaten in Betracht gezogen würde. ${ }^{750}$ Als Vorboten der in den Herbstmonaten 1944 einsetzenden Massendesertionen innerhalb der „Handschar“ und ihrer Schwesterdivisionen sieht Schmider die bereits hohe Zahl von „Vermissten“ während der Operation „Draufgänger“ Ende Juli 1944. ${ }^{751}$

Die zweite Meuterei gleicht eher einer koordinierten Massendesertion: Organisiert wurde sie von Imam Muhasilović gemeinsam mit SS-Obersturmbannführer Franz Karolyi in Cerna (Kroatien). Am 21. Oktober 1944 verließen 101 Mann geschlossen die Division, mit der Begründung, die Motivation, mit der sie in der Division gekämpft hätten, etwa die Verteidigung ihrer Heimat und die

746 Vgl. Bernwald, Muslime in der Waffen-SS, S. 117.

747 Berger an Neubacher, Geheimvermerk, Oktober 1943, PAAA R100984, Inland IIg, H298705.

748 Vgl. Brief Milan Blažeković an Vopersal, 11.3.1979, Nachlass Vopersal, BArchF, N 756/ $168 \mathrm{~b}$.

749 Ferhadbegović, Schuldig, im Namen des Volkes, S. 3.

750 Vgl. Schreiben Phleps an Himmler, 7.5.1944, BArchB, NS 19/2601.

751 Vgl. Schmider, Partisanenkrieg, S. 506. 
Aussicht auf Autonomie, wären nicht berücksichtigt und die Division auch auBerhalb Bosniens eingesetzt worden. ${ }^{752}$ Unter Mitnahme einiger Waffen und Fahrzeuge brachen die Meuterer bzw. Deserteure Richtung Bosnien auf. Im Vergleich zur Meuterei ein Jahr zuvor offenbarte sich die Schwäche der Deutschen deutlich: Divisionskommandeur Hampel forderte den Nachrichtenoffizier Fritz Wegemann auf, die Deserteure ausfindig zu machen und zurückzubringen. Wegemann fand diese zwar rasch, war aber nicht in der Lage, sie zur Rückkehr zu bewegen. ${ }^{753}$ Doch damit nicht genug: Am 30. Oktober entwaffnete die Gruppe eine Patrouille der „Handschar“ von 14 Mann, sieben davon blieben bei den Deserteuren. Die Gruppe um Muhasilović schloss sich schließlich in der MaočaRahić-Region einer größeren Gruppe von 600 Deserteuren an. ${ }^{754}$ Gemeinsam wollten sie der 18. Kroatischen Partisanen-Brigade, die in der gleichen Region kämpfte, beitreten. Die „Hronologija narodnooslobodilačkog rata“ (Chronologie des Volksbefreiungskriegs) bestätigt oben genannte Massendesertion ebenso wie die Tatsache, dass am 29. Oktober 1944 zwischen Tuzla und Brčko 700 Soldaten der „Handschar“ mit 17 Kraftfahrzeugen zur 18. Kroatischen (ostbosnischen) Brigade der 38. Division der Jugoslawischen Volksbefreiungsarmee überliefen. ${ }^{755}$

Im Oktober 1944 meldete der Leiter der Referatsgruppe Inland II Horst Wagner bei der Gesandtschaft in Budapest „Zersetzungserscheinungen“ in der Bosniaken-Division. ${ }^{756}$ Die Division sollte schließlich aufgelöst, die Werbung endgültig eingestellt werden. ${ }^{757}$ Muhasilovićs Spur verliert sich nach dem Krieg, über sein Schicksal in den Nachkriegsjahren ist bislang nichts bekannt. Nach Bernwald soll er 1945 in Zagreb unter nicht geklärten Umständen zu Tode gekommen sein. ${ }^{758}$

\subsection{Das Ende des Krieges}

Obwohl die KPJ im September 1944 ein Amnestieversprechen veröffentlicht hatte und die Deutschen viele Bosnier aus der „Handschar“ entließen, gab es

752 Vgl. Brief Wilhelm Ebeling an Lepre, 15.9.1994, nach: Lepre, Himmler's Bosnian Division, S. 266.

753 Vgl. Lepre, Himmler's Bosnian Division, S. $266 \mathrm{f}$.

754 Vgl. ebd., S. 267.

755 Vgl. Stojan Nikolić, Josif Stefanović, Hranislav A. Rakić, Hronologija narodnooslobodilačkog rata 1941-1945, Leskovac 1966, S. 946.

756 Vgl. Leiter Referatsgruppe Inland II Horst Wagner an Gesandtschaft Budapest, 6.10.1944, PAAA Inland IIg R100998.

757 Vgl. Gesandter Kasche an AA, 27.10.1944, PAAA Inland IIg R100998, H297359.

758 Vgl. Bernwald, Muslime in der Waffen-SS, S. 82. 
unter ihnen auch solche, die die Division nicht verlassen wollten und bis zum Schluss blieben. Diese traten gemeinsam mit ihren „volks-“ und „reichsdeutschen“ Vorgesetzten den Rückzug Richtung Nordwesten an, beispielsweise der Truppenimam Kasim Mašić, der bis zuletzt bei den sich zurückziehenden Einheiten der „Handschar“ blieb. ${ }^{759}$

Zvonimir Bernwald, in den letzten Wochen von der „Handschar“ zur 31. Freiwilligen-Grenadier-Division versetzt, beschreibt das Ende des Krieges als eine „totale Veränderung“ seiner Situation - sowohl innerlicher als auch äußerlicher Lebensumstände. Ihm fiel jetzt vor allem eines auf:

Einige Stunden später stelle ich für mich persönlich ganz nüchtern fest, dass wir, damit meinte ich alle Organe der Waffen-SS, in der Unterführerschule und später auch in der Junkerschule nirgends ein einziges Wort darüber gehört hatten, wie man sich in der Kriegsgefangenschaft verhalten sollte. ${ }^{760}$

Die Angehörigen der „Handschar“ erlebten das Kriegsende an verschiedenen Orten, in verschiedenen Ländern. Erich Schäfer etwa gab zu Protokoll, dass er mit seiner Einheit gegen Ende 1944 Ungarn erreichte, als er vernahm, dass der Krieg zu Ende war. ${ }^{761}$ Günter Borkowsky hingegen war in den letzten Kriegstagen in Berlin und erlitt noch am 28. April 1945 eine Gesichtsverletzung durch Granatsplitter. Kurz vor Kriegsende war er im Gefangenen-Lazarett Rüdersdorf bei Berlin. ${ }^{762}$ Zvonimir Bernwald erinnerte sich an das Kriegsende als eine Odyssee: Ständig auf der Flucht vor einer Festnahme durch die jugoslawische Befreiungsarmee oder sowjetische Truppen erreichte er schließlich den Osten Deutschlands. Er war in verschiedenen Lagern interniert, bis er am 15. September 1947 nach Esslingen am Neckar entlassen wurde. ${ }^{763}$ Über die Botschaft, der Krieg sei zu Ende, schrieb er später: „In uns und um uns war eine bedrückende Leere, eine Verlassenheit. [...] Wir lebten im Zustand einer eigenartigen Schwerelosigkeit, schweigend, unbeweglich und warteten auf die Ereignisse, die da kommen würden. “"764 Die Briten hielten viele der von ihnen entwaffneten Soldaten bei St. Veit/Št. Vid ob Glini fest. Nach Erzählungen ehemaliger Soldaten handelte es sich um ein Feld, das zur westlichen Seite hin kaum bewacht war. So gelang zahlreichen Angehörigen des I/28 die Flucht, wie sich der ehemalige Bataillonskommandeur Cord-Hen-

759 Vgl. Ferhadbegović, Schuldig im Namen des Volkes, S. 3.

760 Bernwald, Muslime, S. 233.

761 Vgl. Fall Günter Borkowsky, Aussage Erich Schäfer, 23.4.1964, USHMM, BArchL, B162/ 20812, Bl. 70.

762 Vgl. Fall Günter Borkowsky, Aussage Günter Borkowsky, 26.8.1963, USHMM, BArchL, B 162/20812, Bl. 10.

763 Vgl. Bernwald, Muslime in der Waffen-SS, S. 229-270.

764 Vgl. ebd. 232. 
ning Knospe erinnerte. Sie fürchteten eine Auslieferung an Jugoslawien. Auch Imam Ibrahimović, der in einem Lager bei Klagenfurt, in welchem die Angehörigen der „Handschar“ zwei Drittel ausmachten, stationiert war, gibt an, dass sie eine solche Auslieferung gefürchtet hätten. ${ }^{765}$

Obwohl dies in bestimmten Fällen auch wirklich zutraf und die Briten Auslieferungsforderungen der Jugoslawen nachkamen, beschreibt Lepre noch ein anderes Phänomen: Mehrmals seien Offiziere der jugoslawischen Volksbefreiungsarmee in verschiedene Gefangenenlager, so etwa in Rimini oder Tarent/Taranto, gekommen und hätten sowohl Bosnier als auch „Volksdeutsche“ von einer Rückkehr nach Jugoslawien zu überzeugen versucht. Ibrahimović erinnert sich, dass dies weder mit Gewalt noch mit Zwang versucht wurde und er nicht davon ausgehe, dass diese Männer nach ihrer Rückkehr exekutiert wurden. Die Bosnier, welche sich gegen eine Rückkehr entschieden und in den Lagern blieben, wanderten später oft in den Westen oder in Arabische Staaten aus, beispielsweise, um in Palästina gegen den neuen israelischen Staat zu kämpfen. ${ }^{766}$

Trotz den Versuchen, ihre SS-Blutgruppentätowierung auf den Armen unkenntlich zu machen, ${ }^{767}$ wurden zahlreiche ehemalige „Handschar“-Angehörige von Partisaneneinheiten erschossen. So sollen beispielsweise am 22. April 1945 neun km südöstlich Raamanders 1.400 Mann erschossenen worden sein, darunter befand sich eine große Anzahl „Handschar“-Soldaten. Im Lagerbereich 101 Agram/Zagreb soll es sechs Massengräber geben, die für die Erschießungen nach dem Krieg ausgehoben worden waren. Einwohner der Gegend schätzen die Zahl der dort vergrabenen Personen auf 800 Mann. Die Massengräber liegen $10 \mathrm{~km}$ westlich von Schloss Kerestinec, einem ehemaligen KZ der Ustaša, zwei Massengräber 350 m vom Schloss Richtung Flugplatz, ein Massengrab 120 m hinter der Serumfabrik Kalinovać. ${ }^{768}$

Anders verhielt es sich mit den höheren Rängen. Bereits kurz nach der deutschen Kapitulation ging das Gerücht um, Eisenhower fordere, jeder Angehörige der Waffen-SS mit einem Rang ab Oberscharführer aufwärts sei für mindestens zwanzig Jahre einzusperren. Viele versuchten daraufhin mit verschiedensten Mitteln, die verräterische Blutgruppentätowierung unsichtbar zu machen und sich entlastende Papiere, beispielsweise einer Wehrmachtseinheit, $\mathrm{zu}$ verschaffen. Einige hatten das Glück, nie tätowiert worden zu sein. ${ }^{769}$

765 Vgl. Lepre, Himmler's Bosnian Division, S. 305.

766 Vgl. ebd., S. 308.

767 Ferhadbegović, Sabina, Schuldig, im Namen des Volkes,, S. 3.

768 Vgl. Lepre, Himnmler's Bosnian Division, S. 302-304 und Nachlass Vopersal, BArchF N $756 / 168 b$.

769 Vgl. ebd., S. $309 f$. 
Das deutsche Rahmenpersonal, welches in jugoslawische Kriegsgefangenschaft kam, hatte mit harten Strafen zu rechnen. In den meisten Fällen wurden die Angeklagten nicht für spezifische Gewaltakte angeklagt, sondern kollektiv für die Ermordung von rund 5.000 Personen. ${ }^{770}$ Zehn Mann in höheren Rängen ${ }^{771}$ wurden zum Tode verurteilt, darunter Rolf Baumeister, Walter Eipel, von dem ein ausführlicher Bericht zur „Handschar“ aus seiner Kriegsgefangenschaft überliefert ist, ${ }^{772}$ Kurt Lütkemüller, Bruno Lütjens, Heinz Masannek, Josef Pälmke, Wilhelm Schmidt, Willi Scheer, Erich Schwerin und Kurt Weber. 27 weitere wurden zu Gefängnisstrafen von fünf Jahren bis lebenslänglich verurteilt. ${ }^{773}$ Die Todesurteile wurden am 17. Juli 1948 vollstreckt, ${ }^{774}$ die letzten Gefangenen 1952 aus dem Gefängnis entlassen. ${ }^{775}$ Die in der Retrospektive relativ geordnet erscheinenden Stadien von Kriegsgefangenschaft und Verurteilung dürfen aber nicht über die Tatsache hinwegtäuschen, dass viele Soldaten der „Handschar“ auch spontanen Vergeltungsaktionen oder so genannten Hungermärschen, die der Gefangennahme folgten, zum Opfer fielen. ${ }^{776}$ Ein Problem stellt aus heutiger Sicht die Willkür während der Gerichtsverhandlungen dar: Kollektive Verurteilungen, keine Angabe konkreter Ereignisse, ein Pflichtverteidiger für 13 Angeklagte und teilweise absurde Beschuldigung, wie etwa die nachträgliche Verstümmelung eigener Toter, um diese Verbrechen später den Partisanen anzulasten, lassen nicht auf einen geordneten und rechtmäßigen Verlauf der Verhandlungen schließen. ${ }^{777}$

770 Vgl. ebd., S. 312.

771 In den Rängen von SS-Hauptsturmführer bis SS-Oberscharführer. Hier stellt sich die Frage, welche Verbrechen den Deutschen in vergleichsweise niedrigen Rängen wie SS-Oberscharführer angelastet wurden, dass das Urteil auf Todesstrafe lautete.

772 Vgl. Kriegsgefangenenbericht „Bericht über die 13. SS Division ,Handschar‘, ihre Aufstellung, Gliederung und 1. Einsätze im jugoslawischen Raum“, Walter Eipel, 14.11.1947, VA, HEM. OK.BOJCKA, 72-A/1-a/32.

773 Vgl. Rochas, La Handschar, S. 200 f. Hier sind vor allem die Ränge SS-Sturmscharführer, SS-Hauptscharführer, SS-Oberscharführer und SS-Unterscharführer, sowie ein SS-Sturmmann vertreten.

774 Vgl. Kriegsgefangenenbericht „Bericht über die 13. SS Division ,Handschar‘, ihre Aufstellung, Gliederung und 1. Einsätze im jugoslawischen Raum“, Walter Eipel, 14.11.1947, VA, HEM. OK.BOJCKA, 72-A/1-a/32.

775 Lepre, Himmler's Bosnian Division, S. 314.

776 Vgl. bspw. Böhme, Geschichte der deutschen Kriegsgefangenen, S. 107, 129-131.

777 Lepre, Himmler's Bosnian Division, S. 312. 